\title{
Discerning the variation in fungal-treated wheat straw as ruminant feed
}

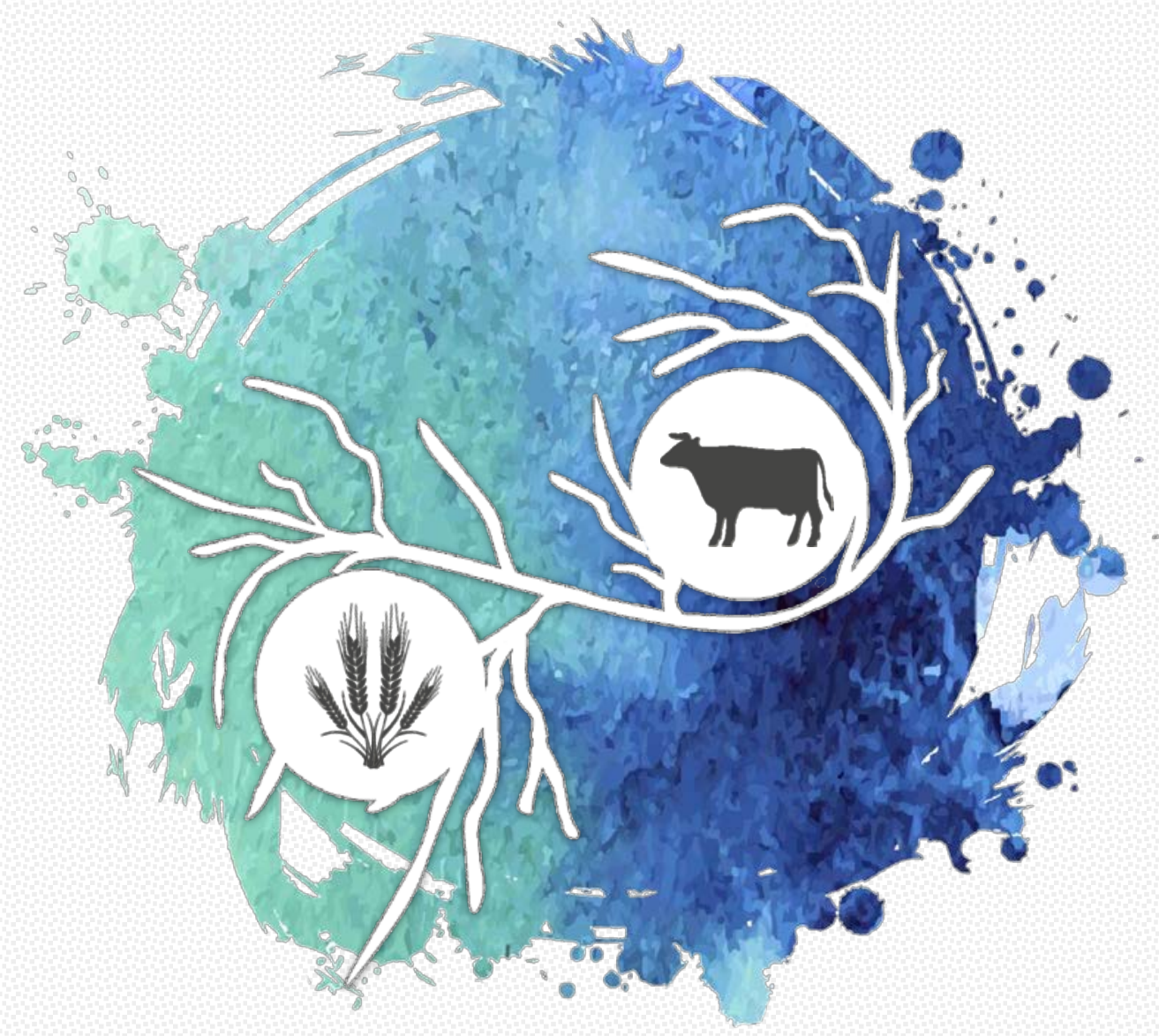

NAZRI NAYAN 


\section{Propositions}

1. The effectiveness of biomass processing using different fungal strains is as varied as that of different species.

(this thesis)

2. High potential white-rot fungal species perform well on different types of wheat straw.

(this thesis)

3. Aesthetic judgement of data promotes good science.

4. Collaboration is great for scientists, but ethnocentrism undermines science.

5. "It is a capital mistake to theorize before one has data" - Sir Arthur Conan Doyle in A Scandal in Bohemia (1891); but one can always speculate.

6. On social media, the number of self-proclaimed 'experts' is blooming.

7. Craving for flattery is a clear sign of a lack of covert self-esteem.

Propositions belonging to the thesis, entitled:

'Discerning the variation in fungal-treated wheat straw as ruminant feed'

\section{Nazri Nayan}

Wageningen, 26 October 2018 
Discerning the variation in fungal-treated wheat straw as ruminant feed

Nazri Nayan 


\section{Thesis committee}

\section{Promotor}

Prof. Dr W.H. Hendriks

Professor of Animal Nutrition

Wageningen University \& Research

\section{Co-promotors}

Dr J.W. Cone

Researcher, Animal Nutrition Group

Wageningen University \& Research

Dr A.S.M. Sonnenberg

Researcher, Plant Breeding

Wageningen University \& Research

\section{Other members}

Prof. Dr AJM Stams, Wageningen University \& Research

Dr JT Schonewille, Utrecht University, Utrecht

Dr MAM Rodrigues, University of Trás-os-Montes and Alto Douro, Vila Real, Portugal Prof. Dr JPM Sanders, Wageningen University \& Research

This research was conducted under the auspices of the Graduate School of Wageningen Institute of Animal Sciences (WIAS). 


\title{
Discerning the variation in fungal-treated wheat straw as ruminant feed
}

\author{
Nazri Nayan
}

Thesis

submitted in fulfilment of the requirements for the degree of doctor at Wageningen University

by the authority of the Rector Magnificus

Prof. Dr A.P.J. Mol,

in the presence of the

Thesis Committee appointed by the Academic Board

to be defended in public

on Friday 26 October 2018

at 11 a.m. in the Aula. 
Nazri Nayan

Discerning fungal variations in the bioprocessing of wheat straw into ruminant feed, 216 pages.

$\mathrm{PhD}$ thesis, Wageningen University, Wageningen, NL (2018)

With references, with summary in English

ISBN 978-94-6343-505-5

DOI https://doi.org/10.18174/458924 


\section{Table of contents}

Chapter 1 General introduction 1

$\begin{array}{lll}\text { Chapter } 2 & \text { Differences between two strains of Ceriporiopsis }\end{array}$

Subvermispora on improving the nutritive value of wheat straw for ruminants

Chapter 3 Screening of white-rot fungi for bioprocessing of wheat straw into ruminant feed

Chapter 4 Variation in the solubilization of crude protein of wheat straw by different white-rot fungi

Chapter 5 The relevance of different analytical methods to assess fungal degradation of lignocellulose and explaining the subsequent ruminal degradability

Supplementary information

Chapter 6 Mechanistic insight in the selective delignification of wheat straw by three white-rot fungal species through quantitative ${ }^{13} \mathrm{C}$-IS Py-GC/MS and whole cell wall HSQC-NMR

Supplementary information

Chapter 7 Improving ruminal digestibility of various wheat straw types by white-rot fungi

Supplementary information

Chapter 8 General discussion

Summary

Acknowledgement

About the author 

Ohtuk abah dan mak 


\section{4}

Optimism is the faith that leads to achievement. Nothing can be done without hope and confidence

- Helen Keller 
CHAPTER

General introduction 



\section{Towards a sustainable world}

7 he food, feed and fuel competition - is one of the most talked about sustainability 1 issues which sparks debate on socio-economics and environmental impact. The world average food consumption per capita is expected to increase from 2,680 kcal person $^{-1}$ day $^{-1}$ in 2015 to 3,000 kcal person ${ }^{-1}$ day $^{-1}$ in 2030 (Bruinsma, 2003). The decrease in poverty in developing countries and the increasing demand for animal-based products, as well as a projected $30 \%$ increase in the human population by 2050 , will place great pressure on food and animal production systems. Concerning "food vs. feed", much research has been done on converting poor energy sources into more efficient and economically viable option (Banerjee, 2011). Biomass, particularly residues from agricultural harvests, are produced in abundant quantities and have great potential as valuable alternative energy sources for various applications. The worldwide production of wheat straw (Triticum aestivum L.), for instance, is estimated at 577 million metric tons per year, based on the assumption that about $77 \%$ of the total wheat production is straw (Ruiz et al., 2012; FAO, 2016). For the next decades, biomass becomes increasingly important as a major source of bioenergy. Besides biofuels, biomass such as wheat and rice straw, has been used as a roughage source for animals by farmers, especially in the developing countries (Sarnklong et al., 2010). However, this biomass has a low feeding value compared to other conventional roughage sources. Meanwhile, stubble burning after a crop harvest is still being practiced in some parts of the world, such as India, which negatively impacts global air quality (Mittal et al., 2009). This stresses the importance for a more efficient use of this biomass by processing it into higher value products.

\section{The lignocellulosic biomass}

The main components of lignocellulose are cellulose, hemicellulose and lignin which account for $\sim 86 \%$ of the dry matter. When analyzed in the same laboratory, wheat straw for instance, contains (on dry matter basis) 46 - 50\% cellulose, 26 - 31\% hemicellulose and 7 - 9\% lignin (Tuyen et al., 2012; Van Kuijk et al., 2015a). It also contains pectin and other minor components such as protein, lipid and low molecular weight carbohydrates (Chen, 2014). The structural proteins are usually classified as hydroxyproline-rich glycoproteins (HRGPs), arabinogalactan proteins (AGPs), glycine-rich proteins (GRPs) and proline-rich proteins (PRPs) (Kubicek, 2013). These components are widely distributed throughout the plant structures, which depends on the anatomical parts and stage of the cell differentiation (Hansen et al., 2013; Moore and Jung, 2001). Two main parts that constitute the wheat straw are leaves and stems, which make up 25 - 50 and 45 
- 70\%, respectively, of the total straw weight (Zhang et al., 2014). The leaves contain mainly parenchyma cells, which are composed of only primary cell walls, but without highly-lignified secondary cell walls; whereas, the vascular bundles (xylem and phloem) in stems are supported by thick sclerified parenchyma cells, which contain also lignified secondary walls (Hansen et al., 2013; Zhang et al., 2014). Both parts are also coated with a dense epicuticular wax-rich epidermis. All these factors - leaf to stem ratio, wax coating, arrangement and density of the vascular bundles, amount of sclereids, degree of lignification and also the structural complexity of the cell wall constituents, lead to the recalcitrance and heterogenic nature of the biomass (Himmel et al., 2007; Moore and Jung, 2001).

\section{Valorization of biomass for ruminant and its challenges}

One of the main challenges to use biomass as a ruminant feed is to overcome the lignin barrier. Lignin is a vital component of the plant cell wall that provides structural strength and rigidity, limits water permeability and impedes pathogenic organisms (Moore and Jung, 2001). Lignin is deposited at a later stage of cell maturation and crosslinks with other cell wall polymers, particularly to arabinoxylans via ether and ester-linked hydroxycynnamic acids (Buranov and Mazza, 2008). The composition of the cell wall components with respect to lignification is highly variable and influenced by various extrinsic and intrinsic factors - among others, different genotypes and physiological responses to environmental stimuli (Moore and Jung, 2001). In ruminant nutrition, lignin is generally regarded as an anti-quality factor in forages. In the rumen, structural polysaccharides can be degraded by fibrolytic microbes, such as Fibrobacter succinogenes, Ruminococcus albus and Ruminococcus flavefaciens (Krause et al., 2003). The degradation of lignin by the rumen microbes, however, has not been completely resolved. A monoculture of the rumen fungus, Neocallimastix patriciarum has been shown to solubilize $34 \%$ of the lignin extracted from pre-digested sorghum stem (McSweeney et al., 1994). In the same study, they also showed the inability of the fungus to break ether linkages between lignin and polysaccharides, and interunit linkages of the lignin model compounds. The in vivo degradation of lignocellulose by rumen fungi is rather complex due to their slower growth rates and interactions with other rumen microbes. In addition, lignin has an inhibitory effect on other polysaccharide degrading enzyme productions (Lowe et al., 1987). The loss of lignin reported in an in vitro study is likely due to the solubilization from the plant cell wall (Akin and Benner, 1988). Therefore, in general, the encrustation of lignin in the cell wall matrix presents a great 
challenge for an efficient utilization of the cell wall polysaccharides by the rumen microbes, thus making biomass with higher lignin content a poorly digestible feed source. Besides lignin, other factors such as cellulose crystallinity, degree of polymerization and surface area can also limit an efficient utilization (Hendriks and Zeeman, 2009).

A crucial step in optimizing the utilization of biomass for ruminants is to make the polysaccharides more accessible for the carbohydrate lysing enzymes produced by the rumen microbes. For this purpose, there are various pretreatment methods available including physical and chemical approaches (Chaturvedi and Verma, 2013; Hendriks and Zeeman, 2009; Sarnklong et al., 2010). Physical processing can be performed by milling, irradiation, steam pretreatment/steam explosion (ST/SE) and hydrothermal treatments. Using thermal treatments, the biomass can be heated up to $150-180^{\circ} \mathrm{C}$, which will solubilize hemicellulose and later lignin. The biomass can also be processed chemically through acid or alkaline pretreatments. Acid hydrolysis, for instance, results in a high recovery of hemicellulosic sugars in the liquid fraction and an enhanced digestibility of cellulose in the solid fraction (Jönsson and Martín, 2016). A physicochemical treatment combination such as Ammonia Fiber Explosion (AFEX) also offers a great potential as a pretreatment method. Using AFEX, biomass is treated with liquid anhydrous ammonia at moderate temperatures $\left(60-100^{\circ} \mathrm{C}\right)$ and high pressure $(250-300 \mathrm{psi})$, before a rapid release of pressure (Teymouri et al., 2005). All these pretreatment methods are able to increase the cellulose accessibility by decreasing its crystallinity and increasing the extent of delignification in a relatively short time, which makes them promising for industryscale applications (Hendriks and Zeeman, 2009; Isroi et al., 2011). Some disadvantages of these physicochemical methods include concerns regarding their environmental impact, as well as significant production costs, which makes these various pretreatment methods unsuitable for small-scale farmers' application. In addition, there is a risk that the formation of volatile products can inhibit anaerobic fermentation (Hendriks and Zeeman, 2009; Jönsson and Martín, 2016). Examples are furan aldehydes and hydroxymethylfurfural (HMF) that can be formed when treating biomass at a temperature higher than $160^{\circ} \mathrm{C}$, especially in an acidic environment; while acid hydrolysis may lead to an increase in formic and levulinic acids from sugar degradation. These compounds may inhibit microbial activity and hence, lower the fermentation of carbohydrates in the rumen. 
There are at least 26 review papers (in my collection) that discuss the available processing methods to transform biomass into various value-added products and for numerous applications. Sixteen of these review papers also acknowledge the great potential of using fungi in the valorization of biomass for various purposes. The extensive discussion on this topic in the scientific domain, especially since the last 20 years, is evidence of a keen interest to bring this eco-friendly approach into practice. The prospect of fungi as an alternative processing method of biomass into ruminant feed has received great attention in recent years (Shrivastava et al., 2014; Tuyen et al., 2012; Van Kuijk et al., 2017). White-rot fungi are the most studied group of wood decaying fungi - the others being brown-rot and soft-rot fungi. Nearly all of these fungi are members of the class basidiomycetes, although some ascomycetes that cause pseudo-white rot are also classified into this group (Hatakka and Hammel, 2010). White-rot fungi are the only fungi that are capable of depolymerizing lignin completely by cleaving the $\mathrm{C}_{\alpha}-\mathrm{C}_{\beta}$ bond in its substructures (Kubicek, 2013). In comparison, brown-rot fungi act primarily on cellulose and hemicellulose but they are not able to completely depolymerize lignin although some modification through demethylation may occur. The soft-rot mechanisms are characterized by an extensive loss of structural carbohydrates and the fungi do not affect lignin (Hatakka and Hammel, 2010; Kubicek, 2013).

Although white-rot fungi possess a great potential in the bioprocessing of biomass, there are numerous challenges and issues that still need to be addressed to make this method feasible for industrial application, which have recently been reviewed (Van Kuijk et al., 2015a). Among factors that influence the effectiveness of the pretreatment are fungal species/strains, substrates used, culture conditions and colonization time. The relatively longer pretreatment time is one of the biggest shortcomings in using this biological approach, which may take weeks compared to just several minutes, for instance, when using AFEX (Teymouri et al., 2005; Van Kuijk et al., 2015b). A period of at least 4 to 8 weeks is typically needed to have a significant improvement in the ruminal degradability of the treated substrates (Tuyen et al., 2012; Van Kuijk et al., 2015b). Research to optimize fungal treatment of biomass has been carried out, which included finding the best fungi-substrate combinations (Tuyen et al., 2013), varying particle size of the substrate (Van Kuijk et al., 2016) and supplementing the substrate with additives such as manganese and linoleic acid (Van Kuijk et al., 2015b). Another uncertainty using fungal pretreatment is the extent of carbohydrate loss in terms of relative enrichment of the biomass and also possible release of inhibitory by-products. 


\section{Variation in the fungal pretreatment}

The usual classification of wood-decaying fungi into white-rot, brown rot and soft rot does not necessarily justify the variation in mechanisms of degradation of lignocellulose found in the basidiomycetes An analysis of 33 genomes of basidiomycetes revealed that some species lack lignin-degrading peroxidases (PODs), which resemble brown-rot fungi, but possess the cellulose-degrading traits typical for white-rot fungi (Riley et al., 2014). Therefore, selecting the right fungal species (and strains; see definition in Textbox 1.1) is an integral element in advancing the potential in improving the nutritive value of biomass for ruminants. White-rot fungi can be further characterized based on their ability to degrade different constituents of the cell wall, which is selective or non-selective delignification (Blanchette, 1995; Martinez et al., 2005). Figure 1.1 illustrates general mechanisms of fungal attack on lignocellulosic biomass. A nonselective fungus colonizes progressively from the lumen and the growing tip of the hyphae fill the eroded zones. This type of fungus causes a simultaneous loss of lignin and polysaccharides. On the other hand, some species preferentially degrade lignin and cause a minimum loss of the polysaccharides. This type of fungi are able to degrade lignin with less protruded hyphae in the secondary wall and middle lamella matrices through diffusion mechanisms (small radicals chelated with organic acids or low molecular weight mediators) (Hatakka and Hammel, 2010). These classifications are not exclusive, whereby, a particular fungus may be selective on a substrate, but show an opposite characteristic when grown on a different substrate. Some fungi can even show both characteristics on the same substrate which was observed for wood decay by Ganoderma spp. (Adaskaveg et al., 1990; Adaskaveg and Gilbertson, 1986).

\section{Textbox 1.1. Definition of 'species' and 'strain'}

Throughout the thesis, the terms 'species' and 'strain' are frequently used. A fungal species is defined as a group of related organisms that are capable of exchanging genes and interbreeding, which is designated by a Latin binomial, e.g. Ceriporiopsis subvermispora. A strain is a subvariety of a particular fungal species that has clear-cut phenotypic and/or genetic characteristics. Therefore, the white-rot fungi species Ceriporiopsis subvermispora have multiple strains that can be characteristically different from each other. 
Fungi degrade the cell wall components by secreting a complex mixture of extracellular enzymes as their main mode of action (Dashtban et al., 2010; Hatakka and Hammel, 2010). The major lignin-degrading enzymes that are produced by white-rot fungi are class II peroxidases, such as lignin peroxidase (LiP), manganese peroxidase $(\mathrm{MnP})$ and versatile peroxidases (VP) as well as phenol oxidase, such as laccase (Kirk and Farrell, 1987; Pollegioni et al., 2015). The LiP, MnP and VP are heme-containing peroxidases that act on the lignin through the formation of intermediate radicals in multiple electron transfer steps (Hatakka and Hammel, 2010). Together with laccase, these peroxidases can act on both phenolic ( $<20 \%$ of lignin) and non-phenolic $(>80 \%)$ lignin substructures, with or without the presence of mediators. LiP is a mediator-free peroxidase that can degrade both phenolic and non-phenolic lignin by various structural modification, i.e. $\mathrm{C}_{\alpha}-\mathrm{C}_{\beta}$ cleavage, demethylation and oxidation of benzylic methyl groups (Asina et al., 2017). MnP preferentially oxidizes $\mathrm{Mn}^{2+}$ into reactive $\mathrm{Mn}^{3+}$, which in its chelated form (with carboxylic acids) can only attack phenolic lignin (Hofrichter, 2002; Pollegioni et al., 2015). MnP forms reactive radicals by oxidizing mediators, such as glutathione as well as unsaturated fatty acids, which can also attack nonphenolic lignin (Hofrichter, 2002). VP has a broad substrate preference and shows typical features of both LiP and MnP (Pollegioni et al., 2015). Although laccase has broader functions in fungi, it

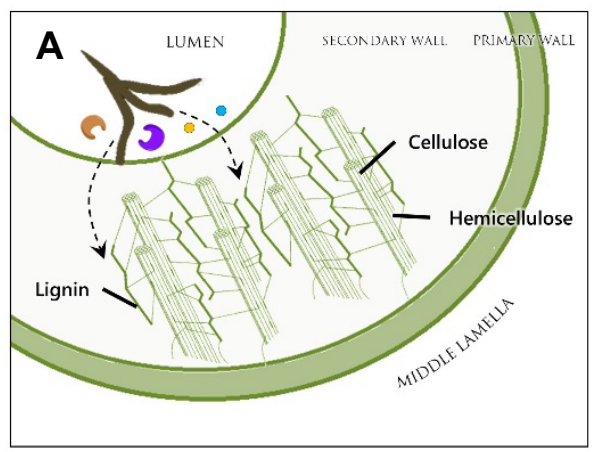

Laccase

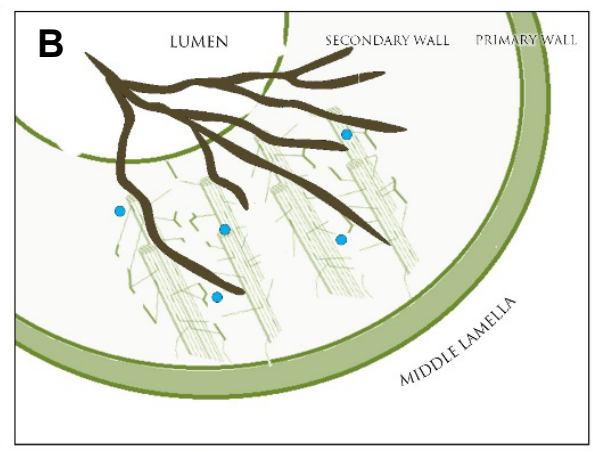

Glycoside Hydrolases

Fig. 1.1. Schematic representation of a fungal attack on lignocellulosic biomass. Fungal hyphae grow progressively from the lumen into the secondary cell wall (A to B). Depending on the species, various extracellular enzymes are excreted to degrade lignin (e.g. manganese peroxidase $(\mathrm{MnP})$ and laccase) and also hydrolyze polysaccharides (glycoside hydrolases, GHs). A selective fungus causes less erosion that furrowed with hyphal growth, but rather degrade the cell wall constituents through diffusion mechanisms using various chelating agents or low molecular weight mediators. 
can also oxidize both phenolic and non-phenolic lignin where its extensive mediator system has been reviewed (Christopher et al., 2014). It has been suggested that laccase (and also $\mathrm{MnP}$ ) attacks the phenolic lignin first, before degrading the more recalcitrant non-phenolic structure (Camarero et al., 1994; Christopher et al., 2014). The complete mineralization of lignin into water-soluble compounds and $\mathrm{CO}_{2}$ by these enzymes is a highly oxidative process, which explains the limited degradability in the rumen environment. The extent of this enzymatic degradation can be species-dependent and variable under different culture conditions, such as varying $\mathrm{pH}$ and nitrogen sources (Boyle et al., 1992).

The availability of nutrients, particularly carbon and nitrogen sources have great effects on the activity of lignin-degrading enzymes, which contribute to the variation in the effectiveness of fungal pretreatment. Nutrient manipulation of the growth medium, especially nitrogen, will affect the level of enzyme production by the fungi. Phanerochaete chrysosporium showed a decrease in its lignin-degrading enzyme activity by a high nitrogen supplementation, in contrast to a high activity in Pleurotus ostreatus (Commanday and Macy, 1985; Leatham and Kent Kirk, 1983). The selective delignification of Bjerkandera sp. was improved by removing nitrogen from hemp stemwood (Dorado et al., 2001). Nitrogen seems also to inhibit the delignification of ${ }^{14} \mathrm{C}$ labelled wood lignin by Lentinula edodes, P. chrysosporium and Schizophyllum commune (Boyle et al., 1992). Lignin itself is not a growth substrate for fungi (Kirk and Farrell, 1987) - these are the cell wall polysaccharides. Thus, fungi also secrete glycoside hydrolases, the most diverse group of enzymes that cleave the glycosidic bonds of cellulose and hemicellulose (Kubicek, 2013). Among the important enzymes that hydrolyze cellulose are endo- $\beta$-1,4-glucanases, exo- $\beta$-1,4-glucanases and $\beta$-glucosidases; while the hydrolysis of hemicellulose involves a wide variety of enzymes due to the nature of the polymer (Jovanovic et al., 2009). These enzymes work synergistically in degrading the cell wall polysaccharides and are vital for fungal growth and metabolism (Wan and Li, 2012). As such, fungal pretreatment results in an inevitable loss of the valuable carbohydrates. With a great variety of fungal species (and strains) and also the heterogeneity of the lignocellulosic biomass available, a variable success in improving the nutritive value of the biomass can be expected, which has been extensively reviewed (Van Kuijk et al., 2015b). 


\section{The fungi and model substrates}

A simple meta-analysis was performed on 37 studies that used white-rot fungi to treat various types of biomass, with specific focus to bioprocess them into animal feed (Fig. 1.2). These studies were published between 1982 and January 2018 in peer-reviewed journals. Of these studies, $63 \%$ used wheat straw as the model substrate, while rice straw (15\%), oil palm fronds (7\%) and sugarcane bagasse (7\%) were among other popular choices. There were 44 different fungal species tested with only 3 studies including different strains of a particular species as part of their treatments (Fazaeli et al., 2004; Okano et al., 2006; Rodrigues et al., 2008). Since 2006, C. subvermispora is the most studied species (11\%) for bioprocessing of biomass into ruminant feed, followed by $L$. edodes (10.2\%) and P. ostreatus (9.3\%); P. eryngii is at the fourth place. C. subvermispora showed the highest potential in improving the ruminal degradability of wheat straw (17.4 $-57.5 \% ; \mathrm{n}=5)$ with a high delignification capability $(25.2-76.9 \% ; \mathrm{n}=5)$. The mean improvement of ruminal degradability by $C$. subvermispora and L. edodes were relatively comparable when grown on rice straw (18.7 vs. $12.6 \%$ for C. subvermispora and L. edodes, respectively; $\mathrm{n}=2$ ), oil palm fronds ( 105.6 vs $96.0 \% ; \mathrm{n}=2$ ) and sugarcane bagasse (40.6 vs $47.6 \% ; \mathrm{n}=2)$. P. eryngii caused a considerable increase in ruminal degradability on oil palm fronds $(74 \% ; \mathrm{n}=2)$, wheat straw $(21.4 \% ; \mathrm{n}=3)$ and rice straw $(4.2 \% ; \mathrm{n}=2)$, but not on sugarcane bagasse where a $3.8 \%(n=2)$ decrease was observed. Although a larger set of studies may be required to be more conclusive, this pilot meta-analysis reveals a significant variation in fungal pretreatment of different biomasses, and even on the same type of biomass (Jalč et al., 1998; Rahman et al., 2011; Tuyen et al., 2012).

Many of these studies have reported considerable successes in the bioprocessing of biomass into value-added products using fungi for various purposes, including animal feed (Sharma and Arora, 2010; Tuyen et al., 2012; Van Kuijk et al., 2015b). Different biomasses that are used as the growth substrates, produce variable effects on the effectiveness of a particular fungal species. For instance, C. subvermispora degraded 16\% of the lignin in maize stover, but showed a higher delignification capability on rice straw, oil palm frond and sugarcane bagasse, where more than half of the lignin contents were degraded (Tuyen et al., 2013). In the latter study, the lignin content of the untreated maize stover $(7.8 \%)$ was comparable to that of rice straw (6.2\%), while lignin contents of oil palm fronds and sugarcane bagasse were 16.7 and $11.4 \%$, respectively. This study indicates the importance to screen different fungal species/strains using the same substrate; and later, reproduce the same selection trial on other biomasses. A considerable variation is also seen when different species were used to treat the same biomass, i.e. wheat straw (Table 
1.1). Tuyen et al. (2012) tested the capabilities of 11 different white-rot fungi species in improving the ruminal degradability of wheat straw - only 3 species showed significant potential: C. subvermispora, L. edodes and P. eryngii. Different strains of each of these 3 species were subjected to the selection trial of this thesis; and wheat straw was used as the model substrate.

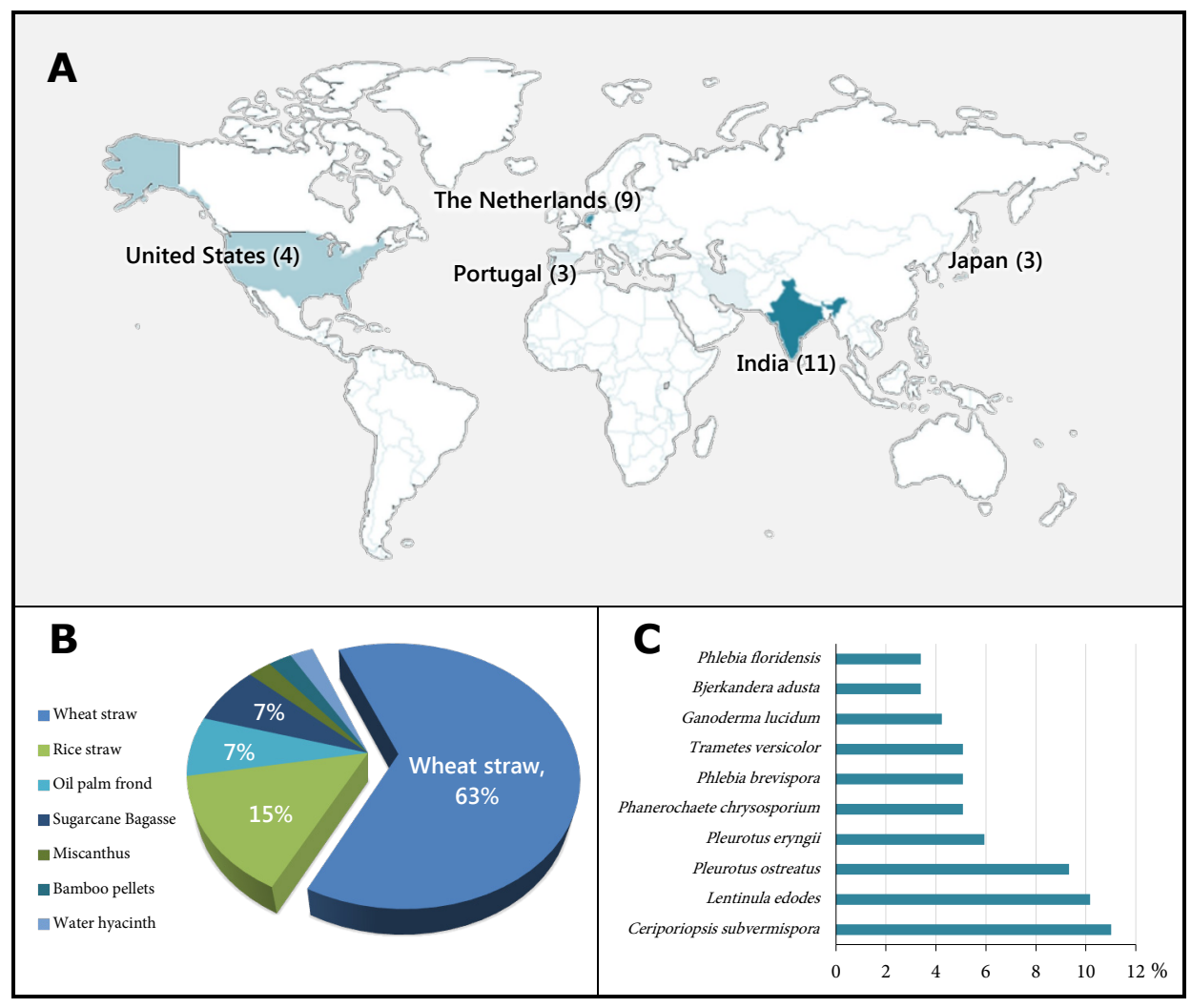

Fig. 1.2. Summary of 37 scientific articles dealing with bioprocessing of biomass into animal feed using white-rot fungi. A: Heat map showing locations of the principal research groups with a darker shade indicating a higher number of publications. Selected countries are indicated with the number of papers in parentheses; B: Types of biomass used. Wood chips (used in 6 studies) was excluded from the analysis; C: Top 10 choices of fungal species (out of 44 different species). 
Table 1.1. Degradation of the cell wall components and changes in the in vitro degradability of wheat straw treated with various white-rot fungi species.

\begin{tabular}{|c|c|c|c|c|c|c|c|c|c|}
\hline \multirow{2}{*}{ Fungi } & \multirow{2}{*}{ 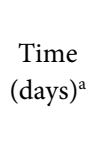 } & \multicolumn{3}{|c|}{$\begin{array}{c}\text { Composition of } \\
\text { untreated straw }(\%)^{b}\end{array}$} & \multicolumn{3}{|c|}{ Degradation (\%) } & \multirow{2}{*}{$\begin{array}{c}\text { Changes } \\
\text { in deg. } \\
(\%)^{c}\end{array}$} & \multirow[t]{2}{*}{ Ref. } \\
\hline & & Cell & Hcell & $\mathrm{ADL}$ & Cell & Hcell & $\mathrm{ADL}$ & & \\
\hline C. subvermispora & 56 & $44 . .0$ & 32.3 & 7.5 & -11.4 & 73.1 & 77.3 & +34.6 & {$[8]$} \\
\hline C. subvermispora & 49 & 46.1 & 28.9 & 9.2 & -5.0 & 53.6 & 59.8 & +57.5 & [7] \\
\hline Crinipellis sp. & 15 & 39.5 & 29.4 & 10.5 & 15.9 & 48.3 & 27.6 & +10.3 & {$[5]$} \\
\hline L. edodes & 84 & 48.0 & 26.0 & 8.1 & -5.6 & 34.2 & 45.7 & +23.1 & {$[9]$} \\
\hline L. edodes & 56 & 44.0 & 32.3 & 7.5 & -18.0 & 58.7 & 61.3 & +27.7 & {$[8]$} \\
\hline L. edodes & 49 & 46.1 & 28.9 & 9.2 & -3.9 & 46.0 & 52.2 & +35.0 & {$[7]$} \\
\hline L. ulmadum & 30 & 41.2 & 25.0 & 8.9 & -1.9 & 15.2 & 10.1 & -18.2 & {$[4]$} \\
\hline P. eryngii & 21 & 54.8 & 20.7 & 8.0 & 8.2 & 10.6 & 10.0 & +33.8 & {$[3]$} \\
\hline P. ostreatus & 30 & 34.1 & 30.8 & 9.8 & 37.8 & 45.1 & 37.8 & -8.8 & {$[6]$} \\
\hline P. ostreatus & 120 & 45.3 & 26.3 & 10.9 & 24.7 & 71.9 & 34.9 & $\mathrm{n} / \mathrm{d}$ & {$[1]$} \\
\hline P. ostreatus & 30 & 41.2 & 25.0 & 8.9 & 5.1 & 26.4 & 30.3 & +22.7 & {$[4]$} \\
\hline P. sajor-caju & 20 & 30.8 & 25.8 & 13.6 & 55.8 & 48.1 & 52.9 & +35.3 & {$[2]$} \\
\hline P. eryngii & 49 & 46.1 & 28.9 & 9.2 & -1.7 & 22.5 & 27.2 & +25.0 & {$[7]$} \\
\hline P. ostreatus & 30 & 41.2 & 25.0 & 8.9 & 12.4 & 40.4 & 15.7 & +15.9 & {$[4]$} \\
\hline T. gibbosa & 30 & 41.2 & 25.0 & 8.9 & 7.5 & 62.4 & 27.0 & +29.5 & {$[4]$} \\
\hline T. versicolor & 30 & 34.1 & 30.8 & 9.8 & 34.0 & 39.9 & 31.6 & +1.4 & {$[6]$} \\
\hline
\end{tabular}

ADL: acid detergent lignin; Cell: cellulose; Hcell: hemicellulose; $\mathrm{n} / \mathrm{d}$ : not determined; References: [1] Adamović et al., 1998; [2] Bisaria et al., 1997; [3] Fazaeli et al., 2004; [4] Jalč et al., 1998; [5] Shrivastava et al., 2014; [6] Shrivastava et al., 2011; [7] Tuyen et al., 2012; [8] Van Kuijk et al., 2017; [9] Van Kuijk et al., 2015a.

a colonization time.

${ }^{\mathrm{b}}$ determined by Van Soest et al. (1991) method.

${ }^{c}$ measure of ruminal degradability (in vitro gas production or organic matter digestibility).

\section{Research justification}

This research was part of the "More Meat and Milk from Straw" project (see Textbox 1.2). The unique capability of fungi during their vegetative growth stage is being exploited in this project to improve the degradability of wheat straw, which has a relatively poor nutritional value for ruminants. The outcome of this thesis will contribute to a better understanding of variation among different fungal strains in changing the nutrient composition and structural characteristics of the wheat straw. Furthermore, these phenotypic variations will benefit fungal breeder in selecting strains with the desired traits, to produce a superior strain with a better bioprocess capability. 


\section{Textbox 1.2. "More Meat and Milk from Straw" Project}

A partnership project between the Animal Nutrition and Mushroom Research Groups of Wageningen University, the Netherlands and funded by the Victam Foundation, Deka and Agrifirm. The project encompasses 3 main aspects, which are translated into 3 different $\mathrm{PhD}$ sub-projects: (1) Selecting the best performing fungal strains (this thesis); (2) Possibility to ensile the fungal-treated straw; (3) Production performance of animals fed with rations containing fungal treated straw. These sub-projects have the common aim: increasing the efficiency of ruminants in utilizing poorly digestible biomass by an optimized method of fungal pretreatment, i.e. using high potential fungal strains.

This eco-friendly approach has the potential to make a significant contribution to the global feed and food supply, to meet the increasing demand for animal-based products of the ever growing human population, in a sustainable manner.

\section{Aim and thesis outline}

The general aim of this thesis is to discern the biological variation among genetically different fungi in the bioprocessing of biomass into ruminant feed and selecting the best performing fungal strains, by using wheat straw as the model substrate. The outline of this thesis is illustrated in Fig. 1.2. As a start to the screening trial, in Chapter 2, two strains of $C$. subvermispora were assessed for their capabilities to improve the in vitro degradability in the rumen, as measured using a gas production technique (Cone et al., 1996) in relation to their growth characteristics and lignin-degrading enzyme activities. In the next stage (Chapter 3), different strains from 3 promising fungal species (Tuyen et al., 2012): C. subvermispora, P. eryngii and L. edodes were assessed for their growth characteristics and the screening of the best performing fungal strains was investigated using in vitro degradability in rumen fluid as a selection criterion. In the same chapter, three of the best strains for each species were further compared for their differences in gas production kinetics and other fermentation characteristics; as well as changes in the mass balance of the wheat straw. Two high-ranked strains of each species were subjected to three follow-up studies involving variation in protein solubilization (Chapter 4) and advanced assessment of the fungal-treated wheat straw (Chapter 5 and 6). In Chapter 4, the crude protein of the fungal-treated wheat straw was fractionated according to Sniffen et al. (1992); and the substrate was also evaluated for in vitro protein fermentation (Cone 
et al., 2009). In Chapter 5, accuracy in the assessment of cell wall components in the fungal-treated straw using the standard gravimetric method was compared to the more specific pyrolysis-GC/MS and monosaccharide analysis methods, and their relationship to the in vitro gas production. Chapter 6 characterized the unique mechanisms of different fungal species in degrading lignin using a combined pyrolysis-GC/MS and 2Dnuclear magnetic resonance (NMR) approach. The persistency of the selected high potential strains of C. subvermispora and L. edodes on improving wheat straw of different maturities and cultivars were studied in Chapter 7. Finally, the findings from all 6 research chapters are discussed in Chapter 8.

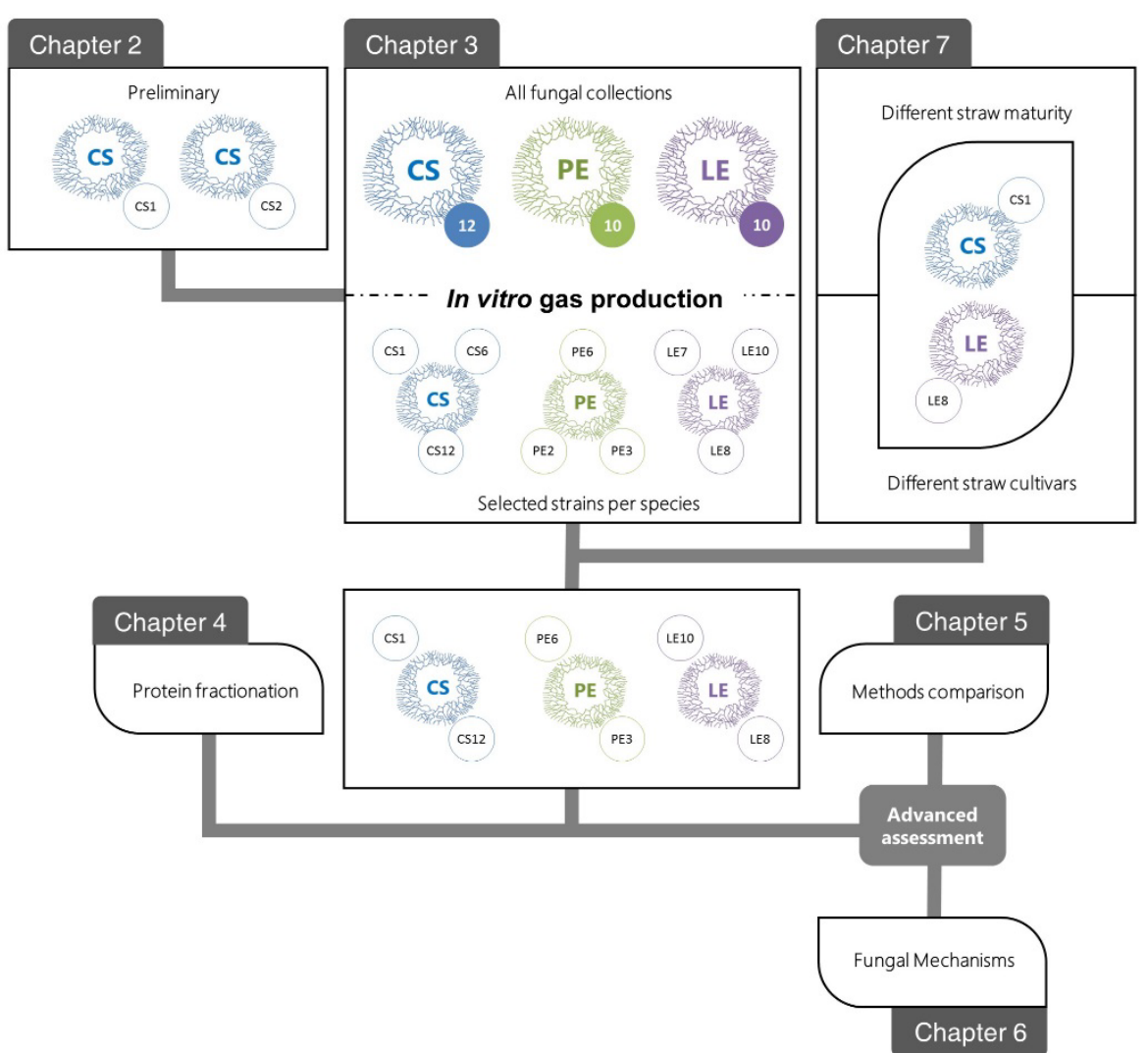

Fig. 1.3. The general outline of this thesis. CS: Ceriporiopsis subvermispora; PE: Pleurotus eryngii; LE: Lentinula edodes. Shaded circles indicate number of strains used, while selected strain numbers are shown in white circles. 


\section{REFERENCES}

Adamović, M., Grubić, G., Milenković, I., Jovanović, R., Protić, R., Sretenović, L., and Stoićević, L. (1998). The biodegradation of wheat straw by Pleurotus ostreatus mushrooms and its use in cattle feeding. Anim. Feed Sci. Technol. 71, 357-362.

Adaskaveg, J.E., and Gilbertson, R.L. (1986). In vitro decay studies of selective delignification and simultaneous decay by the white rot fungi Ganoderma lucidum and G. tsugae. Botany 64, 1611-1619.

Adaskaveg, J.E., Gilbertson, R.L., and Blanchette, R.A. (1990). Comparative studies of delignification caused by Ganoderma species. Appl. Environ. Microbiol. 56, 1932-1943.

Akin, D.E., and Benner, R. (1988). Degradation of polysaccharides and lignin by ruminal bacteria and fungi. Appl. Environ. Microbiol. 54, 1117-1125.

Asina, F.N.U., Brzonova, I., Kozliak, E., Kubátová, A., and Ji, Y. (2017). Microbial treatment of industrial lignin: Successes, problems and challenges. Renew. Sustain. Energy Rev. 77, 1179-1205.

Banerjee, A. (2011). Food, Feed, Fuel: Transforming the competition for grains. Dev. Change 42, 529-557.

Bisaria, R., Madan, M., and Vasudevan, P. (1997). Utilisation of agro-residues as animal feed through bioconversion. Bioresour. Technol. 59, 5-8.

Blanchette, R.A. (1995). Degradation of the lignocellulose complex in wood. Can. J. Bot. 73, 999-1010.

Boyle, C.D., Kropp, B.R., and Reid, I.D. (1992). Solubilization and mineralization of lignin by white rot fungi. Appl. Environ. Microbiol. 58, 3217-3224.

Bruinsma, J. (2003). World agriculture: towards 2015/2030. An FAO perspective., Food and Agriculture Organization of the United Nations. Earthscan, Rome.

Buranov, A.U., and Mazza, G. (2008). Lignin in straw of herbaceous crops. Ind. Crops Prod. 28, 237-259.

Camarero, S., Galletti, G.C., and Martinez, A.T. (1994). Preferential degradation of phenolic lignin units by two white rot fungi. Appl. Environ. Microbiol. 60, 4509-4516.

Chaturvedi, V., and Verma, P. (2013). An overview of key pretreatment processes employed for bioconversion of lignocellulosic biomass into biofuels and value added products. 3 Biotech 3, 415-431.

Chen, H. (2014). Chemical composition and structure of natural lignocellulose. In: Chen, H. (Ed.), Biotechnology of Lignocellulose: Theory and Practice. Springer, Dordrecht, pp. 25-68.

Christopher, L.P., Yao, B., and Ji, Y. (2014). Lignin biodegradation with laccase-mediator systems. Front. Energy Res. 2, 1-13.

Commanday, F., and Macy, J.M. (1985). Effect of substrate nitrogen on lignin degradation by Pleurotus ostreatus. Arch. Microbiol. 142, 61-65.

Cone, J.W., Rodrigues, M.A.M., Guedes, C.M., and Blok, M.C. (2009). Comparison of protein fermentation characteristics in rumen fluid determined with the gas production technique and the nylon bag technique. Anim. Feed Sci. Technol. 153, 28-38.

Cone, J.W., van Gelder, A.H., Visscher, G.J.W., and Oudshoorn, L. (1996). Influence of rumen fluid and substrate concentration on fermentation kinetics measured with a fully automated time related gas production apparatus. Anim. Feed Sci. Technol. 61, 113-128.

Dashtban, M., Schraft, H., Syed, T.A., and Qin, W. (2010). Fungal biodegradation and enzymatic modification of lignin. Int. J. Biochem. Mol. Biol. 1, 36-50.

Dorado, J., Field, J.A., Almendros, G., and Sierra-Alvarez, R. (2001). Nitrogen-removal with protease as a method to improve the selective delignification of hemp stemwood by the white-rot fungus Bjerkandera sp. strain BOS55. Appl. Microbiol. Biotechnol. 57, 205-211. 
Fazaeli, H., Mahmodzadeh, H., Azizi, A., Jelan, Z.A., Liang, J.B., Rouzbehan, Y., and Osman, A. (2004). Nutritive value of wheat straw treated with Pleurotus fungi. Asian-Australasian J. Anim. Sci. 17, 1681-1688.

FAO (2016). FAOSTAT. Crop production (wheat). Accessed 9 July 2018 from http://www.fao.org/faostat.

Hansen, M.A.T., Hidayat, B.J., Mogensen, K.K., Jeppesen, M.D., Jørgensen, B., Johansen, K.S., and Thygesen, L.G. (2013). Enzyme affinity to cell types in wheat straw (Triticum aestivum L.) before and after hydrothermal pretreatment. Biotechnol. Biofuels 6, 1-15.

Hatakka, A., and Hammel, K. (2010). Fungal biodegradation of lignocelluloses. In: Hofrichter, M. (Ed.), Industrial Applications (The Mycota). Springer, pp. 319-340.

Hendriks, A.T.W.M., and Zeeman, G. (2009). Pretreatments to enhance the digestibility of lignocellulosic biomass. Bioresour. Technol. 100, 10-18.

Himmel, M.E., Ding, S., Johnson, D.K., Adney, W.S., Nimlos, M.R., Brady, J.W., and Foust, T.D. (2007). Biomass recalcitrance: Engineering plants and enzymes for biofuels production. Science (80-. ). 454, 804-807.

Hofrichter, M. (2002). Review: lignin conversion by manganese peroxidase (MnP). Enzyme Microb. Technol. 30, 454-466.

Isroi, Millati, R., Syamsiah, S., Niklasson, C., Cahyanto, M.N., Lundquist, K., and Taherzadeh, M.J. (2011). Biological pretreatment of lignocelluloses with white-rot fungi and its applications: A review. BioResources 6, 5224-5259.

Jalč, D., Nerud, F., and Siroka, P. (1998). The effectiveness of biological treatment of wheat straw by white-rot fungi. Folia Microbiol. (Praha). 43, 687-689.

Jönsson, L.J., and Martín, C. (2016). Pretreatment of lignocellulose: Formation of inhibitory by-products and strategies for minimizing their effects. Bioresour. Technol. 199, 103-112.

Jovanovic, I., Magnuson, J.K., Collart, F., Robbertse, B., Adney, W.S., Himmel, M.E., and Baker, S.E. (2009). Fungal glycoside hydrolases for saccharification of lignocellulose: Outlook for new discoveries fueled by genomics and functional studies. Cellulose 16, 687-697.

Kirk, T.K., and Farrell, R.L. (1987). Enzymatic "combustion": The microbial degradation of lignin. Annu. Rev. Microbiol. 41, 465-505.

Krause, D.O., Denman, S.E., Mackie, R.I., Morrison, M., Rae, A.L., Attwood, G.T., and McSweeney, C.S. (2003). Opportunities to improve fiber degradation in the rumen: Microbiology, ecology, and genomics. FEMS Microbiol. Rev. 27, 663-693.

Kubicek, C.P. (2013). Fungi and Lignocellulosic Biomass, 1st ed. Wiley-Blackwell, Hoboken.

Leatham, G.F., and Kent Kirk, T. (1983). Regulation of ligninolytic activity by nutrient nitrogen in white-rot basidiomycetes. FEMS Microbiol. Lett. 16, 65-67.

Lowe, S.E., Theodorou, M.K., and Trinci, A.P.J. (1987). Cellulases and xylanase of an anaerobic rumen fungus grown on wheat straw, wheat straw holocellulose, cellulose, and xylan. Appl. Environ. Microbiol. 53, 1216-1223.

Martinez, A.T., Speranza, M., Ruiz-Duenas, F.J., Ferreira, P., Camarero, S., Guillen, F., Martinez, M.J., Gutierrez, A., and del Rio, J.C. (2005). Biodegradation of lignocellulosics: Microbial, chemical, and enzymatic aspects of the fungal attack of lignin. Int. Microbiol. 8, 195-204.

McSweeney, C.S., Dulieu, A., Katayama, Y., and Lowry, J.B. (1994). Solubilization of lignin by the ruminal anaerobic fungus Neocallimastix patriciarum. Appl. Environ. Microbiol. 60, 2985-2989.

Mittal, S.K., Singh, N., Agarwal, R., Awasthi, A., and Gupta, P.K. (2009). Ambient air quality during wheat and rice crop stubble burning episodes in Patiala. Atmos. Environ. 43, 238-244.

Moore, K.J., and Jung, H.-J.G. (2001). Lignin and Fiber Digestion. J. Range Manag. 54, 420-430. 
Okano, K., Iida, Y., Samsuri, M., Prasetya, B., Usagawa, T., and Watanabe, T. (2006). Comparison of in vitro digestibility and chemical composition among sugarcane bagasses treated by four white-rot fungi. Anim. Sci. J. 77, 308-313.

Pollegioni, L., Tonin, F., and Rosini, E. (2015). Lignin-degrading enzymes. FEBS J. 282, 1190-1213.

Rahman, M.M., Lourenço, M., Hassim, H.A., Baars, J.J.P., Sonnenberg, A.S.M., Cone, J.W., De Boever, J., and Fievez, V. (2011). Improving ruminal degradability of oil palm fronds using white rot fungi. Anim. Feed Sci. Technol. 169, 157-166.

Riley, R., Salamov, A.A., Brown, D.W., Nagy, L.G., Floudas, D., Held, B.W., Levasseur, A., Lombard, V., Morin, E., Otillar, R., Lindquist, E.A., Sun, H., LaButti, K.M., Schmutz, J., Jabbour, D., Luo, H., Baker, S.E., Pisabarro, A.G., Walton, J.D., Blanchette, R.A., Henrissat, B., Martin, F., Cullen, D., Hibbett, D.S., and Grigoriev, I. V. (2014). Extensive sampling of basidiomycete genomes demonstrates inadequacy of the white-rot/brown-rot paradigm for wood decay fungi. Proc. Natl. Acad. Sci. 111, 9923-9928.

Rodrigues, M.A.M., Pinto, P., Bezerra, R.M.F., Dias, A.A., Guedes, C.V.M., Cardoso, V.M.G., Cone, J.W., Ferreira, L.M.M., Colaço, J., and Sequeira, C.A. (2008). Effect of enzyme extracts isolated from white-rot fungi on chemical composition and in vitro digestibility of wheat straw. Anim. Feed Sci. Technol. 141, 326-338.

Ruiz, H.A., Vicente, A.A., and Teixeira, J.A. (2012). Kinetic modeling of enzymatic saccharification using wheat straw pretreated under autohydrolysis and organosolv process. Ind. Crops Prod. 36, 100-107.

Sarnklong, C., Cone, J.W., Pellikaan, W., and Hendriks, W.H. (2010). Utilization of rice straw and different treatments to improve its feed value for ruminants: A review. Asian-Australasian J. Anim. Sci. 23, 680 692.

Sharma, R.K., and Arora, D.S. (2010). Changes in biochemical constituents of paddy straw during degradation by white rot fungi and its impact on in vitro digestibility. J. Appl. Microbiol. 109, 679-686.

Shrivastava, B., Jain, K.K., Kalra, A., and Kuhad, R.C. (2014). Bioprocessing of wheat straw into nutritionally rich and digested cattle feed. Sci. Rep. 4, 6360.

Shrivastava, B., Thakur, S., Khasa, Y.P., Gupte, A., Puniya, A.K., and Kuhad, R.C. (2011). White-rot fungal conversion of wheat straw to energy rich cattle feed. Biodegradation 22, 823-831.

Sniffen, C.J.J., Connor, D.O., and Russell, J.B. (1992). A Net Carbohydrate and Protein System for evaluating cattle diets : II . Carbohydrate and protein availability. J. Anim. Sci. 70, 3562-3577.

Teymouri, F., Laureano-Perez, L., Alizadeh, H., and Dale, B.E. (2005). Optimization of the ammonia fiber explosion (AFEX) treatment parameters for enzymatic hydrolysis of corn stover. Bioresour. Technol. 96, 2014-2018.

Tuyen, V.D., Phuong, H.N., Cone, J.W., Baars, J.J.P., Sonnenberg, A.S.M., and Hendriks, W.H. (2013). Effect of fungal treatments of fibrous agricultural by-products on chemical composition and in vitro rumen fermentation and methane production. Bioresour. Technol. 129, 256-263.

Tuyen, V.D., Cone, J.W., Baars, J.J.P., Sonnenberg, A.S.M., and Hendriks, W.H. (2012). Fungal strain and incubation period affect chemical composition and nutrient availability of wheat straw for rumen fermentation. Bioresour. Technol. 111, 336-342.

Van Kuijk, S.J.A., Sonnenberg, A.S.M., Baars, J.J.P., Hendriks, W.H., and Cone, J.W. (2015a). Fungal treated lignocellulosic biomass as ruminant feed ingredient: A review. Biotechnol. Adv. 33, 191-202.

Van Kuijk, S.J.A., Sonnenberg, A.S.M., Baars, J.J.P., Hendriks, W.H., and Cone, J.W. (2015b). Fungal treatment of lignocellulosic biomass: Importance of fungal species, colonization and time on chemical composition and in vitro rumen degradability. Anim. Feed Sci. Technol. 209, 40-50. 
Van Kuijk, S.J.A., Sonnenberg, A.S.M., Baars, J.J.P., Hendriks, W.H., del Río, J.C., Rencoret, J., Gutiérrez, A., de Ruijter, N.C.A., and Cone, J.W. (2017). Chemical changes and increased degradability of wheat straw and oak wood chips treated with the white rot fungi Ceriporiopsis subvermispora and Lentinula edodes. Biomass Bioenergy 105, 381-391.

Van Soest, P.J., Robertson, J.B., and Lewis, B.A. (1991). Methods for dietary fiber, neutral detergent fiber, and nonstarch polysaccharides in relation to animal nutrition. J. Dairy Sci. 74, 3583-3597.

Wan, C., and Li, Y. (2012). Fungal pretreatment of lignocellulosic biomass. Biotechnol. Adv. 30, 1447-1457.

Zhang, H., Thygesen, L.G., Mortensen, K., Kádár, Z., Lindedam, J., Jørgensen, H., and Felby, C. (2014). Structure and enzymatic accessibility of leaf and stem from wheat straw before and after hydrothermal pretreatment. Biotechnol. Biofuels 7, 74. 


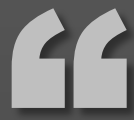

We need an opposition to remind us if we are making mistakes. When you are not opposed you think everything you do is right.

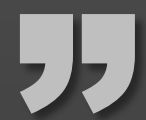

- MAHATHIR MOHAMAD 


\section{Differences between two strains of Ceriporiopsis subvermisporaon improving the nutritive value of wheat straw for ruminants}

Nazri Nayan ${ }^{1}$, Anton S.M. Sonnenberg ${ }^{2}$, Wouter H. Hendriks ${ }^{1}$, and John W. Cone ${ }^{1}$

J. Appl. Microbiol. (2017). 123(2):352-361.

1 Animal Nutrition Group, Wageningen University, De Elst 1, 6708 WD Wageningen, the Netherlands

2 Plant Breeding, Wageningen University and Research, Droevendaalsesteeg 1, 6708 PB Wageningen, the Netherlands 


\section{ABSTRACT}

The present study evaluated differences between two strains of Ceriporiopsis subvermispora on improving the nutritive value and in vitro degradability of wheat straw. Wheat straw was treated with the fungi for 7 weeks. Weekly samples were analyzed for ergosterol content, in vitrogas production (IVGP), chemical composition and lignin degrading enzyme activity. Ergosterol data showed CS1 to have a faster initial growth than CS2 and reaching a stationary phase after 3 weeks. The IVGP of CS1-treated wheat straw exceeded the control earlier than CS2 (4 vs 5 weeks). CS1 showed a significantly higher $(P<0.001)$ selectivity in lignin degradation compared to CS2. Both strains showed peak activity of laccase and manganese peroxidase $(\mathrm{MnP})$ at week 1 . CS1 showed a significantly higher $(P<0.001)$ laccase activity, but lower $(P=$ $0.008) \mathrm{MnP}$ activity compared to CS2. Both CS strains improved the nutritive value of wheat straw. Variation between strains was clearly demonstrated by their growth pattern and enzyme activities. The differences among the two strains provide an opportunity for future selection and breeding programs in improving the extent and selectivity of lignin degradation in agricultural biomass.

Keywords: Ceriporiopsis subvermispora; strains differences; lignin degradation; in vitro gas production; enzymes; wheat straw; ruminants 


\section{INTRODUCTION}

gricultural biomass, such as wheat straw has great potential as a valuable resource 1 for a wide range of applications, including utilization as an animal feed. Many of these agricultural by-products are available in abundant quantities (Isroi et al., 2011). Utilization of wheat straw as a feed ingredient by ruminants is considered to be relatively low - 51\% digestible organic matter in vivo (Lesoing et al., 1980), due to encrustation with lignin that hinders the degradation of cellulose and hemicellulose by the rumen microbes (Van Kuijk et al., 2015a). Therefore, complete or partial removal of lignin in the wheat straw is a prerequisite to realize its potential as a ruminant feed.

Several physical and chemical methods have been used to overcome the lignin barrier in the utilization of lignin-rich biomass (Hendriks and Zeeman, 2009). These methods, however, are often associated with significant costs and/or produce waste that can be detrimental to the environment (Isroi et al., 2011). Biological methods, including the use of fungi have many advantages over chemical and physical methods (Dinis et al., 2009; Shrivastava et al., 2011; Tuyen et al., 2012). Among the white-rot fungi, Ceriporiopsis subvermispora (Gilbertson \& Ryvarden, 1985), has been shown to have unique abilities to selectively degrade lignin and increase the fermentability of treated biomass by the rumen microflora (Shrivastava et al., 2011; Tuyen et al., 2012; Van Kuijk et al., 2015a). C. subvermispora has been studied in various other applications such as biopulping (Aguiar et al., 2010; de Souza-Cruz et al., 2004), enzymatic hydrolysis and bioethanol production (Wan and Li, 2010).

Degradation of lignin by white-rot fungi is a multi-enzymatic process with four major lignin degrading oxidases being involved with a number of auxiliary enzymes (Pollegioni et al., 2015). Lignin peroxidase (LiP) is an important enzyme in fungal ligninolysis, due to its very high redox potential, allowing the oxidation of recalcitrant non-phenolic lignin substructures (> 80\% of lignin) (Hatakka and Hammel, 2010; Pollegioni et al., 2015). Manganese peroxidase (MnP) is the most common peroxidase and is secreted by many white-rot fungi. This heme enzyme catalyzes the oxidation of $\mathrm{Mn}^{2+}$ into $\mathrm{Mn}^{3+}$. The latter is chelated by organic acids and acts as a diffusible oxidant of phenolic lignin substructures (<20\% of lignin) (Kirk and Farrell, 1987). Versatile peroxidase (VP) has a broad substrate specificity and shares the typical features of LiP and $\mathrm{MnP}$. Laccase is a copper-containing enzyme which has a wide range of functions in fungi, including the formation of fruiting bodies, pigmentation, stress defense, as well as lignin degradation. The role of laccase in lignin degradation has been the subject of interest in numerous studies (Arora et al., 2002; Arantes and Milagres, 2007; Dinis et al., 2009). 
Assessment of enzyme activities will provide a better understanding on the selectivity of different fungal species/strains in degrading lignin. It can be an important criterion for selecting a potential fungus for breeding programs. Different white-rot fungi species showed different effects on the lignocellulose composition and ruminal degradability of the treated substrate (Tuyen et al., 2012). In addition, Mata et al. (1998) observed quantitative variations in the enzyme activities of six strains of Lentinula edodes grown on wheat straw, although they exhibited a similar pattern along the colonization weeks. These studies indicate that not only examining fungi-biomass combination is important but also screening strains within species to optimize the selective lignin degradation of lignin-rich biomass.

As a start for future selection of the best performing fungal species and strains, a study was conducted with the aim to evaluate differences between two strains of $C$. subvermispora for their ability to improve the in vitro degradability and nutritive value of the wheat straw in the rumen in relation to their growth characteristics and lignindegrading enzymes activities.

\section{MATERIALS AND METHODS}

\section{Preparation of fungal strains and spawn}

Two strains of C. subvermispora, CS1 (MES 13094/CBS 347.63) and CS2 (MES 14407/ACCC31512) maintained in the liquid nitrogen collection of the Plant Breeding group, Wageningen, the Netherlands were used. Both strains were propagated on malt agar extract, containing malt extract $20.0 \mathrm{~g} \mathrm{l}^{-1}, \mathrm{KH}_{2} \mathrm{PO}_{4} 0.5 \mathrm{~g} \mathrm{l}^{-1}, \mathrm{MgSO}_{4} \cdot 7 \mathrm{H}_{2} \mathrm{O} 0.5 \mathrm{~g} \mathrm{l}^{-1}$, $\mathrm{Ca}\left(\mathrm{NO}_{3}\right)_{2} \cdot 4 \mathrm{H}_{2} \mathrm{O} 0.5 \mathrm{~g} \mathrm{l}^{-1}$ with a $\mathrm{pH}$ of 5.4 and incubated at $24^{\circ} \mathrm{C}$ until the mycelia colonized most of the agar surface. The spawns of CS1 and CS2 were prepared by placing a piece of the agar culture $(1.5 \times 2.0 \mathrm{~cm})$ into a container containing sterilized sorghum grains and incubated at $24^{\circ} \mathrm{C}$ for 4 to 5 weeks. The sorghum grains were sterilized by submerging in boiled water, then drained for the excess water and autoclaved at $121^{\circ} \mathrm{C}$ for $20 \mathrm{~min}$.

\section{Substrate preparation, fungal inoculation and sampling}

Wheat straw (Triticum aestivum L.) was used as substrate which was chopped into approximately $3 \mathrm{~cm}$ pieces and soaked in tap water for 3 days at room temperature. Water was drained from the wet straw through a perforated strainer (pore size $=5 \mathrm{~mm}$ ) for 5 hours resulting in a final moisture content of $76.8 \%$. The straw was then distributed into $172 \times 110 \times 70 \mathrm{~mm}(1200 \mathrm{ml})$ micropropagation containers (Combiness, Nevele, Belgium) 
with approximately $160 \mathrm{~g}$ per container. All containers were autoclaved at $121^{\circ} \mathrm{C}$ for $1 \mathrm{~h}$ and allowed to cool overnight in an aseptic room at room temperature. Pre- and postautoclaved wheat straw was sampled to determine the effect of autoclaving on the chemical composition. The autoclaved straw was aseptically inoculated with the spawn at $10 \%$ of the estimated dry weight. The containers containing inoculated straw, along with containers of only autoclaved straw (control) were incubated in triplicate at $24^{\circ} \mathrm{C}$ for 7 weeks in a climate controlled chamber. Treatments (control, CS1 and CS2) were randomized in each week (block). No repeated measurement was done on the same straw sample. At each week, independent samples were weighed, thoroughly mixed and $\sim 40 \mathrm{~g}$ from each container was freeze-dried for the ergosterol and enzyme assays. The remaining sample from the same container $(\sim 120 \mathrm{~g})$ was air-dried at $70^{\circ} \mathrm{C}$ for a week and ground over a $1 \mathrm{~mm}$ sieve using a cross beater mill (100AN, Peppink, Olst, the Netherlands) for chemical analyses and in vitro gas production.

\section{Estimation of fungal biomass}

Fungal biomass was estimated by an ergosterol assay as described by Niemenmaa et al. (2008). In brief, a freeze-dried sample ( $200 \mathrm{mg})$ was weighed into a glass tube and extracted with a $3 \mathrm{ml} \mathrm{10 \%} \mathrm{potassium} \mathrm{hydroxide} \mathrm{in} \mathrm{methanol} \mathrm{solution} \mathrm{on} \mathrm{a} \mathrm{rotary} \mathrm{shaker}$ (Labotech, Maharashtra, India) for $10 \mathrm{~min}$ at $230 \mathrm{rev} \mathrm{min}^{-1}$ before saponification at $80^{\circ} \mathrm{C}$ in a heating block for $60 \mathrm{~min}$. The ergosterol was extracted by adding $1 \mathrm{ml}$ distilled water and $2 \mathrm{ml}$ hexane to the tube. The hexane phase was dried in a vacuum evaporation system (Rapidvap, Kansas, MO, USA) before being re-dissolved in methanol. The solution was filtered into a HPLC vial for Waters HPLC-PDA analysis (Alliance HPLC system, Milford, USA). A reversed phase C18 column $(250 \times 4.6 \mathrm{~mm}$, Phenomex aqua $5 \mu \mathrm{m})$ was used with the liquid phase in the HPLC system being $90 \%$ methanol and $10 \%(1: 1) 2$ propanol/hexane. Cholecalciferol (vitamin $\mathrm{D}_{3}$ ) was used as an internal standard and the ergosterol peak was detected at $280 \mathrm{~nm}$.

\section{In vitro gas production}

In vitro gas production, expressed as $\mathrm{ml} \mathrm{g}^{-1}$ of organic matter $(\mathrm{OM})$, was performed as described by Cone et al. (1996). In brief, rumen fluid was collected from two nonlactating, rumen fistulated cows fed $1 \mathrm{~kg}$ concentrate, and grass silage ad libitum. The strained rumen fluid was filtered through 2 layers of cheese cloth and mixed with a mineral-buffer solution. All procedures were conducted under continuous flushing with $\mathrm{CO}_{2}$. Samples were incubated with the buffered rumen fluid for $72 \mathrm{~h}$ and the gas 
production was automatically registered. The kinetic parameters $\left(A, B, C, t_{R \mathrm{~m}}\right.$ and $\left.R_{\mathrm{m}}\right)$ were determined by fitting a biphasic model (Groot et al., 1996) to the gas production data where $A$ is the asymptotic gas production $\left(\mathrm{ml} \mathrm{g}^{-1} \mathrm{OM}\right)$ at the two different phases that represents the fermentation of soluble (phase 1) and non-soluble fractions (phase 2); $B$ the half time of the maximum gas production (h); $C$ is a parameter to determine the steepness of the curve; $t_{R \mathrm{~m}}$ time of the maximum fractional rate of substrate degradation (h); and $R_{\mathrm{m}}$ the maximum fractional rate of substrate degradation $\left(\mathrm{h}^{-1}\right)$. As there was no significant change in $B$ and $C$ values of the first phase, only $A_{1}, A_{2}$ and the kinetic parameters of the second phase are presented.

\section{Chemical analysis}

The air-dried samples were dried in an oven at $103^{\circ} \mathrm{C}$ to determine the dry matter (DM) content (ISO 6496, 1999). Ash content was determined after combustion at $550^{\circ} \mathrm{C}$ for $3 \mathrm{~h}$ in a muffle furnace (ISO 5984, 2002). Nitrogen content was determined by the Kjeldahl method (ISO 5983, 2005) and crude protein calculated as $\mathrm{N} \times 6.25$. Neutral detergent fiber (NDF) was determined using heat-stable amylase (thermamyl) and alcalase, using the standard procedures of Van Soest et al. (1991). Acid detergent fiber (ADF) and acid detergent lignin (ADL) were also determined using the standard method (Van Soest et al., 1991). Hemicellulose was calculated as the difference between NDF and ADF, while cellulose was calculated as the different between ADF and ADL. Absolute amounts were calculated using data on the remaining air dry matter after fungal incubation corrected for DM content in the dried materials.

\section{Enzyme assays}

The freeze-dried samples were extracted with cold sodium acetate buffer ( $20 \mathrm{mmol} \mathrm{l}^{-}$ ${ }^{1}, \mathrm{pH} 5.0$ ) supplemented with $0.01 \%$ Tween 80 and $2 \%$ of polyvinylpolypyrrolidone

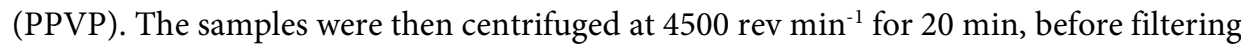
the supernatant through a Whatman No. 3 (Maidstone, UK) paper to obtain crude enzyme extracts. The LiP assay was based on the oxidation of Azure B $\left(\varepsilon_{651}=4.88 \times 104\right.$ $\mathrm{mol} \mathrm{l}^{-1} \mathrm{~cm}^{-1}$ ) (Archibald, 1992) with a final concentration in the mixture of $6.4 \mu \mathrm{mol} \mathrm{l}^{-1}$ in $50 \mathrm{mmol} \mathrm{l}^{-1}$ sodium tartrate buffer $(\mathrm{pH} \mathrm{3})$ in the presence of $0.5 \mathrm{mmol} \mathrm{l}^{-1} \mathrm{H}_{2} \mathrm{O}_{2}$ and measurement at $651 \mathrm{~nm}$. MnP activity was determined by the oxidation of phenol red $\left(\varepsilon_{610}=2.2 \times 10^{4} \mathrm{~mol} \mathrm{l}^{-1} \mathrm{~cm}^{-1}\right)$ with addition of $\mathrm{MnSO}_{4}$ (Arora et al., 2002). The final concentration of the reagents in the mixture were $20 \mathrm{mmol} \mathrm{l}^{-1}$ sodium succinate buffer (pH 4.5), $0.5 \mathrm{mmol} \mathrm{l}^{-1} \mathrm{MnSO}_{4}, 34 \mu \mathrm{mol} \mathrm{l}^{-1}$ phenol red (0.01\%), $25 \mathrm{mmol} \mathrm{l}^{-1}$ lactate buffer 
( $\mathrm{pH}$ 4.5) and $0.5 \mathrm{mmol} \mathrm{l}^{-1} \mathrm{H}_{2} \mathrm{O}_{2}$. The absorbance was monitored at $610 \mathrm{~nm}$. The reactions in the $\mathrm{LiP}$ and $\mathrm{MnP}$ assays were initiated by the addition of $\mathrm{H}_{2} \mathrm{O}_{2}$. Laccase was assayed using 2,6-dimethoxyphenol (DMP) as a substrate $\left(\varepsilon_{468}=4.96 \times 10^{4} \mathrm{~mol} \mathrm{l}^{-1} \mathrm{~cm}^{-1}\right)$ (More et al., 2011). The final concentration of the reagents in the mixture was $100 \mathrm{mmol}^{-1}$ sodium acetate buffer (pH 6.0) and $1 \mathrm{mmol} \mathrm{l}^{-1} \mathrm{DMP}$ (Sigma-Aldrich, St. Louis, MO, USA). The reaction was monitored at $468 \mathrm{~nm}$. One $\mathrm{ml}$ of enzyme extract was used in all three assays. The activities of the lignin degrading enzymes were calculated as follows:

$$
\text { Enzyme activity }\left(\mathrm{U} \mathrm{ml}^{-1}\right)=\frac{\Delta O D \times V_{A} \times D F \times 10^{6}}{V_{E} \times \varepsilon \times \Delta t}
$$

where $\triangle O D$ is the difference in absorbance $\left(A_{\text {samples }}-A_{\text {blanks }}\right)$ at a respective wavelength, $V_{A}$ is the volume of the assay mixture $(\mathrm{ml}), V_{E}$ is the volume of the enzyme extract $(\mu \mathrm{L})$, $D F$ is the dilution factor, $\varepsilon$ is the molar extinction coefficient and $\Delta t$ is the time difference (min). The final enzyme activity results were expressed as $\mathrm{U} \mathrm{kg}^{-1} \mathrm{DM}$.

\section{Statistical analysis}

Data were analyzed by two-way analysis of variance using the general linear model in SAS 9.3, followed by post-hoc multiple comparison using least significance differences. The statistical model used was as follows:

$$
Y_{i j}=\mu+\alpha_{i}+\tau_{j}+(\alpha \times \tau)_{i j}+\varepsilon_{i j}
$$

where $Y_{i j}=$ response variable $i j, \mu=$ overall mean, $\alpha_{i}=$ the effect of treatment $i, \tau_{j}=$ effect of week $j,(\alpha \times \tau)_{i j}=$ interaction of treatment $i$ and week $j$ and $\varepsilon_{i j}=$ residual error with a mean of 0 and variance $\sigma^{2} . \alpha_{i}$ was considered a fixed effect and $\tau_{j}$ a random effect. Minimum significance threshold was set at 0.05 . Pearson Product-Moment Correlation ( $r$ ) coefficients were also determined among the measured variables.

\section{RESULTS}

\section{Fungal growth}

Ergosterol analyses showed that CS1 grew more rapid during the first week of colonization compared to CS2, and achieved a stationary growth phase after 3 weeks (Fig. 2.1). At week $7, \mathrm{CS} 1$ had an ergosterol content of $159.6 \mu \mathrm{g} \mathrm{g} \mathrm{g}^{-1}$ substrate, which was significantly lower $(P<0.001)$ than CS2 which had an ergosterol content of $178 \mu \mathrm{gg}^{-1}$ substrate. The ergosterol content of the autoclaved straw (control) remained low and had a mean ergosterol content of $78.1 \mu \mathrm{g} \mathrm{g}^{-1}$ substrate after 7 weeks. 


\section{In vitro gas production}

Figure 2.2 shows the cumulative IVGP after $72 \mathrm{~h}$ of incubation in rumen fluid of wheat straw treated with CS1 and CS2, in comparison with the autoclaved wheat straw over the 7 week period. Both fungal-treated samples showed significantly higher $(P<$ 0.001) IVGP after 7 weeks of colonization compared to the autoclaved wheat straw. The difference in IVGP of the 7 week CS1 and CS2-treated straw, however, was not significant. The CS1-treated straw had a significant decrease $(P=0.006)$ in IVGP at week 1 compared to the corresponding straw at week 0 , while CS2-treated straw continued to decrease until week $2(P<0.001)$. Both CS-treated straw showed an increase in IVGP in the following weeks and significantly exceeded $(P<0.001)$ the autoclaved straw after week 4 and 5 for CS1 and CS2, respectively.

The gas production kinetic parameters of the control, CS1 and CS2-treated straw are summarized in Table 2.1. The increase in IVGP, along the colonization weeks are reflected by the $A_{1}$ and $A_{2}$ values. The second phase, gas production as a result of fermentation of the non-soluble fraction, showed significant increases $(P<0.001)$ in $C_{2}$ and $R_{\mathrm{m} 2}$ values during the incubation of the straw with both fungal strains. Contrast-wise, the fungal-treated straw was significantly different in the $C_{2}(P=0.025)$ and $R_{\mathrm{m} 2}(P=$ $0.002)$ values.

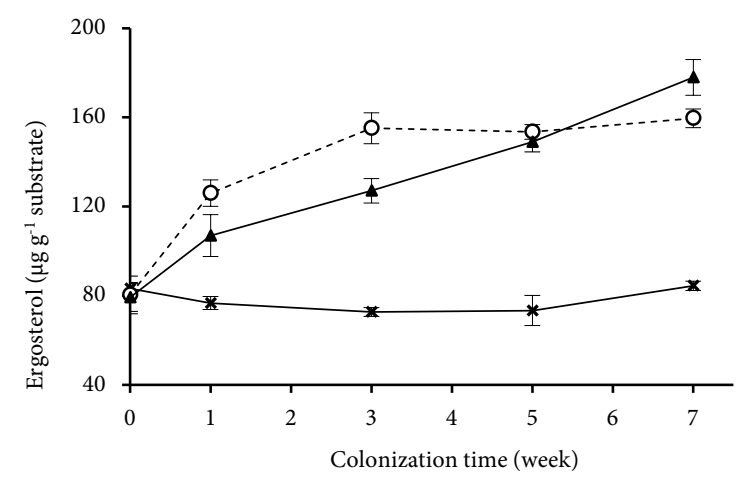

Fig. 2.1. Ergosterol content of autoclaved wheat straw $(X)$ or the same straw colonized by two strains of Ceriporiopsis subvermispora, CS1 (O) and CS2 ( $\mathbf{\Delta})$ for up to 7 weeks. Error bars represent standard deviations. 


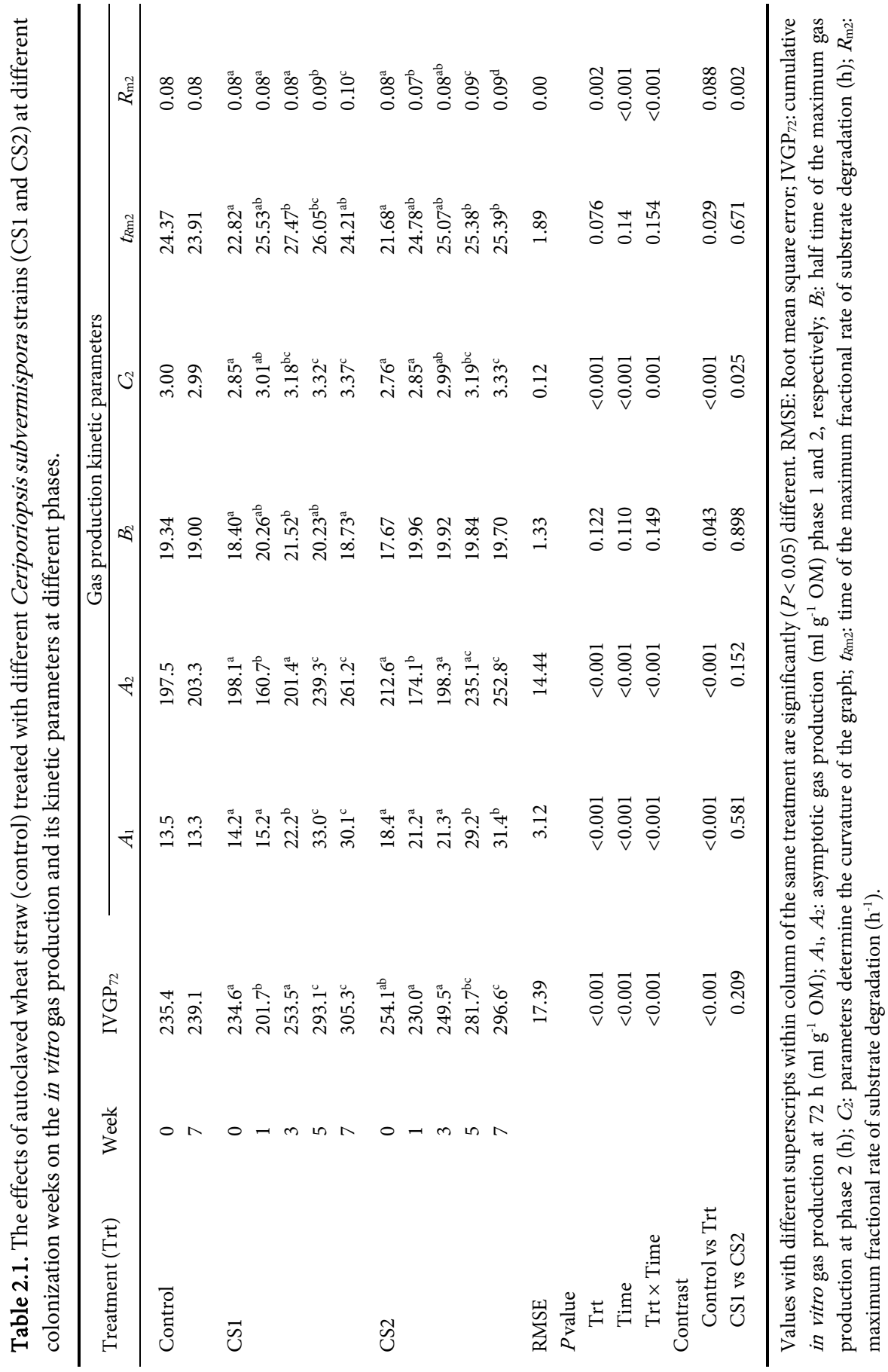




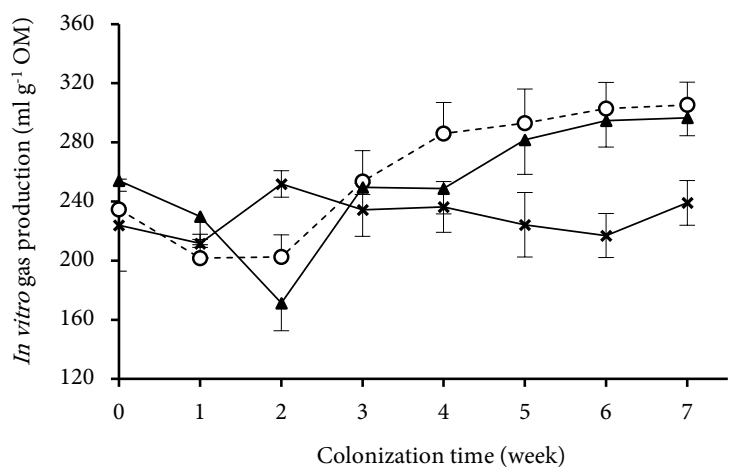

Fig. 2.2. Cumulative in vitro gas production after $72 \mathrm{~h}$ of incubation in rumen fluid for autoclaved wheat straw $(\mathbf{X})$ or the same straw colonized by two strains of Ceriporiopsis subvermispora, CS1 (O) and CS2 ( $\mathbf{\Delta})$ for up to 7 weeks. Error bars represent standard deviations.

\section{Chemical composition}

There was a significant increase $(P<0.012)$ in the ADL content in the DM of the substrate as a result of autoclaving (Table 2.2). Along the colonization weeks, treatment by both $C$. subvermispora strains resulted in a significant increase $(P<0.05)$ in the cellulose and CP contents; but a decrease $(P<0.001)$ in the DM, NDF, ADF, ADL and hemicellulose contents (Table 2.2). The CS1 and CS2-treated straw were remarkably different in their cell wall compositions. At week 7 , the cellulose content was higher $(P<$ 0.001) in the CS1-treated straw, but showed a lower $(P<0.001)$ hemicellulose content compared to the CS2-treated straw. Difference in the ADL content between both fungaltreated substrates was not significant. The contrast between the two strains in the absolute amounts of these cell wall components, however, was only significant for cellulose.

\section{Enzyme activities}

No lignin peroxidase (LiP) could be detected in any of the samples analyzed. There were significant effects $(P<0.001)$ of the fungal treatment of the straw on laccase and manganese peroxidase (MnP) activity (Fig. 2.3). Both lignin degrading enzymes showed peak activities at week 1 of fungal colonization. CS1-treated straw showed a significantly $(P<0.001)$ higher laccase activity at week $1\left(49.19 \mathrm{U} \mathrm{kg}^{-1} \mathrm{DM}\right)$ compared to CS2-treated straw which showed an activity of $19.76 \mathrm{U} \mathrm{kg}^{-1} \mathrm{DM}$. On the other hand, CS2-treated straw showed a MnP activity of $22.20 \mathrm{U} \mathrm{kg}^{-1} \mathrm{DM}$ at week 1 , which was significantly $(P=0.008)$ higher than the CS1-treated straw which had an activity of $10.59 \mathrm{U} \mathrm{kg}^{-1} \mathrm{DM}$. After a sharp 
Chapter 2 | Degradation of wheat straw by Ceriporiopsis sp. strains

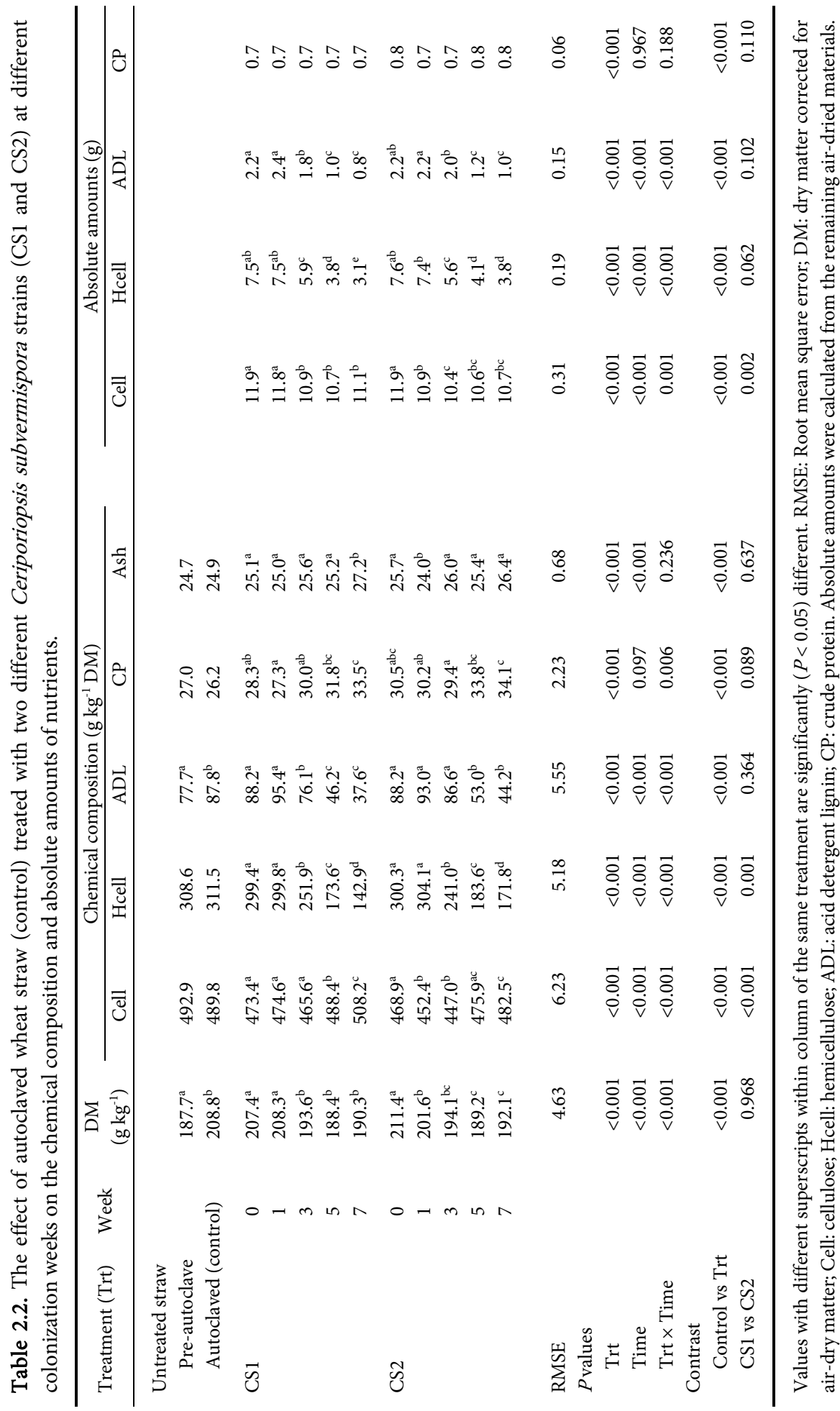



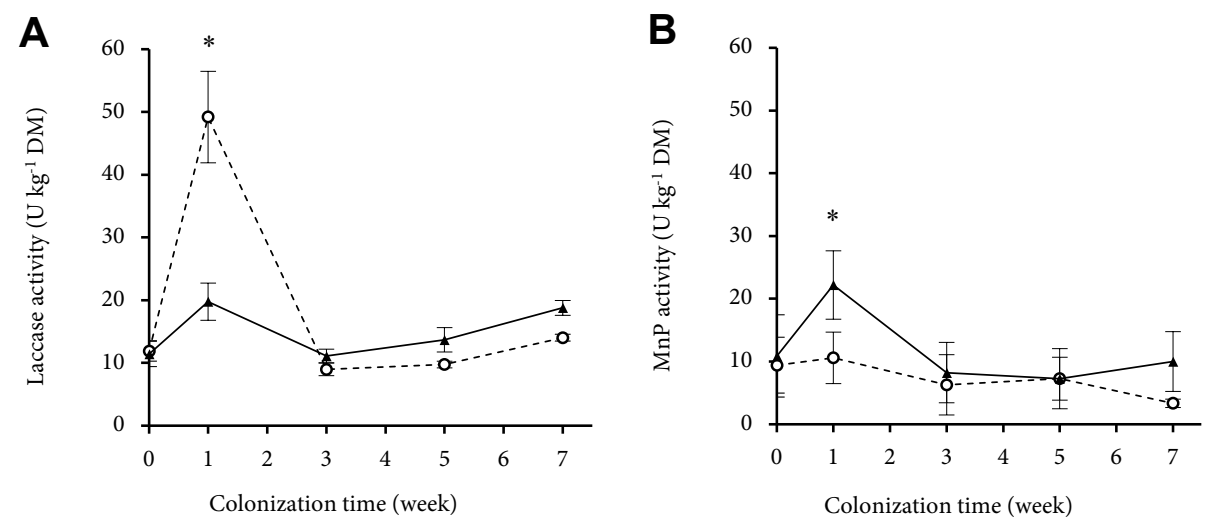

Fig. 2.3. Laccase (A) and manganese peroxidase (MnP; B) activity in autoclaved wheat straw colonized by two Ceriporiopsis subvermispora strains, CS1 (O) and CS2 ( $\mathbf{\Delta})$ for up to 7 weeks. Asterisks indicate significant $(P<0.01)$ difference of enzyme activity between the two strains. Error bars represent standard deviations.

decline at week 3 , there was a significant increase $(P<0.05)$ in laccase activity of the treated straw for both strains at week 7. No significant increase was observed in $\mathrm{MnP}$ activity after week 3 . Contrast-wise, laccase $(P<0.001)$ and $\mathrm{MnP}(P=0.021)$ activity in the CS1 and CS2-treated straw were significantly different.

\section{DISCUSSION}

The present study investigated the in vitro degradability and compositional changes in wheat straw treated with two strains of $C$. subvermispora over a 7 week period. We also assessed the activities of enzymes involved in lignin degradation and the colonization of the fungi over time. From previous work in our laboratory, C. subvermispora (CS1; MES 13094) has been shown to be a good candidate for the bioprocessing of wheat straw and other agricultural biomass for ruminant feed (Tuyen et al., 2013; Van Kuijk et al., 2016b). The present study compared the performance of the previously used strain CS1 (Tuyen et al., 2012) with a recently acquired strain CS2 (MES 14407). Variation within species offers opportunities to improve strain performance by breeding.

Ergosterol is regarded as a good indicator of fungal biomass, especially when the fungus is grown on solid medium (Gao et al, 1993). In the present study, background ergosterol content was detected in the autoclaved wheat straw. This is not unexpected since fungal microflora of the wheat plants have been described in several reports (Larran 
et al., 2007; Vujanovic et al., 2012). The persistence of ergosterol after sterilization has been reported by Mille-Lindblom et al. (2004). They found an ergosterol content of up to $250 \mu \mathrm{g} \mathrm{g}^{-1}$ dry weight in common reed (Phragmites) litter after autoclaving, indicating that ergosterol survives sterilization. Results from the ergosterol assay showed that both C. subvermispora strains successfully colonized the substrate. The variation among strains of the same species is clearly demonstrated by a marked difference in the growth pattern of both C. subvermispora strains. The initial growth of CS1 was faster than CS2 and reached a stationary phase after 3 weeks, similar as reported for this same strain (Van Kuijk et al., 2016b). CS2 on the other hand, had a slower initial colonization but sustained growth during the 7 weeks. The same growth pattern has been reported in studies on wood chips (Messner et al., 1998; Niemenmaa et al., 2008). Messner et al. (1998) for instance, observed a rapid increase in ergosterol content of $C$. subvermispora for the first 6 days of colonization, before it remained constant until day 14 with a plateau value of 45 $\mu \mathrm{g} \mathrm{g}^{-1}$ wood. These increases coincide with a more intensive production of aerial mycelia as the oxygen tension outside the substrate is higher allowing intensive fungal growth (Messner et al., 1998). After all easily accessible resources have been used for a rapid initial growth, the rate of biomass accumulation declines as the fungus starts producing secondary metabolites (Drew and Wallis, 1983; Liao et al., 1995).

In vitro gas production can be used as a tool to evaluate the degradability of fungaltreated wheat straw in rumen fluid. The IVGP values obtained for C. subvermispora by Tuyen et al. (2012) are comparable to the result presented here for CS1-treated wheat straw in the range of 300 to $310 \mathrm{ml} \mathrm{g}^{-1} \mathrm{OM}$ after 7 weeks of colonization. Both fungaltreated straw samples did not differ in their IVGP values at week 7. There was also a significant improvement in the IVGP of CS1-treated straw earlier in the colonization than of the CS2-treated straw. To investigate differences in their fermentation kinetics, a simple biphasic approach was used to represent the fermentation of the soluble (phase 1) and non-soluble fractions (phase 2). The $A, B$ and $C$ values at different phases of gas production for CS1 observed by Tuyen et al. (2012) are almost identical to the results presented here. In the present study, higher $A_{1}$ and $A_{2}$ values with colonization week are indicative of increased amounts of fermentable soluble and non-soluble fractions. The increase in the soluble fraction is expected as fungi liberate free sugars during their colonization. Free sugars were not measured in the present study, but a three-fold increase in the amount of total non-structural carbohydrates have been reported in fungal-treated rice straw (Karunanandaa and Varga, 1996). Phase 2 is related to the fermentation of structural (non-soluble) carbohydrates. With increasing colonization time, the gas 
production profiles became more sigmoidal with an increasing slope, as indicated by the higher $C_{2}$ values. Significant contrasts between CS1 and CS2-treated straw in their $C_{2}$ and $R_{\mathrm{m} 2}$ values show that CS1 has a slight advantage over CS2 in improving the fermentation of structural carbohydrates.

The autoclaving process significantly affected the DM and ADL content of the wheat straw. The increase of the ADL content in the autoclaved substrate is in agreement with previous reports (Tuyen et al., 2012, 2013). The loss of water through evaporation during autoclaving increases the relative proportion of the cell wall components. The effect of the fungal treatment on the chemical composition of the wheat straw confirms the results of previous studies (Shrivastava et al., 2011; Van Kuijk et al., 2016a). The data presented here are again comparable to Tuyen et al. (2012) and small differences may be due to variation in the different batches of wheat straw. These data shows that by providing the same growth conditions and a comparable substrate composition, CS1 is capable of producing repeatable results. C. subvermispora has been regarded as a selective lignin degrader (Tuyen et al., 2012; Van Kuijk et al., 2016b) and to compare the selectivity between CS1 and CS2, the ratio of total cellulose and hemicellulose (carbohydrates) to lignin $(\mathrm{C} / \mathrm{L}$ ratio) was calculated. A higher $\mathrm{C} / \mathrm{L}$ ratio indicates more selective lignin degradation. After 7 weeks of colonization, CS1-treated straw showed a 1.2 times higher $(P<0.001) \mathrm{C} / \mathrm{L}$ ratio, compared to the CS2-treated straw.

The changes in chemical composition can explain the IVGP profile of the fungaltreated straw, as well as the growth of the fungi. The correlations among all lignocellulose components with IVGP during the fungal colonization have been previously described (Tuyen et al., 2012). In the present study, however, the IVGP was significantly $(P<0.001)$ correlated to only hemicellulose $(r=-0.85)$ and lignin $(r=-0.82)$ content, but not to cellulose. Given both hemicellulose and cellulose may have positive effects on the IVGP, while lignin has a negative effect, a relationship between IVGP and C/L ratio was derived (Fig. 2.4). The IVGP of the CS 1 and CS2-treated straw was significantly correlated to their respective $\mathrm{C} / \mathrm{L}$ ratios with the same Pearson's $r$ values $(r=0.86 ; P<0.001)$. A significant correlation between the IVGP and CP content was also observed $(r=0.59 ; P<$ 0.001). This observation suggests that the fungal treatment may have increased the availability and solubility of the protein for rumen microbes. However, this hypothesis needs to be tested with an incubation trial using N-free buffer medium (Cone et al., 2009). Protein solubility and availability has a positive effect on the growth of the rumen microbes, hence the nutritive value of the substrate (Cone and Van Gelder, 1999). The ergosterol content was negatively correlated to the DM content of the substrate $(r=-0.75$; 
$P<0.001)$, but positively correlated to the $\mathrm{C} / \mathrm{L}$ ratio $(r=0.73 ; P<0.001)$ indicating that the fungal growth corresponds to the degradation of the DM and also the availability of the structural carbohydrates.

The presence of only laccase and $\mathrm{MnP}$ are consistent with the enzyme activities reported for C. subvermispora when they were grown in liquid media (Lobos et al., 1994) or on biomass such as wood chips (Ferraz et al., 2003; de Souza-Cruz et al., 2004) and corn stover (Wan and $\mathrm{Li}, 2010$ ). Nonetheless, there is limited information on the enzyme activities of $C$. subvermispora, particularly grown on wheat straw, for a direct comparison. In previous reports, there were large variations in the activities of these enzymes, which is not surprising as different substrates and/or fungal strains were used. A quantitative comparison is difficult as various assay methods are used and different units to express enzyme activities. Wan and $\mathrm{Li}$ (2010) also showed a peak activity of MnP and laccase during the first week of colonization of $C$. subvermispora on corn stover. In the present study, the laccase activity of CS1 is much lower compared to C. subvermispora grown on corn stover with an activity of $1500 \mathrm{U} \mathrm{kg}^{-1}$ solids at week 1 (Wan and Li, 2010). Meanwhile, MnP of CS2 is also much lower when compared to C. subvermispora grown on corn stover (2200 $\mathrm{U} \mathrm{kg}^{-1}$ solids) (Wan and Li, 2010), or wood chips (156 $\mathrm{U} \mathrm{kg}^{-1}$ wood) (de Souza-Cruz et al., 2004) at week 1.

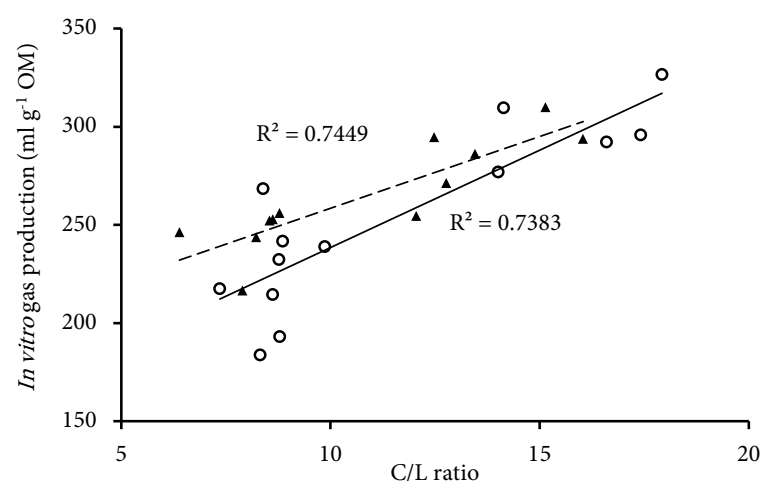

Fig. 2.4. Relationship between cumulative in vitro gas production after $72 \mathrm{~h}$ with total carbohydrate to lignin $(\mathrm{C} / \mathrm{L})$ ratio for autoclaved wheat straw colonized by Ceriporiopsis subvermispora strains CS1 (O) and CS2 ( $\boldsymbol{\Delta})$ for up to 7 weeks. The continuous line is the regression line of CS1, and the dashed-line of CS2, with both being significant at $P<0.001$. 
According to Fernández-Fueyo et al. (2012), LiP activity might be expected in $C$. subvermispora as the genome of this fungus contains a LiP and a VP like gene, both likely representing an intermediate evolutionary state between LiP and VP. As LiP is considered important for an efficient ligninolysis, particularly related to its ability to cleave recalcitrant non-phenolic lignin, several mechanistic hypotheses have been proposed such as MnP-mediated lipid peroxidation (Jensen et al., 1996) and involvement of laccase. The function of MnP was thought to be the least important for lignin degradation, as the chelated $\mathrm{Mn}^{3+}$ which is oxidized by $\mathrm{MnP}$, can only act on phenolic lignin substructures. However, several authors provided evidences that $\mathrm{MnP}$ could promote the oxidation of non-phenolic lignin through lipid peroxidation (Bao et al., 1994; Jensen et al., 1996). Nishimura et al. (2012) identified the production of itaconic acids by $C$. subvermispora and showed that these compounds initiate lipid peroxidation with MnP. The latter might explain the substantial degradation of lignin by this fungus using mainly MnP enzymes. This process, however, is relatively slow and inefficient (Fernández-Fueyo et al., 2012) compared to LiP. Laccase alone is incapable of depolymerizing macromolecular lignin due to its low redox potential (Hatakka and Hammel, 2010). However, in the presence of low molecular weight mediator compounds such as syringaldehyde and vanillin, the substrate range of laccase can be expanded which includes non-phenolic lignin (Christopher et al., 2014). Therefore, laccase together with mediators compounds greatly improves delignification by the fungi (Hatakka and Hammel, 2010; Christopher et al., 2014). Laccase has been shown as essential in lignin degradation for white-rot fungus Pycnoporus cinnabarinus, which lack both LiP and MnP. This information indicates that laccase may be more important in the degradation of lignin compared to $\mathrm{MnP}$, when there is no LiP present.

At peak activity, the CS1-treated straw showed 2.5 times more laccase compared to CS2 while, on the other hand, CS2-treated straw showed 2 times more MnP. It can be assumed that CS1 may have higher lignin-degrading enzyme capabilities compared to CS2, which may explain the higher selectivity of this strain to degrade lignin. The ADL content showed no significant correlation to any lignin degrading enzyme. Thus, the correlation of these main enzymes with lignin remain unproven, which is in agreement with previous studies (Sharma and Arora, 2010; Shrivastava et al., 2011). This outcome is due to the fact that, although these enzymes only have peak activities at week 1 , the degradation of lignin continues throughout colonization. High activities of these main, lignin degrading enzymes may also indicate that the fungus start degrading lignin when all freely available carbohydrates become limiting at the beginning of colonization. This 
will subsequently increase the accessibility of the lignocellulose complex to the action of other enzyme systems. It is worth noting that lignin degradation does not only involve peroxidases, such as LiP and MnP and phenol oxidases, such as laccase, but also other accessory enzymes and even non-enzymatic pathways (Dashtban et al., 2010).

\section{CONCLUSION}

In conclusion, the two strains of $C$. subvermispora were capable to selectively degrade lignin and improve in vitro degradability in rumen fluid of the wheat straw, with CS1 showing a higher potential than CS2. Both strains differ in their growth pattern and enzymatic activities as well as in the degree of selectivity in lignin degradation. For future investigations, assessing enzyme profiles, using more advanced techniques, such as secretome analysis, would provide better insight into the ability of a particular fungus. The observation that CS1 and CS2 clearly differ in the amount and timing of the production of enzymes involved in lignin degradation offers the opportunity to combine these activities in one strain by breeding. This new strain may have stronger growth characteristics and be more selective in degrading lignin, which can benefit the bioprocessing of lignocellulose biomass, not only for animal feed, but also other purposes such as biofuels production and biopulping.

\section{ACKNOWLEDGEMENT}

The authors gratefully acknowledge the financial support from the Wageningen UR Fund (WUF) as part of the project "More Meat and Milk from Straw" which is sponsored by DEKA, Forfarmers and the Victam Foundation. The authors also would like to acknowledge the scholarship provided by the Ministry of Higher Education Malaysia and Universiti Putra Malaysia for NN. 
Chapter 2 | Degradation of wheat straw by Ceriporiopsis sp. strains

\section{REFERENCES}

Aguiar, A., Mendonça, R., Rodriguez, J., and Ferraz, A. (2010). Behavior of Ceriporiopsis subvermispora during Pinus taeda biotreatment in soybean-oil-amended cultures. Int. Biodeterior. Biodegrad. 64, 588-593.

Arantes, V., and Milagres, A.M.F. (2007). The synergistic action of ligninolytic enzymes (MnP and Laccase) and $\mathrm{Fe}^{3+}$-reducing activity from white-rot fungi for degradation of Azure B. Enzyme Microb. Technol. 42, $17-22$.

Archibald, F.S. (1992). A new assay for lignin-type peroxidases employing the dye Azure B. Appl. Environ. Microbiol. 58, 3110-3116.

Arora, D.S., Chander, M., and Gill, P.K. (2002). Involvement of lignin peroxidase, manganese peroxidase and laccase in degradation and selective ligninolysis of wheat straw. Int. Biodeterior. Biodegrad. 50, 115-120.

Bao, W., Fukushima, Y., Jensen, K.A., Moen, M.A., and Hammel, K.E. (1994). Oxidative degradation of nonphenolic lignin during lipid peroxidation by fungal manganese peroxidase. FEBS Lett. 354, 297-300.

Christopher, L.P., Yao, B., and Ji, Y. (2014). Lignin biodegradation with laccase-mediator systems. Front. Energy Res. 2, 1-13.

Cone, J.W., Rodrigues, M.A.M., Guedes, C.M., and Blok, M.C. (2009). Comparison of protein fermentation characteristics in rumen fluid determined with the gas production technique and the nylon bag technique. Anim. Feed Sci. Technol. 153, 28-38.

Cone, J.W., and van Gelder, A.H. (1999). Influence of protein fermentation on gas production profiles. Anim. Feed Sci. Technol. 76, 251-264.

Cone, J.W., van Gelder, A.H., Visscher, G.J.W., and Oudshoorn, L. (1996). Influence of rumen fluid and substrate concentration on fermentation kinetics measured with a fully automated time related gas production apparatus. Anim. Feed Sci. Technol. 61, 113-128.

Dashtban, M., Schraft, H., Syed, T.A., and Qin, W. (2010). Fungal biodegradation and enzymatic modification of lignin. Int. J. Biochem. Mol. Biol. 1, 36-50.

de Souza-Cruz, P.B., Freer, J., Siika-Aho, M., and Ferraz, A. (2004). Extraction and determination of enzymes produced by Ceriporiopsis subvermispora during biopulping of Pinus taeda wood chips. Enzyme Microb. Technol. 34, 228-234.

Dinis, M.J., Bezerra, R.M.F., Nunes, F., Dias, A.A., Guedes, C. V., Ferreira, L.M.M., Cone, J.W., Marques, G.S.M., Barros, A.R.N., and Rodrigues, M.A.M. (2009). Modification of wheat straw lignin by solid state fermentation with white-rot fungi. Bioresour. Technol. 100, 4829-4835.

Drew, S.W., and Wallis, D.A. (1983). Regulatory of secondary metabolism and keys to its manipulation. In: Bennet, J.W., and Ciegler, A. (Eds.), Secondary Metabolism and Differentiation in Fungi. CRC Press, New York, pp. 35-50.

Fernández-Fueyo, E., Ruiz-Dueñas, F.J., Miki, Y., Martínez, M.J., Hammel, K.E., and Martínez, A.T. (2012). Lignin-degrading peroxidases from genome of selective ligninolytic fungus Ceriporiopsis subvermispora. J. Biol. Chem. 287, 16903-16916.

Ferraz, A., Córdova, A.M., and Machuca, A. (2003). Wood biodegradation and enzyme production by Ceriporiopsis subvermispora during solid-state fermentation of Eucalyptus grandis. Enzyme Microb. Technol. 32, 59-65.

Gao, Y., Chen, T., and Breuil, C. (1993). Ergosterol - A measure of fungal growth in wood for staining and pitch control fungi. Biotechnol. Tech. 7, 621-626.

Groot, J.C., Cone, J.W., Williams, B.A., Debersaques, F.M.A., and Lantinga, E.A. (1996). Multiphasic analysis of gas production kinetics for in vitro fermentation of ruminant feeds. Anim. Feed Sci. Technol. 64, 77-89. 
Hatakka, A., and Hammel, K. (2010). Fungal biodegradation of lignocelluloses. In: Hofrichter, M. (Ed.), Industrial Applications (The Mycota). Springer, pp. 319-2340.

Hendriks, A.T.W.M., and Zeeman, G. (2009). Pretreatments to enhance the digestibility of lignocellulosic biomass. Bioresour. Technol. 100, 10-18.

Isroi, Millati, R., Syamsiah, S., Niklasson, C., Cahyanto, M.N., Lundquist, K., and Taherzadeh, M.J. (2011). Biological pretreatment of lignocelluloses with white-rot fungi and its applications: A review. BioResources 6, 5224-5259.

Jensen, K.A., Bao, W., Kawai, S., Srebotnik, E., and Hammel, K.E. (1996). Manganese-dependent cleavage of nonphenolic lignin structures by Ceriporiopsis subvermispora in the absence of lignin peroxidase. Appl. Environ. Microbiol. 62, 3679-3686.

Karunanandaa, K., and Varga, G.A. (1996). Colonization of crop residues by white-rot fungi: cell wall monosaccharides, phenolic acids, ruminal fermentation characteristics and digestibility of cell wall fiber components in vitro. Anim. Feed Sci. Technol. 63, 273-288.

Kirk, T.K., and Farrell, R.L. (1987). Enzymatic “combustion”: The microbial degradation of lignin. Annu. Rev. Microbiol. 41, 465-505.

Larran, S., Perelló, A., Simón, M.R., and Moreno, V. (2007). The endophytic fungi from wheat (Triticum aestivum L.). World J. Microbiol. Biotechnol. 23, 565-572.

Lesoing, G., Klopfenstein, T., Rush, I., and Ward, J. (1980). Chemical treatment of wheat straw. J. Anim. Sci. 51, 263-269.

Liao, X., Vining, L.C., and Doull, J.L. (1995). Physiological control of trophophase-idiophase separation in streptomycete cultures producing secondary metabolites. Can. J. Microbiol. 315, 309-315.

Lobos, S., Larrain, J., Salas, L., Cullen, D., and Vicuna, R. (1994). Isoenzymes of manganese-dependent peroxidase and laccase produced by the lignin-degrading basidiomycete Ceriporiopsis subvermispora. Microbiology 140, 2691-2698.

Mata, G., and Savoie, J.M. (1998). Extracellular enzyme activities in six Lentinula edodes strains during cultivation in wheat straw. World J. Microbiol. Biotechnol. 14, 513-519.

Messner, K., Koller, K., Wall, M.B., Akhtar, M., and Scott, G.M. (1998). Fungal treatment or wood chips for chemical pulping. In: Young, R.A., and Akhtar, M. (Eds.), Environmental Friendly Technologies for the Pulp and Paper Industry. Wiley, Inc., New York, pp. 385-419.

Mille-Lindblom, C., von Wachenfeldt, E., and Tranvik, L.J. (2004). Ergosterol as a measure of living fungal biomass: persistence in environmental samples after fungal death. J. Microbiol. Methods 59, 253-262.

More, S.S., Renuka, P.S., Pruthvi, K., Swetha, M., Malini, S., and Veena, S.M. (2011). Isolation, purification, and characterization of fungal laccase from Pleurotus sp. Enzyme Res. 2011, 1-7.

Niemenmaa, O., Galkin, S., and Hatakka, A. (2008). Ergosterol contents of some wood-rotting basidiomycete fungi grown in liquid and solid culture conditions. Int. Biodeterior. Biodegradation 62, 125-134.

Nishimura, H., Sasaki, M., Seike, H., Nakamura, M., and Watanabe, T. (2012). Alkadienyl and alkenyl itaconic acids (ceriporic acids $\mathrm{G}$ and $\mathrm{H}$ ) from the selective white-rot fungus Ceriporiopsis subvermispora: a new class of metabolites initiating ligninolytic lipid peroxidation. Org. Biomol. Chem. 10, 6432.

Pollegioni, L., Tonin, F., and Rosini, E. (2015). Lignin-degrading enzymes. FEBS J. 282, 1190-1213.

Sharma, R.K., and Arora, D.S. (2010). Changes in biochemical constituents of paddy straw during degradation by white rot fungi and its impact on in vitro digestibility. J. Appl. Microbiol. 109, 679-686.

Shrivastava, B., Thakur, S., Khasa, Y.P., Gupte, A., Puniya, A.K., and Kuhad, R.C. (2011). White-rot fungal conversion of wheat straw to energy rich cattle feed. Biodegradation 22, 823-831. 
Tuyen, V.D., Phuong, H.N., Cone, J.W., Baars, J.J.P., Sonnenberg, A.S.M., and Hendriks, W.H. (2013). Effect of fungal treatments of fibrous agricultural by-products on chemical composition and in vitro rumen fermentation and methane production. Bioresour. Technol. 129, 256-263.

Tuyen, V.D., Cone, J.W., Baars, J.J.P., Sonnenberg, A.S.M., and Hendriks, W.H. (2012). Fungal strain and incubation period affect chemical composition and nutrient availability of wheat straw for rumen fermentation. Bioresour. Technol. 111, 336-342.

Van Kuijk, S.J.A., Sonnenberg, A.S.M., Baars, J.J.P., Hendriks, W.H., and Cone, J.W. (2015). Fungal treated lignocellulosic biomass as ruminant feed ingredient: A review. Biotechnol. Adv. 33, 191-202.

Van Kuijk, S.J.A., Sonnenberg, A.S.M., Baars, J.J.P., Hendriks, W.H., and Cone, J.W. (2016). The effect of adding urea, manganese and linoleic acid to wheat straw and wood chips on lignin degradation by fungi and subsequent in vitro rumen degradation. Anim. Feed Sci. Technol. 213, 22-28.

Van Kuijk, S.J.A., Sonnenberg, A.S.M., Baars, J.J.P., Hendriks, W.H., and Cone, J.W. (2016). The effect of particle size and amount of inoculum on fungal treatment of wheat straw and wood chips. J. Anim. Sci. Biotechnol. 7, 39.

Van Soest, P.J., Robertson, J.B., and Lewis, B.A. (1991). Methods for dietary fiber, neutral detergent fiber, and nonstarch polysaccharides in relation to animal nutrition. J. Dairy Sci. 74, 3583-3597.

Vujanovic, V., Mavragani, D., and Hamel, C. (2012). Fungal communities associated with durum wheat production system: A characterization by growth stage, plant organ and preceding crop. Crop Prot. 37, 26-34.

Wan, C., and Li, Y. (2010). Microbial delignification of corn stover by Ceriporiopsis subvermispora for improving cellulose digestibility. Enzyme Microb. Technol. 47, 31-36. 
Chapter 2 | Degradation of wheat straw by Ceriporiopsis sp. strains 


\section{4}

We can't solve problems by using the same kind of thinking we used when we created them.

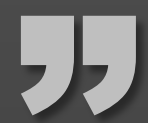

- ALBERT EINSTEIN 


\section{Screening of white-rot fungi for} bioprocessing of wheat straw into ruminant feed

Nazri Nayan ${ }^{1}$, Anton S.M. Sonnenberg ${ }^{2}$, Wouter H. Hendriks ${ }^{1}$, and John W. Cone ${ }^{1}$

J. Appl. Microbiol. (2018). 125(2):468-479.

1 Animal Nutrition Group, Wageningen University, De Elst 1, 6708 WD Wageningen, the Netherlands

2 Plant Breeding, Wageningen University and Research, Droevendaalsesteeg 1, 6708 PB Wageningen, the Netherlands 


\section{ABSTRACT}

In this study, the biological variation for improvement of the nutritive value of wheat straw by 12 Ceriporiopsis subvermispora, 10 Pleurotus eryngii and 10 Lentinula edodes strains was assessed. Screening of the best performing strains within each species was made based on the in vitro degradability of fungal treated wheat straw. Wheat straw was inoculated with each strain for 7 weeks of solid state fermentation. Weekly samples were evaluated for in vitro gas production (IVGP) in buffered rumen fluid for $72 \mathrm{~h}$. Out of the 32 fungal strains studied, 17 strains showed a significantly higher $(P<0.05)$ IVGP compared to the control after 7 weeks $\left(227.7 \mathrm{ml} \mathrm{g}^{-1} \mathrm{OM}\right)$. The three best $C$. subvermispora strains showed a mean IVGP of $297.0 \mathrm{ml} \mathrm{g}^{-1} \mathrm{OM}$, while the three best $P$. eryngii and L. edodes strains showed a mean IVGP of 257.8 and 291.5 $\mathrm{ml} \mathrm{g}^{-1} \mathrm{OM}$, respectively. C. subvermispora strains show an overall high potential to improve the ruminal degradability of wheat straw, followed by L. edodes and P. eryngii strains. Large variation exists within and among different fungal species in the valorization of wheat straw, which offers opportunities to improve the fungal genotype by breeding.

Keywords: White-rot fungi; different strains/species; screening; in vitro gas production; degradability; wheat straw; ruminant 


\section{INTRODUCTION}

xploring alternative feed ingredients for ruminant nutrition is important, not only
for a sustainable animal production, but also to further ensure human food security. Agricultural biomass, such as wheat straw, is an attractive choice for this purpose. The use and challenges in the processing of this highly lignified biomass into a more digestible animal feed has been addressed in many studies (Shrivastava et al., 2014; Van Kuijk et al., 2015a). Different pretreatment methods have been used, including physical, chemical and biological methods (Sarnklong et al., 2010; Isroi et al., 2011). The goal of any pretreatment method is to break the lignin barrier and make cellulose and hemicellulose more accessible to fermentation in the rumen (Sarnklong et al., 2010). Each method, however, has a varying effect on the composition and structure of cellulose, hemicellulose and lignin (Mosier et al., 2005; Hendriks and Zeeman, 2009). Biological methods, including the use of fungi have attracted the interest of many researchers due to an increasing global demand for eco-friendly approaches (Dinis et al., 2009; Sharma and Arora, 2014; Shrivastava et al., 2011; Tuyen et al., 2012).

Lignin has a negative impact on the degradation of fiber in ruminants (Moore and Jung, 2001). Degradation of lignin is a chemically difficult process since these polyphenolic compounds have a dense three-dimensional, highly branched structure that is linked with hemicellulose (Kubicek, 2013). White-rot fungi are the only organisms capable of degrading lignin aerobically to $\mathrm{CO}_{2}$ and water (Hatakka and Hammel, 2010). This unique ability makes them favorable as candidates for the bioprocessing of highly lignified agricultural biomass into ruminant feed. However, not all fungal species exhibit a preferential degradation of lignin, i.e. selectively degrade lignin while utilizing low amounts of the structural carbohydrates. Tuyen et al. (2012) showed that out of 11 fungal species tested, only Ceriporiopsis subvermispora (Pilat) Gilb. \& Ryvarden 1985, Lentinula edodes (Berkeley) Pegler 1975 and Pleurotus eryngiivar. eryngii(DC.) Quél 1872, showed a high lignin to cellulose loss ratio, which increased the in vitro degradability in rumen fluid of the treated wheat straw by 20 to $60 \%$ after 7 weeks of solid state incubation.

Bioprocessing of agricultural biomass, using white-rot fungi, is a complex process which is influenced by many factors, such as fungal species and strain, substrate and culture conditions (Van Kuijk et al., 2015a). Several studies worked on the optimization of the process, such as exploring the best fungi-substrate combinations (Tuyen et al., 2013), varying particle sizes of the substrate (Van Kuijk et al., 2016a) and supplementing additives such as manganese and linoleic acid to the substrate (Van Kuijk et al., 2016b). However, little work has been done on selecting the best fungal strain to maximize the 
valorization of biomass for ruminant use. Fungi are diverse in their lignocellulose deconstruction mechanisms (Cragg et al., 2015), which emphasize the need to not only investigate and screen for the best performing fungal species, but also different strains within a particular species. Most studies selected fungal strains based on their enzyme activity ( Mata and Savoie, 1998; Cavallazzi et al., 2004). However, correlating qualitative enzyme activities with the selectivity of a fungus was difficult (Sharma and Arora, 2010). Recently, we showed differences between two strains of $C$. subvermispora in improving the in vitro degradability of wheat straw, as well as in their growth and lignin-degrading enzyme characteristics (Nayan et al., 2017). The ultimate goal of the ongoing research is to study the variation among fungal strains, which can be a valuable input for future breeding activities to expand the potential of fungi in the bioprocessing of agricultural biomass into ruminant feed. Therefore, the degradability of the substrate, as determined by the in vitro gas production (IVGP) (Cone et al., 1996) was used as the main screening criterion.

The aim of the present study was to assess the biological variation among different strains within three species of white-rot fungi - C. subvermispora, $P$. eryngii and $L$. edodes, with respect to the formation of fungal biomass in time and the effect on IVGP. Three of the best strains for each species were selected based on IVGP and further compared for differences in the gas production kinetics and other fermentation characteristics; as well as changes in the mass balance of the wheat straw.

\section{MATERIALS AND METHODS}

\section{Preparation of fungal strains and spawn}

Different strains of 3 white-rot fungi species: C. subvermispora (CS; 12 strains), $P$. eryngii (PE; 10 strains) and L. edodes (LE; 10 strains) (Table 3.1) from the collection of the Plant Breeding Group, Wageningen University \& Research, the Netherlands, were used. All strains were cultured on malt extract agar (malt extract $20 \mathrm{~g} \mathrm{l}^{-1}, \mathrm{KH}_{2} \mathrm{PO}_{4} 0.5 \mathrm{~g} \mathrm{l}^{-}$ ${ }^{1}, \mathrm{MgSO}_{4} \cdot 7 \mathrm{H}_{2} \mathrm{O} 0.5 \mathrm{~g} \mathrm{l}^{-1}$ and $\mathrm{Ca}\left(\mathrm{NO}_{3}\right)_{2} \cdot 4 \mathrm{H}_{2} \mathrm{O} 0.5 \mathrm{~g} \mathrm{l}^{-1}$ with a $\mathrm{pH}$ of 5.4) and incubated at $24^{\circ} \mathrm{C}$ until the mycelia colonized most of the agar surface. The spawn of each strain was prepared by placing a piece of the agar culture $(1.5 \times 2.0 \mathrm{~cm})$ into a container with sterilized $\left(20 \mathrm{~min}, 121^{\circ} \mathrm{C}\right)$ sorghum grains and incubated at $24^{\circ} \mathrm{C}$ for 5 weeks. 
Table 3.1. List of strains from three different white-rot fungi species, with respective notations, used in the study.

\begin{tabular}{|c|c|c|}
\hline Species/ Strain no & Original annotation & Origin \\
\hline \multicolumn{3}{|c|}{ Ceriporiopsis subvermispora } \\
\hline $1^{\star \#}$ & CBS 347.63 & USA \\
\hline $2^{\#}$ & ACCC 31512 & China \\
\hline $3^{\mathrm{a}}$ & AR-93 & Forest Product Laboratory, USDA, USA \\
\hline 4 & FP-104027-T & USA \\
\hline 5 & FP-105752-Sp & USA \\
\hline 6 & L-3292-R & USA \\
\hline 7 & L-6133-Sp & USA \\
\hline 8 & L-6332-Sp & USA \\
\hline 9 & L-9186-Sp & USA \\
\hline 10 & L-14807-Sp & USA \\
\hline 11 & L-15225-Sp & USA \\
\hline 12 & ME-485 & USA \\
\hline \multicolumn{3}{|l|}{ Pleurotus eryngii } \\
\hline 1 & $\mathrm{pl} \mathrm{03/04}$ & Commercial cultivar \\
\hline $2^{*}$ & pl 02/08 & China \\
\hline 3 & Mycelia2600 & Commercial cultivar \\
\hline 4 & P.eryngii 87 & Unknown \\
\hline 5 & $\mathrm{AH} 03$ & Iran \\
\hline 6 & AL04 & Iran \\
\hline 7 & BA19 & Iran \\
\hline 8 & F23 & Iran \\
\hline 9 & HE05 & Iran \\
\hline 10 & P02 & Iran \\
\hline \multicolumn{3}{|l|}{ Lentinula edodes } \\
\hline 1 & $\operatorname{sh} 02 / 05$ & China \\
\hline 2 & SP-1A & Germany \\
\hline 3 & sh00/01 & China \\
\hline 4 & Somycel 4087 & Commercial cultivar \\
\hline 5 & ML 12 & Japan \\
\hline 6 & UGM & Indonesia \\
\hline $7^{\star \mathrm{b}}$ & CCBAS389 & Czech Republic \\
\hline 8 & $\operatorname{sh} 03 / 08$ & Japan \\
\hline 9 & $\operatorname{msc} 03$ & Japan \\
\hline 10 & LE (75) & Ghana \\
\hline
\end{tabular}

* Reference strains as used by Tuyen et al. (2012).

\# Homokaryon (no clamp connections).

${ }^{a}$ https://www.fpl.fs.fed.us/research/centers/mycology/culture-collection.shtml.

${ }^{\mathrm{b}}$ http://www.biomed.cas.cz/ccbas/fungi.htm. 


\section{Substrate preparation, fungi inoculation and sampling}

A bale of organic wheat straw (Triticum aestivum L.) (300 kg; dry matter content $880.4 \mathrm{~g} \mathrm{~kg}^{-1}$ ) was purchased from a local farmer in the Netherlands and used for all incubations. Due to the limited capacity of the incubation chamber, treatments were conducted in three independent but adjacent periods with only one species (with different strains) for each period. Straw was chopped into approximately $3 \mathrm{~cm}$ pieces and soaked in water for 3 days at room temperature. After draining the excess of water for $5 \mathrm{~h}$, the moisture content of each batch of straw was recorded. The wheat straw was then distributed into $185 \times 185 \times 78 \mathrm{~mm}$ micropropagation containers (Combiness, Nevele, Belgium), which is equipped with a depth-filtration strip on the lid, and the amount of wet straw in each container was adjusted to contain $90.2 \pm 0.3 \mathrm{~g}$ of dry matter for all batches.

All containers were autoclaved at $121^{\circ} \mathrm{C}$ for $1 \mathrm{~h}$ and allowed to cool overnight at room temperature. Pre- and post-autoclaved wheat straw samples were taken for comparing the dry matter content. The handling and processing of the wheat straw was maintained in the same order throughout the experiment. The autoclaved straw was aseptically inoculated with the previously prepared spawn for each strain/species at $10 \%$ of the dry weight of the straw. Containers with inoculated straw and autoclaved straw (control) were incubated aerobically in triplicate at $24^{\circ} \mathrm{C}$ for 7 weeks in a climate-controlled chamber. Weekly samples were weighed, thoroughly mixed and $\sim 5 \mathrm{~g}$ of fresh sample was taken for $\mathrm{pH}$ measurements. The remaining sample was freeze-dried and ground over a $1 \mathrm{~mm}$ sieve using a cross beater mill (100AN, Peppink, Olst, the Netherlands).

\section{Ergosterol estimation}

Fungal biomass was estimated with an ergosterol assay (Niemenmaa et al., 2008). In brief, $200 \pm 10 \mathrm{mg}$ sample was weighed into a glass tube and after extraction with $10 \%$ (1:9) $\mathrm{KOH} / \mathrm{methanol} \mathrm{solution} \mathrm{for} 10 \mathrm{~min}$, the tube was saponified at $80^{\circ} \mathrm{C}$ for $60 \mathrm{~min}$. After cooling to room temperature, $1 \mathrm{ml}$ distilled water and $2 \mathrm{ml}$ hexane was added before each tube was thoroughly shaken. The hexane layer was subsequently collected and the extraction steps were repeated. The pooled hexane layer was dried in a vacuum evaporation system (Rapidvap, Kansas, MO, USA). The extracted ergosterol was redissolved in methanol and the solution was filtered into a high performance liquid chromatography (HPLC) vial for Waters HPLC-PDA analysis (Alliance HPLC system, Milford, USA). A reversed phase C18 column $(250 \times 4.6 \mathrm{~mm}$, Phenomex aqua $5 \mu \mathrm{m})$ was used in the HPLC instrument and the liquid phase was $90 \%$ methanol and $10 \%(1: 1) 2$ - 
propanol/hexane. Cholecalciferol (vitamin $\mathrm{D}_{3}$ ) was used as an internal standard. The ergosterol peak was detected at $280 \mathrm{~nm}$.

\section{In vitro gas production}

All samples were subjected to in vitro gas production (IVGP), expressed as $\mathrm{ml} \mathrm{g}^{-1}$ organic matter (OM) (Cone et al., 1996), where $0.5 \pm 0.01 \mathrm{~g}$ of sample was incubated in $60 \mathrm{ml}$ of buffered rumen fluid at $39^{\circ} \mathrm{C}$. The incubation was conducted in 250 -ml bottles (Schott, Mainz, Germany) for $72 \mathrm{~h}$ and the gas production was registered automatically. At the end of the incubation, rumen fluid samples from each bottle $(600 \mu \mathrm{l})$ were taken for the determination of volatile fatty acids (VFA) and ammonia- $\mathrm{N}\left(\mathrm{NH}_{3}-\mathrm{N}\right)$. The remaining content in the bottles was filtered through a crucible and dried in an oven at $103^{\circ} \mathrm{C}$ to determine the dry matter (DM) content (ISO 6496, 1999) and the ash content in a furnace at $550^{\circ} \mathrm{C}$ for $3 \mathrm{~h}$ (ISO 5984, 2002). The organic matter (OM) digestibility was calculated as a percentage of digested OM from the pre-incubated sample.

Only samples of selected fungal strains/species (3 best performing strains from each species) were analyzed for VFA and $\mathrm{NH}_{3}-\mathrm{N}$. Individual VFA concentrations were separated by gas chromatography using hydrogen as carrier gas, while reaction of ammonia with phenol and hypochlorite was measured spectrophotometrically at $623 \mathrm{~nm}$ for $\mathrm{NH}_{3}-\mathrm{N}$ determinations. The kinetic parameters were determined by fitting the gas production data to a biphasic model (Groot et al., 1996), representing fermentation of the soluble (phase $1 ; 0$ to $4 \mathrm{~h}$ ) and the non-soluble fractions (phase $2 ; 4$ to $48 \mathrm{~h}$ ) according to Tuyen et al. (2012). Only parameters of phase $2\left(A_{2}, B_{2}, C_{2}, t_{R \mathrm{~m} 2}, R_{\mathrm{m} 2}\right)$ are presented here. $A_{2}$ is the asymptotic gas production $\left(\mathrm{ml} \mathrm{g}^{-1} \mathrm{OM}\right)$ of phase $2 ; B$ is the half time of the maximum gas production (h); $C$ is a parameter to determine the steepness of the curve; $t_{R \mathrm{~m}}$ is the time of the maximum fractional rate of substrate degradation (h); and $R_{\mathrm{m}}$ the maximum fractional rate of substrate degradation $\left(\mathrm{h}^{-1}\right)$.

\section{Chemical analysis}

All freeze-dried samples were analyzed for DM and ash content. Only selected fungal strains/species samples were analyzed for nitrogen and fiber content. Nitrogen content was determined by the Kjeldahl method (ISO 5983, 2005) and crude protein was calculated as $\mathrm{N} \times 6.25$. Neutral detergent fiber $(\mathrm{NDF})$ was determined using a heat-stable amylase (thermamyl) and alcalase, using the standard procedures of Van Soest et al. (1991). Acid detergent fiber (ADF) and acid detergent lignin (ADL) were also determined using the standard method (Van Soest et al., 1991). Hemicellulose was calculated as the 
difference between NDF and ADF, while cellulose was calculated as the difference between ADF and ADL. Absolute amounts (g) of each component was calculated from the remaining amount $(\mathrm{g})$ of freeze-dried sample which was corrected for the dry matter content.

\section{Statistics}

Data were analyzed per species using the general linear model in SAS 9.3, followed by a post-hoc multiple comparison using least significance differences. The statistical model was as follows:

$$
Y_{i j}=\mu+S T_{i}+\tau_{j}+(S T \times \tau)_{i j}+\varepsilon_{i j}
$$

where $Y_{i j}=$ response variable, $\mu=$ overall mean, $S T_{i}=$ the effect of strain $i, \tau_{j}=$ effect of week $j,(S T \times \tau)_{i j}=$ interaction of strain $i$ and week $j$, and $\varepsilon_{i j}=$ residual error with a mean of 0 and variance $\sigma^{2}$. For assessment and comparison of selected strains across species, nested analysis of variance without time interaction was conducted using the following statistical model:

$$
\Upsilon_{i j k}=\mu+S P_{i}+S T_{j(i)}+\tau_{k(i j)}+\varepsilon_{i j k}
$$

where $Y_{i j k}=$ response variable $i j k$, $\mu$ = overall mean, $S P_{i}=$ the effect of species $i, S T_{j(i)}=$ the effect of strain $j$ nested within species $i, \tau_{k(i j)}=$ effect of week $k$, and $\varepsilon_{i j k}=$ residual error with a mean of 0 and variance $\sigma^{2} . S P_{i}$ was considered a fixed effect, $S T_{j(i)}$ and $\tau_{k(i j)}$ as random effects. The CONTRAST statement was also used in SAS to allow comparison among different species group. Pearson Product-Moment Correlation $(r)$ coefficients were determined among the measured variables. Probability values below 5\% were considered significant. The ergosterol data were fitted to a polynomial regression models. A linear model was fitted first to the ergosterol data of a strain where after a quadratic term was added. If the quadratic term was significant, a cubic term was added to the model. The model with the highest significant $(P<0.05)$ coefficient was taken as the best fit model. The rate of ergosterol changes over time $\left(\delta_{\text {Erg }}\right)$ was calculated by substituting week $7\left(x_{2}=7\right)$ and week $0\left(x_{1}=0\right)$ into respective polynomial functions, $f(x)$, and dividing the value by 7 .

\section{RESULTS}

\section{Fungal growth and changes in the $\mathrm{pH}$ of substrate}

Fig. 3.1 shows the pattern of change in ergosterol content in time for all fungal strains within each species. In general, the ergosterol concentrations in fungal treated straw 
showed a curvilinear pattern for all strains, with a lag phase up to 3 weeks for L. edodes. The ergosterol data of each strain were fitted to a polynomial regression model to describe the growth pattern and to estimate the changes in ergosterol ( $\left.\delta_{\mathrm{Erg}}\right)$ over time (Table 3.2). Most of $C$. subvermispora strains showed quadratic and linear growth patterns. All $P$. eryngii and L. edodes strains (except LE1 and LE9) mostly followed a cubic function. Four C. subvermispora strains (CS3, CS7, CS4 and CS11), showed a significantly higher $(P<$ 0.001) $\delta_{\mathrm{Erg}}$ compared to other CS strains and CS1 had the lowest $\delta_{\mathrm{Erg}}$. Among P. eryngii

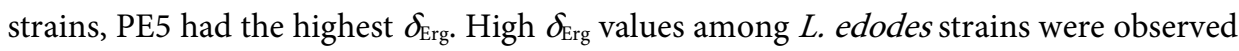
for LE10, LE1, LE2 and LE3. Two L. edodes strains (LE4 and LE5), showed irregular changes with the ergosterol contents of 271.4 and $449.4 \mu \mathrm{g} \mathrm{g}^{-1}$, respectively, despite no apparent mycelium being observed after 7 weeks. These data were excluded from the analysis.

Typical changes in $\mathrm{pH}$ for all fungal strains/species are shown in Fig. 3.2. $C$. subvermispora strains significantly $(P<0.001)$ decreased the $\mathrm{pH}$ of wheat straw from 5.00 to 3.52, while L. edodes strains (excluding LE4 and LE5) decreased $(P<0.001)$ the $\mathrm{pH}$ to 3.95. For $P$. eryngii strains, there were significant $(P<0.001)$ increases in $\mathrm{pH}$ up to week 3 , before it significantly decreased to $\mathrm{pH} 4.46$ at week 7 . After 7 weeks of colonization, the $\mathrm{pH}$ of wheat straw treated with LE4 and LE5 increased to $\mathrm{pH} 6.87$ and 7.17, respectively.
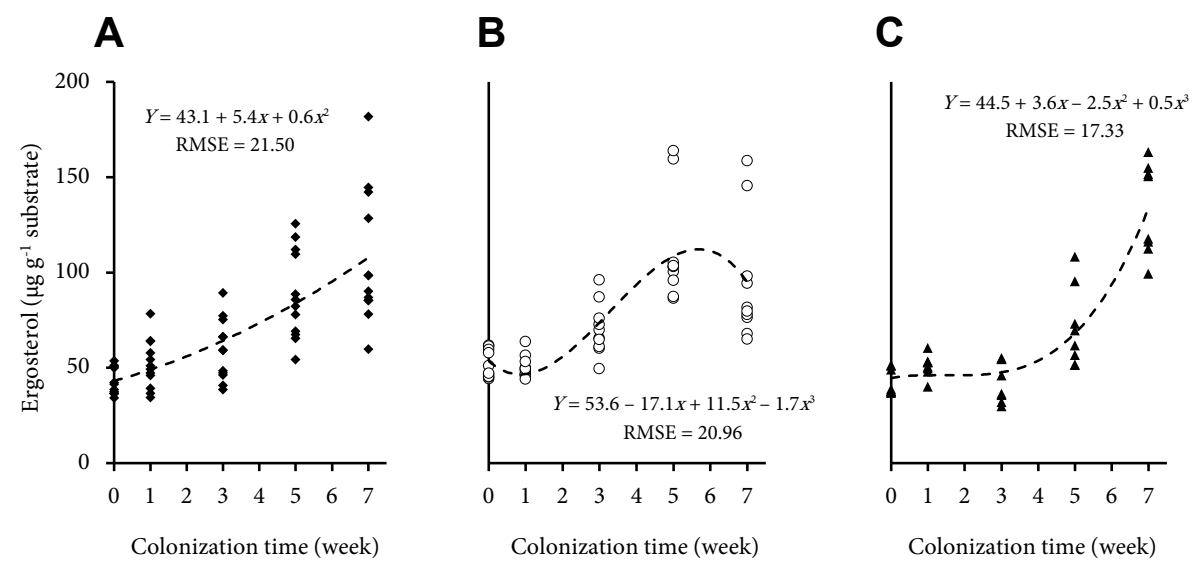

Fig. 3.1. Growth patterns of Ceriporiopsis subvermispora (A), Pleurotus eryngii (B) and Lentinula edodes (C) strains, as estimated by the ergosterol amount during 7 weeks of colonization on wheat straw. LE4 and LE5 were omitted from the graph, due to irregular changes. Dashed-lines indicate the average polynomial trend for each species with respective model and root mean square error (RMSE) are shown. The Y-axes are equally scaled. 
Chapter 3 | Fungal screening for bioprocessing of wheat straw

Table 3.2. Changes in ergosterol $\left(\delta_{\mathrm{Erg}}\right)$ contents of different fungal strains grown on wheat straw for 7 weeks and their respective regression coefficients.

\begin{tabular}{|c|c|c|c|c|c|c|c|c|}
\hline \multirow{2}{*}{$\begin{array}{l}\text { Species/ } \\
\text { strains }\end{array}$} & \multirow{2}{*}{$\begin{array}{c}\text { Erg }_{\text {week } 7} \\
\left(\mu \mathrm{g} \mathrm{g}^{-1}\right)\end{array}$} & \multirow{2}{*}{$\delta_{\text {Erg }}$} & \multicolumn{4}{|c|}{ Regression coefficients $^{\mathrm{a}}$} & \multirow{2}{*}{$R^{2}$} & \multirow{2}{*}{ RMSE } \\
\hline & & & $\beta_{0}$ & $\beta_{1}$ & $\beta_{2}$ & $\beta_{3}$ & & \\
\hline
\end{tabular}

\section{Ceriporiopsis subvermispora}

\begin{tabular}{|c|c|c|c|c|c|c|c|c|}
\hline CS1 & $59.6^{\mathrm{a}}$ & $1.6^{\mathrm{f}}$ & 49.1 & -1.6 & 0.5 & & 0.72 & 3.21 \\
\hline CS2 & $98.4^{\mathrm{c}}$ & $7.2^{\mathrm{d}}$ & 44.1 & 7.2 & & & 0.67 & 13.97 \\
\hline CS3 & $181.6^{\mathrm{f}}$ & $18.4^{\mathrm{a}}$ & 51.9 & -1.8 & 2.9 & & 0.98 & 7.73 \\
\hline CS4 & $144.6^{\mathrm{e}}$ & $13.0^{\mathrm{bc}}$ & 53.2 & 13.0 & & & 0.83 & 16.24 \\
\hline CS5 & $85.2^{\mathrm{b}}$ & $7.4^{\mathrm{d}}$ & 34.9 & -0.4 & 1.1 & & 0.94 & 5.56 \\
\hline CS6 & $78.0^{\mathrm{b}}$ & $4.6^{\mathrm{e}}$ & 44.0 & 4.6 & & & 0.60 & 10.37 \\
\hline CS7 & $142.1^{\mathrm{e}}$ & $14.6^{\mathrm{b}}$ & 41.9 & 6.6 & 1.2 & & 0.97 & 7.14 \\
\hline CS8 & $98.3^{c}$ & $7.8^{\mathrm{d}}$ & 45.1 & -23.9 & 10.8 & -0.9 & 0.93 & 8.03 \\
\hline CS9 & $85.3^{\mathrm{b}}$ & $7.2^{\mathrm{d}}$ & 38.0 & 7.2 & & & 0.90 & 6.72 \\
\hline CS10 & $86.8^{\mathrm{b}}$ & $7.4^{\mathrm{d}}$ & 34.2 & 7.4 & & & 0.94 & 5.29 \\
\hline CS11 & $128.4^{\mathrm{d}}$ & $12.7^{\mathrm{c}}$ & 40.2 & 21.4 & -1.2 & & 0.97 & 6.74 \\
\hline CS12 & $90.2^{\mathrm{bc}}$ & $7.3^{\mathrm{d}}$ & 38.4 & 12.6 & -0.8 & & 0.91 & 6.63 \\
\hline
\end{tabular}

\section{Pleurotus eryngii}

\begin{tabular}{lcrrrrrrr} 
PE1 & $67.9^{\mathrm{ab}}$ & $2.4^{\mathrm{e}}$ & 63.4 & -37.1 & 17.7 & -1.8 & 0.87 & 8.43 \\
PE2 & $81.5^{\mathrm{cd}}$ & $2.4^{\mathrm{e}}$ & 64.6 & -38.9 & 16.8 & -1.6 & 0.91 & 7.07 \\
PE3 & $76.4^{\mathrm{abc}}$ & $2.3^{\mathrm{e}}$ & 60.3 & -28.1 & 13.6 & -1.3 & 0.87 & 7.68 \\
PE4 & $145.3^{\mathrm{f}}$ & $8.8^{\mathrm{b}}$ & 60.6 & -16.3 & 14.5 & -1.5 & 0.89 & 16.52 \\
PE5 & $158.6^{\mathrm{f}}$ & $15.2^{\mathrm{a}}$ & 52.9 & -28.6 & 19.5 & -1.9 & 0.95 & 14.19 \\
PE6 & $64.9^{\mathrm{a}}$ & $2.5^{\mathrm{e}}$ & 48.7 & -0.6 & 4.2 & -0.5 & 0.84 & 6.37 \\
PE7 & $77.9^{\mathrm{bc}}$ & $4.8^{\mathrm{d}}$ & 44.4 & 1.8 & 3.6 & -0.5 & 0.93 & 5.22 \\
PE8 & $79.6^{\mathrm{bc}}$ & $4.6^{\mathrm{d}}$ & 47.9 & -14.2 & 10.7 & -1.1 & 0.92 & 7.57 \\
PE9 & $94.2^{\mathrm{de}}$ & $6.9^{\mathrm{c}}$ & 46.8 & -2.0 & 5.9 & -0.7 & 0.96 & 5.28 \\
PE10 & $98.0^{\mathrm{e}}$ & $7.4^{\mathrm{c}}$ & 46.0 & -7.2 & 8.0 & -0.9 & 0.98 & 3.73 \\
& & & & & & & \\
Lentinula & edodes & & & & & & & 0.95 \\
LE1 & $163.1^{\mathrm{a}}$ & $16.0^{\mathrm{a}}$ & 51.7 & -12.0 & 4.0 & & & 11.32 \\
LE2 & $151.5^{\mathrm{a}}$ & $14.4^{\mathrm{ab}}$ & 50.8 & 6.4 & -4.1 & 0.8 & 0.95 & 10.75 \\
LE3 & $150.3^{\mathrm{a}}$ & $14.0^{\mathrm{ab}}$ & 51.8 & -24.0 & 10.9 & -0.8 & 0.97 & 8.19 \\
LE6 & $99.2^{\mathrm{b}}$ & $8.5^{\mathrm{c}}$ & 40.2 & 9.3 & -5.1 & 0.7 & 0.94 & 6.75 \\
LE7 & $116.0^{\mathrm{c}}$ & $11.0^{\mathrm{bc}}$ & 40.2 & 3.0 & -3.3 & 0.6 & 0.95 & 8.37 \\
LE8 & $112.3^{\mathrm{c}}$ & $10.2^{\mathrm{c}}$ & 41.2 & 12.1 & -6.9 & 0.9 & 0.92 & 9.43 \\
LE9 & $117.6^{\mathrm{c}}$ & $9.8^{\mathrm{c}}$ & 47.0 & -12.7 & 3.2 & & 0.85 & 13.55 \\
LE10 & $154.9^{\mathrm{a}}$ & $16.8^{\mathrm{a}}$ & 38.6 & 29.0 & -11.8 & 1.4 & 0.92 & 14.50 \\
\hline
\end{tabular}

Values with different superscripts within column of the same species are significantly $(P<0.05)$ different. Erg week

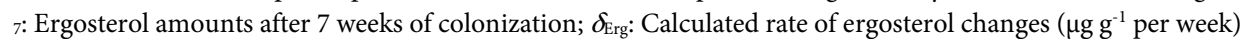
over 7 weeks using respective regression functions. LE4 and LE5 are omitted from the table due to irregular changes.

a Regression coefficients of the polynomial functions with intercept $\beta_{0}$ with respective coefficient of determination $\left(R^{2}\right)$ and root mean square error (RMSE). 


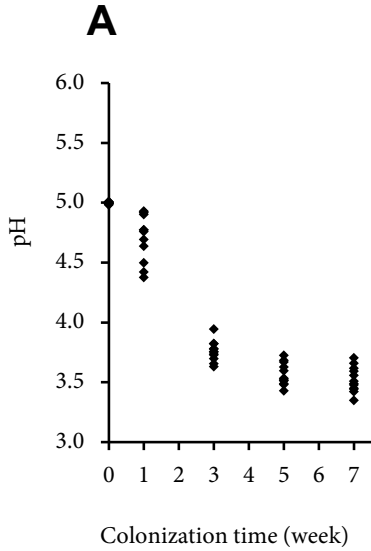

B

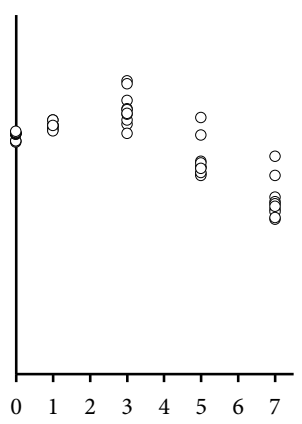

Colonization time (week)
C

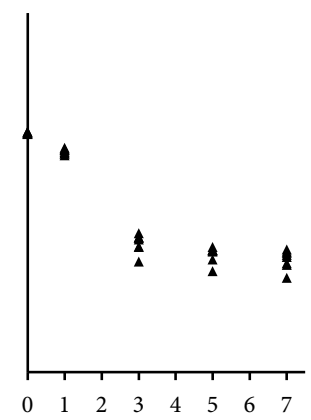

Colonization time (week)

Fig. 3.2. Trends in $\mathrm{pH}$ changes of wheat straw treated with different strains of Ceriporiopsis subvermispora (A), Pleurotus eryngii (B) and Lentinula edodes (C) during 7 weeks of colonization. LE4 and LE5 were omitted from the graph due to irregular changes. The Y-axes are equally scaled.

\section{In vitro gas production}

In vitro gas production (IVGP) was used to select the best performing fungal strains for each species. Overall, 17 out of 32 fungal strains tested, significantly $(P<0.05)$ improved the IVGP of wheat straw after 7 weeks of colonization (Fig. 3.3). Seven strains of $C$. subvermispora significantly $(P<0.05)$ increased the IVGP of the wheat straw, with CS1, CS6, CS12, CS8 and CS5 being highly significant $(P<0.001)$ compared to untreated straw. Fermentation of CS1-treated wheat straw produced most gas $\left(313.2 \mathrm{ml} \mathrm{g}^{-1} \mathrm{OM}\right)$, followed by CS6 and CS12 (293.6 and $284.2 \mathrm{ml} \mathrm{g}^{-1} \mathrm{OM}$, respectively). Among P. eryngii strains, 3 strains - PE6, PE2 and PE3 significantly $(P<0.05)$ increased the IVGP of the wheat straw. PE6 had the highest IVGP $\left(263.0 \mathrm{ml} \mathrm{g}^{-1} \mathrm{OM}\right)$, followed by PE2 and PE3 with a mean IVGP of 257.9 and $252.4 \mathrm{ml} \mathrm{g}^{-1} \mathrm{OM}$, respectively. Seven strains of $L$. edodes significantly $(P<0.05)$ increased the IVGP of the straw where five of them were highly significant $(P<0.001)$. LE8 showed the highest IVGP $\left(297.7 \mathrm{ml} \mathrm{g}^{-1} \mathrm{OM}\right)$, followed by LE7 (289.4 $\left.\mathrm{ml} \mathrm{g}^{-1} \mathrm{OM}\right)$ and LE10 (287.3 $\left.\mathrm{ml} \mathrm{g}^{-1} \mathrm{OM}\right)$. LE4 and LE5, for which irregular changes in growth and $\mathrm{pH}$ were observed, showed a significantly $(P<0.05)$ lower IVGP compared to the untreated straw.

Three strains from each species with the highest IVGP values were selected for further assessment and comparison across species. The selected strains (in order of IVGP values) were CS1, CS6 and CS12 for C. subvermispora; PE6, PE2 and PE3 for P. eryngii; and LE8, LE7 and LE10 for L. edodes. 

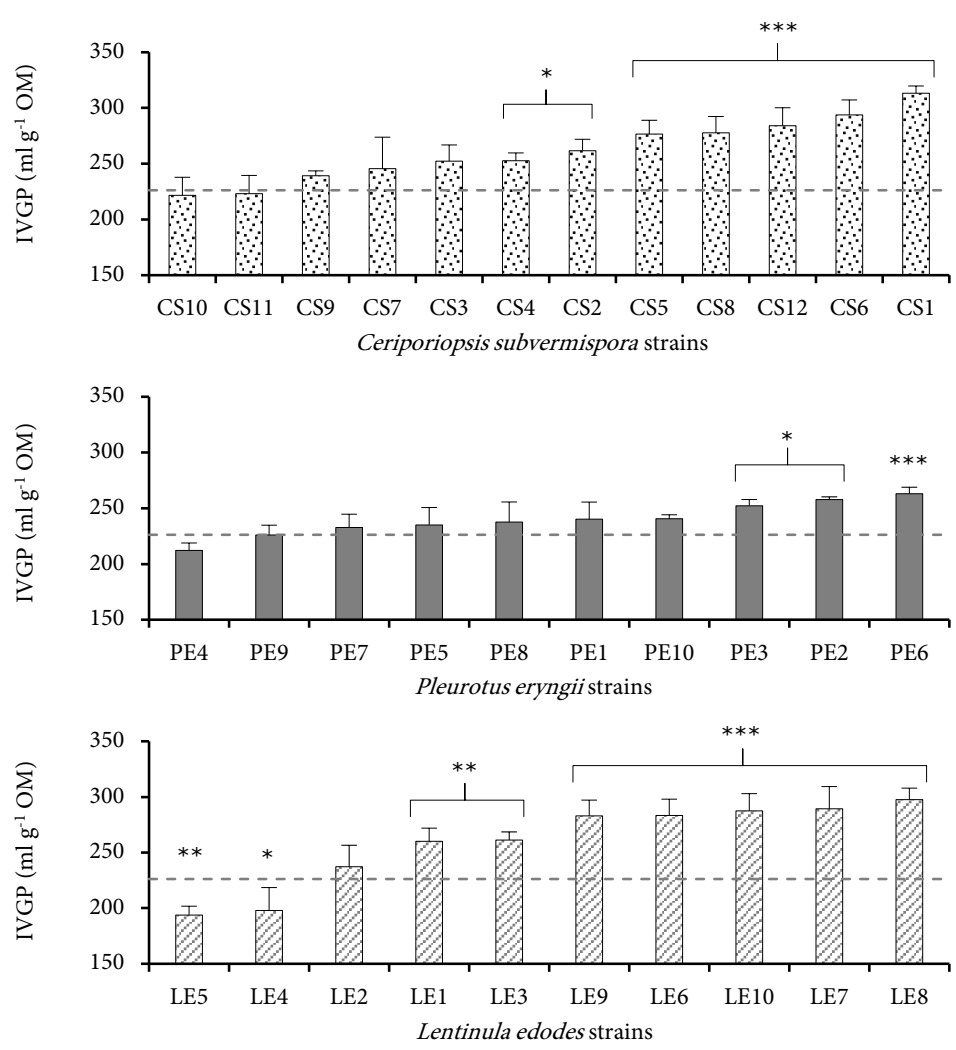

Fig. 3.3. Total in vitro gas production (IVGP) of wheat straw treated with different fungal strains (within species) after 7 weeks of colonization. The IVGP values were sorted ascendingly within each species. Dashed-line marks the gas production of the control (untreated straw) and error bars indicate the standard deviation. Asterisks show significant differences from the control at $P<0.001$ $\left.{ }^{(* *}\right), P<0.01\left(^{* *}\right)$ and $P<0.05\left(^{*}\right)$.

\section{Gas production kinetics and fermentation characteristics}

The kinetic parameters of the second (non-soluble) phase of the gas production curves ( 4 to $48 \mathrm{~h}$ ) for the selected fungal strains are summarized in Table 3.3. Compared to the untreated wheat straw, all fungal-treated wheat straw showed significantly $(P<$ $0.01)$ higher $A_{2}$ values (except PE2 and PE3) and significantly $(P<0.001)$ lower $B_{2}$ values, indicating a higher and faster fermentation of the substrate. High $A_{2}$ and low $B_{2}$ were accompanied by significantly $(P<0.01)$ lower $t_{R \mathrm{~m} 2}$ and higher $R_{\mathrm{m} 2}$ values for all fungaltreated straw samples, compared to the control. Among different species, $C$. 
Chapter 3 | Fungal screening for bioprocessing of wheat straw

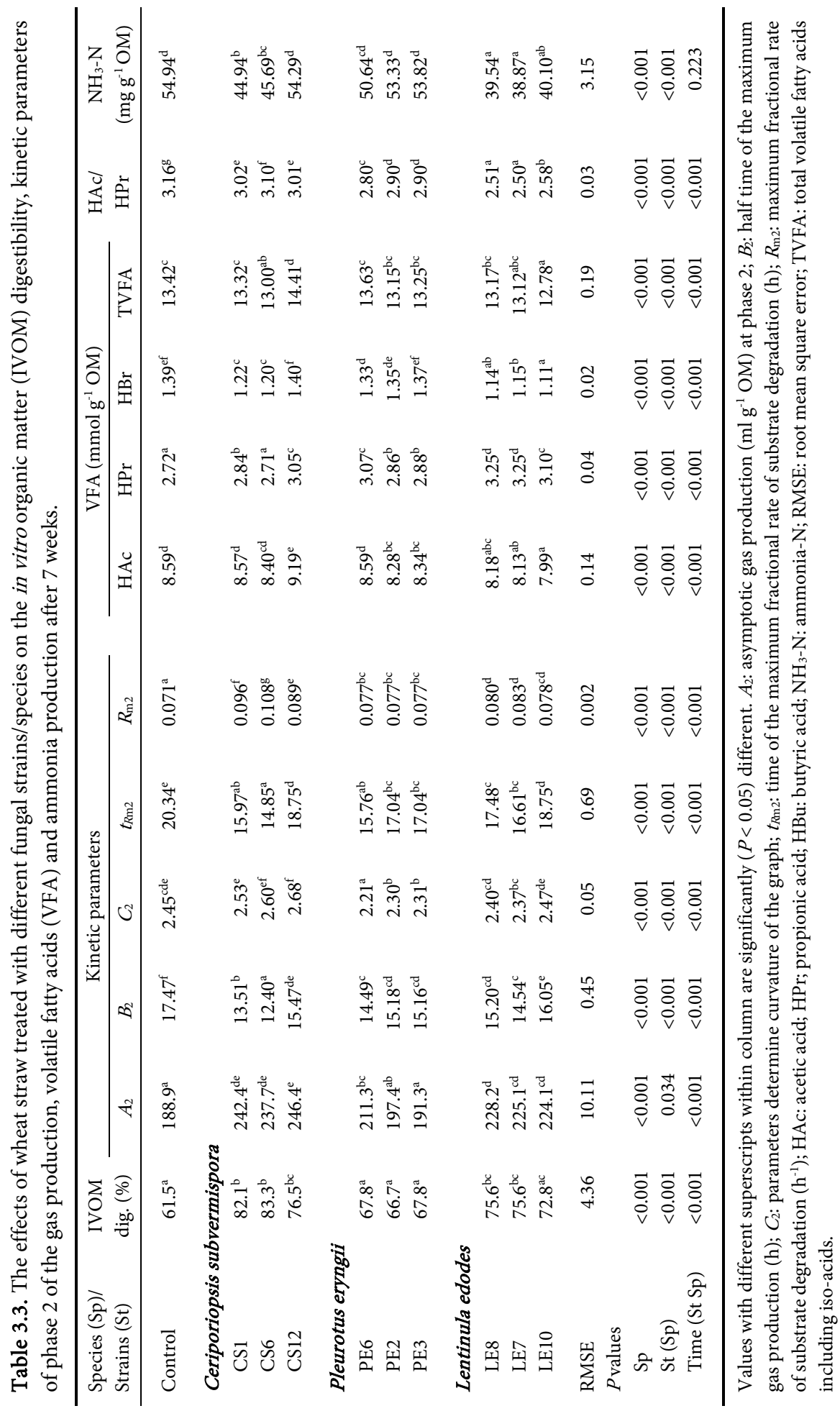


subvermispora strains showed a significant contrast $(P<0.001)$ to the $P$. eryngii strains in all kinetic parameters. Other contrast wise comparisons among different fungal species showed significant differences $(P<0.05)$, except for $A_{2}$ values for $C$. subvermispora vs. $L$. edodes strains, and $R_{\mathrm{m} 2}$ for $P$. eryngii vs. L. edodes strains. The increases in IVGP correlated with the increases in in vitro OM digestibility $(r=0.81 ; P<0.001)$.

All fungal-treated wheat straw showed a decrease in acetate (except for CS12) during fermentation in rumen fluid, but an increase in propionate production (Table 3.3). This observation was also reflected by the changes in acetate/propionate ratio with the lowest values observed for L. edodes strains, followed by P. eryngii and C. subvermispora strains. All species were significantly $(P<0.001)$ different to each other in their acetate/propionate ratio. There was a significant $(P<0.001)$ decrease in $\mathrm{NH}_{3}-\mathrm{N}$ production for C. subvermispora (except CS12) and L. edodes strains. The changes observed in all P. eryngii strains, however, were not significant. L. edodes strains showed the lowest $\mathrm{NH}_{3}-\mathrm{N}$, followed by $C$. subvermispora and $P$. eryngii strains. Contrast wise, strains were significantly $(P<0.001)$ different from each other.

\section{Mass balance}

The control, untreated wheat straw contained $213.8 \mathrm{~g} \mathrm{~kg}^{-1}$ of DM and $33.3 \mathrm{~g} \mathrm{~kg}^{-1}$ ash (on DM basis) with an absolute OM amount of $87.2 \pm 0.3 \mathrm{~g}$. All mass balance data were presented as g per $100 \mathrm{~g}$ of this starting OM. The mass balance data of the selected fungal species/strains are summarized in Table 3.4. All fungal pretreatments decreased the amount of OM of the wheat straw by 1.6 to $7.8 \%$, with the decreases in CS6 and CS12treated straw were not significant. The fungal pretreatment resulted in 6.3 to $30.1 \%$ increase in the amount of crude protein. All fungi significantly $(P<0.001)$ degraded ADL and hemicellulose in the wheat straw. The largest decrease in the amount of ADL and hemicellulose was observed in CS1-treated straw with 52.2 and 49.7\% lower ADL and hemicellulose, respectively, compared to the control. The absolute amount of cellulose, however, did not change significantly, except for CS1. Although CS1-treated straw showed a decrease in cellulose, it contained the highest "enrichment" of total carbohydrates, i.e. highest carbohydrate to lignin ratio $(\mathrm{C} / \mathrm{L})$ in the remaining material. Wheat straw treated with C. subvermispora strains (except CS12) showed an overall high C/L, followed by L. edodes and P. eryngii strains. The total mass which was not identified ranged from 7.8 to $24.4 \%$ from the total amount of OM. 
Chapter 3 | Fungal screening for bioprocessing of wheat straw

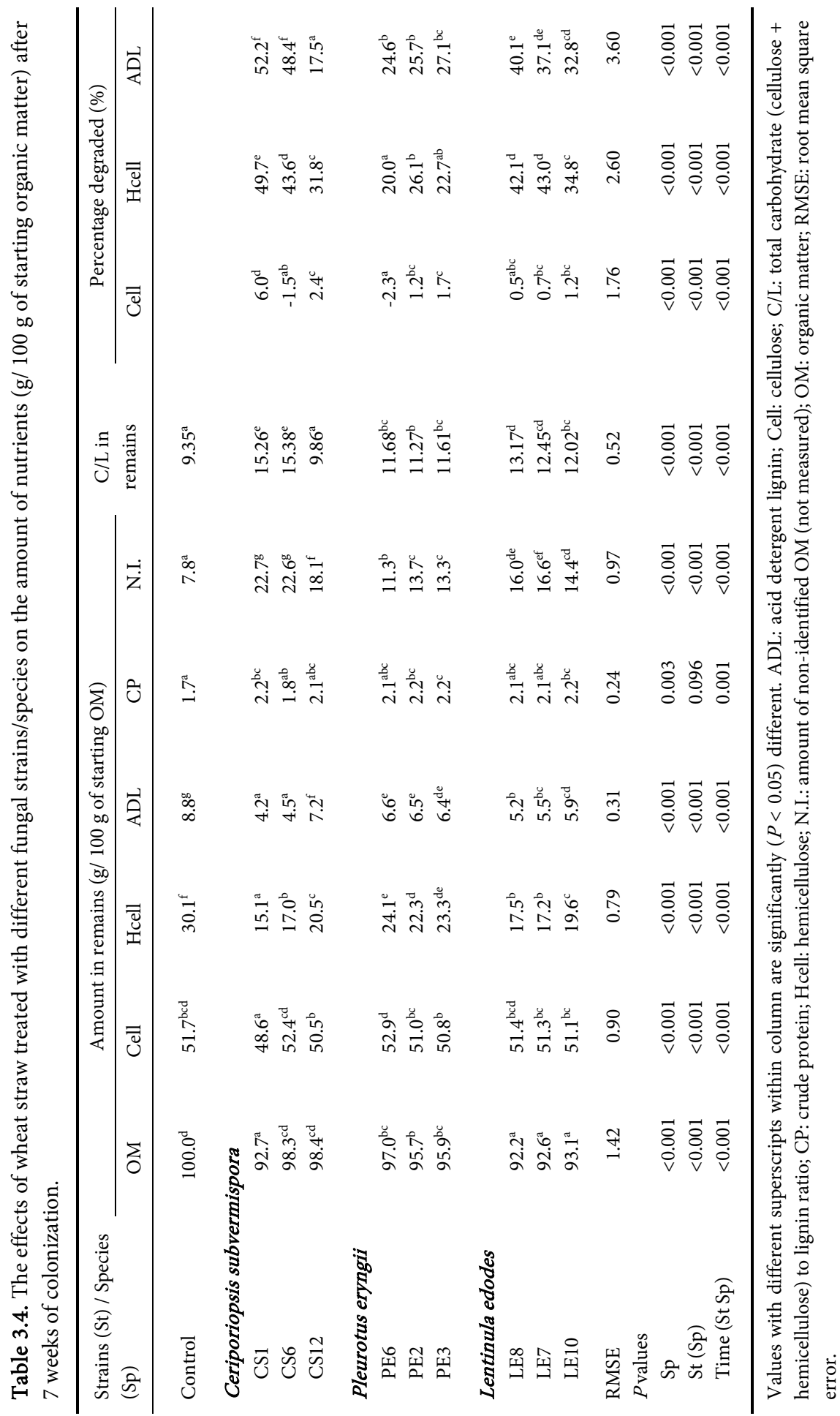




\section{DISCUSSION}

A complete colonization of the substrate is a prerequisite for an effective fungal pretreatment (Van Kuijk et al., 2015a). The ergosterol content of the treated wheat straw in the present study varied greatly among the different fungal strains/species, which has also been reported in other studies (Klamer and Bååth, 2004; Niemenmaa et al., 2008). A simple polynomial regression was used as an empirical approach to compare the growth rate of different strains within species. Other mathematical approaches have also been used (Mirón et al., 2002; Gutarowska and Zakowska, 2009), however a longer lag phase in our study contradicts the assumption made for these liquid-culture based models that growth should mainly occur at the beginning of the colonization. Fungi undergo a lag phase as a physiological preparation for an exponential phase, which depends on inoculum and available nutrients (Griffin, 1996). A longer lag phase was observed for CS1 and CS2, compared to a previous study which used the same strains grown under similar conditions (Nayan et al., 2017). This was expected as the present study used 2.6 times more substrate (fresh weight basis) compared to the latter study.

The present study shows that $L$. edodes strains had a longer lag time compared to $C$. subvermispora and P. eryngii strains. For P. eryngii strains, there was an indication of a decrease in fungal biomass after week 5 . Since ergosterol is relatively stable in substrate (Mille-Lindblom et al., 2004), this observation indicates that the fungi recycled mycelium, probably due to a decline in their ability to obtain nutrients from the substrate. A continuing decrease in the $\mathrm{pH}$ of the substrate (Fig. 3.2) signals the generation of metabolites that lower the $\mathrm{pH}$, indicating a persistent formation of new biomass at the expense of old biomass (Falconer et al., 2005). Meanwhile, it is difficult to provide an explanation for the irregular changes observed in the ergosterol contents of LE4 and LE5 treated straw. A visual observation of these samples provided no indication for the presence of green molds (a sign of contamination). An increase in $\mathrm{pH}$ to near neutral and slightly alkaline for LE4 and LE5, respectively, might indicate that these fungi did not grow well on wheat straw or a probable bacterial contamination due to poor fungal growth. A decrease in substrate $\mathrm{pH}$ during the fungal colonization is a characteristic of lignin-degrading enzyme secretions (Liers et al., 2011), in addition to the production of organic acids (Hofrichter et al., 1999).

Degradability of treated wheat straw in rumen fluid, as measured using the IVGP technique (Cone et al., 1996), was used here (Fig. 3.3) as a screening criterion for the best performing fungal strains. This accurate time-related technique has been widely used in feed evaluation research, including in assessing the degradability of fungal-treated 
agricultural biomass (Tuyen et al., 2013; Van Kuijk et al., 2015a). Other important parameters have also been used as screening criteria such as selective delignification which resulted in a high $\mathrm{C} / \mathrm{L}$, growth characteristics and enzyme activities ( Li et al., 2008; Chang et al., 2012; Cruz Ramírez et al., 2012). Our choice of using the IVGP for strains screening is based on the fact that it provides a good indication for the improvement in the nutritive value of wheat straw in a convenient and robust manner. Moreover, an increase in IVGP has been correlated with an increase of $\mathrm{C} / \mathrm{L}$ in the substrate (Karunanandaa and Varga, 1996a; Tuyen et al., 2012). A selective fungus is desirable for bioprocessing of wheat straw into ruminant feed.

CS1, PE2 and LE7 were the same fungal strains as used in previous studies (Tuyen et al., 2012; Van Kuijk et al., 2015b; Nayan et al., 2017). The IVGP of CS1-treated wheat straw in the present study $\left(313.2 \mathrm{ml} \mathrm{g}^{-1} \mathrm{OM}\right)$ was slightly higher than previously reported (300 to $\left.305 \mathrm{ml} \mathrm{g}^{-1} \mathrm{OM}\right)$. The IVGP of PE2-treated straw (257.9 $\mathrm{ml} \mathrm{g}^{-1} \mathrm{OM}$ ) was also within the range of previously reported for wheat straw treated with this strain (250 to $260 \mathrm{ml} \mathrm{g}$ $\left.{ }^{1} \mathrm{OM}\right)$. The IVGP of LE7-treated wheat straw reported here $\left(289.4 \mathrm{ml} \mathrm{g}^{-1} \mathrm{OM}\right)$ was slightly higher than that of Tuyen et al. (2012) (270 to $280 \mathrm{ml} \mathrm{g}^{-1} \mathrm{OM}$ ). Van Kuijk et al. (2015b) reported an IVGP value of $311.3 \mathrm{ml} \mathrm{g}^{-1} \mathrm{OM}$ when wheat straw was treated with this strain for 12 weeks. All selected IVGP data were subjected to a biphasic model (Groot et al., 1996) to assess the kinetic parameters of the gas production curves. This curve-fitting tool has been shown to be useful in comparing the gas production profiles of wheat straw treated with two strains of $C$. subvermispora, although the total IVGP values of both fungi were not significantly different (Nayan et al., 2017). We present only parameters of the second phase as it is related to the fermentation of structural carbohydrates (Groot et al., 1996; Cone et al., 1997). Results show that wheat straw treated with $C$. subvermispora strains had an overall better gas production profile - higher $A_{2}$ and lower $B_{2}$, followed by L. edodes and P. eryngii strains.

Fermentation of a low quality, highly fibrous feed results in an increase in acetate production, while an increase in rapidly fermentable carbohydrates will result in an increase in propionate production (Van Houtert, 1993). Other factors that can also affect the acetate/propionate ratio, including substrate composition and availability, as well as microbial species present (Dijkstra, 1994). An increase in IVGP indicates that the fungal pretreatment modifies the complexity of the cell wall and transforms the wheat straw into a more fermentable fiber source. The effect of a change from complex to easily digestible fiber sources (by means of chemical pretreatment) on the VFA production has been demonstrated by Griffith et al. (2016). They reported a similar decrease in acetate and 
acetate/propionate ratio, as well as an increase in propionate molar proportion. Similar results were also reported for rice straw treated with Cyathus stercoreus (Karunanandaa and Varga, 1996b). However, Karunanandaa and Varga (1996a) reported an increased acetate and acetate/propionate ratio in rice straw treated with Phanerochaete chrysosporium. A likely explanation is that this fungus is considered to be less selective and reduces the amount of carbohydrates considerably (Tuyen et al., 2012). A lower $\mathrm{NH}_{3}$ $\mathrm{N}$ was also reported for fungal treated rice straw, compared to a control (Karunanandaa and Varga, 1996b). During the in vitro incubation, a decrease in $\mathrm{NH}_{3}-\mathrm{N}$ concentration in the rumen fluid was followed by a concurrent increase in microbial $\mathrm{N}$ (Cone et al., 1997), suggesting that the fungal treated straw may lead to a more efficient microbial $\mathrm{N}$ conversion in the rumen.

The selectivity of fungi in degrading lignin, as indicated by the "carbohydrate enrichment" or $\mathrm{C} / \mathrm{L}$ in the remaining material, was significantly correlated $(r=0.64, P<$ $0.001)$ to the IVGP values. Although the chemical analysis were not carried out for all 32 strains involved in this study, these correlations indicate the potency of the IVGP technique as a tool in screening the best performing fungal strains. One of the limitations of using the Van Soest et al. (1991) method to analyze the cell wall composition of the fungal-treated material is that, it does not differentiate cellulose in the substrate from chitin in the fungal biomass (cellulose-like structure with $\mathrm{N}$-acetylglucosamine monomers). This is because the hydrolysis of chitin polymers requires a stronger concentrated acid (Einbu and Vårum, 2008). This may lead to an overestimation of the cell wall composition, which can explain the slight increase in cellulose observed for CS6 and PE6-treated wheat straw. Nonetheless, in the context of fungal pretreatment of lignocellulosic biomass, a selective fungus should be defined for its ability to degrade lignin and enrich the biomass with high amounts of available carbohydrates in the end products, i.e. high $\mathrm{C} / \mathrm{L}$ in the remaining materials. Meanwhile, the increases of $\mathrm{CP}$ in fungal-treated straw may erroneously suggest that these fungi could fix atmospheric $\mathrm{N}$, which is not true. The relative enrichment of $\mathrm{CP}$ is due to degradation of the cell wall components, leading to a concentration of $\mathrm{N}$ content (Van Kuijk et al., 2015a).

The present study also provides fundamental information for breeding purposes. For example, CS1 is one of the strains in the C. subvermispora collection that has no clamp connection and, therefore, is a monokaryon (Sonnenberg, personal observation, 2017). Tello et al. (2001) showed that this monokaryon produced less biomass in liquid cultures and showed a higher lignin-degrading enzyme activity compared to dikaryons. In our study, the low growth rate in the monokaryotic CS1 resulted in a high $\mathrm{C} / \mathrm{L}$, which 
corresponds to the higher IVGP of the treated wheat straw. Considering all these features, it might be worthwhile to recover the constituent nucleus of all dikaryotic strains and evaluate all recovered nuclei as monokaryons in future breeding activities.

Results clearly show the variation among strains within species in terms of growth patterns, fiber degradation capabilities, as well as improving the in vitro digestibility of wheat straw in rumen fluid. Nevertheless, there are some limitations in this screening study. White-rot fungi are known to vary in their performance on different lignocellulosic biomasses (Tuyen et al., 2013). Hence, the selected strains in this study will not necessarily be applicable for other agricultural biomasses. The wheat straw used in the study was heterogeneous in nature, which consisted of different parts of the plant. No prior separation of leaves and stalks was carried out, which may lead to variation in the chemical composition of the straw used. Nevertheless, thorough mixing was carefully done for each sub-batch of the straw to avoid biases. The variation in the wheat straw used, i.e. different cultivars and maturity stages with different culture conditions, may also influence the outcome of future studies using the selected fungal strains. In addition, under various treatment and environmental conditions, these fungi can differ in their enzyme activities and also the production of diverse secondary metabolites, which may affect the subsequent enrichment of the biomass and its degradability by the rumen microbes. This study presents a promising step towards capitalizing on the unique abilities of white-rot fungi to bio-transform high lignin-containing agricultural biomasses into digestible animal feed. Moreover, this finding could be further broadened into various applications such as in the production of biofuels and industrial bioremediation.

\section{CONCLUSION}

In conclusion, there is a large biological variation among fungal strains within the same species for their capacity to degrade lignin in wheat straw. C. subvermispora strains, especially strain 1, showed an overall high potential in improving the nutritive value of wheat straw, followed by L. edodes and P. eryngii strains. The outcome of this study underlines the importance to also assess different strains of the same species and select the best strain for bioprocessing of biomass into ruminant feed. The variation among fungal strains offers opportunities for breeders to map genomic regions that explain the difference in extent and selectivity of lignocellulose degradation. This knowledge can be used to stack favorable alleles and generate superior strains. 


\section{ACKNOWLEDGEMENTS}

The authors gratefully acknowledge the financial support from the University Fund Wageningen (UFW) as part of the project "More Meat and Milk from Straw" which is sponsored by DEKA, ForFarmers and the Victam Foundation. The authors would like to acknowledge the scholarship provided by the Ministry of Higher Education of Malaysia and the Universiti Putra Malaysia. All funding bodies had no involvement in planning and conduct of the research. The authors also acknowledge Mrs. Saskia van Laar, Mrs. Xuan Huong van der Schans-Le and Ms. Laura Berns for their technical assistance.

\section{REFERENCES}

Cavallazzi, J.R.P., Brito, M.D.S., Oliveira, M.G.D.A., Villas-bôas, S.G. and Kasuya, M.C.M. (2004) Lignocellulolytic enzymes profile of three Lentinula edodes (Berk.) Pegler strains during cultivation on eucalyptus bark-based medium. Food Agric. Environ. 2, 291-297.

Chang, A.J., Fan, J. and Wen, X. (2012) Screening of fungi capable of highly selective degradation of lignin in rice straw. Int. Biodeterior. Biodegrad. 72, 26-30.

Cone, J.W., van Gelder, A.H. and Driehuis, F. (1997) Description of gas production profiles with a three-phasic model. Anim. Feed Sci. Technol. 66, 31-45.

Cone, J.W., van Gelder, A.H., Visscher, G.J.W. and Oudshoorn, L. (1996) Influence of rumen fluid and substrate concentration on fermentation kinetics measured with a fully automated time related gas production apparatus. Anim. Feed Sci. Technol. 61, 113-128.

Cragg, S.M., Beckham, G.T., Bruce, N.C., Bugg, T.D.H., Distel, D.L., Dupree, P., Etxabe, A.G., Goodell, B.S., Jellison, J., McGeehan, J.E., McQueen-Mason, S.J., Schnorr, K., Walton, P.H., Watts, J.E.M., and Zimmer, M. (2015) Lignocellulose degradation mechanisms across the Tree of Life. Curr. Opin. Chem. Biol. 29, $108-119$.

Cruz Ramírez, M.G., Rivera-Ríos, J.M., Téllez-Jurado, A., Maqueda Gálvez, A.P., Mercado-Flores, Y. and AranaCuenca, A. (2012) Screening for thermotolerant ligninolytic fungi with laccase, lipase, and protease activity isolated in Mexico. J. Environ. Manage. 95, S256-S259.

Dijkstra, J. (1994) Production and absorption of volatile fatty acids in the rumen. Livest. Prod. Sci. 39, 61-69.

Dinis, M.J., Bezerra, R.M.F., Nunes, F., Dias, A.A., Guedes, C. V., Ferreira, L.M.M., Cone, J.W., Marques, G.S.M., Barros, A.R.N. and Rodrigues, M.A.M. (2009) Modification of wheat straw lignin by solid state fermentation with white-rot fungi. Bioresour. Technol. 100, 4829-4835.

Einbu, A. and Vårum, K.M. (2008) Characterization of chitin and its hydrolysis to GlcNAc and GlcN. Biomacromol. 9, 1870-1875.

Falconer, R.E., Bown, J.L., White, N. and Crawford, J.W. (2005) Biomass recycling and the origin of phenotype in fungal mycelia. Proc. Biol. Sci. 272, 1727-34.

Gilbertson, R.L. and Ryvarden, L. (1985) Some new combinations in Polyporaceae. Mycotaxon, 22, 363-365.

Griffin, D.H. (1996) Growth. In: Griffin, D.H. (Ed.), Fungal Physiology. Wiley, Inc., New York, pp. $102-129$.

Griffith, C.L., Jr, G.O.R., Oba, M., Mcallister, T.A., Beauchemin, K.A. and Newbold, C.J. (2016) Fermentation of ammonia fiber expansion treated and untreated barley straw in a rumen simulation technique using rumen inoculum from cattle with slow versus fast rate of fiber disappearance. Front. Microbiol. 7, 1-10. 
Groot, J.C., Cone, J.W., Williams, B.A., Debersaques, F.M.A. and Lantinga, E.A. (1996) Multiphasic analysis of gas production kinetics for in vitro fermentation of ruminant feeds. Anim. Feed Sci. Technol. 64, 77-89.

Gutarowska, B. and Zakowska, Z. (2009) Mathematical models of mycelium growth and ergosterol synthesis in stationary mould culture. Lett. Appl. Microbiol. 48, 605-610.

Hatakka, A. and Hammel, K. (2010) Fungal biodegradation of lignocelluloses. In: Hofrichter, M. (Ed.), Industrial Applications (The Mycota). Springer, pp. 319-2340.

Hendriks, A.T.W.M. and Zeeman, G. (2009) Pretreatments to enhance the digestibility of lignocellulosic biomass. Bioresour. Technol. 100, 10-18.

Hofrichter, M., Hofrichter, M., Vares, T., Vares, T., Kalsi, M., Kalsi, M., Galkin, S., Galkin, S., Scheibner, K., Scheibner, K., Fritsche, W., Fritsche, W., Hatakka, A. and Hatakka, A. (1999) Production of manganese peroxidase and organic acids and mineralization of ${ }^{14} \mathrm{C}$-labelled lignin $\left({ }^{14} \mathrm{C}\right.$-DHP) during solid-state fermentation of wheat straw with the white rot fungus. Appl. Environ. Microbiol. 65, 1864-1870.

Isroi, I., Millati, R., Syamsiah, S., Niklasson, C., Cahyanto, M.N., Lundquist, K. and Taherzadeh, M.J. (2011) Biological pretreatment of lignocelluloses with white-rot fungi and its applications: A review. BioResources 6, 5224-5259.

Karunanandaa, K. and Varga, G.A. (1996a) Colonization of crop residues by white-rot fungi: cell wall monosaccharides, phenolic acids, ruminal fermentation characteristics and digestibility of cell wall fiber components in vitro. Anim. Feed Sci. Technol. 63, 273-288.

Karunanandaa, K. and Varga, G.A. (1996b). Colonization of rice straw by white-rot fungi (Cyathus stercoreus): Effect on ruminal fermentation pattern, nitrogen metabolism, and fiber utilization during continuous culture. Anim. Feed Sci. Technol. 61, 1-16.

Klamer, M. and Bååth, E. (2004) Estimation of conversion factors for fungal biomass determination in compost using ergosterol and PLFA 18:2w6,9. Soil Biol. Biochem. 36, 57-65.

Kubicek, C.P. (2013) The plant biomass. In: Kubicek, C.P. (Ed.), Fungi and Lignocellulosic Biomass. WileyBlackwell, Hoboken, pp. 1-28.

Li, L., Li, X.Z., Tang, W.Z., Zhao, J. and Qu, Y.B. (2008) Screening of a fungus capable of powerful and selective delignification on wheat straw. Lett. Appl. Microbiol. 47, 415-420.

Liers, C., Arnstadt, T., Ullrich, R. and Hofrichter, M. (2011) Patterns of lignin degradation and oxidative enzyme secretion by different wood- and litter-colonizing basidiomycetes and ascomycetes grown on beechwood. FEMS Microbiol. Ecol. 78, 91-102.

Mata, G. and Savoie, J.M. (1998) Extracellular enzyme activities in six Lentinula edodes strains during cultivation in wheat straw. World J. Microbiol. Biotechnol. 14, 513-519.

Mille-Lindblom, C., von Wachenfeldt, E. and Tranvik, L.J. (2004) Ergosterol as a measure of living fungal biomass: persistence in environmental samples after fungal death. J. Microbiol. Methods 59, 253-262.

Mirón, J., González, M.P., Pastrana, L. and Murado, M.A. (2002) Diauxic production of glucose oxidase by Aspergillus niger in submerged culture. Enzyme Microb. Technol. 31, 615-620.

Moore, K.J., Jung and H.-J.G. (2001) Lignin and Fiber Digestion. J. Range Manag. 54, 420.

Mosier, N., Wyman, C., Dale, B., Elander, R., Lee, Y.Y., Holtzapple, M. and Ladisch, M. (2005) Features of promising technologies for pretreatment of lignocellulosic biomass. Bioresour. Technol. 96, 673-686.

Nayan, N., Sonnenberg, A.S.M., Hendriks, W.H. and Cone, J.W. (2017) Differences between two strains of Ceriporiopsis subvermispora on improving the nutritive value of wheat straw for ruminants. J. Appl. Microbiol. 123, 352-361. 
Chapter 3 | Fungal screening for bioprocessing of wheat straw

Niemenmaa, O., Galkin, S. and Hatakka, A., (2008) Ergosterol contents of some wood-rotting basidiomycete fungi grown in liquid and solid culture conditions. Int. Biodeterior. Biodegradation 62, 125-134.

Pegler, D. (1975) The classification of the genus Lentinus Fr. (Basidiomycota). Kavaka 3: 11-20.

Quélet, L. (1872) Les Champignons du Jura et des Vosges. Mémoires de la Société d'Émulation de Montbéliard. 5:43-332

Sarnklong, C., Cone, J.W., Pellikaan, W. and Hendriks, W.H. (2010) Utilization of rice straw and different treatments to improve its feed value for ruminants: A review. Asian-Australas. J. Anim. Sci. 23, 680-692.

Sharma, R.K. and Arora, D.S. (2010) Production of lignocellulolytic enzymes and enhancement of in vitro digestibility during solid state fermentation of wheat straw by Phlebia floridensis. Bioresour. Technol. 101, 9248-9253.

Sharma, R.K. and Arora, D.S. (2014). Bioprocessing of wheat and paddy straw for their nutritional up-gradation. Bioprocess Biosyst. Eng. 37, 1437-1445.

Shrivastava, B., Jain, K.K., Kalra, A. and Kuhad, R.C. (2014) Bioprocessing of wheat straw into nutritionally rich and digested cattle feed. Sci. Rep. 4, 6360.

Shrivastava, B., Thakur, S., Khasa, Y.P., Gupte, A., Puniya, A.K. and Kuhad, R.C. (2011) White-rot fungal conversion of wheat straw to energy rich cattle feed. Biodegradation 22, 823-831.

Tello, M., Seelenfreund, D., Lobos, S., Gaskell, J., Cullen, D. and Vicuña, R. (2001) Isolation and characterization of homokaryotic strains from the ligninolytic basidiomycete Ceriporiopsis subvermispora. FEMS Microbiol. Lett. 199, 91-96.

Tuyen, V.D., Cone, J.W., Baars, J.J.P., Sonnenberg, A.S.M. and Hendriks, W.H. (2012) Fungal strain and incubation period affect chemical composition and nutrient availability of wheat straw for rumen fermentation. Bioresour. Technol. 111, 336-342.

Tuyen, V.D., Phuong, H.N., Cone, J.W., Baars, J.J.P., Sonnenberg, A.S.M. and Hendriks, W.H. (2013) Effect of fungal treatments of fibrous agricultural by-products on chemical composition and in vitro rumen fermentation and methane production. Bioresour. Technol. 129, 256-263.

Van Houtert, M.F.J. (1993) The production and metabolism of volatile fatty acids by ruminants fed roughages: A review. Anim. Feed Sci. Technol. 43, 189-225.

Van Kuijk, S.J.A., Sonnenberg, A.S.M., Baars, J.J.P., Hendriks, W.H. and Cone, J.W. (2015a) Fungal treated lignocellulosic biomass as ruminant feed ingredient: A review. Biotechnol. Adv. 33, 191-202.

Van Kuijk, S.J.A., Sonnenberg, A.S.M., Baars, J.J.P., Hendriks, W.H. and Cone, J.W. (2015b) Fungal treatment of lignocellulosic biomass: Importance of fungal species, colonization and time on chemical composition and in vitro rumen degradability. Anim. Feed Sci. Technol. 209, 40-50.

Van Kuijk, S.J.A., Sonnenberg, A.S.M., Baars, J.J.P., Hendriks, W.H. and Cone, J.W. (2016a) The effect of particle size and amount of inoculum on fungal treatment of wheat straw and wood chips. J. Anim. Sci. Biotechnol. 7, 39.

Van Kuijk, S.J.A., Sonnenberg, A.S.M., Baars, J.J.P., Hendriks, W.H. and Cone, J.W. (2016b) The effect of adding urea, manganese and linoleic acid to wheat straw and wood chips on lignin degradation by fungi and subsequent in vitro rumen degradation. Anim. Feed Sci. Technol. 213, 22-28.

Van Soest, P.J., Robertson, J.B. and Lewis, B.A. (1991) Methods for dietary fiber, neutral detergent fiber, and nonstarch polysaccharides in relation to animal nutrition. J. Dairy Sci. 74, 3583-3597. 
Chapter 3 | Fungal screening for bioprocessing of wheat straw 


\section{4}

A fool thinks himself to be wise, but a wise man knows himself to be a fool. 


\section{Variation in the solubilization of crude protein in wheat straw by different white-rot fungi}

Nazri Nayan ${ }^{1}$, Anton S.M. Sonnenberg ${ }^{2}$, Wouter H. Hendriks ${ }^{1}$, and John W. Cone ${ }^{1}$

Anim. Feed Sci. Technol. (2018). 242:135-143.

1 Animal Nutrition Group, Wageningen University, De Elst 1, 6708 WD Wageningen, the Netherlands

2 Plant Breeding, Wageningen University and Research, Droevendaalsesteeg 1, 6708 PB Wageningen, the Netherlands 


\section{ABSTRACT}

Besides their unique ability to depolymerize cell wall components, white-rot fungi are known to assimilate nitrogenous compounds from substrates. This modification may change protein solubility and fermentation in the rumen. To investigate this, the crude protein (CP) in fungal treated wheat straw (3 fungal species, 2 strains each) was fractioned according to the Cornell Net Carbohydrate and Protein System (CNCPS) and assessed for in vitro protein fermentation using a modified gas production technique (IVGP ${ }_{\mathrm{N}}$ ). Results showed that fungi increased fraction A (instantaneously soluble CP; $\sim 2.6$ times) and $\mathrm{B}_{1}$ (rapidly degradable; $\sim 1.2$ times); and decreased the slowly degradable fraction $\mathrm{B}_{3}(\sim 41.6 \%)$ and unavailable fraction $\mathrm{C}(\sim 48.3 \%)$. The $\mathrm{IVGP}_{\mathrm{N}}$ of straw treated with Ceriporiopsis subvermispora strains were not different to the control, but increased by 30.2 to $47.1 \%$ in Pleurotus eryngii and Lentinula edodes strains. The $\operatorname{IVGP}_{\mathrm{N}}$ was significantly $(P<0.01)$ correlated to all fractions of $\mathrm{CP}$, except fraction $\mathrm{B}_{1}$ and $\mathrm{B}_{2}$ (intermediately degradable). All fungi also increased the arginine $(\sim 56 \%)$ and lysine $(\sim 15 \%)$ contents. This study shows the importance of assessing the protein solubilization by different fungal strains, which can uncover unique mechanisms in the cell wall depolymerization.

Keywords: White-rot fungi; different strains/species; protein fractionation; in vitrogas production; wheat straw; ruminant feed. 


\section{INTRODUCTION}

Tn recent years, white-rot fungi such as Ceriporiopsis subvermispora and Lentinula

1 edodes, have been studied for their ability to improve the degradability of agricultural biomass in ruminants (Tuyen et al., 2013; Van Kuijk et al., 2015a). These reports demonstrate clearly that these fungi are able to modify cell wall properties by selectively degrading lignin and increase the amount of potentially fermentable structural carbohydrates. However, little attention has been paid to the effect of the fungal pretreatment on other nutrients in the biomass, particularly protein. Literature shows an increase of total protein content in fungal-treated biomass (Arora and Sharma, 2011; Sharma and Arora, 2010). Although the protein content in biomass such as wheat straw is low ( 16.1 $\mathrm{g} \mathrm{kg}^{-1}$ on dry matter basis) (Nayan et al., 2018), the knowledge on fungal modification of protein availability and solubility is useful and can be applied on various biomasses and even forages. Fungi are known for their capabilities in assimilating nitrogen $(\mathrm{N})$ from the substrate (Davis and Wong, 2010). Although ammonium and glutamine are their preferred nitrogenous compounds, fungi can also use $\mathrm{N}$ from various other sources, such as nitrate, urea and amines, to synthesize protein (Tudzynski, 2014). We hypothesize that the modification and assimilation of nitrogenous compounds by fungi may change the solubility and availability of protein in the wheat straw for rumen microbes.

Rumen microbes are able to degrade protein from the feed or directly use ammonia and other non-protein nitrogen (NPN) compounds to synthesize microbial N. Utilization of protein from the feed, however, depends on varying proportions of its soluble and insoluble fractions. Different fractions of crude protein in feed have been estimated using the Cornell Net Carbohydrate and Protein System (CNCPS) (Licitra et al., 1996; Sniffen et al., 1992). This method allows partitioning of feed protein into five fractions: Nonprotein nitrogen (NPN; fraction $A$ ), available true protein (fraction $B_{1}, B_{2}$ and $B_{3}$ ) and unavailable protein (fraction $\mathrm{C}$ ), which are different in their inherent rates of degradation in the rumen. Fraction $A$ and $B_{1}$ are rapidly degraded, while fraction $B_{2}$ is fermented at lower rates and can escape the rumen. Fraction $\mathrm{B}_{3}$ is degraded more slowly due to its association with cell walls and a large proportion escapes the rumen. Fraction $\mathrm{C}$ is highly resistant to breakdown in the rumen.

Characterization of the rumen fermentability of the protein fraction in fungal-treated wheat straw has hitherto not been studied. There are a number of in vitro techniques to estimate rumen protein fermentation, including enzymatic techniques (Aufrère et al., 1991; Cone et al., 2004). A modified in vitro gas production technique has also been used 
to estimate protein fermentation characteristics in the rumen (Cone et al., 2009) and large intestine of pigs (Cone et al., 2005). Cone et al. (2009) concluded that there was a good relationship $\left(R^{2}=0.85\right)$ between the gas production data and the amount of rumen escape protein determined with the nylon bag technique. In brief, the modified technique involves a pre-incubation of diluted rumen fluid with rapidly fermentable carbohydrates in a $\mathrm{N}$-free buffer medium. The approach ensures $\mathrm{N}$ to be the limiting factor for microbial growth, so that the subsequent fermentation (and gas production) depend on the availability of $\mathrm{N}$ in the samples.

To test the above-mentioned hypothesis, this study aimed to: (1) study the solubilization of the crude protein content, using the Net Carbohydrate and Protein System; (2) evaluate the protein fermentation characteristics, using a modified gas production technique as described by Cone et al. (2009); and (3) determine the changes in the amino acid composition of the wheat straw, treated with different fungal strains.

\section{MATERIALS AND METHODS}

\section{Preparation of the fungal-treated wheat straw}

The fungal-treated samples used in the present study were part of a previous experiment (Nayan et al., 2018) where selection of the best performing fungal strains to improve the nutritive value of wheat straw was studied. Two high potential strains from three different fungal species, based on in vitro degradability in rumen fluid, were selected for the present study: CS1 (CBS 347.63) and CS12 (ME-485) strains of Ceriporiopsis subvermispora; PE3 (Mycelia2600) and PE6 (AL04) of Pleurotus eryngii and LE8 (sh 03/08) and LE10 (LE75) of Lentinula edodes. A detailed procedure for fungal strain preparation and pretreatment of the wheat straw has been previously described (Nayan et al., 2017). In brief, all strains were grown on malt extract agar and a part of the fungal colony was used as an inoculum to prepare the spawn for each fungus on autoclaved sorghum grains. The inoculated grains was incubated at $24^{\circ} \mathrm{C}$ until a complete colonization for 4 to 5 weeks. Wheat straw was chopped into approximately $3 \mathrm{~cm}$ pieces and soaked in water for 3 days at room temperature. After draining the excess water, the straw was distributed into 2.11 micropropagation containers (Combiness, Nevele, Belgium). After autoclaving at $121^{\circ} \mathrm{C}$ for $1 \mathrm{~h}$, the straw was inoculated with the prepared spawn at $10 \%$ of the dry weight of the straw in the container. The wheat straw was incubated in triplicate at $24^{\circ} \mathrm{C}$ for 7 weeks in a climate-controlled chamber. After the 
incubation, all samples were freeze-dried and ground over a $1 \mathrm{~mm}$ sieve, using a cross beater mill (100AN, Peppink, Olst, the Netherlands).

\section{Crude protein fractionation}

Crude protein (CP) fractionation was performed according to procedures described by Licitra et al. (1996), with modifications. Samples were analyzed for total $\mathrm{N}$ by Kjeldahl analysis (ISO 5983, 2005) and crude protein was calculated as $\mathrm{N} \times 6.25$. The non-protein nitrogen (NPN) was obtained by precipitation of true protein in the sample with $10 \%$ $(\mathrm{w} / \mathrm{v})$ trichloroacetic acid (TCA) for $30 \mathrm{~min}$. After washing 2 times with TCA, the $\mathrm{N}$ content in the residues was determined and the NPN was calculated by subtracting residual $\mathrm{N}$ from total $\mathrm{N}$. The soluble $\mathrm{N}$ was determined by incubating the samples with phosphate-borate buffer (containing $13.79 \mathrm{~g} \mathrm{l}^{-1} \quad \mathrm{NaH}_{2} \mathrm{PO}_{4} \cdot 2 \mathrm{H}_{2} \mathrm{O}$ and $8.91 \mathrm{~g} \mathrm{l}^{-1}$ $\mathrm{Na}_{2} \mathrm{~B}_{4} \mathrm{O}_{7} \cdot 10 \mathrm{H}_{2} \mathrm{O}$ at $\mathrm{pH} 6.8$ ) at $37^{\circ} \mathrm{C}$ for $3 \mathrm{~h}$. After incubation, the samples were filtered (Whatman 541, Maidstone, UK) and residual $\mathrm{N}$ was determined to yield the insoluble $\mathrm{N}$ fraction. The $\mathrm{CP}$ contents were presented as absolute amounts, i.e. $\mathrm{g}$ per $100 \mathrm{~g}$ of starting organic matter $(\mathrm{OM})$. The absolute amount was calculated from the remaining amount (g) of freeze-dried sample, which was corrected for the dry matter content. Neutral detergent insoluble nitrogen (NDIN) and acid detergent insoluble nitrogen (ADIN) were determined by $\mathrm{N}$ analysis of the neutral detergent fiber (NDF) and acid detergent fiber (ADF) residues (Van Soest et al., 1991), respectively. All five fractions in Cornell Net Carbohydrate and Protein System (CNCPS) were expressed as a percentage of total CP and were calculated according to Sniffen et al. (1992). These fractions are illustrated in Fig. 4.1.

\section{Modified in vitro gas production}

The modified in vitro gas production technique $\left(\mathrm{IVGP}_{\mathrm{N}}\right)$ was performed according to the procedures described by Cone et al. (2009). Rumen fluid was collected from nonlactating cows, fed concentrate and grass silage ad libitum. The $\mathrm{N}$-free buffer/mineral solution contained $10.03 \mathrm{~g} \mathrm{l}^{-1} \mathrm{NaHCO}_{3}, 1.43 \mathrm{~g} \mathrm{l}^{-1} \mathrm{Na}_{2} \mathrm{HPO}_{4}, 1.55 \mathrm{~g} \mathrm{l}^{-1} \mathrm{KH}_{2} \mathrm{PO}_{4}, 0.15 \mathrm{~g} \mathrm{l}^{-1}$ $\mathrm{MgSO}_{4} \cdot 7 \mathrm{H}_{2} \mathrm{O}, 0.52 \mathrm{~g} \mathrm{l}^{-1} \mathrm{Na}_{2} \mathrm{~S}, 0.017 \mathrm{~g} \mathrm{l}^{-1} \mathrm{CaCl}_{2} \cdot 2 \mathrm{H}_{2} \mathrm{O}, 0.015 \mathrm{~g} \mathrm{l}^{-1} \mathrm{MnCl}_{2} \cdot 4 \mathrm{H}_{2} \mathrm{O}, 0.002 \mathrm{~g} \mathrm{l}^{-1}$ $\mathrm{CoCl}_{3} \cdot 6 \mathrm{H}_{2} \mathrm{O}, 0.012 \mathrm{~g} \mathrm{l}^{-1} \mathrm{FeCl}_{3} \cdot 6 \mathrm{H}_{2} \mathrm{O}$ and $0.125 \mathrm{mg} \mathrm{l}^{-1}$ resazurin. The rumen fluid was diluted 1:19 with buffer/mineral solution to minimize the $\mathrm{N}$ input from the rumen fluid. The buffered rumen fluid was pre-incubated with $10 \mathrm{~g} \mathrm{l}^{-1}$ rapidly fermentable carbohydrates, consisting of $3.33 \mathrm{~g} \mathrm{l}^{-1}$ glucose, $3.33 \mathrm{~g} \mathrm{l}^{-1}$ xylose and $3.33 \mathrm{~g} \mathrm{l}^{-1}$ soluble starch, 


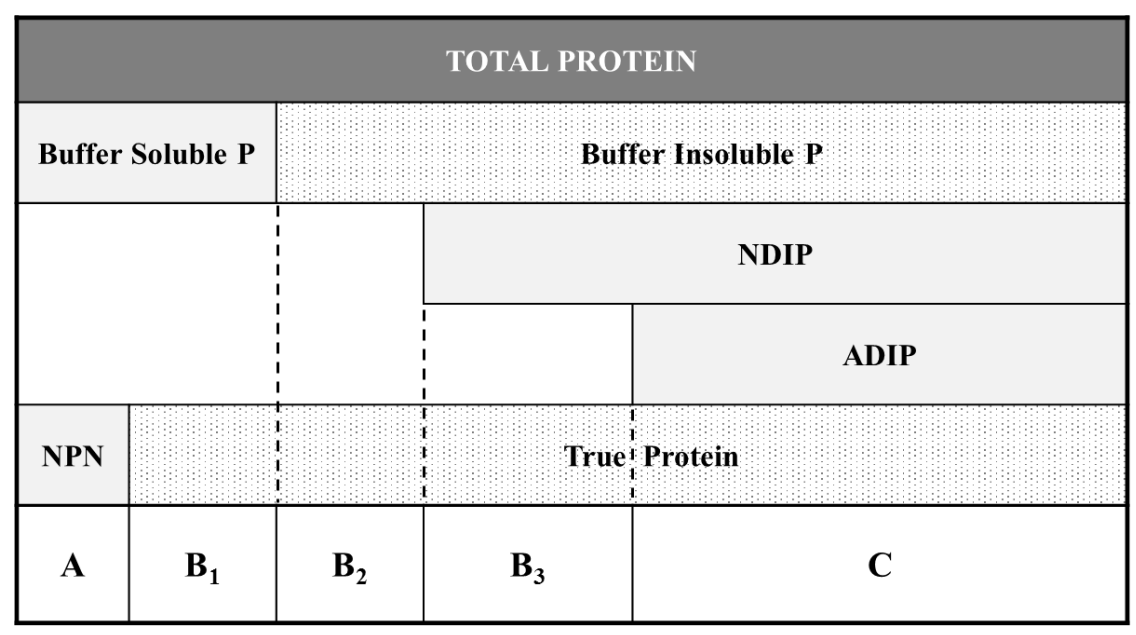

Fig. 4.1. Fractionation of total crude protein, based on Sniffen et al. (1992). P: protein; NDIP: neutral detergent insoluble protein; ADIP: acid detergent insoluble protein; NPN: non-protein nitrogen.

for $5 \mathrm{~h}$ at $37^{\circ} \mathrm{C}$ in a 51 bottle, under continuous flushing with $\mathrm{CO}_{2}$. During this preincubation, all available $\mathrm{N}$ from the rumen fluid was incorporated into bacterial $\mathrm{N}$ components in order to make $\mathrm{N}$ limiting for microbial growth. The pre-incubation was also carried out in four 250-ml bottles connected to the gas production equipment for recording the gas production data. After $5 \mathrm{~h}$ of pre-incubation, $60 \mathrm{ml}$ of buffered rumen fluid, together with the excess carbohydrates, was added to the bottles with pre-weighed samples containing exactly $5 \mathrm{mg}$ of $\mathrm{N}$ (sample DM weight ranged from 1.4 to $2.2 \mathrm{~g}$ ). Samples were incubated for $72 \mathrm{~h}$ and the gas production data were registered automatically. At the end of the incubation, a sample of rumen fluid from each bottle (600 $\mu \mathrm{l})$ was mixed with $10 \%$ trichloroacetic acid (TCA) to determine the ammonia- $\mathrm{N}_{\left(\mathrm{NH}_{3}-\right.}$ $\mathrm{N})$ content spectrophotometrically at $623 \mathrm{~nm}$. The kinetic parameters were determined by fitting the gas production data to a monophasic model (Groot et al., 1996).

\section{Chemical composition and amino acids determination}

Samples were dried for $4 \mathrm{~h}$ in an oven at $103^{\circ} \mathrm{C}$ to determine the dry matter (DM) content (ISO 6496, 1999) with ash content determined after combustion at $550^{\circ} \mathrm{C}$ for $3 \mathrm{~h}$ in a muffle furnace (ISO 5984, 2002). The fiber contents - exclusive of residual ash, were determined using Van Soest et al. (1991), with modification. Neutral detergent fiber (aNDFom) was determined using a heat-stable amylase (thermamyl) and alcalase. Acid 
detergent fiber (ADFom) and acid detergent lignin (solubilize cellulose with sulphuric acid; lignin-(sa)), were also determined using the standard method. Amino acids were analyzed using the standard AOAC method (AOAC, 2000). The protein in the samples were hydrolyzed with $6 \mathrm{M}$ hydrochloric acids before the individual amino acid composition was separated, detected and quantified using high performance liquid chromatography (HPLC). Tryptophan was not determined. No corrections were made for amino acid loss during hydrolysis, and amino acid weights were calculated using free amino acid molecular weights.

\section{Statistics}

Data were analyzed by two-way analysis of variance using the general linear model in SAS 9.3, followed by post-hoc multiple comparison using least significance differences. The statistical model used was as follows:

$$
\Upsilon_{i j k}=\mu+S P_{i}+S T_{j(i)}+\tau_{k(i j)}+\varepsilon_{i j k}
$$

where $Y_{i j k}=$ response variable $i j k, \mu=$ overall mean, $S P_{i}=$ the effect of species $i, S T_{j(i)}=$ the effect of strain $j$ nested within species $i, \tau_{k(i j)}=$ effect of week $k$, and $\varepsilon_{i j k}=$ residual error with a mean of 0 and variance $\sigma^{2} . S P_{i}$ was considered a fixed effect, $S T_{j(i)}$ and $\tau_{k(i j)}$ as random effects. Probability values below 5\% were considered significant. Pearson Product-Moment Correlation $(r)$ coefficients were also determined among the measured variables.

\section{RESULTS}

\section{Chemical composition and fractionation of crude protein}

Table 4.1 summarizes the chemical composition and the fractionation of $\mathrm{CP}$ in wheat straw, treated with different fungal strains. The untreated, autoclaved wheat straw contained 87.2 $\pm 0.3 \mathrm{~g}$ of organic matter $(\mathrm{g})$ per container. All CP fractionation data are presented per $100 \mathrm{~g}$ of the starting OM. Fungal pretreatment caused a 1.6 to $7.3 \%$ decrease in the total amount of OM by the end of the colonization weeks. The fiber contents were noticeably lower in all fungal-treated wheat straws, particularly the lignin-(sa) content which were decreased by $48.5 \%$ in CS1-treated straw. After 7 weeks of colonization, the total amount of CP when expressed per unit starting OM was significantly $(P<0.001)$ increased by 23.3 to $30.9 \%$ in the fungal-treated wheat straw, compared to the control. The amount of true protein was lower in straw treated with P. eryngii and L. edodes 


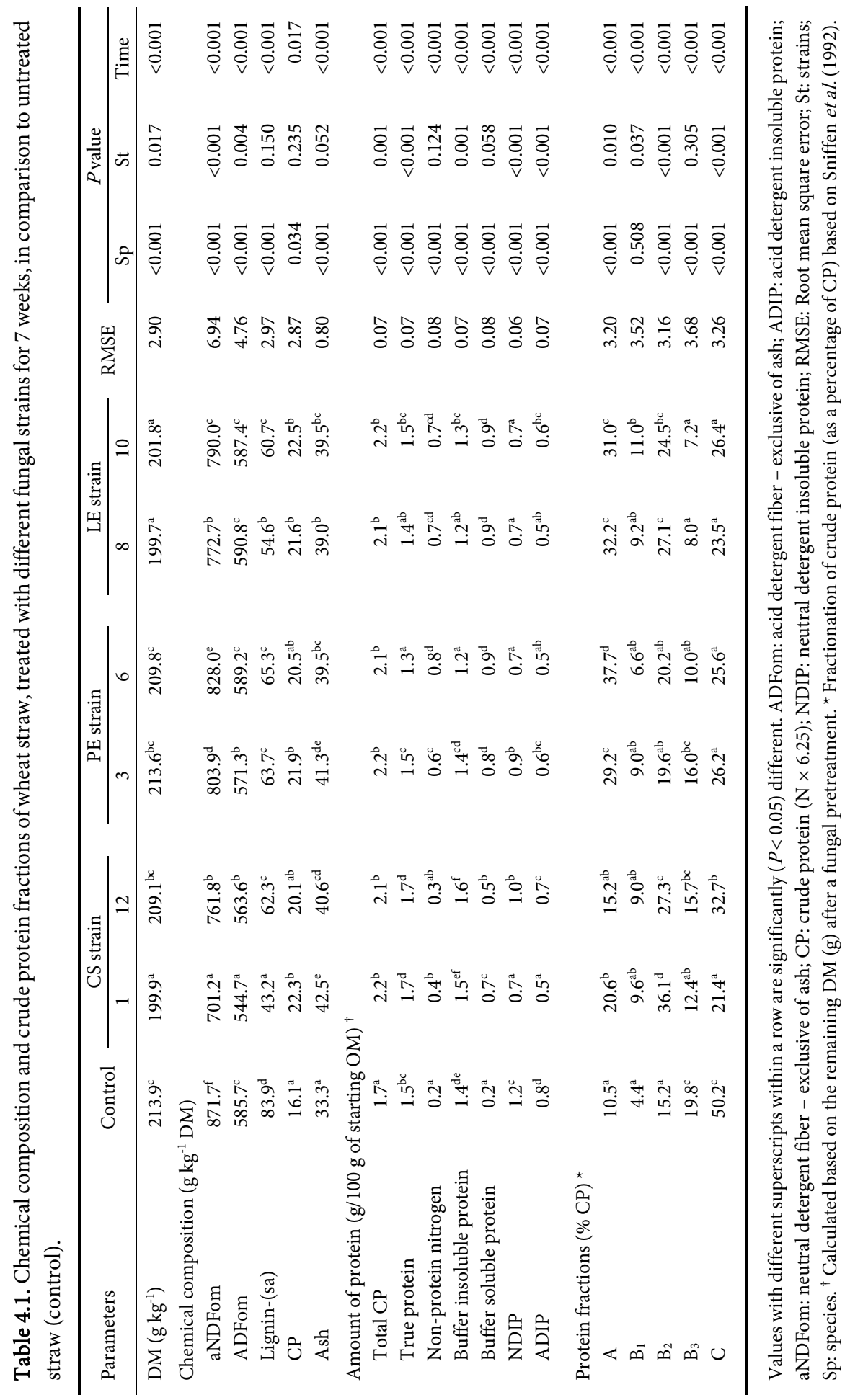


strains compared to the control, with the true protein content in PE6-treated straw being significantly $(P=0.003)$ lower. CS1 and CS12-treated straw had a significantly $(P<0.01)$ higher amount of true protein, compared to the control. On the other hand, the amount of NPN was significantly $(P<0.01)$ higher using $P$. eryngii and $L$. edodes strains, compared to $C$. subvermispora strains. All fungal-treated wheat straw had a significantly $(P<0.001)$ higher amount of NPN than the control, except for the CS12-treated straw.

Wheat straw treated with $P$. eryngii and $L$. edodes strains were significantly $(P<0.01)$ lower in the amount of buffer insoluble protein, compared to C. subvermispora strains. Contrarily, P. eryngii and L. edodes strains were higher $(P<0.01)$ in buffer soluble protein than $C$. subvermispora strains. All fungal-treated straw contained a higher $(P<0.01)$ amount of available protein compared to the control. The amount of protein bound to the cell wall was significantly $(P<0.05)$ decreased in fungal-treated wheat straw. The solubilization of the cell wall bound protein resulted in an overall increase of soluble fractions $\left(A\right.$ and $\left.B_{1}\right)$, while the protein fractions related to cell wall ( $B_{3}$ and $C$ ) were decreased by fungal pretreatment.

\section{In vitro gas production}

The IVGP during the $5 \mathrm{~h}$ pre-incubation with easily fermentable carbohydrates is shown in Fig. 4.2. A rapid increase of IVGP at a rate of $4.9 \mathrm{ml} \mathrm{h}^{-1}$ during the first hour was observed. The rate of IVGP then slowed down to $1.35 \mathrm{ml} \mathrm{h}^{-1}$ from 2 to $4 \mathrm{~h}$ and to $0.9 \mathrm{ml}$ $\mathrm{h}^{-1}$ after $4 \mathrm{~h}$. After $5 \mathrm{~h}$ of pre-incubation, the buffered rumen fluid was transferred to the gas production unit and the $72 \mathrm{~h}$ incubation with the samples started. The uncorrected gas production profiles for all treatments are also shown in Fig. 4.3. The blanks (N-free

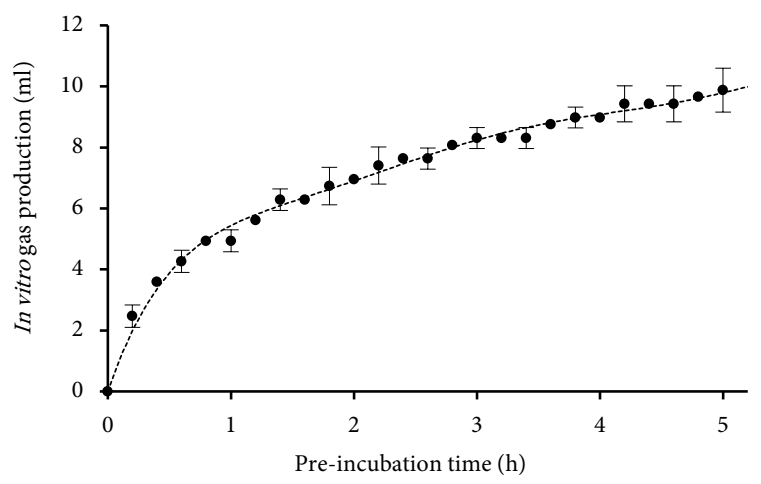

Fig. 4.2. In vitro gas production during pre-incubation with easily fermentable carbohydrates for 5 h. Error bars indicate standard deviation. 


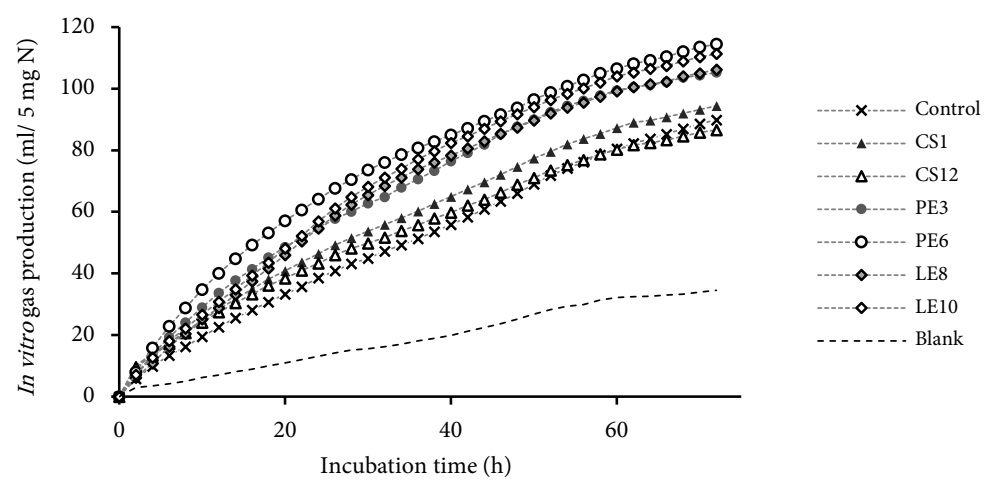

Fig. 4.3. In vitrogas production for all fungal-treated wheat straw in comparison to untreated wheat straw (control, $\times$ ) and a blank, being buffered rumen fluid without sample (-). The gas production profile were not corrected for the blanks.

buffered rumen fluid with the remaining of fermentable carbohydrates) maintained a gas production lower than $10 \mathrm{ml}$ for the first $18 \mathrm{~h}$ of incubation. Nonetheless, the gas production continued in blanks and reached a total IVGP of $34.5 \mathrm{ml}$ after $72 \mathrm{~h}$. Ammonia$\mathrm{N}\left(\mathrm{NH}_{3}-\mathrm{N}\right)$ was below a detectable amount in all samples of rumen fluid for all treatments after $72 \mathrm{~h}$ of incubation.

The corrected gas production profiles $\left(\operatorname{IVGP}_{\mathrm{N}}\right)$ and their kinetic parameters are summarized in Table 4.2. The IVGP $_{\mathrm{N}}$ of wheat straw treated with $P$. eryngii and $L$. edodes strains was significantly $(P<0.05)$ higher than with $C$. subvermispora strains. Differences in the $\operatorname{IVGP}_{\mathrm{N}}$ between wheat straw treated with the $C$. subvermispora strains and the control were not significant. The IVGP $_{\mathrm{N}}$ of CS12-treated straw was even lower than that of the control, although not significant. The kinetics data showed an overall better fermentation profile in all fungal-treated wheat straw as indicated by parameters $B$ (halftime of maximum gas production) and $R_{\mathrm{m}}$ (maximum fractional rate of degradation) values.

\section{Changes in amino acids composition}

Glutamic acid (Glu), aspartic acid (Asp), histidine (His), alanine (Ala) and glycine (Gly) were the main amino acids (AAs) present in the untreated (control) wheat straw (Table 4.3). Overall, there were no marked changes in the total AA-N content when 
Chapter 4 | Protein solubilization by fungi

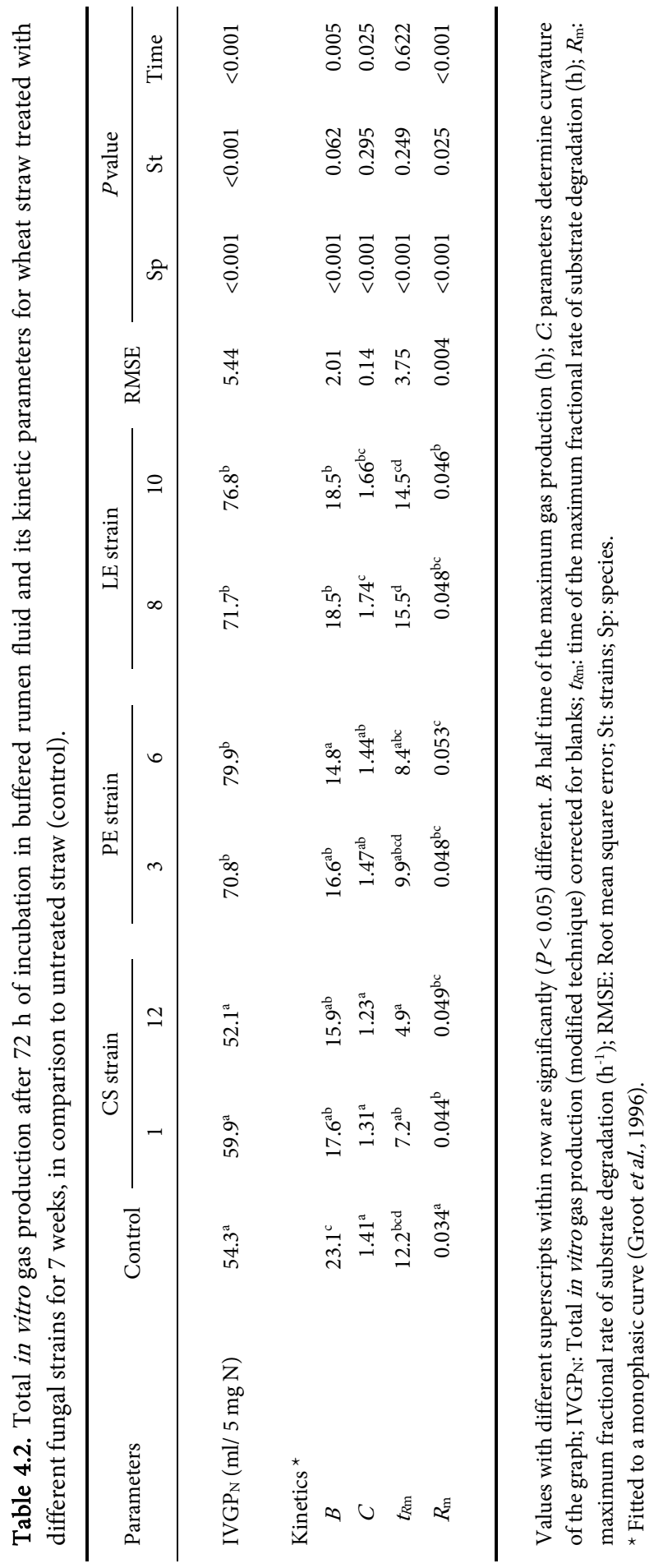


Chapter 4 | Protein solubilization by fungi

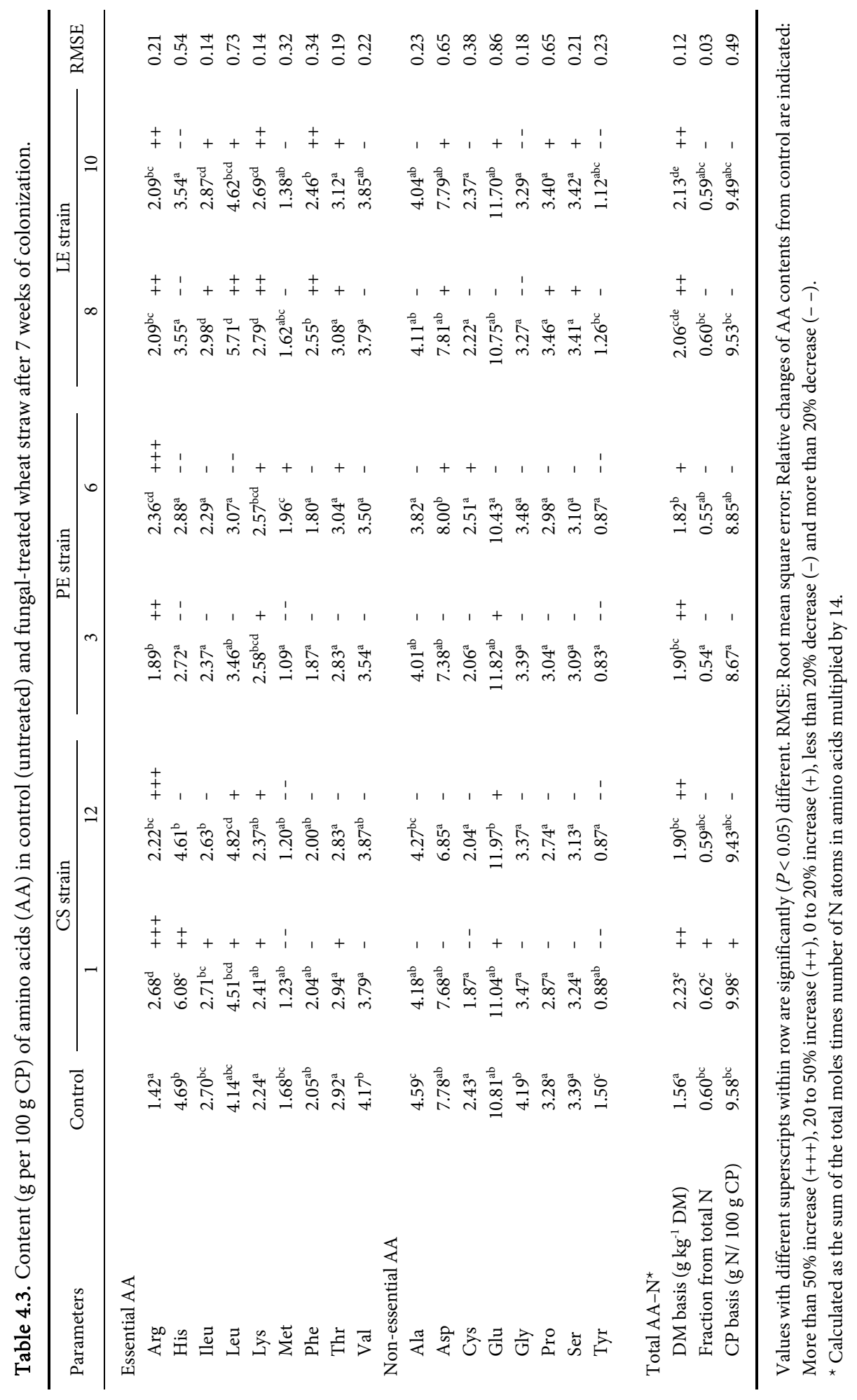


expressed on a CP basis, except for PE3-treated straw which showed a significantly $(P<$ $0.05)$ lower total AA-N content. PE3 significantly $(P<0.01)$ decreased the total essential AAs of the straw by $14.1 \%$. However, all fungi did not cause any significant changes in the non-essential AA content of the straw, although relative decreases were observed in all samples. The changes in the composition of each AA were mostly species-dependent. The strain effect was only significant $(P<0.05)$ for His and methionine (Met). Threonine (Thr), Asp and proline (Pro), however, were not affected by fungal pretreatment. All fungi significantly $(P<0.05)$ increased the arginine (Arg) content of the wheat straw $(\sim 56 \%)$, but decreased $(P<0.001)$ the Gly content $(\sim 19 \%)$. Ala was decreased $(P<0.05)$ in wheat straw treated with CS1 (9\%), P. eryngii $(15 \%)$ and L. edodes strains ( 11\%). Glu and Asp contents of the fungal-treated straw were not different to the control.

\section{DISCUSSION}

The present study encompasses two main parts: (1) fractionation of crude protein content in fungal-treated wheat straw; and (2) in vitro assessment of protein availability for the fermentation in the rumen. Results show that fungal colonization leads to an increase in the total amount of CP. An increase in the absolute amount of CP suggests an increase of $\mathrm{N}$ in the pre-treated straw. This observation needs a further clarification as it is generally accepted that white-rot fungi are unable to fix atmospheric $\mathrm{N}$ and only acquire $\mathrm{N}$ bound in biomolecules. In nature, fungi utilize fixed atmospheric $\mathrm{N}$ through their symbiotic interactions with nitrogen-fixing bacteria and mycorrhizal fungi (Kneip et al., 2007). Since the straw was sterilized, bacteria cannot play a role in $\mathrm{N}$ fixation. The increase in the absolute amount of $\mathrm{CP}$ can be attributed to the spawn that was prepared on sorghum grains, which contains $\sim 12 \%$ of crude protein (Neucere and Sumrell, 1980). The enrichment of the CP content is also due to the expense of other nutrients (Van Kuijk et al., 2015b). Degraded carbohydrates are converted into fungal biomass and into $\mathrm{CO}_{2}$ leading to a concentration of $\mathrm{N}$ content. Due to the quantitative differences in the absolute amounts of CP (control vs. fungal-treated straw), the fractions are expressed on CP basis to allow comparison among different treatments.

There was no quantitative difference in the total amount of $\mathrm{CP}$ among fungal treatments. However, the fractionation of the $\mathrm{CP}$ provides a unique insight into the solubilization of protein by different fungal strains. Fungi increased the amount of NPN (fraction A) of the treated straw. The increase of NPN is likely due to the known production of nitrogen-containing secondary metabolites compounds by these higher 
fungi, such as nitrogen heterocycles, nucleosides, free amino acids (not bound by peptide bonds) and cyclic peptides (Chen and Liu, 2017). Chitin is also an important NPN component of fungal biomass (Ravi Kumar, 1999). The inclusion of chitin $\mathrm{N}$ from fungal biomass in fraction A, however, is disputable. Although trichloroacetic (TCA) has been used as chitin solvent (but at a higher temperature or concentration) (Ravi Kumar, 1999), the amount of $\mathrm{N}$ from chitin that is solubilized by TCA in this trial was inferred as low. Chitin can also react with $\alpha$-amino acids to give stable complexes (Tharanathan and Kittur, 2003), which would end up in the true protein fraction. We assume that fraction A in this study does not contain chitin and is directly available for the utilization by the rumen microbes. Therefore, wheat straw treated with CS12, all P. eryngii and L. edodes strains, had a relatively high content of NPN.

All fungi increased the buffer soluble $\mathrm{N}$ fractions ( $\mathrm{A}$ and $\mathrm{B}_{1}$ ) of the wheat straw, especially in $P$. eryngii and L. edodes treatments. As expected, there was a decrease in the cell wall bound proteins (fraction $\mathrm{B}_{3}$ and $\mathrm{C}$ ). This observation indicates the capability of fungi to liberate more protein associated with the cell wall. Fraction $\mathrm{C}$ is likely solubilized by fungi as a consequence of cell wall polymers degradation. There is indeed a clear correlation of a decrease in fraction $\mathrm{C}$ to the amount of lignin $(r=0.83 ; P<0.001)$ and hemicellulose $(r=0.76 ; P<0.001)$ - the main components degraded by fungi, but not to cellulose. It is worth noting that, cellulose as calculated by subtracting lignin-(sa) from ADFom using the Van Soest et al. (1991) method, does not exclude chitin (cellulose-like structure with $\mathrm{N}$-acetylglucosamine monomers) from fungal biomass. A complete hydrolysis of chitin requires a stronger concentrated acid (Einbu and Vårum, 2008). Protein compounds that are covalently bound to the cell wall, are partly hydrolyzed in the rumen (Debroas and Blanchart, 1993). Thus, fungal pretreatment can contribute to a higher availability of protein for the rumen microbes.

In vitro evaluation of protein fermentation in the rumen provides a complementary finding to the fractionation of protein data. Availability of protein from the gas production was calculated by correcting the values of gas production with blanks. Gas production of the blank is caused by $\mathrm{N}$ from the rumen fluid and later on by $\mathrm{N}$ released because of microbial turnover (Cone et al., 2009). The incubated samples contained exactly $5 \mathrm{mg} \mathrm{N}$, which made comparison of $\mathrm{N}$ availability between the different samples possible. The gas production curves showed a curvilinear to almost linear pattern, indicating a gradual release of $\mathrm{N}$ from the samples after the pre-incubation with easily fermentable carbohydrates (Cone et al., 2009). Therefore, a monophasic fit was used, to determine a simple kinetic parameter for the $72 \mathrm{~h}$ gas production curve. Results show that 
only the $\mathrm{IVGP}_{\mathrm{N}}$ of straw treated with $C$. subvermispora strains were not different to the control, but shows a better kinetic profile, i.e. a higher fractional rate of the substrate degradation $\left(R_{\mathrm{m}}\right)$. The $\mathrm{IVGP}_{\mathrm{N}}$ was significantly $(P<0.01)$ correlated to all fractions of CP, except fraction $\mathrm{B}_{1}$ and $\mathrm{B}_{2}$. Figure 4.4 shows the correlation plots of $\operatorname{IVGP}_{\mathrm{N}}$ with fraction $\mathrm{A}, \mathrm{B}_{1}, \mathrm{~B}_{3}$ and $\mathrm{C}$. We also found significant correlations of $\mathrm{IVGP}_{\mathrm{N}}$ to all measured variables, i.e. NPN $(r=0.78 ; P<0.001)$, buffer soluble protein $(r=0.68 ; P<0.001)$, NDIP $(r=-0.49$; $P<0.001)$ and ADIP $(r=-0.44 ; P<0.001)$. These observations further support the reliability of using a modified gas production technique in estimating the availability of protein in vitro (Cone et al., 2009, 2005). Meanwhile, ammonia-N was below the detection level in the rumen fluid samples, indicating an efficient conversion of available $\mathrm{N}$ to microbial N (Cone et al., 1997). This is due to the limited amount of available $\mathrm{N}$ in the buffered rumen fluid, with the only $\mathrm{N}$ coming from the samples, which is the limiting factor for microbial growth.
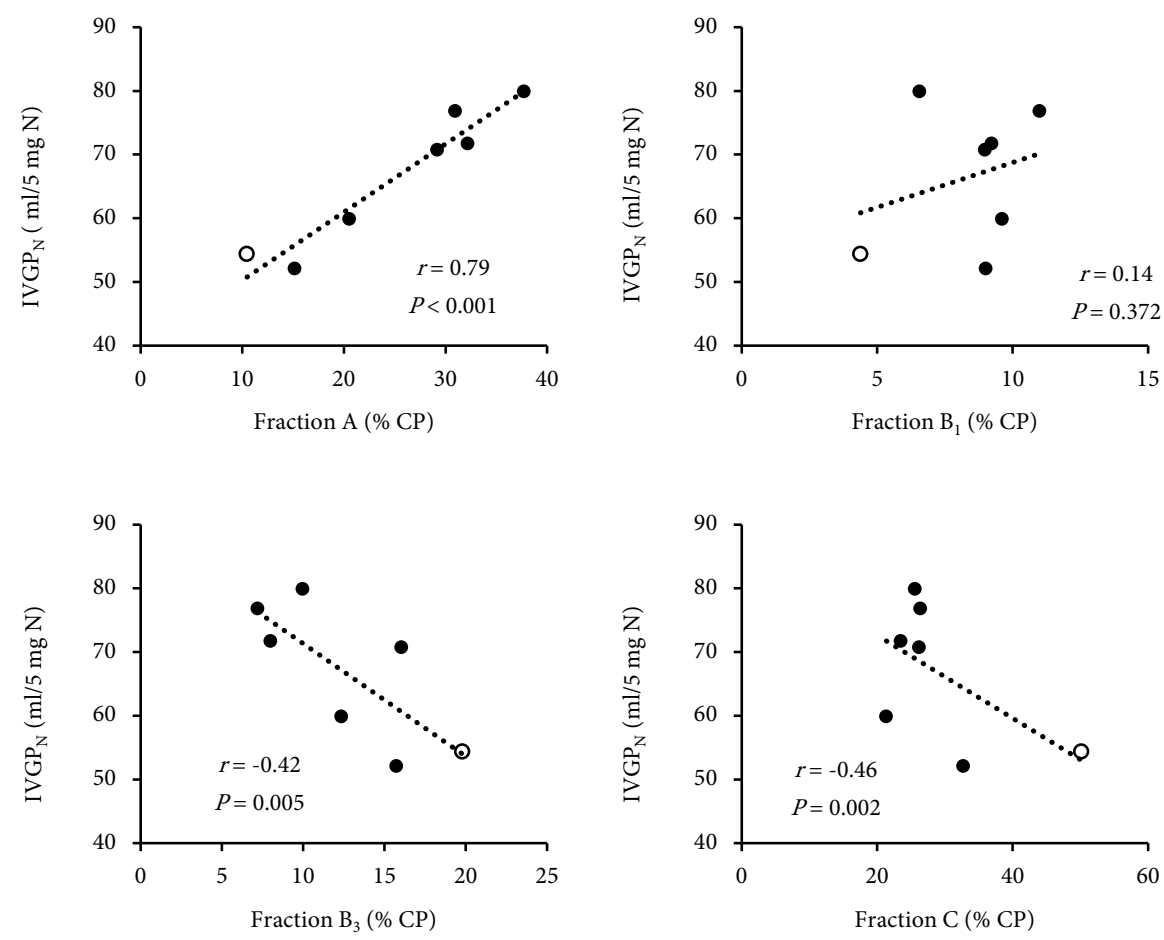

Fig. 4.4. Correlations among the in vitro gas production $\left(\mathrm{IVGP}_{\mathrm{N}}\right)$, soluble protein fractions (A and $\mathrm{B}_{1}$ ) and cell wall bound protein fractions $\left(\mathrm{B}_{3}\right.$ and $\mathrm{C}$ ) with respective Pearson's $r$ and $P$ values. Each point represents mean value for each treatment with ' $O$ ' indicates control. 
In total, 17 amino acids (AAs) were determined, of which 9 of them are essential for ruminants (Kung and Rode, 1996). All fungi increased the Arg and Lys content of the straw. It is inferred that these AAs are part of the building blocks of fungal protein. These AAs play various roles in the fungal growth and metabolisms, which will not be discussed here. The present study could not provide an accurate view on the roles of each AA in fungi as it requires a more advanced and in-depth study, such as gene expression. An increase in Lys, as one of the limiting AAs in ruminants (Kung and Rode, 1996), is valuable although its total amount in the treated wheat straw may be insignificant. However, fungi did not show a favorable effect on Met, another limiting AA for ruminants. There were variable changes among different fungal strains on other AAs. Some fungi incorporate them in their protein building blocks, while others may use them as a substrate for various biological functions. The total fractions of $\mathrm{N}$ in AAs (AA-N) from the total $\mathrm{N}$ (from Kjeldahl) showed no significant changes, except a significantly $(P$ $<0.05$ ) lower fraction observed for PE3-treated wheat straw. A lower AA-N/total N fraction in most fungal-treated straw also indicates an increase in NPN fraction. Nonetheless, the partitioning of protein in fungal-treated wheat straw needs a further study using a more robust and accurate method, for instance using a ${ }^{15} \mathrm{~N}$-labeling methods.

The outcome of this study underlines the need to further investigate the ability of fungi to liberate cell wall bound protein and make it more available for the fermentation in the rumen. The relationship between the changes in cell wall polymers to the availability of protein is of great interest. Results indicate a good correlation among them. However, the relationship of available protein with the extent of available carbohydrate "enrichment" (total carbohydrate to lignin ratio in the remaining materials) and in vitro degradability of the total OM, remains unclear. For instance, our previous trial showed that CS1 increased the fermentable OM of the straw by $\sim 38 \%$, which is significantly $(P<$ 0.001) higher than PE6 treatment (Nayan et al., 2018). However, PE6 had the highest IVGP $_{\mathrm{N}}$ and a higher amount of NPN and available protein than CS1. The differences in NDIP and ADIP between the two fungi were not significant. It is certain that a higher fermentability of the total OM is more important compared to the improvement in utilization of protein, although the latter is also of a great interest. In the literature, ligninolytic enzyme activity of Phanerochaete chrysosporium is suppressed by a high $\mathrm{N}$ concentration, while Pleurotus ostreatus shows a high activity (Leatham and Kent Kirk, 1983). Van Kuijk et al. (2016) did not find a significant improvement in the extent of lignin degradation and in vitro degradability with urea supplementation for $C$. 
subvermispora and L. edodes treatments. Removal of $\mathrm{N}$ from hemp with protease improved the selective delignification by Bjerkandera sp. (Dorado et al., 2001). These reports clearly indicate a large variation among different fungal species in metabolizing protein and affect their selectivity in lignin degradation. In the comparison between CS1 and PE6, CS1 released most of the protein from the cell wall (fraction $\mathrm{B}_{3}$ and C), but resulted in a lower protein availability (fraction A and $B_{1}$ ). Instead, CS1-treated straw showed a higher buffer insoluble fraction $\left(B_{2}\right)$ compared to PE6. This is probably a mechanism possessed by CS1 to stimulate a higher production of lignin degrading enzymes that may explain its higher selectivity than PE6. Nonetheless, lower protein availability for the fermentation in the rumen is not necessarily a shortcoming as it may also mean that the substrate contains a higher amount of rumen protected protein. This protein can pass through the rumen and may be digested and absorbed in the small intestine of ruminants.

\section{CONCLUSIONS}

Wheat straw treated with $P$. eryngii and $L$. edodes strains resulted in a higher protein availability for fermentation in the rumen. C. subvermispora strains on the other hand, did not improve the protein availability. All fungi resulted in a relative enrichment of the protein content. The fungi also increased the arginine and lysine content of the wheat straw. Fractionation of protein and in vitro evaluation of protein fermentation in rumen fluid are reliable parameters in assessing protein solubilization by different fungal strains.

\section{ACKNOWLEDGEMENTS}

The authors gratefully acknowledge the financial support from the Wageningen University Fund (WUF) as part of the project "More Meat and Milk from Straw" which is sponsored by DEKA, Forfarmers and the Victam Foundation. The authors also would like to acknowledge the scholarship provided by the Ministry of Higher Education Malaysia and Universiti Putra Malaysia. The authors also acknowledge Mrs. Saskia van Laar, Mrs. Xuan Huong van der Schans-Le and Mrs. Jane-Martine Muijlaert for their technical assistance. 


\section{REFERENCES}

AOAC, (2000). Official methods of analysis, 17th edn. Assoc. Off. Anal. Chem., Arlington, VA, USA.

Arora, D.S., and Sharma, R.K. (2011). Effect of different supplements on bioprocessing of wheat straw by Phlebia brevispora: changes in its chemical composition, in vitro digestibility and nutritional properties. Bioresour. Technol. 102, 8085-91.

Aufrère, J., Graviou, D., Demarquilly, C., Vérité, R., Michalet-Doreau, B., and Chapoutot, P. (1991). Predicting in situ degradability of feed proteins in the rumen by two laboratory methods (solubility and enzymatic degradation). Anim. Feed Sci. Technol. 33, 97-116.

Chen, H.-P., and Liu, J.-K. (2017). Secondary metabolites from higher fungi. In: Kinghorn, A.D., Falk, H., Gibbons, S., and Kobayashi, J. (Eds.), Progress in the Chemistry of Organic Natural Products 106. Springer International Publishing, Cham, pp. 1-201.

Cone, J.W., Jongbloed, A.W., Gelder, A.H. Van, and Lange, L. de (2005). Estimation of protein fermentation in the large intestine of pigs using a gas production technique. Anim. Feed Sci. Technol. 123-124, 463472.

Cone, J.W., Rodrigues, M.A.M., Guedes, C.M., and Blok, M.C. (2009). Comparison of protein fermentation characteristics in rumen fluid determined with the gas production technique and the nylon bag technique. Anim. Feed Sci. Technol. 153, 28-38.

Cone, J.W., van Gelder, A.H., and Driehuis, F. (1997). Description of gas production profiles with a three-phasic model. Anim. Feed Sci. Technol. 66, 31-45.

Cone, J.W., van Gelder, A.H., Mathijssen-Kamman, A.A., and Hindle, V.A. (2004). Rumen escape protein in grass and grass silage determined with a nylon bag and an enzymatic technique. Anim. Feed Sci. Technol. $111,1-9$.

Davis, M.A., and Wong, K.H. (2010). Nitrogen metabolism in filamentous fungi. In: Borkovich, K.A., and Ebbole, D.J. (Eds.), Cellular and Molecular Biology of Filamentous Fungi. ASM Press, Washington, pp. 325-338.

Debroas, D., and Blanchart, G. (1993). Interactions between proteolytic and cellulolytic rumen bacteria during hydrolysis of plant cell wall protein. Reprod. Nutr. Dev. 33, 283-288.

Dorado, J., Field, J.A., Almendros, G., and Sierra-Alvarez, R. (2001). Nitrogen-removal with protease as a method to improve the selective delignification of hemp stemwood by the white-rot fungus Bjerkandera sp. strain BOS55. Appl. Microbiol. Biotechnol. 57, 205-211.

Einbu, A., and Vårum, K.M. (2008). Characterization of chitin and its hydrolysis to GlcNAc and GlcN. Biomacromolecules $9,1870-1875$.

Groot, J.C., Cone, J.W., Williams, B.A., Debersaques, F.M.A., and Lantinga, E.A. (1996). Multiphasic analysis of gas production kinetics for in vitro fermentation of ruminant feeds. Anim. Feed Sci. Technol. 64, 77-89.

ISO 6496, (1999). Animal feeding stuffs. Determination of moisture and other volatile matter content. Geneva, Switzerland.

ISO 5984, (2002). Animal feeding stuffs. Determination of crude ash. Geneva, Switzerland.

Kneip, C., Lockhart, P., Voß, C., and Maier, U.G. (2007). Nitrogen fixation in eukaryotes - New models for symbiosis. BMC Evol. Biol. 7, 1-12.

Kung, L., and Rode, L.M. (1996). Amino acid metabolism in ruminants. Anim. Feed Sci. Technol. 59, $167-172$. Leatham, G.F., and Kent Kirk, T. (1983). Regulation of ligninolytic activity by nutrient nitrogen in white-rot basidiomycetes. FEMS Microbiol. Lett. 16, 65-67. 
Licitra, G., Hernandez, T.M., and Van Soest, P.J. (1996). Standardization of procedures for nitrogen fractionation of ruminant feeds. Anim. Feed Sci. Technol. 57, 347-358.

Nayan, N., Sonnenberg, A.S.M., Hendriks, W.H., and Cone, J.W. (2017). Differences between two strains of Ceriporiopsis subvermispora on improving the nutritive value of wheat straw for ruminants. J. Appl. Microbiol. 123, 352-361.

Nayan, N., Sonnenberg, A.S.M., Hendriks, W.H., and Cone, J.W. (2018). Screening of white-rot fungi for bioprocessing of wheat straw into ruminant feed. J. Appl. Microbiol. 125, 368-379.

Neucere, N.J., and Sumrell, G. (1980). Chemical composition of different varieties of grain sorghum. J. Agric. Food Chem. 28, 19-21.

Ravi Kumar, M.N.V. (1999). Chitin and chitosan fibres: A review. Bull. Mater. Sci. 22, 905-915.

Sharma, R.K., and Arora, D.S. (2010). Production of lignocellulolytic enzymes and enhancement of in vitro digestibility during solid state fermentation of wheat straw by Phlebia floridensis. Bioresour. Technol. 101, 9248-9253.

Sniffen, C.J.J., Connor, D.O., and Russell, J.B. (1992). A Net Carbohydrate and Protein System for evaluating cattle diets : II . Carbohydrate and protein availability. J. Anim. Sci. 70, 3562-3577.

Tharanathan, R.N., and Kittur, F.S. (2003). Chitin - The undisputed biomolecule of great potential. Crit. Rev. Food Sci. Nutr. 43, 61-87.

Tudzynski, B. (2014). Nitrogen regulation of fungal secondary metabolism in fungi. Front. Microbiol. 5, 1-15.

Tuyen, V.D., Phuong, H.N., Cone, J.W., Baars, J.J.P., Sonnenberg, A.S.M., and Hendriks, W.H. (2013). Effect of fungal treatments of fibrous agricultural by-products on chemical composition and in vitro rumen fermentation and methane production. Bioresour. Technol. 129, 256-263.

Van Kuijk, S.J.A., Sonnenberg, A.S.M., Baars, J.J.P., Hendriks, W.H., and Cone, J.W. (2015a). Fungal treatment of lignocellulosic biomass: Importance of fungal species, colonization and time on chemical composition and in vitro rumen degradability. Anim. Feed Sci. Technol. 209, 40-50.

Van Kuijk, S.J.A., Sonnenberg, A.S.M., Baars, J.J.P., Hendriks, W.H., and Cone, J.W. (2015b). Fungal treated lignocellulosic biomass as ruminant feed ingredient: A review. Biotechnol. Adv. 33, 191-202.

Van Kuijk, S.J.A., Sonnenberg, A.S.M., Baars, J.J.P., Hendriks, W.H., and Cone, J.W. (2016). The effect of adding urea, manganese and linoleic acid to wheat straw and wood chips on lignin degradation by fungi and subsequent in vitro rumen degradation. Anim. Feed Sci. Technol. 213, 22-28.

Van Soest, P.J., Robertson, J.B., and Lewis, B.A. (1991). Methods for dietary fiber, neutral detergent fiber, and nonstarch polysaccharides in relation to animal nutrition. J. Dairy Sci. 74, 3583-3597. 


\section{4}

It takes 20 years to build a reputation and five minutes to ruin it. If you think about that, you'll do things differently.

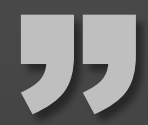

- WARREN BUFFETT 


\section{The relevance of different analytical methods to assess fungal degradation of lignocellulose and explaining the subsequent ruminal degradability}

Nazri Nayan ${ }^{1}$, Gijs van Erven ${ }^{2}$, Mirjam A. Kabel², Anton S.M. Sonnenberg ${ }^{3}$, Wouter H. Hendriks ${ }^{1}$, and John W. Cone ${ }^{1}$

Submitted to J. Sci. Food Agric.

1 Animal Nutrition Group, Wageningen University, De Elst 1, 6708 WD Wageningen, the Netherlands

2 Laboratory of Food Chemistry, Wageningen University \& Research, Bornse Weilanden 9, 6708 WG Wageningen, The Netherlands

3 Plant Breeding, Wageningen University and Research, Droevendaalsesteeg 1, 6708 PB Wageningen, the Netherlands 


\section{ABSTRACT}

The improved degradability of plant biomass by fungal pretreatment has been attributed to the capability of fungi to modify and degrade the cell wall. We compared two analytical procedures (A: Gravimetric method of Van Soest; and B: Py-GC/MS with monosaccharide analysis) for determining the cell wall contents, in order to explain effects on wheat straw degradability as measured by in vitro gas production (IVGP).

Although the lignin to carbohydrate ratio of both procedures showed a significant $(P<0.01)$ negative correlation with the IVGP, Procedure A showed a higher correlation coefficient $(r)$ compared to Procedure B (-0.84 vs. -0.69). Procedure A accounts for the residual insoluble cell wall population, particularly acid detergent lignin (ADL), which explains its strong inverse relationship with the IVGP. Nevertheless, Procedure B results in detailed elucidation of remaining lignin and carbohydrate structures, thereby, reflecting the actual modification and degradation of cell wall by fungi. Based on quantitative Py-GC/MS, we showed that IVGP was mainly influenced by lignin content rather than the structural features of lignin. At comparable magnitudes of lignin degradation, differences observed in the remaining lignin structures indicate unique delignification mechanisms of different fungi.

Specific analyses of lignin and carbohydrates contents are required for accurate description of the ruminal degradability of fungal-treated wheat straw. Lignin content rather than its structure, mainly explains the observed degradability.

Keywords: White-rot fungi; lignin; carbohydrates; lignin quantification; in vitro gas production; Pyrolysis-GC/MS 


\section{INTRODUCTION}

Tignocellulosic biomass, such as wheat straw, is used for a broad range of applications Uincluding animal feed (Van Kuijk et al., 2015a). Based on routine feed analysis (Van Soest et al., 1991), wheat straw contains (on a dry matter basis, w/w) 46 - 50\% cellulose, 26 - 31\% hemicellulose and 7 - 9\% lignin (acid detergent lignin) (Nayan et al., 2017; Tuyen et al., 2012; Van Kuijk et al., 2015b). Based on more elaborated analyses, the actual cell wall polymer contents (w/w) are $34-43 \%$ cellulose, $26-35 \%$ hemicellulosic xylan and 14 - 25\% Klason lignin (Kabel et al., 2007; Sun et al., 2004; Szczodrak, 1988). The presence of lignin hinders the enzymatic accessibility to the cell wall polysaccharides, making this biomass a relatively poor source of animal feed, and unsuitable for other applications such as biofuel production (Donkin et al., 2013; Himmel et al., 2007). Unlocking the lignin-carbohydrate complex in the cell wall is a key step in improving the utilization of biomass for various applications. To break the lignin barrier, biomass can be treated physically and/or chemically (Hendriks and Zeeman, 2009; Rabemanolontsoa and Saka, 2016). Due to an increased demand for eco-friendly approaches, biological methods, including the use of white-rot fungi have received much attention in recent years (Nayan et al., 2017; Van Kuijk et al., 2016).

Recent studies reported considerable successes in using fungi such as Ceriporiopsis subvermispora, Lentinula edodes and Pleurotus eryngii for improving the degradability of biomasses in rumen fluid (Nayan et al., 2017; Tuyen et al., 2012; Van Kuijk et al., 2017), as determined using the in vitro gas production (IVGP) technique (Cone et al., 1996). The IVGP technique is a robust and effective method to assess in vitro degradability of substrate in the rumen and has been used as a decisive parameter in selecting high performing fungal strains (Nayan et al., 2018). To assess the relationship of IVGP with changes in the cell wall compositions, routine feed compositional analysis, such as the Van Soest et al. (1991) method has been used. Using this gravimetric method, good correlations have been reported for cell wall components - particularly lignin, with IVGP of fungal-treated straw (Nayan et al., 2017; Tuyen et al., 2013; Van Kuijk et al., 2015b). While this gravimetric method is practical and provides a good estimate, it is, however, unspecific. For instance, acid detergent lignin (ADL) - a fraction of the Van Soest et al. (1991) method, only represents the recalcitrant lignin content, and does not quantify the acid soluble lignin (Jung et al., 1999). During fungal growth, part of the remaining carbohydrate and lignin may have become soluble and is subsequently removed in the (acid-) soluble fractions, thus further interfere the composition of cell wall, determined by the Van Soest method (Van Kuijk et al., 2016). 
The ADL may well correlate with the IVGP as it accounts for the recalcitrant lignin, but provides no information about the remaining lignin structures. The current lack of information regarding exact structures of remaining lignin and carbohydrates limits the understanding of the actual lignin modification by fungi and the subsequent effect on IVGP. As an alternative, semi-quantitative pyrolysis coupled to gas chromatography and mass spectrometry (Py-GC/MS) has been shown to be a powerful tool in estimating the lignin content, while simultaneously providing information on the lignin structural features (Jurak et al., 2015). Recently, lignin quantification by py-GC/MS has been improved by the incorporation of ${ }^{13} \mathrm{C}$ lignin as internal standard, which allows highly accurate determination of the lignin content (Van Erven et al., 2017). Together with more specific analysis of carbohydrates - by monosaccharides analysis (Englyst and Cummings, 1984), these methods offer a great opportunity for the accurate quantification of lignin and carbohydrate contents, and could provide a better explanation on the changes seen in in vitro degradation in rumen fluid, using the IVGP technique.

Recently, high potential strains of $C$. subvermispora, $P$. eryngii and L. edodes were identified, based on their ability to improve IVGP of wheat straw (Nayan et al., 2018). These high potential strains showed a high variability in degrading the ADL content of wheat straw (22.3 to 52.2\%), which provided a good range of data for the purpose of this study. The aim of this study was to determine the relevance of different analytical methods to measure the cell wall contents in explaining the subsequent changes in the IVGP of wheat straw treated with 6 different fungal strains. To achieve this, two procedures were compared: (1) Procedure A, based on Van Soest et al. (1991) method; (2) Procedure B, by combined methods of assessing lignin and carbohydrates, based on Py-GC/MS (Jurak et al., 2015; Van Erven et al., 2017) and monosaccharide analysis (Englyst and Cummings, 1984), respectively.

\section{MATERIALS AND METHODS}

\section{Preparation of the fungal-treated wheat straw}

Two high potential strains from three different fungal species were previously selected based on their ability to improve IVGP of wheat straw: CS1 (CBS 347.63) and CS12 (ME-485) strains of Ceriporiopsis subvermispora, PE3 (Mycelia2600) and PE6 (AL04) of Pleurotus eryngii and LE8 (sh 03/08) and LE10 (LE75) of Lentinula edodes (Nayan et al., 2018). Procedures for the fungal strain preparations and treatment of the wheat straw have been described previously in detail (Nayan et al., 2017). All strains were 
maintained on malt extract agar before a piece of that agar $(1.5 \times 2.0 \mathrm{~cm})$ was used to prepare the spawn for each fungus. The spawn was prepared using sterilized sorghum grains and was incubated at $24^{\circ} \mathrm{C}$ for 5 weeks. Organic wheat straw was purchased from a local farmer in the Netherlands, and chopped into approximately $3 \mathrm{~cm}$ pieces. The wheat straw was soaked in water for 3 days at room temperature and excess water was drained for $5 \mathrm{~h}$. Adjustments were made based on the final moisture content of the straw $(\sim 74 \%$ $\mathrm{w} / \mathrm{w}$ ), for each container (Combiness, Nevele, Belgium) to contain $90.2 \pm 0.3 \mathrm{~g}$ of dry matter. After autoclaving at $121^{\circ} \mathrm{C}$ for $1 \mathrm{~h}$, the straw was inoculated with the prepared spawn at $10 \%$ of the dry weight. The wheat straw (treated and untreated with fungi) was incubated in triplicate aerobically at $24^{\circ} \mathrm{C}$ for 7 weeks in a climate-controlled chamber. All samples were freeze-dried and ground over a $1 \mathrm{~mm}$ sieve using a cross beater mill (100AN, Peppink, Olst, the Netherlands).

\section{In vitro gas production}

The in vitro gas production (IVGP) - expressed as $\mathrm{ml} \mathrm{g}^{-1}$ organic matter (OM), was performed according to Cone et al. (1996). In brief, $\sim 0.5 \pm 0.01 \mathrm{~g}$ of sample was incubated in $60 \mathrm{ml}$ buffered rumen fluid at $39^{\circ} \mathrm{C}$. The incubation was carried out for $72 \mathrm{~h}$ and the gas production was recorded automatically.

\section{Estimation of fungal biomass and its ruminal degradability}

Only one strain per fungal species (CS12, PE6 and LE8) was randomly selected for the estimation of fungal biomass and determining the IVGP of its pure mycelial mass. These fungal strains were grown on malt extract agar plates ( 300 plates per species), layered with a cellophane on the surface. After 10 days (6 days for CS12), the fully colonized mycelia were harvested. The harvested fresh biomass (3.5 to $6.9 \mathrm{~g}$ ) was freezedried before being subjected to the IVGP and expressed as $\mathrm{ml} \mathrm{g}^{-1}$. In the IVGP run, the corresponding fungal-treated wheat straws were also included in the same run for comparison. Fungal biomass was estimated with an ergosterol assay, which has been described in detail (Nayan et al., 2018; Niemenmaa et al., 2008). In brief, $200 \pm 10 \mathrm{mg}$ sample was extracted with $10 \%(1: 9) \mathrm{KOH} /$ methanol solution, before saponification at $80^{\circ} \mathrm{C}$ for $60 \mathrm{~min}$. Two series of extractions with distilled water and hexane followed. The collected hexane layers were pooled and dried under vacuum (Rapidvap, Kansas, MO, USA). The extracted ergosterol was re-dissolved in methanol and the solution was filtered before analysis by high performance liquid chromatography (PDA-HPLC) (Alliance HPLC system, Waters, Milford, USA). Cholecalciferol (vitamin $\mathrm{D}_{3}$ ) was used as an 
internal standard. The ergosterol peak was detected at $280 \mathrm{~nm}$. Previous ergosterol data for wheat straw treated with the selected fungi (Nayan et al., 2018) were used in calculating the conversion factor, CF (Ergosterol treated straw / Ergosterol pure fungal biomass) and estimating the fungal biomass ( $\mathrm{CF} \times$ total amount of organic matter, in $\mathrm{g}$ ) present in the treated straw.

\section{Conventional feed analyses: 'Van Soest'}

Samples were dried in an oven at $103^{\circ} \mathrm{C}$ to determine the dry matter (DM) content (ISO 6496, 1999); and then further combusted at $550^{\circ} \mathrm{C}$ for $3 \mathrm{~h}$ in a muffle furnace for the ash content (ISO 5984, 2002). Nitrogen content was determined by the Kjeldahl method (ISO 5983, 2005) and crude protein was calculated as $\mathrm{N} \times 6.25$. Compositional analysis of the fiber contents was carried out according to Van Soest et al. (1991), in an $\mathrm{ANKOM}^{200}$ fiber analyzer (ANKOM Technology, NY). Neutral detergent fiber (NDF) was determined using a heat-stable amylase (thermamyl) and alcalase. Acid detergent fiber (ADF) and acid detergent lignin (ADL) were determined by boiling the sample in an acid detergent solution, and to determine ADL the residue was further treated with $72 \% \mathrm{v} / \mathrm{v}$ $\mathrm{H}_{2} \mathrm{SO}_{4}$. All fiber contents were corrected for ash. Hemicellulose was calculated by subtracting $\mathrm{ADF}$ from NDF values, while cellulose was calculated as the difference between ADF and ADL. The cell wall contents were expressed on dry matter basis ( $\% \mathrm{w} / \mathrm{w}$ $\mathrm{DM})$. Absolute amounts were calculated from the remaining freeze-dried materials (g), which were corrected for their DM contents. Prior to the monosaccharides and PyGC/MS analyses, an equal amount of each biological replicate belonging to the same treatment was thoroughly mixed into one sample.

\section{Carbohydrate content and composition: 'Englyst'}

The carbohydrate content and composition was determined in duplicate according to Englyst and Cummings (1984), using inositol as an internal standard. Samples were treated with $72 \%(\mathrm{w} / \mathrm{w}) \mathrm{H}_{2} \mathrm{SO}_{4}\left(1 \mathrm{~h}, 30^{\circ} \mathrm{C}\right)$ followed by hydrolysis with $1 \mathrm{M} \mathrm{H}_{2} \mathrm{SO}_{4}$ for $3 \mathrm{~h}$ at $100^{\circ} \mathrm{C}$. The constituent sugars released were analyzed as their alditol-acetates using gas chromatography (ThermoScientific, Waltham, MA, USA) and determined as anhydrocarbohydrates. A standard with a known concentration of glucose, galactose, mannose, arabinose, rhamnose and xylose was taken along in the procedure. The uronic acids released after the acid hydrolysis step, were determined in duplicate as anhydrouronic acid by an automated meta-hydroxydiphenyl assay (Thibault, 1979) with addition of sodium tetraborate using an auto-analyzer (Skalar Analytical BV, Breda, The 
Netherlands). Glucuronic acid (Fluka AG, Buchs, Switzerland) was used as a reference (0 - $100 \mu \mathrm{g} \mathrm{ml} \mathrm{m}^{-1}$ ). Glucan was considered as a total cellulosic polymer, while glucuronoarabinoxylan (GAX) as the hemicellulosic polymer by summing up xylan, arabinan and uronic acid.

\section{Semi-quantitative and quantitative pyrolysis}

Prior to Py-GC/MS, ground wheat straw $(1 \mathrm{~mm})$ was ball-milled in a MM200 mixer mill (Retsch, Haan, Germany). Detailed procedures have been described previously (Jurak et al., 2015; Van Erven et al., 2017). Pyrolysis was performed with an EGA/PY3030D Multi-shot pyrolyzer (Frontier Laboratories, New Ulm, MN, USA) equipped with an AS-1020E Autoshot auto-sampler. The pyrolyzer was coupled to a GC-MS, using a Trace GC, coupled to a DSQ-II mass spectrometer (both Thermo Scientific, Waltham, MA, USA). Pyrolysis of samples $(\sim 80 \mu \mathrm{g})$ was performed at $500^{\circ} \mathrm{C}$ for $1 \mathrm{~min}$. Pyrolysis products were injected into the column via a split/splitless injection (at $250^{\circ} \mathrm{C}$ ) with a splitratio of 1:133 and helium was used as carrier gas. The GC oven was programmed at $270{ }^{\circ} \mathrm{C}$ for $15 \mathrm{~min}$. MS detection was used with a scan range of 50-550 $\mathrm{m} \mathrm{Z}^{-1}$ and a scan rate of 4.0 scans s ${ }^{-1}$. Compounds were identified by comparing the retention time and mass spectra with standards, the NIST library and published data (Ralph and Hatfield, 1991). For semi-quantitative analysis (samples of week 0, 1, 3 and 7), pyrograms were processed with Xcalibur 2.2 software. Areas were normalized by dividing by corresponding relative response factors $(\mathrm{RRF})$, multiplied with the molecular weight of the respective compound and summed (Van Erven et al., 2017). Lignin content was estimated on the basis of the total area of lignin-derived pyrolysis products and compared to a wheat straw reference sample with known total Klason lignin content $(20.5 \% \mathrm{w} / \mathrm{w})$ (Jurak et al., 2015).

Only samples of week 0 and 7 were subjected to the quantitative Py-GC/MS, using previously described procedures (Van Erven et al., 2017). Briefly, $10 \mu \mathrm{L}$ of a ${ }^{13} \mathrm{C}$ lignin internal standard (IS) solution $\left(1 \mathrm{mg} \mathrm{ml}^{-1}\right)$ was mixed with $\sim 80 \mu \mathrm{g}$ of sample and dried before analysis. Lignin-derived pyrolysis products were monitored in the selected ion monitoring (SIM) mode on the two most abundant fragments per compound (both ${ }^{12} \mathrm{C}$ and ${ }^{13} \mathrm{C}$ ). The area for each compound was normalized by dividing by the RRF. The RRF values were updated to system performance by recalculation to obtain an identical relative abundance of lignin-derived pyrolysis products of the ${ }^{13} \mathrm{C}$ IS added to the wheat straw reference sample. Lignin content $(\%, w / w)$ was determined as the sum of lignin-derived pyrolysis products by the established formula (Van Erven et al., 2017). Relative 
abundances of lignin-derived pyrolysis products were based on areas normalized for the ${ }^{13} \mathrm{C}$ analogues from the IS present in the same sample to distinguish matrix and treatment effects. Areas were not corrected for molecular weight. Compounds were classified according to their structural features (Table 5-S1) and summed. All samples were prepared and analyzed in triplicate.

\section{Statistics}

Data were analyzed using the general linear model (analysis of variance, ANOVA) in SAS 9.3, followed by post-hoc multiple comparison with least significance differences. The statistical model used was as follows:

$$
Y_{i j}=\mu+S P_{i}+S T_{j(i)}+\tau_{k(i j)}+\varepsilon_{i j k}
$$

where $Y_{i j k}=$ response variable $i j k, \mu=$ overall mean, $S P_{i}=$ the effect of species $i, S T_{j(i)}=$ the effect of strain $j$ nested within species $i, \tau_{k(i j)}=$ effect of week $k$, and $\varepsilon_{i j k}=$ residual error with a mean of 0 and variance $\sigma^{2} . S P_{i}$ was considered a fixed effect, $S T_{j(i)}$ and $\tau_{k(i j)}$ as random effects. Pearson Product-Moment Correlation $(r)$ coefficients were also determined among the measured variables. Probability values below 5\% were considered significant. No ANOVA was applied on the analytical replicates data of the mixed samples (monosaccharides and Py-GC/MS analyses). However, the coefficient of variation (CV) was calculated as a measure of proportional error (Udén et al., 2012).

\section{RESULTS AND DISCUSSION}

\section{Cell wall analyses using two procedures and in vitro gas production}

Changes in the cell wall contents at week 1, 3 and 7, were assessed using two procedures (Fig. 5.1): (1) Procedure A was based on Van Soest et al. (1991); and (2) Procedure B represents a more specific analyses using semi-quantitative Py-GC/MS for lignin (Jurak et al., 2015; Van Erven et al., 2017) and carbohydrates were analyzed based on Englyst and Cummings (1984) method. Based on Procedure A, typical weekly changes of the cell wall contents, similar to previous reports, were observed - e.g. relative increases of the ADL contents at week 1 , proceeded by a large degradation of ADL until the end of colonization week (Nayan et al., 2017; Van Kuijk et al., 2015b). For comparing the two procedures and later discussing their differences in the mass recovery of cell wall components (Fig. 5.1), we focus on the changes in the cell wall composition after 7 weeks of fungal pretreatments (Table 5.1). The cellulose contents, determined by Procedure A, 
Chapter 5 | Different analytical methods of assessing cell wall

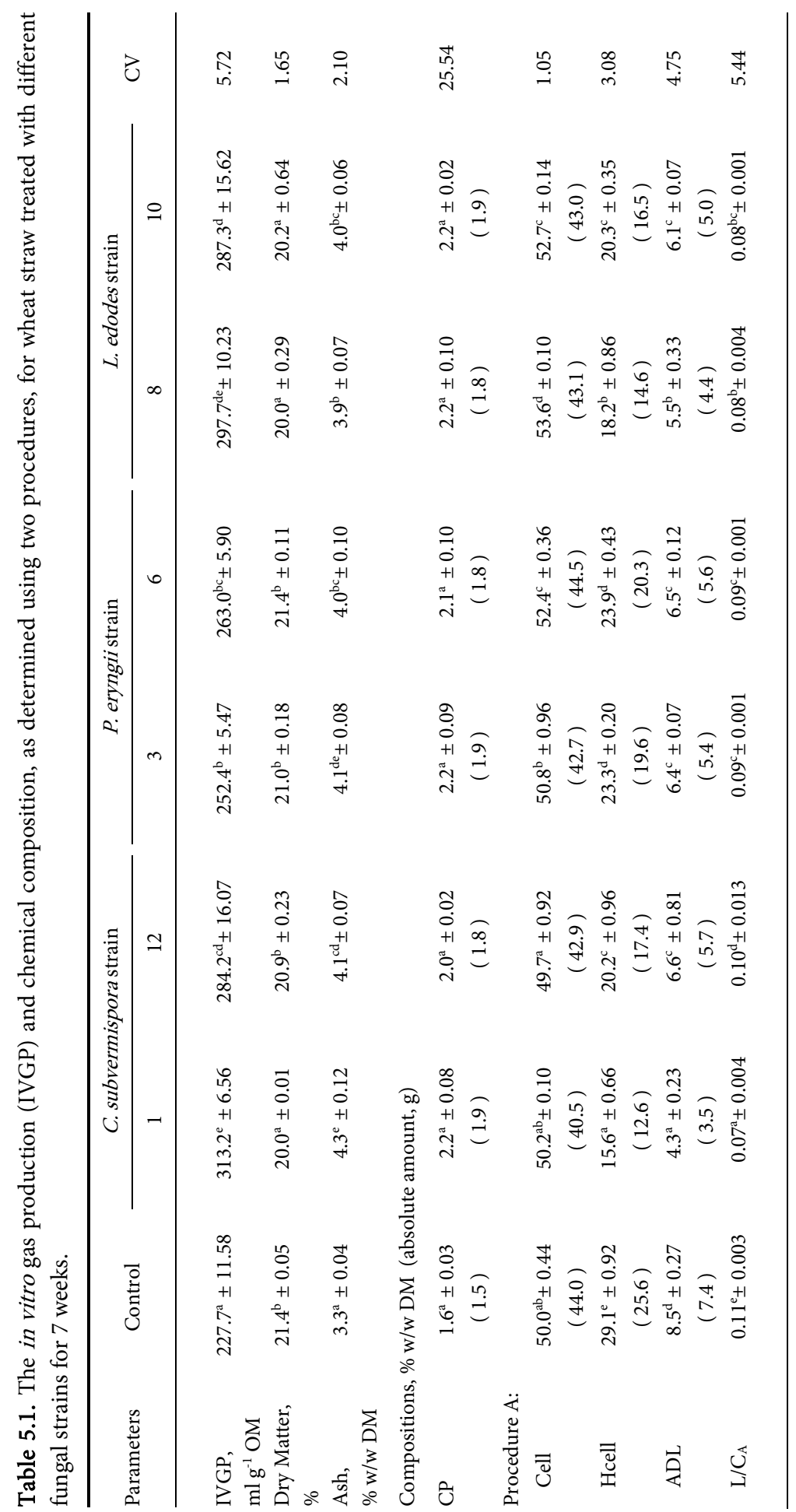


Chapter 5 | Different analytical methods of assessing cell wall

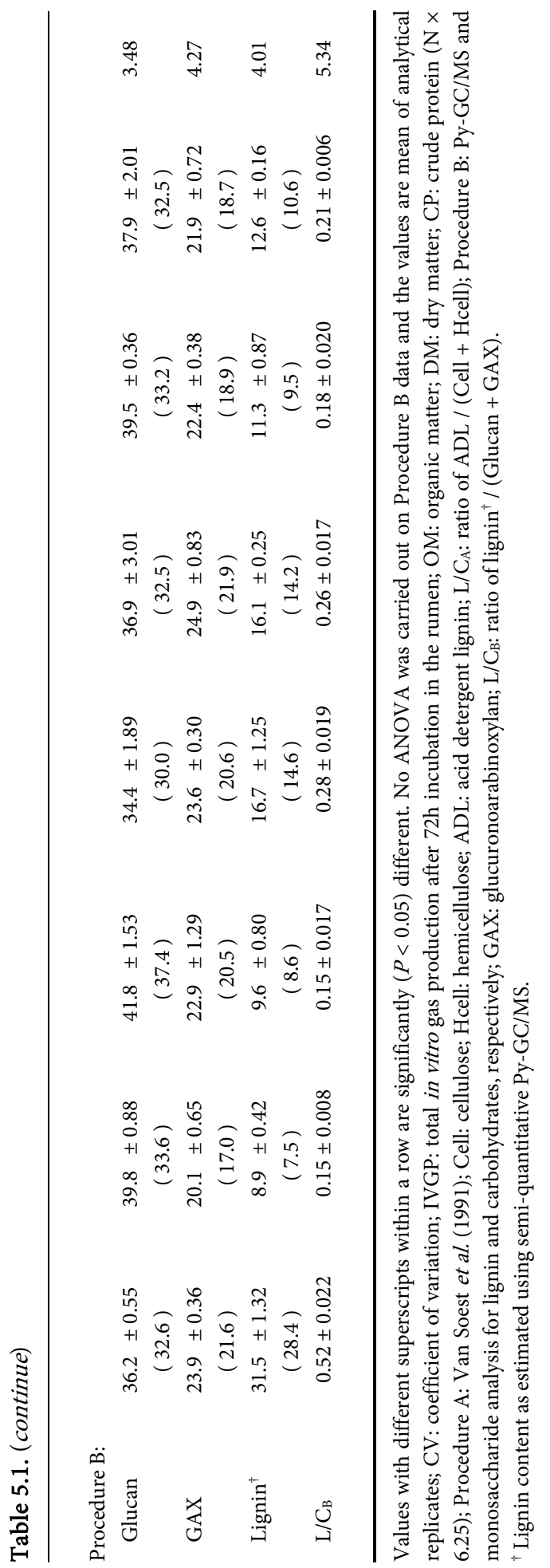




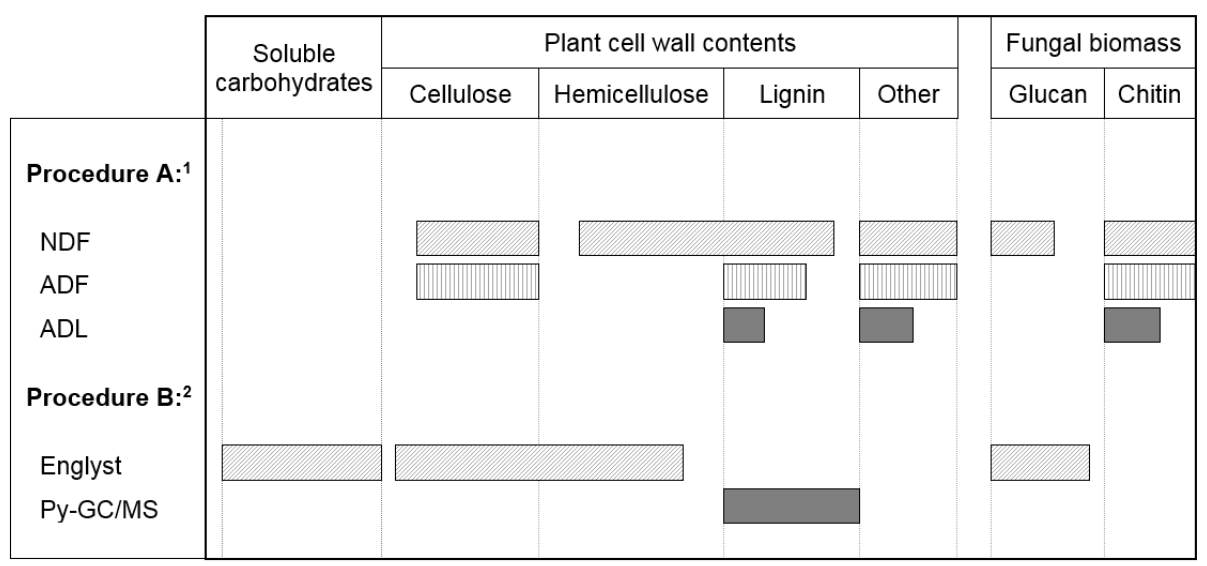

Fig. 5.1. Schematic representation indicating which components are analysed by using two different procedures: (1) Procedure A based on Van Soest et al. (1991); cellulose (ADF - ADL), hemicellulose (NDF - ADF); and (2) Procedure B using the Englyst and Cummings (1984) method for carbohydrate analysis and Py-GC/MS for lignin (Van Erven et al., 2017). NDF: neutral detergent fiber; ADF: acid detergent fiber; ADL: acid detergent lignin.

were relatively comparable among different treatments ( 49.7 to $53.6 \% \mathrm{DM}$, w/w). The degradation (absolute amount) of hemicellulose (20.0 to 49.7\%) followed a similar pattern to that of $\mathrm{ADL}$ (22.3 to 52.2\%). Procedure A showed small variations in the ADL content $(<10 \%)$ among different biological replicates of the same treatment, while other nutrients showed less than $5 \%$ variation. Thereto, the biological replicates were thoroughly mixed to allow analytical triplicates for detailed and more accurate lignin and carbohydrates analyses.

The cellulose content, measured as glucan in Procedure B was 15.8 to $32.2 \%$ lower, compared to cellulose measured with Procedure A. Cellulose of Procedure A is overestimated as parts of hemicellulose (e.g. xylan that is associated with lignin) is present in ADF (Fig. 5.1). In addition, a significant portion of lignin is solubilized by the acid detergent solution, leading to overestimation of cellulose contents (Jung, 1997). Similarly, the limitations of ADF (and NDF) lead to inaccuracies in the quantification of hemicellulose. The glucuronoarabinoxylan (GAX) content of untreated straw was $17.8 \%$ lower than hemicellulose estimated by the Procedure A. Interestingly, all fungal-treated wheat straw showed 1.5 to $28.5 \%$ higher GAX contents, compared to the hemicellulose obtained by Procedure A. It is, however, difficult to deduce a possible explanation for this difference. At week 7, the lignin contents of fungal-treated wheat straw as quantified by 
semi-quantitative Py-GC/MS were 1.4 to 2.8 times higher than ADL. Py.lignin of the untreated straw was even higher (3.7 times), compared to ADL. As mentioned before, ADL greatly underestimates the total lignin contents.

For correlations among all measured variables of the two procedures (Table 5.2), all weekly data (excluding control, week 0) were used. Comparing the two procedures, good correlations were only found in the measurement of GAX-hemicellulose $(r=0.76 ; P<$ $0.001)$ and Py.lignin-ADL $(r=0.84 ; P<0.001)$. However, in terms of degradation of the absolute amount, Py.lignin gave a higher percentage of degradation (61.9\%), compared to the degradation of ADL (33.2\%). The degradation percentage of GAX was only $9.3 \%$, compared to $33.4 \%$ for hemicellulose. These large differences between procedures indicate disparities in the mass recovery of cell wall components, as proposed in Fig. 5.1. To gain insight, we relate the data with the subsequent effects on ruminal degradability, as measured by IVGP. The changes in IVGP of the fungal-treated straws have been previously discussed in details (Nayan et al., 2018) - hence, will only be mentioned briefly. All fungi clearly increased the IVGP of the wheat straw. Still, large IVGP variations were observed among different species (also to a lesser extent, between strains of the same species), with $\sim 24 \%$ difference between CS1 (highest) and PE3 (lowest).

\section{Relationship between IVGP and the cell wall contents}

With Procedure A, the IVGP was positively correlated to cellulose $(r=0.46 ; P=$ $0.070)$, but negatively correlated to hemicellulose $(r=-0.84 ; P<0.001)$ and ADL $(r=-$ $0.88 ; P<0.001)$. These results are consistent with previous reports, which used the same Procedure A (Nayan et al., 2017; Van Kuijk et al., 2015b). It was reported that the degradation of ADL is accompanied by the solubilization or degradation of hemicellulose (Van Kuijk et al., 2015c). In this study, a significant $(P<0.001)$ correlation of ADL with hemicellulose was observed $(r=0.93)$. The reduction of the hemicellulose content alongside lignin is partly attributed to the fungi's need for growth and metabolisms (Van Kuijk et al., 2015c). The accuracy of Procedure A relies to a large extent on the precision of the extraction and filtration steps (Marichal et al., 2011). Smaller lignin and structural carbohydrates degradation products can easily be excluded from the normal pore size filter bags $(\Phi=25 \mu \mathrm{m})$. Therefore, the question remains if the changes in the cell wall content are due to 'degradation' or 'solubilization' from the filtration steps. The high correlation of ADL with the IVGP is expected since the ADL fraction may only account for the recalcitrant lignin, which is highly resistant to fermentation in the rumen. This 
Chapter 5 | Different analytical methods of assessing cell wall

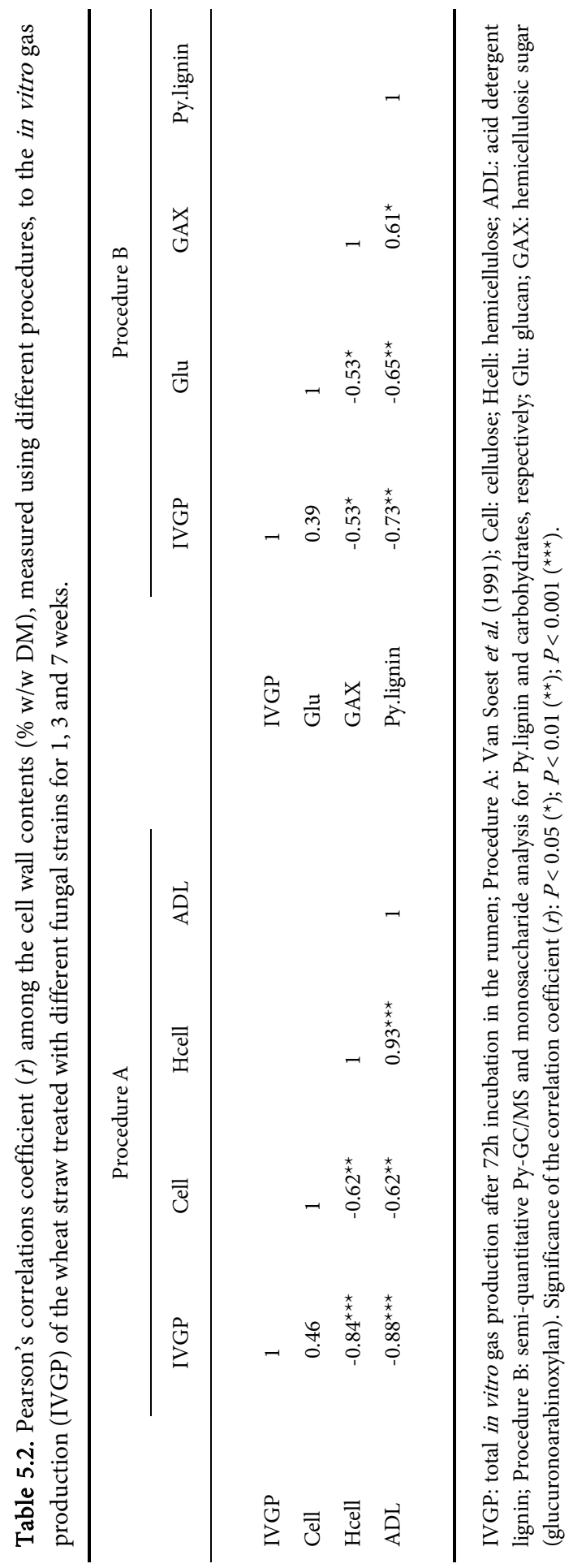


recalcitrant lignin covalently bonds to its associated polysaccharides, which lead to a low degradability of cell walls in the rumen (Moore and Jung, 2001). It is inferred that the residual lignin in the ADL fraction may be structurally modified, but is not fragmented by the fungi. To obtain an insight into a possible relationship of the modification of lignin structural features by different fungi with the IVGP, Py-GC/MS was performed - which will be discuss later. Similar circumstances are also applicable to the cellulose contents, where degraded cellulose is solubilized, leaving behind intact cellulose polymers. This explains a low correlation of cellulose with the IVGP.

To compare with the outcome of Procedure A, we assessed the cell wall contents using the specific analyses (Procedure B) and related it with the IVGP. Figure 5.2 shows correlation plots of the IVGP with the ratio of lignin to carbohydrates (L/C), measured with both procedures. The L/C from the two procedures showed significant $(P<0.01)$ relationships with the IVGP, although Procedure A showed a higher correlation coefficient $(r)$, compared to Procedure B (-0.84 vs. -0.69 , respectively). Both procedures are considered reliable in assessing the IVGP of fungal-treated wheat straw, but there are limitations. Although both procedures show the same trend, the correlation coefficients of the individual cell wall components with the IVGP were noticeably lower for Procedure B. This led to several inferences: (1) Procedure A is more indicative of the cell wall solubility - which explained the IVGP well, rather than indicating the actual cell wall degradation by fungi. The more specific Procedure B elucidates more on the structure, which aids our understanding of variations among fungal strains in modifying the cell wall; (2) Although the recalcitrant lignin (ADL) caused a strong negative effect on the IVGP, the inclusion of all lignin-derived compounds in Py.lignin contents (acid soluble fraction and/or modified lignin fragments) suggested a weaker relationship. The inverse relationship of lignin with digestibility is widely accepted (Moore and Jung, 2001). In their review, Susmel and Stefanon (1993) combined results from several studies, and concluded that an 'apparent' digestion of lignin in the rumen (2 to 53\%) occurs. However, it is still debatable if modified lignin fragments could be fermented in the rumen and contribute to the IVGP. (3) Procedure B suggests a lesser degradation of hemicellulose, compared to lignin, i.e. both polymers are not simultaneously degraded by fungi, as commonly reported in literature (Nayan et al., 2017; Tuyen et al., 2012; Van Kuijk et al., 2015b). The fragmented lignin may also contain intact hemicellulose polymers, especially xylan (Buranov and Mazza, 2008), which explains the strong correlation in Procedure A (simultaneous 'degradation' of ADL and hemicellulose). This is also a valid explanation to the weaker negative relationship of Py.lignin with IVGP, compared to ADL. 
A

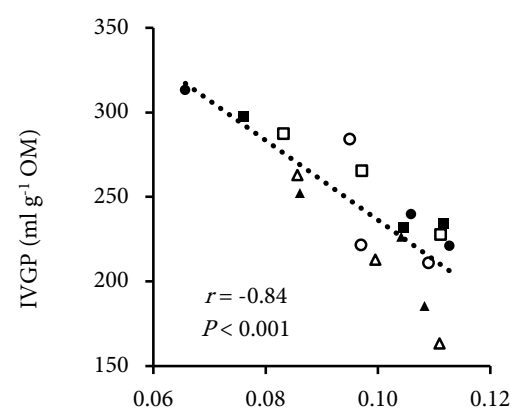

ADL / (Cell + Hcell)
B

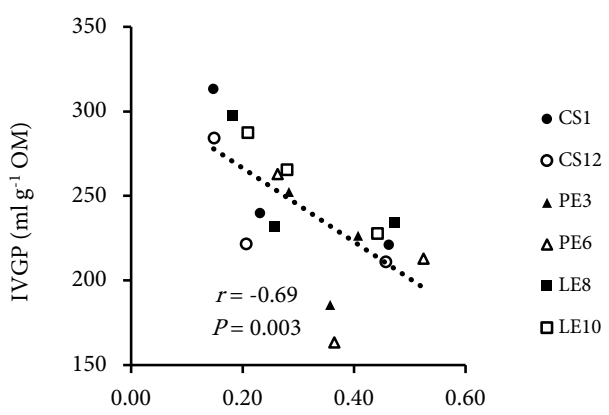

Lignin / (Glu + GAX)

Fig. 5.2. Correlations between IVGP to the ratio of lignin to total structural carbohydrates, measured using method A (Van Soest et al., 1991) and B (semi-quantitative Py-GC/MS and alditolacetates), of wheat straw treated with different fungal strains for 1, 3 and 7 weeks. ADL: acid detergent lignin; Cell: cellulose; Hcell: hemicellulose; Glu: glucan; GAX: glucuronoarabinoxylan. Respective Pearson's $r$ and $P$ values are indicated.

During the growth of fungi, the amount of fungal biomass increased in the wheat straw samples. We hypothesize an interference from the fungal biomass with the cellulose and glucan contents (Fig. 1). True (higher) fungi do not contain cellulose, a $\beta$-(1 $\rightarrow 4)$-Dglucan polymer (Badreddine et al., 2008). However, fungal polysaccharides such as $\beta$ $(1 \rightarrow 3)$-D-glucan and $\alpha$-(1 $\rightarrow 3)$-D-glucan (Fesel and Zuccaro, 2016), as well as chitin $(\beta$ $(1 \rightarrow 4)$-linked $N$-acetyl-D-glucosamine), may be included in the total cellulose content of Procedure A. Meanwhile, the acid hydrolysis step in Procedure B will also hydrolyze all glucan belonging to the fungal biomass; but not chitin, which requires a stronger acid (Einbu and Vårum, 2008). Due to its recalcitrant nature, chitin may end up in the ADL fraction. Hence, it can be concluded that none of the two procedures allow accurate quantification of straw cellulose that distinguished from fungal glucan. Besides interfering in the cell wall compositional analyses, the fungal glucan, like the straw cellulose, are fermentable in the rumen (Morgavi et al., 1994), and hence contribute to the total IVGP. Although chitin is thought to be resistant to microbial degradation, several studies reported the presence of chitinolytic microbes and proved the presence of chitinase and $N$-acetyl- $\beta$-glucosaminidase activities in the rumen (Kopecný et al., 1996; Morgavi et al., 1994). Due to the fact that the IVGP is the cumulative production of $\mathrm{CO}_{2}$ 
( $65 \%)$, methane $(\sim 31 \%)$ and other minor gases (Moate et al., 1997) from any fermentable OM, we also investigated the fermentability of pure fungal biomass in rumen fluid.

\section{Estimation of fungal biomass and its contribution to the total IVGP}

Table 5.3 summarizes the estimation of the fungal biomass (measured as ergosterol) present in the treated wheat straw for one strain of each species after 7 weeks of growth. Results showed that the biomass of CS12 only accounted for $1.7 \%$ of the total OM, lower than that of PE6 (2.3\%) and LE8 (2.8\%). This estimation is in line with the visual observation of these fungi (not shown), where a layer of thin mycelium is a typical growth characteristic of $C$. subvermispora strains. This estimation suggests only a slight contribution of the total fungal biomass to the total weight of OM. However, this rough estimation may not be accurate as the ergosterol content can change with the substrate used (agar plate vs. straw). Furthermore, ergosterol only accounts for less than $3 \%$ of the fungal biomass (Klamer and Bååth, 2004), hence, the calculated conversion factors may be misleading. The IVGP of the pure fungal biomass and the corresponding treated wheat straw is shown in Fig. 5.3. The IVGP data were not corrected for ash and, therefore, expressed as $\mathrm{ml} \mathrm{g}^{-1}$ substrate to show patterns. Overall, the pure mycelial mass resulted in a higher IVGP compared to their respective treated straws, by a factor of 1.03 to 1.20 . A large variation was observed for CS12 biomass, which is probably due to measurement errors $(n=2)$. The maximum IVGP observed for CS12 biomass was $301.4 \mathrm{ml} \mathrm{g}^{-1}$.

Table 5.3. Estimation of fungal biomass present in wheat straw treated with $C$. subvermispora (CS12), P. eryngii (PE6) and L. edodes (LE8) for 7 weeks.

\begin{tabular}{|c|c|c|c|c|c|}
\hline \multirow{2}{*}{ Strain } & \multicolumn{2}{|c|}{ Ergosterol $\left(\mu \mathrm{g} \mathrm{g}^{-1}\right)$} & \multirow{2}{*}{$\begin{array}{l}\text { Conversion } \\
\text { factor }^{\dagger}\end{array}$} & \multicolumn{2}{|c|}{$\begin{array}{l}\text { Estimated fungal biomass in treated } \\
\text { straw }\end{array}$} \\
\hline & Treated straw & $\begin{array}{c}\text { Pure fungal } \\
\text { biomass }\end{array}$ & & Weight (g) & $\%$ in total OM \\
\hline $\mathrm{CS} 12$ & $59.6^{\mathrm{b}}$ & $3466.7^{\mathrm{b}}$ & $0.017^{\mathrm{b}}$ & $1.4^{\mathrm{b}}$ & $1.7^{\mathrm{b}}$ \\
\hline PE6 & $64.9^{\mathrm{b}}$ & $2821.2^{c}$ & $0.023^{\mathrm{ab}}$ & $1.9^{\mathrm{ab}}$ & $2.3^{\mathrm{ab}}$ \\
\hline LE8 & $112.3^{\mathrm{a}}$ & $4049.3^{\mathrm{a}}$ & $0.028^{\mathrm{a}}$ & $2.3^{\mathrm{a}}$ & $2.8^{\mathrm{a}}$ \\
\hline $\mathrm{CV}$ & 10.59 & 7.50 & 15.28 & 16.80 & 15.79 \\
\hline
\end{tabular}

Values with different superscripts within column are significantly $(P<0.05)$ different. CV: coefficient of variation.

${ }^{\dagger}$ Ergosterol ${ }_{\text {treated straw }} /$ Ergosterol $_{\text {pure fungal biomass. }}{ }^{\ddagger}$ Conversion factor $\times$ total amount of organic matter, in $g$. 


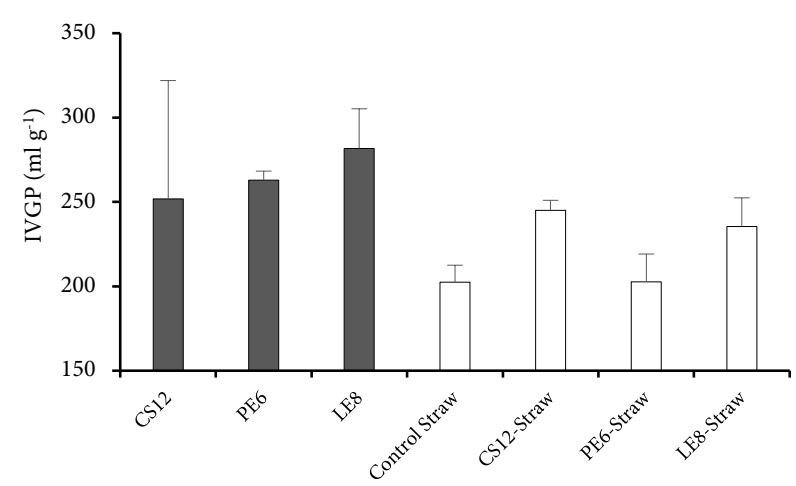

Fig. 5.3. The in vitro gas production (IVGP) of pure fungal biomass ( $\square$ ) and the corresponding wheat straw ( $\square$ ) treated with C. subvermispora (CS12), P. eryngii (PE6) and L. edodes (LE8) for 7 weeks. Error bars indicate standard deviation.

Therefore, we infer that the degradability of pure mycelial mass could have followed the same patterns observed for the respective bioprocessed straw. These results show that the fungal biomass is fermentable in the rumen and may contribute to the total IVGP, although the fermentation of straw polymers is still the major part of the observed IVGP. However, the in situ infiltration of fungal biomass in lignocellulose matrix, may affect its effective degradability in the rumen.

Based on the points that have been discussed, we consider lignin as the main determinant of ruminal degradability. Therefore, an in-depth assessment of both lignin content and structures was carried out using a highly accurate quantitative ${ }^{13} \mathrm{C}-\mathrm{IS}$ PyGC/MS (Van Erven et al., 2017).

\section{The lignin structural features and its relationship with the IVGP}

The quantitative Py-GC/MS of the samples released 49 lignin-derived compounds (see supporting information Table S1), which were used for the determination of Py.lignin $_{(\mathrm{Q})}$ contents and structural features (Table 5.4). Based on this method, a similar species-dependent trend in the extent of Py.lignin(Q) degradation was observed, with $C$. subvermispora strains degrading most lignin $(\sim 63.3 \%)$, followed by L. edodes strains $(\sim 58.0 \%)$ and P. eryngii $(\sim 38.7 \%)$. The Py.lignin $(\mathrm{Q})$ contents were significantly $(P<0.05)$ correlated to the IVGP $(r=-0.87)$. The syringyl to guaiacyl $(\mathrm{S} / \mathrm{G})$ ratio, however, did not follow the same patterns seen with the degradation of Py.lignin $(\mathrm{Q})$ (Fig. 5.4), suggesting an 


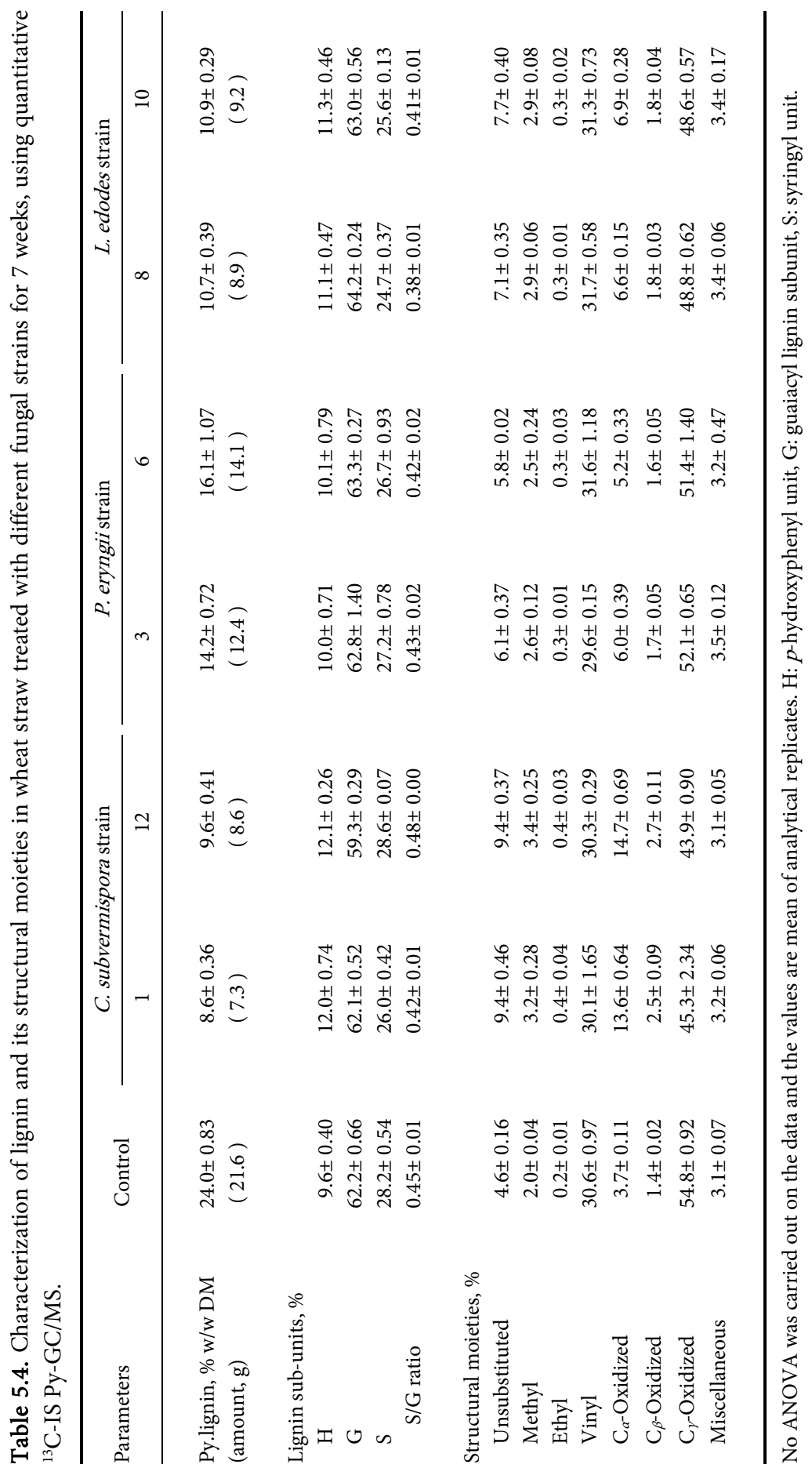



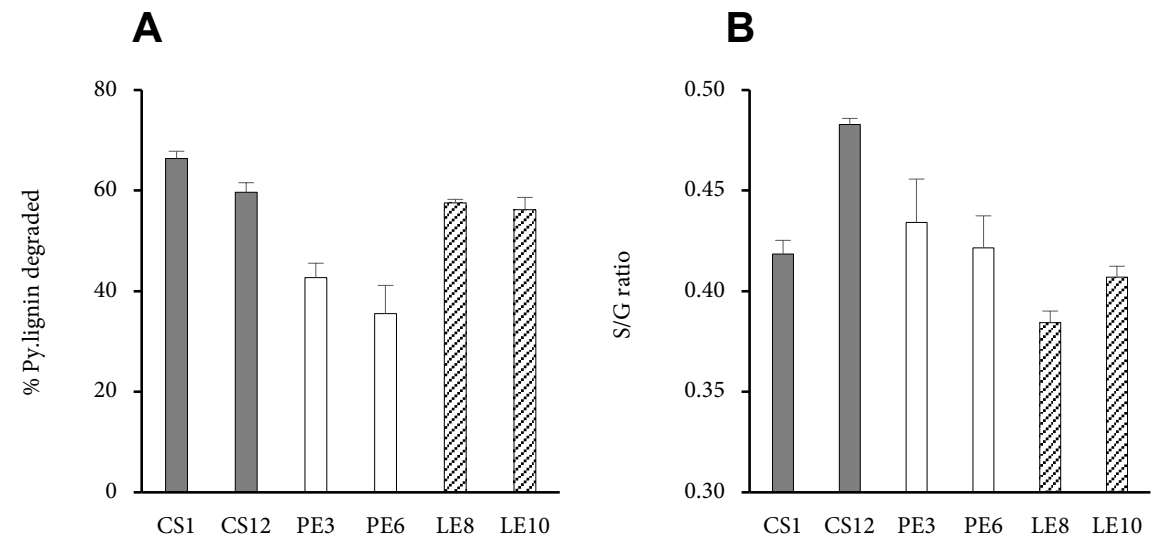

Fig. 5.4. Degradation (\%) of Py.lignin (A), as quantified using Py-GC/MS with ${ }^{13} \mathrm{C}$ as an internal standard for 7 weeks treatments of wheat straw with C. subvermispora (CS1, CS12), P. eryngii (PE3, PE6) and L. edodes (LE8, LE10). The ratio of syringyl (S) to guaiacyl (G) ratio for each treated straw is shown in Graph B. Error bars indicate standard deviation.

independent relationship between the degradation of Py.lignin $(\mathrm{Q})$ contents with the monolignol subunits composition. Previously, Van Kuijk et al. (2016) showed a strong correlation $(r=-0.75)$ of the S/G ratio with the IVGP for wheat straw treated with a single fungus - L. edodes. In the present study, there was a poor correlation of the pooled $\mathrm{S} / \mathrm{G}$ ratio to the IVGP $(r=-0.28)$ and even to the Py.lignin contents $(r=-0.08)$, indicating a unique preference of different fungi in attacking certain lignin subunits. Most of the tested fungi here showed only a slight preference in degrading the S-unit compounds (e.g. transsinapyl alcohol) compared to the G-units, which is a common observation in fungal degradation of lignocellulose (Del Río et al., 2002; Martínez et al., 2011; Van Kuijk et al., 2016). The S-unit compounds have a slightly lower redox potential and fewer aryl- $O$-aryl bonds, making them more susceptible to fungal degradation (Del Río et al., 2002). We also observed a slight tendency of CS12 to decrease the abundances of G-unit compounds (4.7\%). These results suggest that the fungal preference on changing S/G was hardly shown, probably due to the extensive degradation of the total Py.lignin ${ }_{(\mathrm{Q})}$ contents.

Among the remarkable changes observed in structural moieties of lignin were the increases of unsubstituted (1.2 to 2.0 times) and $\mathrm{C}_{\alpha}$-oxidized compounds (1.4 to 4.0 times) in fungal-treated wheat straw, compared to the control (Table 5.4). A familiar speciesdependent order (C. subvermispora $>$ L. edodes $>$ P. eryngii) for these parameters can be seen. These observations clearly indicate extensive degradation of lignin inter-units, 
which resulted in residual lignin with fewer intact linkages. Since the remaining Py.lignin $_{(\mathrm{Q})}$ contents of both strains of $C$. subvermispora and L. edodes were considered comparable (Fig. 4), only the specific lignin moieties from these fungal-treated straw were used to independently assess their relationships with IVGP. By just considering $C$. subvermispora and L. edodes, these specific lignin moieties showed good correlations with the Py.lignin contents, e.g. with substituted $(r=-0.88)$ and $\mathrm{C}_{\alpha}$-oxidized $(r=-0.87)$, although these values were not significant (Table 5.5). There was also no significant correlation of these moieties with the IVGP. This indicates a fundamental difference among different fungal species in modifying lignin structures that requires further investigation. Among the limitations of this study to correlate structural changes to the subsequent IVGP are the assessment on the inter-unit linkages and the associated carbohydrates. In wheat straw, lignin is covalently bound to structural carbohydrates, via ether and ester-linked p-hydroxycynnamic acids (ferulate) (Buranov and Mazza, 2008). Therefore, it is also important to assess fungal modifications of these linkages using a combination of Py-GC/MS with 2D nuclear magnetic resonance (NMR) methods for a better understanding of the underlying delignification mechanisms of different fungi.

Table 5.5. Pearson's correlations coefficient $(r)$ among the lignin content and selected structural features, determined using quantitative Py-GC/MS, with the in vitro gas production (IVGP) of the wheat straw treated with C. subvermispora and L. edodes.

\begin{tabular}{lcccccc}
\hline & IVGP & Py.lignin & Unsub & Methyl & $\mathrm{C}_{\alpha}-\mathrm{Ox}$ & $\mathrm{C}_{r}$-Ox \\
\hline IVGP & 1 & & & & & \\
Py.lignin & -0.62 & 1 & & & & \\
Unsub & 0.20 & -0.88 & 1 & & & \\
Methyl & 0.01 & -0.78 & 0.94 & 1 & & \\
$\mathrm{C}_{\alpha}$-Ox & 0.17 & -0.87 & $0.98^{*}$ & $0.98^{*}$ & 1 & \\
$\mathrm{C}_{r}-\mathrm{Ox}$ & -0.03 & 0.80 & $-0.96^{*}$ & $-1.00^{* *}$ & $-0.99^{*}$ & 1 \\
\hline
\end{tabular}

IVGP: total in vitro gas production after $72 \mathrm{~h}$ incubation in the rumen; Py.lignin: lignin contents quantified using Py-GC/MS with ${ }^{13} \mathrm{C}$ lignin internal standard; Unsub: unsubstituted compounds; Methyl: methylsubstituted compounds; $\mathrm{C}_{\alpha}$-ox, $\mathrm{C}_{\gamma}$-ox: compounds with oxidation at $\mathrm{C}_{\alpha}$ and $\mathrm{C}_{\gamma}$ position, respectively. Significance of the correlation coefficient $(r): P<0.05\left(^{*}\right) ; P<0.01\left(^{* *}\right)$. 


\section{CONCLUSION}

The "classical" gravimetric and more accurate Py-GC/MS methods to characterize plant cell walls provided a clear difference in the amount of lignin degraded by different fungal strains/species. The gravimetric method underestimates lignin degradation, likely due to the fact that only insoluble (recalcitrant) lignin is measured. Since acid detergent lignin provides a good correlation with degradability, it is likely that this recalcitrant lignin is the main factor for the low degradability of lignocellulose by rumen microorganisms. Fungal biomass interferes with the quantification of cellulose contents - for both investigated methods, and contributes slightly to the total IVGP. Lignin content, rather than its structural features, is the main determinant of degradability when assessing bioprocessing of biomass by different fungal strains.

\section{ACKNOWLEDGEMENTS}

The authors gratefully acknowledge the financial support from the Wageningen UR Fund (WUF) as part of the project "More Meat and Milk from Straw" which is sponsored by DEKA, Forfarmers and the Victam Foundation. The authors also would like to acknowledge the scholarship provided by the Ministry of Higher Education Malaysia and Universiti Putra Malaysia for NN.

\section{REFERENCES}

Badreddine, I., Lafitte, C., Heux, L., Skandalis, N., Spanou, Z., Martinez, Y., Esquerré-Tugayé, M.T., Bulone, V., Dumas, B., and Bottin, A. (2008). Cell wall chitosaccharides are essential components and exposed patterns of the phytopathogenic oomycete Aphanomyces euteiches. Eukaryot. Cell 7, 1980-1993.

Buranov, A.U., and Mazza, G. (2008). Lignin in straw of herbaceous crops. Ind. Crops Prod. 28, 237-259.

Cone, J.W., van Gelder, A.H., Visscher, G.J.W., and Oudshoorn, L. (1996). Influence of rumen fluid and substrate concentration on fermentation kinetics measured with a fully automated time related gas production apparatus. Anim. Feed Sci. Technol. 61, 113-128.

Del Río, J.C., Speranza, M., Gutiérrez, A., Martínez, M.J., and Martínez, A.T. (2002). Lignin attack during eucalypt wood decay by selected basidiomycetes: A Py-GC/MS study. J. Anal. Appl. Pyrolysis 64, 421431.

Donkin, S.S., Doane, P.H., and Cecava, M.J. (2013). Expanding the role of crop residues and biofuel co-products as ruminant feedstuffs. Anim. Front. 3, 54-60.

Einbu, A., and Vårum, K.M. (2008). Characterization of chitin and its hydrolysis to GlcNAc and GlcN. Biomacromolecules 9, 1870-1875. 
Chapter 5 | Different analytical methods of assessing cell wall

Englyst, H.N., and Cummings, J.H. (1984). Simplified method for the measurement of total non-starch polysaccharides by gas-liquid chromatography of constituent sugars as alditol acetates. Analyst 109, 937.

Fesel, P.H., and Zuccaro, A. (2016). $\beta$-glucan: Crucial component of the fungal cell wall and elusive MAMP in plants. Fungal Genet. Biol. 90, 53-60.

Hendriks, A.T.W.M., and Zeeman, G. (2009). Pretreatments to enhance the digestibility of lignocellulosic biomass. Bioresour. Technol. 100, 10-18.

Himmel, M.E., Ding, S., Johnson, D.K., Adney, W.S., Nimlos, M.R., Brady, J.W., and Foust, T.D. (2007). Biomass recalcitrance: Engineering plants and enzymes for biofuels production. Science (80-. ). 454, 804-807.

Jung, H.-J.G. (1997). Analysis of forage fiber and cell walls in ruminant nutrition. J. Nutr. 127, 819S-823S.

Jung, H.J.G., Varel, V.H., Weimer, P.J., and Ralph, J. (1999). Accuracy of Klason lignin and acid detergent lignin methods as assessed by bomb calorimetry. J. Agric. Food Chem. 47, 2005-2008.

Jurak, E., Punt, A.M., Arts, W., Kabel, M.A., and Gruppen, H. (2015). Fate of carbohydrates and lignin during composting and mycelium growth of Agaricus Bisporus on wheat straw based compost. PLoS One 10, $1-16$.

Kabel, M.A., Bos, G., Zeevalking, J., Voragen, A.G.J., and Schols, H.A. (2007). Effect of pretreatment severity on xylan solubility and enzymatic breakdown of the remaining cellulose from wheat straw. Bioresour. Technol. 98, 2034-2042.

Klamer, M., and Bååth, E. (2004). Estimation of conversion factors for fungal biomass determination in compost

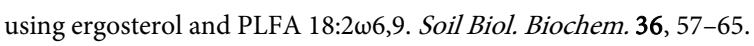

Kopecný, J., Hodrová, B., and Stewart, C.S. (1996). The isolation and characterization of a rumen chitinolytic bacterium. Lett. Appl. Microbiol. 23, 195-198.

Marichal, M. de J., Trujillo, A.I., Cadenazzi, M., and Arias, G. (2011). Fiber analysis: Evaluation of screen printing fabric filters bags by three statistical approaches. Anim. Feed Sci. Technol. 169, 79-85.

Martínez, A.T., Rencoret, J., Nieto, L., Jiménez-Barbero, J., Gutiérrez, A., and Del Río, J.C. (2011). Selective lignin and polysaccharide removal in natural fungal decay of wood as evidenced by in situ structural analyses. Environ. Microbiol. 13, 96-107.

Moate, P.J., Clarke, T., Davis, L.H., and Laby, R.H. (1997). Rumen gases and bloat in grazing dairy cows. J. Agric. Sci. 129, 459-469.

Moore, K.J., and Jung, H.-J.G. (2001). Lignin and Fiber Digestion. J. Range Manag. 54, 420.

Morgavi, D.P., Sakurada, M., Tomita, Y., and Onodera, R. (1994). Presence in rumen bacterial and protozoal populations of enzymes capable of degrading fungal cell walls. Microbiology 140, 631-636.

Nayan, N., Sonnenberg, A.S.M., Hendriks, W.H., and Cone, J.W. (2017). Differences between two strains of Ceriporiopsis subvermispora on improving the nutritive value of wheat straw for ruminants. J. Appl. Microbiol. 123, 352-361.

Nayan, N., Sonnenberg, A.S.M., Hendriks, W.H., and Cone, J.W. (2018). Screening of white-rot fungi for bioprocessing of wheat straw into ruminant feed. J. Appl. Microbiol. 125, 368-379.

Niemenmaa, O., Galkin, S., and Hatakka, A. (2008). Ergosterol contents of some wood-rotting basidiomycete fungi grown in liquid and solid culture conditions. Int. Biodeterior. Biodegradation 62, 125-134.

Rabemanolontsoa, H., and Saka, S. (2016). Various pretreatments of lignocellulosics. Bioresour. Technol. 199, 83-91.

Ralph, J., and Hatfield, R.D. (1991). Pyrolysis-Gc-Ms Characterization of Forage Materials. J. Agric. Food Chem.

39, 1426-1437. 
Chapter 5 | Different analytical methods of assessing cell wall

Sun, X.F., Sun, R.C., Tomkinson, J., and Baird, M.S. (2004). Degradation of wheat straw lignin and hemicellulosic polymers by a totally chlorine-free method. Polym. Degrad. Stab. 83, 47-57.

Susmel, P., and Stefanon, B. (1993). Aspects of lignin degradation by rumen microorganisms. J. Biotechnol. 30 , 141-148.

Szczodrak, J. (1988). The enzymatic hydrolysis and fermentation of pretreated wood substrates. Biotechnol. Adv. 32, 771-776.

Thibault, J.F. (1979). Automatisation du dosage des substances pectiques par la methode au metahydroxydiphenyl. Leb. Wiss. Technol. 12, 247-251.

Tuyen, V.D., Phuong, H.N., Cone, J.W., Baars, J.J.P., Sonnenberg, A.S.M., and Hendriks, W.H. (2013). Effect of fungal treatments of fibrous agricultural by-products on chemical composition and in vitro rumen fermentation and methane production. Bioresour. Technol. 129, 256-263.

Tuyen, V.D., Cone, J.W., Baars, J.J.P., Sonnenberg, A.S.M., and Hendriks, W.H. (2012). Fungal strain and incubation period affect chemical composition and nutrient availability of wheat straw for rumen fermentation. Bioresour. Technol. 111, 336-342.

Udén, P., Robinson, P.H., Mateos, G.G., and Blank, R. (2012). Use of replicates in statistical analyses in papers submitted for publication in Animal Feed Science and Technology. Anim. Feed Sci. Technol. 171, 1-5.

Van Erven, G., De Visser, R., Merkx, D.W.H., Strolenberg, W., De Gijsel, P., Gruppen, H., and Kabel, M.A. (2017). Quantification of lignin and its structural features in plant biomass using ${ }^{13} \mathrm{C}$ lignin as internal standard for pyrolysis-GC-SIM-MS. Anal. Chem. 89, 10907-10916.

Van Kuijk, S.J.A., Del Río, J.C., Rencoret, J., Gutiérrez, A., Sonnenberg, A.S.M., Baars, J.J.P., Hendriks, W.H., and Cone, J.W. (2016). Selective ligninolysis of wheat straw and wood chips by the white-rot fungus Lentinula edodes and its influence on in vitro rumen degradability. J. Anim. Sci. Biotechnol. 7, 55.

Van Kuijk, S.J.A., Sonnenberg, A.S.M., Baars, J.J.P., Hendriks, W.H., and Cone, J.W. (2015a). The effect of adding urea, manganese and linoleic acid to wheat straw and wood chips on lignin degradation by fungi and subsequent in vitro rumen degradation. Anim. Feed Sci. Technol. 213, 22-28.

Van Kuijk, S.J.A., Sonnenberg, A.S.M., Baars, J.J.P., Hendriks, W.H., and Cone, J.W. (2015b). Fungal treatment of lignocellulosic biomass: Importance of fungal species, colonization and time on chemical composition and in vitro rumen degradability. Anim. Feed Sci. Technol. 209, 40-50.

Van Kuijk, S.J.A., Sonnenberg, A.S.M., Baars, J.J.P., Hendriks, W.H., and Cone, J.W. (2015c). Fungal treated lignocellulosic biomass as ruminant feed ingredient: A review. Biotechnol. Adv. 33, 191-202.

Van Kuijk, S.J.A., Sonnenberg, A.S.M., Baars, J.J.P., Hendriks, W.H., del Río, J.C., Rencoret, J., Gutiérrez, A., de Ruijter, N.C.A., and Cone, J.W. (2017). Chemical changes and increased degradability of wheat straw and oak wood chips treated with the white rot fungi Ceriporiopsis subvermispora and Lentinula edodes. Biomass and Bioenergy 105, 381-391.

Van Soest, P.J., Robertson, J.B., and Lewis, B.A. (1991). Methods for dietary fiber, neutral detergent fiber, and nonstarch polysaccharides in relation to animal nutrition. J. Dairy Sci. 74, 3583-3597. 
Supplementary information for:

\section{The relevance of different analytical methods to assess fungal degradation of lignocellulose and explaining the subsequent ruminal degradability}

Nazri Nayan, Gijs van Erven, Mirjam A. Kabel, Anton S.M. Sonnenberg, Wouter H.

Hendriks, and John W. Cone 
Chapter 5 | Different analytical methods of assessing cell wall

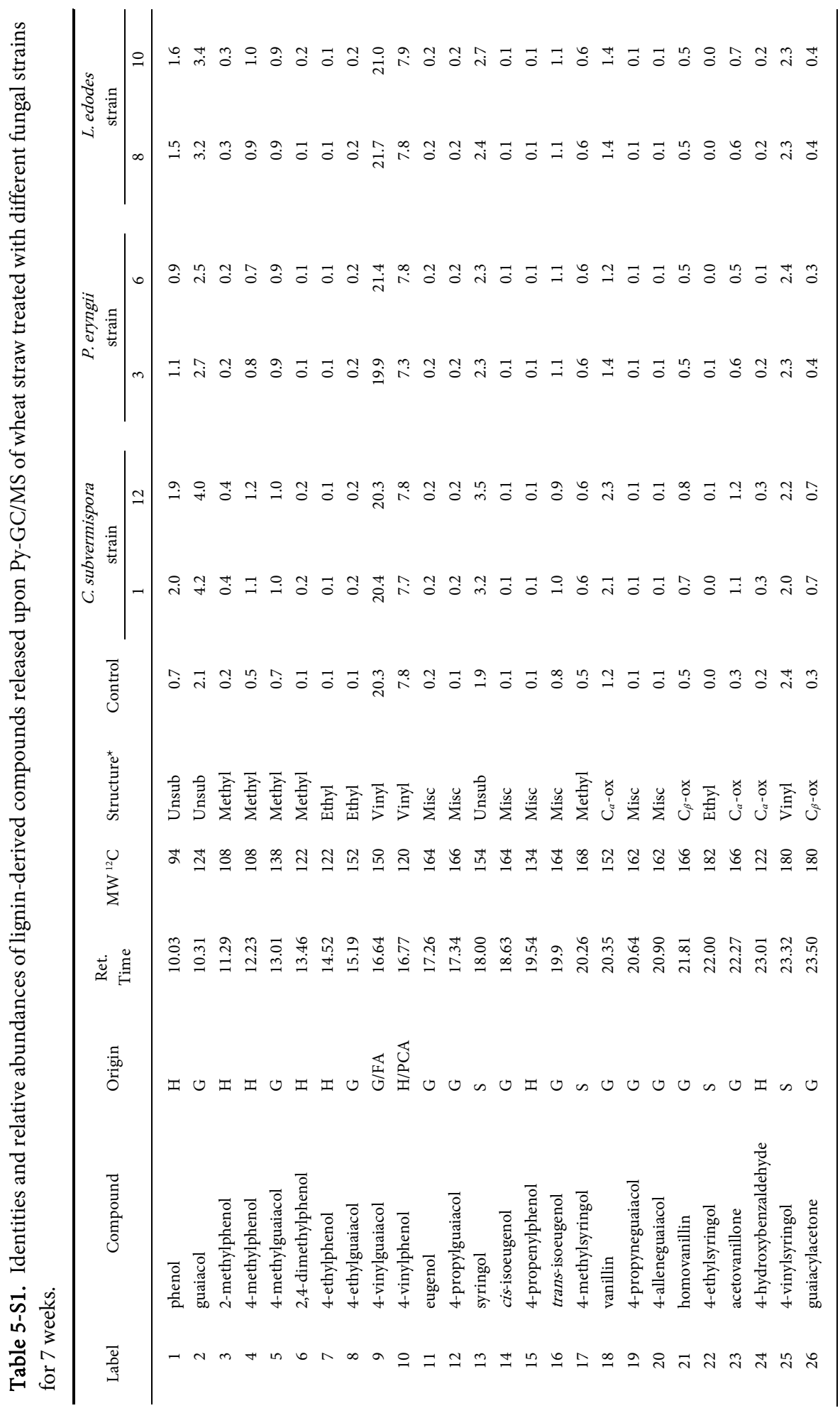


Chapter 5 | Different analytical methods of assessing cell wall

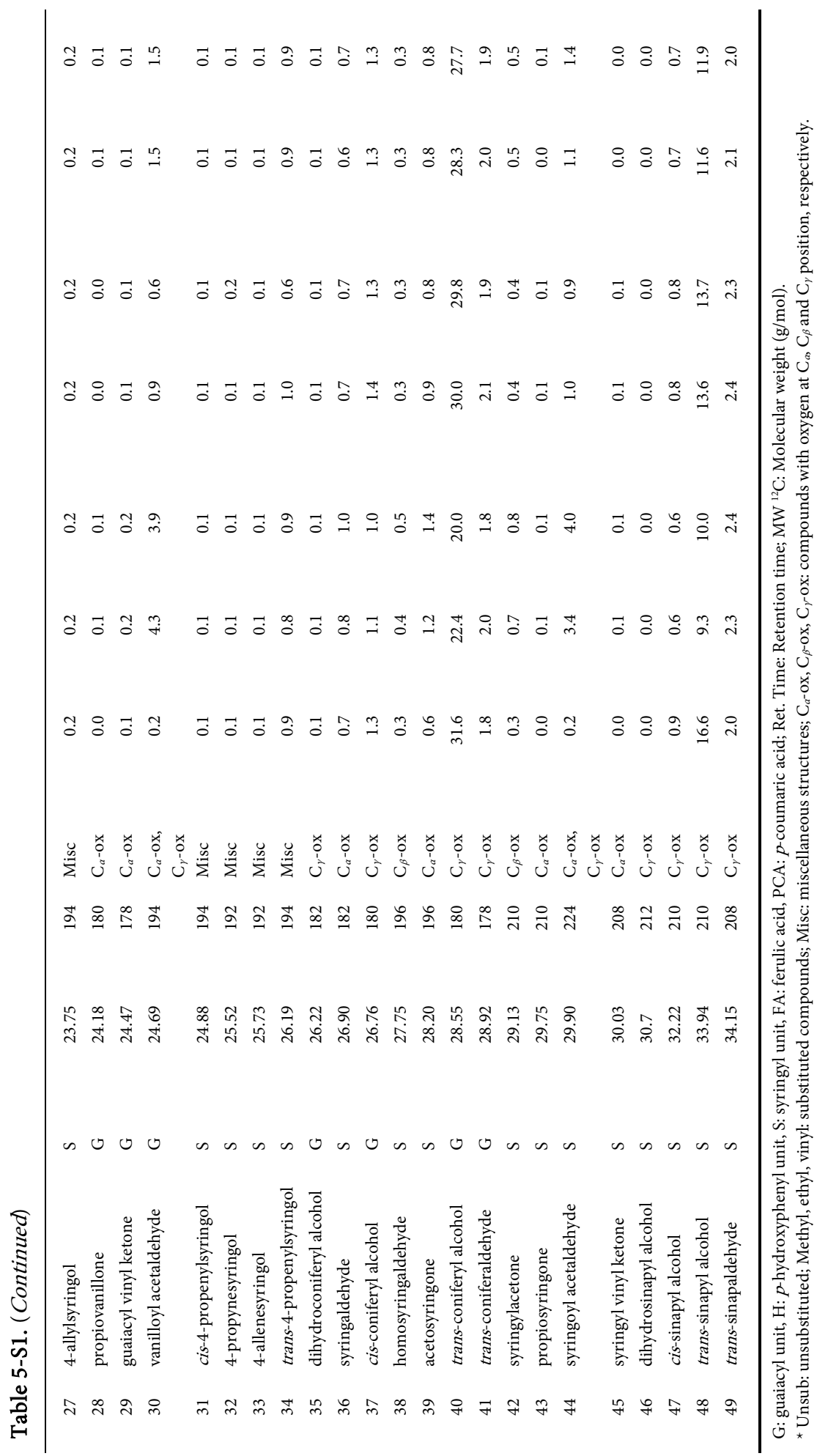


Chapter 5 | Different analytical methods of assessing cell wall 


\section{4}

The weak can never forgive. Forgiveness is the attribute of the strong.

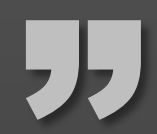

- MAHATMA GANDHI 


\section{Mechanistic insight in the selective} delignification of wheat straw by three white-rot fungal species through

\section{quantitative ${ }^{13} \mathrm{C}-$ IS Py-GC/MS and whole cell wall HSQC-NMR}

Gijs van Erven ${ }^{1}$, Nazri Nayan ${ }^{2}$, Anton S.M. Sonnenberg ${ }^{3}$, Wouter H. Hendriks ${ }^{2}$, John W. Cone ${ }^{2}$ and Mirjam A. Kabel ${ }^{1}$,

Biotechnol. Biofuels (2018). 11(262):1-16.

1 Laboratory of Food Chemistry, Wageningen University \& Research, Bornse Weilanden 9, 6708 WG Wageningen, The Netherlands

2 Animal Nutrition Group, Wageningen University, De Elst 1, 6708 WD Wageningen, the Netherlands

3 Plant Breeding, Wageningen University and Research, Droevendaalsesteeg 1, 6708 PB Wageningen, the Netherlands 


\section{ABSTRACT}

The white-rot fungi Ceriporiopsis subvermispora (CS), Pleurotus eryngii(PE) and Lentinula edodes (LE) have been shown to be high-potential species for selective delignification of plant biomass. This delignification improved polysaccharide degradability, which currently limits the efficient lignocellulose conversion into biochemicals, biofuels and animal feed. Since selectivity and time-efficiency of fungal delignification still needs optimization, detailed understanding of the underlying mechanisms at molecular level is required. The recently developed methodologies for lignin quantification and characterization now allow the in-depth mapping of fungal modification and degradation of lignin and thereby enable resolving of the underlying mechanisms.

Wheat straw treated by two strains of CS (CS1 and CS12), PE (PE3 and PE6) and LE (LE8 and LE10) was characterized by using semi-quantitative Py-GC/MS during fungal growth (1, 3 and 7 weeks). The remaining lignin after 7 weeks was quantified and characterized by using ${ }^{13} \mathrm{C}$ lignin internal standard based Py-GC/MS and whole cell wall HSQC NMR. Strains of the same species showed similar patterns of lignin removal and degradation. CS and LE outperformed PE in terms of extent and selectivity of delignification $(\mathrm{CS} \geq \mathrm{LE}>>\mathrm{PE})$. The highest lignin removal $(66 \% \mathrm{w} / \mathrm{w}$; CS1) was obtained after 7 weeks, without extensive carbohydrate degradation (factor 3 increased carbohydrate/lignin ratio). Further, though after treatment with CS and LE comparable amounts of lignin remained, the structure of the residual lignin vastly differed. For example, $\mathrm{C}_{\alpha}$-oxidized substructures accumulated in CS-treated lignin by up to $24 \%$ of total aromatic lignin, a factor two higher than in LE-treated lignin. Contrarily, ferulic acid substructures were preferentially targeted by LE (and PE). Interestingly, PE-treated lignin was specifically depleted in tricin (40\% reduction). The overall subunit composition (H:G:S) was not affected by fungal treatment.

CS and LE are both able to effectively and selectively delignify wheat straw, though the underlying mechanisms are fundamentally different. We are the first to identify that $\mathrm{CS}$ degrades the major $\beta$-O-4 ether linkage in grass lignin mainly via $\mathrm{C}_{\beta^{-}} O$-aryl cleavage, while $\mathrm{C}_{\alpha}-\mathrm{C}_{\beta}$-cleaved products accumulated for LE. Our research provides new insight on how fungi degrade lignin, which contributes to further optimizing the biological upgrading of lignocellulose. 
Keywords: Ceriporiopsis subvermispora, Lentinula edodes, Pleurotus eryngii, selectivity, lignin degradation, lignin quantification, $\mathrm{C}_{\alpha}$-oxidation, ligninolytic enzymes

\section{INTRODUCTION}

Tignocellulosic biomass, such as wheat straw or corn stover, is a valuable source of Upolysaccharides for the production of animal feed or biofuels and biochemical (Buranov and Mazza, 2008; Isroi et al., 2011; Isikgor and Becer, 2015). The presence of lignin, however, hinders the conversion of these polysaccharides and, therefore, necessitates the use of pre-treatments aiming at lignin removal or degradation. These physical and/or chemical hydrothermal pre-treatments require extensive amounts of energy and chemicals (Behera et al., 2014). A sustainable alternative is the use of whiterot fungi as biological pre-treatment and is increasingly receiving attention (Keller et al., 2003; Isroi et al., 2011; Tian et al., 2012; Van Kuijk et al., 2015a; Sindhu et al., 2016). Among these fungi, the species Ceriporiopsis subvermispora(CS), Pleurotus eryngii(PE) and Lentinula edodes (LE) are particularly promising as they selectively removed lignin over cell wall polysaccharides. This results in a greatly enhanced enzymatic degradability of polysaccharides in further downstream processes (Van Kuijk et al., 2015b; Van Kuijk et al., 2017; Nayan et al., 2018). To optimize the pretreatment with these fungi, mainly regarding selectivity and time-efficiency, it is important to understand delignification and the underlying mechanisms at molecular level. Such mechanistic insight facilitates the pinpointing of potential bottlenecks in the (enzymatic) process and might provide means to circumvent them, e.g. via supplementation of co-factors for the respective enzymes. Besides enabling control of the pre-treatment process, mechanistic insight expands our understanding of how fungi function in nature and how they contribute to terrestrial carbon-recycling.

Lignin is a heterogeneous phenolic polymer that, in grasses, is composed of $p$ hydroxyphenyl $(\mathrm{H})$, guaiacyl $(\mathrm{G})$ and syringyl (S) subunits, which are linked through a variety of carbon-carbon and aryl-ether linkages, with the $\beta$ - $O$-4 ether as most abundant inter-unit linkage ( 80\%) (Ralph et al., 2009a; Vanholme et al., 2010; Del Río et al., 2012). Structural complexity of grass-type lignin is further enhanced by the incorporation of $p$ - 
coumaric acid, ferulic acid and tricin in the macromolecule (Ralph 2010; Lan et al., 2015; Li et al., 2016). A schematic structure of wheat straw lignin is presented in Fig. 6.1.

Lignin degradation by white-rot fungi in general relies on a complex enzymatic machinery which is, depending on the species, mainly based on lignin peroxidases ( $\mathrm{LiP}$ ), manganese peroxidases $(\mathrm{MnP})$, laccases ( $\mathrm{Lac})$ and the $\mathrm{H}_{2} \mathrm{O}_{2}$ generating aryl-alcohol oxidases (AAO). Collectively, the catalytic performance of these enzymes results in the generation of radicals, i.e. aromatic or hydroxyl radicals, which can lead to various reactions such as $\mathrm{C}_{\alpha}-\mathrm{C}_{\beta}$ cleavage, breakdown of the $\beta$ - $O-4$ ether, aromatic ring cleavage

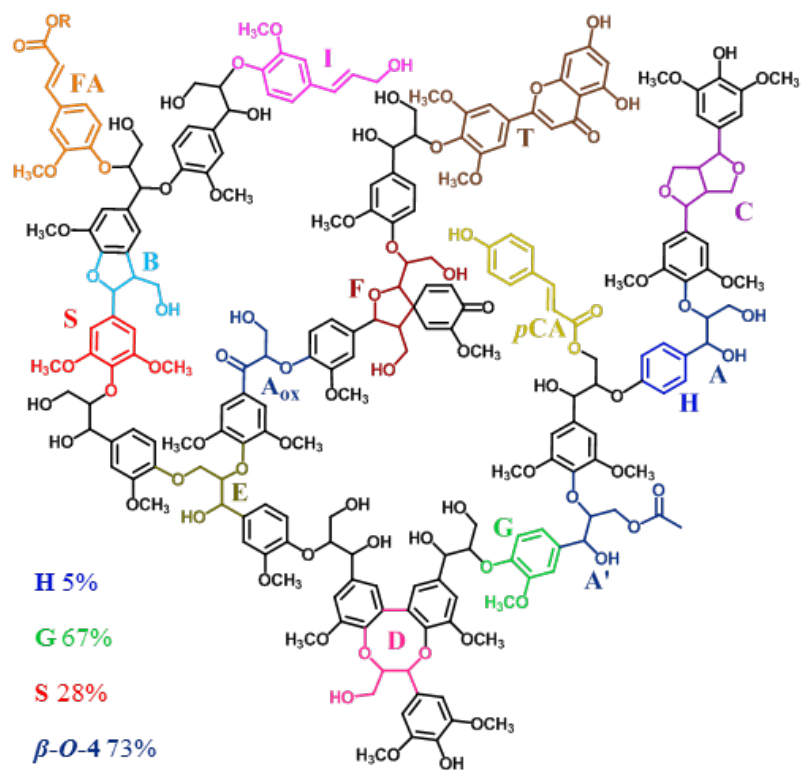

Fig. 6.1 Wheat straw lignin model including the most abundant substructures attempting to fairly represent the relative abundances of each moiety, based on literature (Ralph et al., 2009a; Ralph 2010; Vanholme et al., 2010; Del Río et al., 2012; Lan et al., 2015; Li et al., 2016). Values in the figure are calculated from the structure drawn (excluding $p \mathrm{CA}, \mathrm{FA}$ and $\mathrm{T}$ ). $\mathrm{H}: p$-hydroxyphenyl unit; $\mathrm{G}$ : guaiacyl unit; $\mathrm{S}$ : syringyl unit; $\mathrm{A}: \beta$ - $O$-4'alkyl-aryl ether; $\mathrm{A}^{\prime}: \beta$ - $O$-4'alkyl-aryl ether $\gamma$-acylated; $\mathrm{A}_{\mathrm{ox}}$ : $\beta$-O-4'alkyl-aryl ether $\mathrm{C}_{\alpha}$-oxidized; $\mathrm{B}$ : phenylcoumaran; $\mathrm{C}$ : resinol; $\mathrm{D}$ : dibenzodioxocin; $\mathrm{E}: \alpha, \beta$ diarylether; F: spirodienone; I: cinnamyl alcohol (or aldehyde); T: tricin; $p C A$ : $p$-coumarate; FA: ferulate ( $\mathrm{R}=\mathrm{H}$ or arabinose). Note that $\gamma$-acylation here is only shown on $\beta$-O-4 linkages, while in fact any free $\gamma-\mathrm{OH}$ can by acylated. For simplicity only monomeric FA is shown, though many diferulate linkages are known to exist. For more detailed structures see Fig. 6.5. 
and demethoxylation, but also to polymerization (Ten Have and Teunissen 2001; Martínez et al., 2005; Hatakka and Hammel 2011; Hernández-Ortega et al., 2012; Camarero et al., 2014).

Although CS, PE and LE all produce MnP, Lac and AAO, they differ in the number of genes encoding for these enzymes, which suggests different dependencies on the particular enzymes (Nagai et al., 2007; Fernandez-Fueyo et al., 2012; Yang et al., 2016; Park et al., 2017; Sakamoto et al., 2017). Interestingly, none of these fungi possess genes encoding for LiP. Instead, versatile peroxidases were detected in PE, whereas CS was shown to produce two enzymes with lignin peroxidase and versatile peroxidase like activity (Fernández-Fueyo et al., 2012; Yang et al., 2016). It is clear from this variation in ligninolytic enzyme encoding genes that these fungi employ different strategies for delignification. However, whether these different strategies emerge into different underlying mechanisms remains unknown. Furthermore, it is poorly understood whether certain structural motifs of lignin are preferentially degraded or modified by the respective enzymatic machineries and, thus, lead to different residual lignin structures (Martínez et al., 2005; Hatakka and Hammel 2011).

To the best of our knowledge, research on the conversion of grass lignin is limited (Camarero et al., 1994; Crestini et al., 1998; Martínez et al., 2001), and studies where the fungi were compared under the same experimental conditions are scarce (Dorado et al., 1999; Van Kuijk et al., 2015b; Van Kuijk et al., 2017). Furthermore, lignin degradation was, content-wise, only determined by using unspecific gravimetric analysis, which is thought to be particularly inaccurate for fungal-grown samples due to the presence of residual chitin and includes recalcitrant lignin only (Martínez et al., 2005; Jurak et al., 2015). Moreover, the scarce studies aiming at elucidating structural features of fungaltreated lignin in situ focused on using qualitative pyrolysis gas chromatography mass spectrometry (Py-GC/MS). Though considerable structural changes in fungal-treated wheat straw lignin could be revealed, mainly in terms of preference for phenolic lignin substructures and accumulation of $\mathrm{C}_{\alpha}$-oxidized substructures, underlying mechanisms could not be elucidated (Camarero et al., 1994; Van Kuijk et al., 2015b; Van Kuijk et al., 2017). More accurate and in-depth analysis of both lignin content as well as lignin structural features in fungal-treated biomass is expected to further resolve the employed lignin degrading mechanisms.

The recent development of a highly accurate pyrolysis gas chromatography mass spectrometry (Py-GC/MS) method that uses ${ }^{13} \mathrm{C}$ lignin as internal standard $\left({ }^{13} \mathrm{C}\right.$-IS) offers a great opportunity to specifically quantify residual lignin content in situ, while 
simultaneously providing structural insight (Van Erven et al., 2017). In addition, developments in the use of heteronuclear single quantum coherence (HSQC) nuclear magnetic resonance (NMR) allow the analysis of whole cell wall samples in situ, without prior isolation or derivatisation of lignin (Kim et al., 2008; Mansfield et al., 2012). In situ analysis avoids the need for laborious lignin isolation procedures that may lead to partial extraction and polymer modification, especially for fungal-treated lignin (Björkman 1956; Kirk and Chang 1974; Chang et al., 1975).

In this research, the combination of quantitative ${ }^{13} \mathrm{C}-\mathrm{IS}$ Py-GC/MS and whole cell wall HSQC NMR was applied to fungal-treated wheat straw after growth of two strains of CS, PE and LE to obtain a better understanding of their delignification mechanisms. We found that both CS and LE outperform PE in terms of delignification effectivity and selectivity and, furthermore, vastly differed in residual lignin structures. We were able to identify that these lignin structures originated from fundamentally different delignification mechanisms, which is discussed in genomic context.

\section{MATERIALS AND METHODS}

\section{Materials}

All chemicals were obtained from commercial suppliers and used without further purification. Water used in all experiments was purified via a Milli-Q water system (Millipore, Billerica, MA, USA).

\section{Preparation of the fungal-treated wheat straw}

Samples used in the present study were collected from a main experiment on selecting the best performing fungal strains based on their capability to improve the in vitro ruminal degradability of the treated straw (Nayan et al., 2018). Two high potential strains from three different fungal species were selected: CS1 (CBS 347.63) and CS12 (ME-485) strains for Ceriporiopsis subvermispora, PE3 (Mycelia2600) and PE6 (AL04) for Pleurotus eryngii and LE8 (sh 03/08) and LE10 (LE75) for Lentinula edodes. Procedures for fungal strains preparation and pretreatment of the wheat straw has been previously described in detail (Nayan et al., 2017). Briefly, all strains were maintained on malt extract agar before a piece of that agar $(1.5 \times 2.0 \mathrm{~cm})$ was used to prepare the spawn for each fungus. The spawn was prepared using sterilized sorghum grains and was incubated at $24^{\circ} \mathrm{C}$ for up to 5 weeks. Organic wheat straw (Triticum aestivum L.) was purchased from a local farmer in the Netherlands and chopped into pieces of 
approximately $3 \mathrm{~cm}$. The wheat straw was soaked in water for 3 days at room temperature and excess water was drained for $5 \mathrm{~h}$. Each container $(185 \times 185 \times 78 \mathrm{~mm}$, Combiness, Nevele, Belgium) was adjusted to contain $90.2 \pm 0.3 \mathrm{~g}$ of dry matter with a moisture content of $\sim 74 \% \mathrm{w} / \mathrm{w}$. After autoclaving at $121^{\circ} \mathrm{C}$ for $1 \mathrm{~h}$, the straw was inoculated with the prepared spawn at $10 \%$ of the dry weight. The wheat straw (treated and untreated with fungi) was incubated in triplicate under solid state fermentation at $24^{\circ} \mathrm{C}$ in a climatecontrolled chamber (relative humidity $\sim 75 \%$ ) for 1,3 and 7 weeks. All samples were freeze-dried and ground over a $1 \mathrm{~mm}$ sieve using a cross beater mill (100AN, Peppink, Olst, the Netherlands). Since biological triplicates showed $<5 \%$ RSD in conventional compositional feed analysis, they were thoroughly mixed in equal dry matter amounts to one replicate and ball-milled in a MM200 mixer mill (Retsch, Haan, Germany) for further analyses (Nayan et al., 2018). We previously showed that untreated straws were stable during incubation and showed minimal variation (Nayan et al., 2017). Therefore, the untreated wheat straw without incubation was used as control sample in this study.

\section{Carbohydrate content and composition}

Carbohydrate content and composition was determined in duplicate by a modified method, using inositol as internal standard (Englyst and Cummings 1984). Samples were treated with $72 \%$ (w/w) $\mathrm{H}_{2} \mathrm{SO}_{4}$ for $1 \mathrm{~h}$ at $30^{\circ} \mathrm{C}$ followed by $1 \mathrm{M} \mathrm{H}_{2} \mathrm{SO}_{4}$ for $3 \mathrm{~h}$ at $100{ }^{\circ} \mathrm{C}$. The constituent monosaccharides released were analyzed as their alditol-acetate derivatives by using gas chromatography (Thermo Scientific, Synnyvale, CA, USA) and represented as anhydromonosaccharides. The uronic acids released after acid the hydrolysis step were determined in duplicate as anhydrouronic acid content by an automated meta-hydroxydiphenyl assay with addition of sodium tetraborate using an auto-analyzer (Skalar Analytical BV, Breda, The Netherlands) (Blumenkrantz and AsboeHansen 1973). Glucuronic acid (Fluka AG, Busch, Switzerland) was used as a reference $\left(0-100 \mu \mathrm{g} \mathrm{ml}^{-1}\right)$. Total carbohydrate content was calculated as the sum of neutral anhydrocarbohydrates and anhydrouronic acids.

\section{Semi-quantitative Py-GC/MS}

Pyrolysis was performed with an EGA/PY-3030D Multi-shot pyrolyzer (Frontier Laboratories, New Ulm, MN, USA) equipped with an AS-1020E Autoshot auto-sampler as previously described (Jurak et al., 2015; Van Erven et al., 2017). The pyrolyzer was coupled to GC-MS using a Trace GC equipped with a DB-1701 fused-silica capillary column (30 m $\times 0.25 \mathrm{~mm}$ i.d. $0.25 \mu \mathrm{m}$ film thickness) coupled to a DSQ-II mass 
spectrometer (both Thermo Scientific, Waltham, MA, USA). Samples were weighed using a XP6 excellence-plus microbalance (Mettler Toledo, Columbus, OH, USA). Pyrolysis of total biomass $(\sim 80 \mu \mathrm{g})$ was performed at $500{ }^{\circ} \mathrm{C}$ for $1 \mathrm{~min}$ with an interface temperature of $300{ }^{\circ} \mathrm{C}$. Pyrolysis products were injected on the column via split/splitless injection (at $250{ }^{\circ} \mathrm{C}$ ) with a splitratio of 1:133 and helium was used as carrier gas with constant flow at $1.5 \mathrm{ml} \cdot \mathrm{min}^{-1}$. The GC oven was programmed from $70{ }^{\circ} \mathrm{C}(2 \mathrm{~min})$ to $270{ }^{\circ} \mathrm{C}$ at $5{ }^{\circ} \mathrm{C} \cdot \mathrm{min}^{-1}$ and held at $270{ }^{\circ} \mathrm{C}$ for $15 \mathrm{~min}$. MS detection was used with $\mathrm{EI}$ at $70 \mathrm{eV}$, a source temperature of $250{ }^{\circ} \mathrm{C}$, a scan range of $\mathrm{m} / \mathrm{z} 50-550$ and a scan rate of 4.0 scans $\mathrm{s}^{-1}$. Compounds were identified by comparing retention time and mass spectrum with standards, the NIST library and data published by Ralph and Hatfield (1991).

For semi-quantitative analysis, pyrograms were processed by Xcalibur 2.2 software. The two most abundant fragments per compounds were automatically integrated using ICIS peak integration with optimized settings per compound. A manual correction was only applied when irregular peak shapes led to erroneous peak integration with method settings. Areas were normalized by dividing by corresponding relative response factors, as previously published, multiplied with the molecular weight of the respective compound and summed (Van Erven et al., 2017). Lignin content was estimated on the basis of total area of lignin-derived pyrolysis products and compared to a wheat straw reference sample with known Klason lignin content (acid-insoluble lignin + acid-soluble lignin $=20.5 \%$ w/w), as described by Jurak et al. (2015). Relative abundances of lignin-derived pyrolysis products were based on areas without molecular weight correction as previously described by Del Río et al. (2012), as RRF values are mole-based (Del Río et al., 2012). Compounds were classified according to their structural features (Supporting Information Table 6-S1) and summed. All samples were prepared and analyzed in triplicate.

\section{Quantitative Py-GC/MS with ${ }^{13} \mathrm{C}$ lignin as internal standard}

Pyrolysis was carried out as previously described in detail and in the section semiquantitative Py-GC/MS (Van Erven et al., 2017). Briefly, $10 \mu \mathrm{l}$ of a ${ }^{13} \mathrm{C}$ lignin internal standard (IS) solution ( $1 \mathrm{mg} \mathrm{ml}^{-1}$ ethanol/chloroform 50:50 v/v) was mixed with $\sim 80 \mu \mathrm{g}$ of sample and dried before analysis. Lignin-derived compounds of which fungal action increased the content above detection limits were identified by qualitative Py-GC/MS using full-MS detection and added to the existing SIM method. Lignin-derived pyrolysis products were monitored in selected ion monitoring (SIM) mode on the two most abundant fragments per compound (both ${ }^{12} \mathrm{C}$ and ${ }^{13} \mathrm{C}$ ). The compound vanilloyl 
acetaldehyde (VAL) was not properly detected in SIM due to a shifted segment and therefore was estimated from full MS analysis. The relative area of VAL versus vanillin as measured by full MS was thereto multiplied by the area of vanillin as measured by SIM. For correction of matrix-effects similar behavior as syringoyl acetaldehyde (SAL) was assumed. Areas for each compound were normalized by dividing by the respective relative response factor (RRF). RRF values were updated to system performance by recalculation to obtain an identical relative abundance of lignin-derived pyrolysis products of the ${ }^{13} \mathrm{C}$ IS added to a wheat straw reference sample. Lignin content $(\%, w / w)$ was determined on the sum of lignin-derived pyrolysis products, where RRF corrected areas for each compound were multiplied with the molecular weight of the respective compound and summed instead of the application of the published correction factor of 1.057 (Van Erven et al., 2017). Areas were not corrected for molecular weight before relative abundance determination as previously described by Del Río et al. (2012), to allow direct comparison with data obtained by 2D-NMR analysis. Relative abundances of lignin-derived pyrolysis products were normalized for the ${ }^{13} \mathrm{C}$ analogues from the IS present in the same sample to distinguish matrix and treatment effects. Compounds were classified according to their structural feature (Supporting Information Table 6-S1) and summed. All samples were prepared and analyzed in triplicate. Extractive-free samples were identical to total biomass samples for CS1 and therefore not measured for the other fungi.

\section{Whole cell wall 2D HSQC NMR spectroscopy}

For NMR analysis of the whole cell wall material, ground wheat straw $(1 \mathrm{~mm})$ was successively extracted with acetone until the solvent became clear; followed by hot water treatment $\left(100^{\circ} \mathrm{C}\right)$ for $3 \mathrm{~h}$. The extractive-free samples were then freeze-dried before mixing biological replicates and fine milling in a PM100 planetary ball mill (Retsch, Haan,

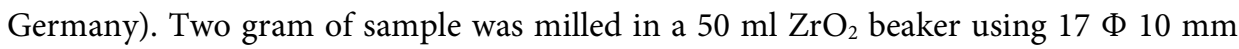
balls of the same material at a frequency of $600 \mathrm{rpm}$ with a net milling time of $4 \mathrm{~h}$. After every 15 min of milling a pause of $10 \mathrm{~min}$ was set to avoid overheating of the sample. Around $100 \mathrm{mg}$ of ball-milled sample was swollen in $0.75 \mathrm{ml}$ DMSO- $d_{6} .2 \mathrm{D}$ heteronuclear single quantum coherence (HSQC) NMR was performed according to previously described methods (Kim et al., 2008; Del Río et al., 2012; Mansfield et al., 2012). The spectra were recorded at $25^{\circ} \mathrm{C}$ with Bruker's standard pulse sequence "hsqcetgpsisp2.2" on a Bruker AVANCE III 600 MHz NMR spectrometer (Bruker BioSpin, Rheinstetten, Germany) equipped with a $5 \mathrm{~mm}$ cryo-probe located at MAGNEFY (Magnetic resonance facility, Wageningen, The Netherlands). The spectral widths were 7,200 and 30,000 Hz 
for the ${ }^{1} \mathrm{H}$ and ${ }^{13} \mathrm{C}$ dimensions, respectively. The number of collected complex points was 2018 in the ${ }^{1} \mathrm{H}$ dimension with a relaxation time of $1 \mathrm{~s}$. The number of collected scans was 16 and 400 increments of time were recorded in the ${ }^{13} \mathrm{C}$ dimension. The ${ }^{1} J_{\mathrm{CH}}$ used was 145 Hz.

The data was processed with Bruker TopSpin 3.5 software. Processing used were Gaussian apodization in ${ }^{1} \mathrm{H}$ and a squared cosine function in ${ }^{13} \mathrm{C}$ dimension. For ${ }^{13} \mathrm{C}$, data were zero filled up to 1024 points prior to Fourier transformation. The solvent peak $\left(\mathrm{DMSO}-d_{6}\right)$ was used as an internal reference $\left(\delta_{\mathrm{C}} 39.5 \mathrm{ppm} ; \delta_{\mathrm{H}} 2.49 \mathrm{ppm}\right)$. HSQC correlation peaks were assigned by comparison with literature (Ralph et al., 2009b; Villaverde et al., 2009; Rencoret et al., 2010; Yuan et al., 2011; Del Río et al., 2012; Del Río et al., 2015; Rencoret et al., 2017; Das et al., 2018). Semi-quantitative analysis of the volume integrals was performed according to Del Río et al. (2012) (Del Río et al., 2012). Alternatively, in the aliphatic oxygenated region $\beta-O-4$ substructures were estimated from their $\mathrm{C}_{\beta}-\mathrm{H}_{\beta}$ correlations, since they were shown to be interfered to a lesser extent by the presence of carbohydrates (Mansfield et al., 2012). For phenylcoumaran and resinol substructures their respective $\mathrm{C}_{\alpha}-\mathrm{H}_{\alpha}$ correlations were used. Volume integrals for resinol substructures were logically halved. $S_{2,6}, G_{2}$ and $H_{2,6}$ signals were used for $S, G$ and $H$ units, respectively, where $\mathrm{S}$ and $\mathrm{H}$ integrals were halved as well. Oxidized analogues were estimated in a similar manner. Tricin, $p C A$ and FA were similarly estimated from their respective $\mathrm{T}_{2,6}, \mathrm{CA}_{2,6}$ and $\mathrm{FA}_{2}$ signals. Volume integration was performed at equal contour levels. Amounts were calculated both as a percentage of total lignin $\left(\mathrm{H}+\mathrm{G}+\mathrm{G}_{\mathrm{ox}}\right.$ $+\mathrm{G}_{\text {mod }}+\mathrm{S}+\mathrm{S}_{\text {ox }}+\mathrm{S}_{\text {mod }}$ ) and total lignin including $p C A$, FA and $\mathrm{T}$ (Sette et al., 2011; Wen et al., 2013).

\section{RESULTS AND DISCUSSION}

\section{Wheat straw delignification during fungal growth}

The extent of wheat straw delignification during growth of the different fungal strains was monitored by semi-quantitative Py-GC/MS (Fig. 6.2). This technique is not interfered by fungal cell wall material and the entire lignin population is measured (Martínez et al., 2005; Jurak et al., 2015). In comparison to conventional gravimetric analysis, semiquantitative Py-GC/MS, therefore, is considered to provide more accurate insight in the delignification characteristics of the studied fungi. Clear lignin removal was observed 


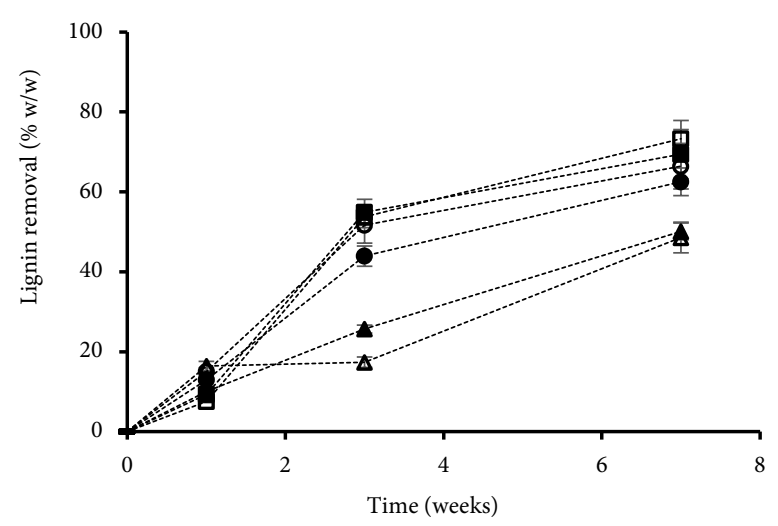

Fig. 6.2. Semi-quantitative Py-GC/MS determination of lignin removal from wheat straw during growth (1, 3 and 7 weeks) of C. subvermispora (CS), P. eryngii (PE) and L. edodes (LE) strains. $\mathrm{CS} 1, \boldsymbol{\mathrm { CS }} 12, \triangle \mathrm{PE} 3, \boldsymbol{\Delta} \mathrm{PE} 6, \mathrm{OLE} 8, \bullet \mathrm{LE} 10$. Average and standard deviation of triplicates.

from the first week of growth and all strains extensively delignified the wheat straw within 7 weeks. CS and LE were the most effective species, which is in line with the initial evaluation of these fungi by conventional compositional feed analysis (Nayan et al., 2018). Not only were CS and LE more effective, compared to PE, they also showed a distinct pattern of lignin removal in time. For CS and LE the major part ( $>70 \%)$ of the final lignin removal occurred within the first 3 weeks, whereas both PE strains showed a more gradual lignin removal in time, reaching less than $50 \%$ of the final lignin removal within 3 weeks. No significant differences were found in the extent of lignin removal after 7 weeks of growth between strains of the same species.

Though semi-quantitative Py-GC/MS clearly proved useful for the comparison of the delignification efficiency of the different fungi, we thrived for more accurate and precise quantification and characterization of the residual lignin. At the end-point of the treatment ( 7 weeks) the wheat straw was most affected by fungal growth and, for that reason, considered the most informative to further investigate the underlying delignification mechanisms (Van Kuijk et al., 2016b; Van Kuijk et al., 2017). Therefore, lignin in fungal-treated wheat straw after 7 weeks of growth was quantified by the recently developed quantitative ${ }^{13} \mathrm{C}$-IS Py-GC/MS method (Van Erven et al., 2017). In this method, a ${ }^{13} \mathrm{C}$ lignin internal standard is incorporated to correct for matrix effects and system performance, which was previously shown to improve the accuracy of lignin quantification in sound biomass samples (Van Erven et al., 2017). From the total dry 
matter recovered and lignin contents in the treated material, the amount of lignin removed was calculated and is presented in Fig. 6.3.

Although semi-quantitative Py-GC/MS gave fair estimates of lignin removal (Fig. 6.2), the method overestimated lignin removal in all samples by approximately $15 \%$, mainly due to overestimation of the lignin content of the starting material (Supporting Information Table 6-S2). The results of quantitative Py-GC/MS confirmed the effectiveness of CS, LE and PE in degrading lignin, where in the case of CS and LE more than $60 \% \mathrm{w} / \mathrm{w}$ of lignin was removed from the wheat straw within 7 weeks of treatment. The three fungal species, furthermore, were capable of removing lignin highly selectively over cell wall carbohydrates (Fig. 6-S1 and 6-S2). After 7 weeks of growth PE strains were found to have degraded significant amounts of glucan ( $8 \% \mathrm{w} / \mathrm{w}$ of initial glucan), whereas CS and LE left glucan less affected. Instead, these species degraded glucuronoarabinoxylan (GAX), but to a lesser extent than lignin. CS1 showed a remarkably higher degradation of GAX than CS12 (21 vs 5\% w/w of initial GAX), while both LE strains degraded approximately $12 \% \mathrm{w} / \mathrm{w}$ of initial GAX. The selective removal of lignin over carbohydrates has been described in previous studies for the three fungi used. Though, more extensive hemicellulose degradation has been reported (Nayan et al., 2017; Van Kuijk et al., 2017; Nayan et al., 2018). This is due to the gravimetrical method that was used, in which solubilization and removal cannot be discriminated.

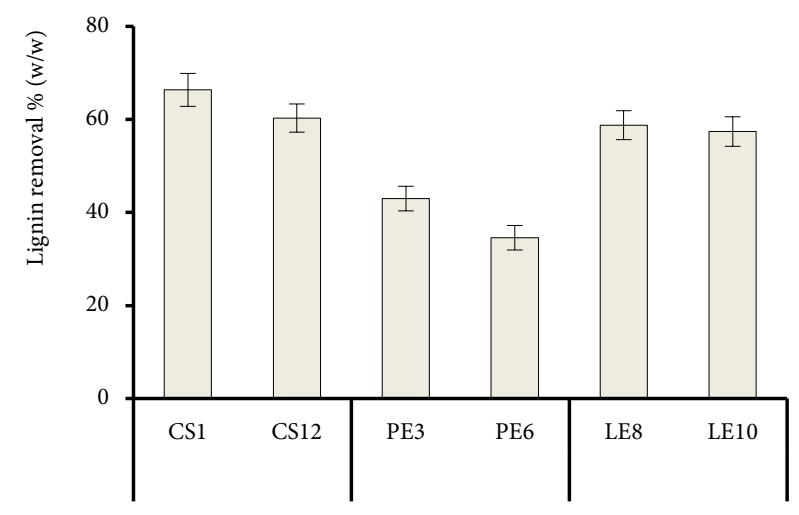

Fig. 6.3 Quantitative ${ }^{13} \mathrm{C}-\mathrm{IS}$ Py-GC/MS determination of lignin degradation in wheat straw after 7 weeks of fungal growth. CS Ceriporiopsis subvermispora, PE Pleurotus eryngii, LE Lentinula edodes. Average and standard deviation of triplicates. 
Based on absolute amounts of remaining polymers, the selectivity of lignin removal over glucan and GAX was the highest for CS, followed by LE and PE. In addition to the effectiveness of lignin removal, CS and LE, thus, also seem to outperform PE in terms of selectivity.

\section{Structural features of fungal treated lignin}

Besides accurate lignin content, quantitative ${ }^{13} \mathrm{C}$-IS Py-GC/MS simultaneously provided accurate insight in the structural features of lignin (Van Erven et al., 2017). The use of a ${ }^{13} \mathrm{C}$-IS lignin ensured that the observed changes in the residual lignin could indeed be ascribed to fungal action. The same samples were also subjected to 2D-HSQC NMR analysis allowing comparison with the ${ }^{13} \mathrm{C}$-IS Py-GC/MS data, which is discussed further on. Table 6.1 shows the relative abundances of the structural features of lignin of untreated and treated wheat straw. The bases of structural classification and relative abundances of individual lignin-derived pyrolysis products can be found in Supplementary Information Table 6-S1. The structural features of the untreated straw matched well with that of wheat straw that was previously analyzed in a similar manner, which confirmed that a representative wheat straw sample was used in our study (Van Erven et al., 2017).

Unexpectedly, fungal treatment was found to minimally affect the overall composition of lignin subunits, with the largest effect observed for LE8 (H:G:S = 11:64:25) as compared to control (H:G:S = 10:62:28), which indicated that all lignin units were targeted in the process of lignin degradation. Although minimal, all fungi except CS12, showed a preference towards the removal of $\mathrm{S}$ units (over $\mathrm{H}$ - and G-units), as demonstrated by slightly lowered S/G ratios (e.g. 0.45 to 0.38 by LE8; Table 6.1). This preference was less pronounced compared to a previous study, where a factor 2 decrease in S/G ratio was found within 8 weeks of treatment by both CS and LE (Van Kuijk et al., 2016b; Van Kuijk et al., 2017). The main difference is the higher S/G ratio of the wheat straw used in the previous study $(S / G=0.7)$, compared to our wheat straw $(S / G=0.45)$. Hence, the most likely explanation of the lower S/G preference in our study was the difference in wheat straw used, which differed not only in the overall subunit composition, but might also have differed in the way these subunits were linked.

Preferential degradation of (sub-)structures with a higher degree of methoxylation has been related to: (1) a lower redox potential and (2) a reduced frequency of carbon- 


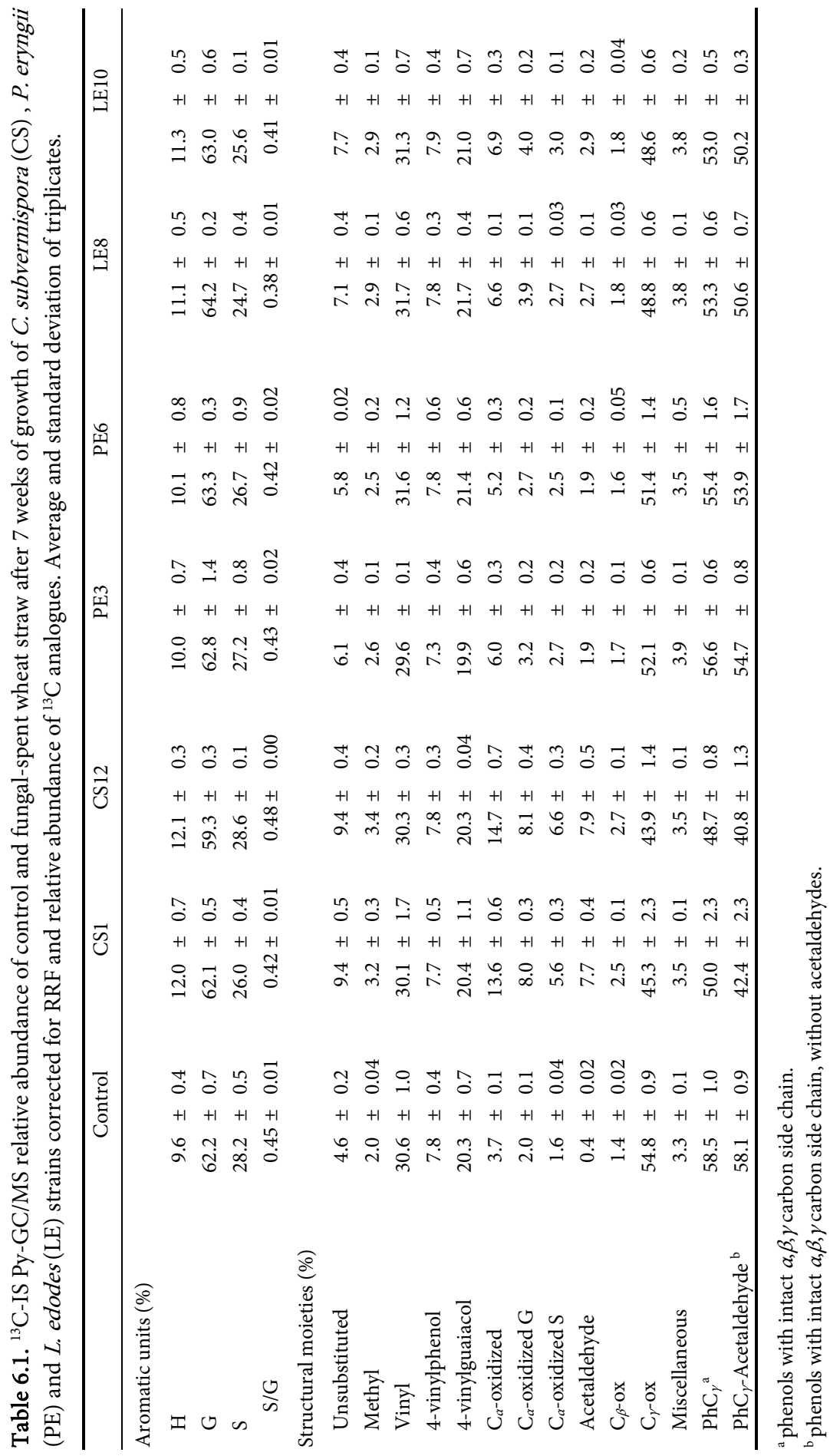


carbon ('condensed') substructures (Martínez et al., 2001; Del Río et al., 2002; van Kuijk et al., 2016b; Van Kuijk et al., 2017). Still, as mentioned above, CS, PE and LE did not show a clear preference for degrading the more methoxylated S-units over G-and H-units in our research. Demethoxylation, due to which S units 'transform' into G units, and likewise $\mathrm{G}$ units into $\mathrm{H}$ units, is known to occur due to fungal action, and might, however, potentially have masked the preferential removal of certain subunits (Martínez et al., 2005; Camarero et al., 2014).

When categorized according to structural moiety, clear effects of fungal growth on residual lignin structures were observed (Table 6.1). Most pronounced was the increase of unsubstituted and $\mathrm{C}_{\alpha}$-oxidized pyrolysis products at the expense of products with three carbons in the side-chain $\left(\mathrm{PhC}_{\gamma}\right)$ in fungal-treated straw. The relative abundances of these moieties greatly varied across species, with the CS strains showing the highest increases in unsubstituted (two-fold) and $\mathrm{C}_{a}$-oxidized (five-fold) substructures as compared to untreated wheat straw. Again, minimal differences were found between strains of the same species. These observations are in line with previous Py-GC/MS studies on fungaltreated biomass and have been suggested to indicate degradation of inter-unit linkages within the lignin macromolecule (Del Río et al., 2002; Choi et al., 2006; Van Kuijk et al., 2016b; Van Kuijk et al., 2017). To add to these previous suggestions, we hypothesize that in particular the relative abundance of $\mathrm{PhC}_{\gamma}$ is a measure for the amount of intact interunit linkages present, which is substantiated by the NMR data shown below. To explain, it is well known that upon pyrolysis of lignin, the intact $(\beta-O-4)$ inter-unit linkages, consisting of $\mathrm{C}_{\alpha}-\mathrm{C}_{\beta}-\mathrm{C}_{\gamma}$ aliphatic chains, decompose into products with various structures and chain-lengths (unsubstituted, $\mathrm{C}_{\omega}, \mathrm{C}_{\beta}$ and $\mathrm{C}_{\gamma}$ side-chains) (Ralph and Hatfield 1991). At the pyrolysis conditions applied in our study, secondary reactions are absent. Therefore, lignin pyrolysis mainly yields monomeric products that are a direct result of bond-cleavage (Patwardhan et al., 2011). Hence, the maximum chain length of the pyrolysis products equals the chain length of the substructures they originate from. $\mathrm{PhC}_{\gamma}$ products can, thus, only form from structures in which the three carbon side-chain was initially present, being mainly intact inter-unit linkages. Further, since the content of pendant cinnamyl alcohol and cinnamyl aldehyde end-groups in wheat straw was found to be rather low (Del Río et al., 2012; Zeng et al., 2013), their contribution to $\mathrm{PhC}_{\gamma}$ products is considered marginal.

Interestingly, for both $C$. subvermispora strains, the increase in $\mathrm{C}_{\alpha}$-oxidized pyrolysis products was for more than half determined by the two compounds vanilloyl acetaldehyde (VAL) and syringoyl acetaldehyde (SAL). These compounds are respectively 
$\mathrm{G}$ and S-unit derivatives with three carbons in the side-chain and a ketone at the $\mathrm{C}_{\alpha}$ position (Supporting Information Table 6-S1, Fig. 6-S3). Analogous to the explanation given above for $\mathrm{PhC}_{\gamma}$ products, we hypothesize that VAL and SAL solely formed from oxidized $\beta$ - $O-4$ linkages and/or their cleavage products of which the three carbon $(\alpha, \beta$ and $\gamma$ ) side chain remained intact. To challenge this hypothesis, it can be postulated that pyrolysis of tricin (Fig. 6.5) can result in SAL from the cleavage of the A-ring and rearrangement of the double bond. However, since we observed no SAL in the pyrograms of tricin-enriched extracts, tricin can be ruled out as potential (interfering) source of acetaldehyde products. If indeed acetaldehyde products originated from cleavage products of the inter-unit linkages, rather than oxidized $\beta-O-4$ linkages, they should be subtracted from the $\mathrm{PhC}_{\gamma}$ for a more fair representation of the intact inter-unit linkages ( $\mathrm{PhC}_{\gamma}$-acetaldehyde in Table 6.1). Our results, thus, suggest that fungal-treated lignin was considerably reduced in intact inter-unit linkages, in particular for CS strains $(-30 \%$ compared to control). As $\mathrm{C}_{\alpha}$-oxidized products greatly accumulated, this reduction in intact inter-unit linkages was likely caused by oxidative cleavage.

Semi-quantitative Py-GC/MS confirmed that the observed structures were a direct effect of lignin degradation, i.e. that they accumulated during fungal growth as lignin degradation proceeded (Supporting Information Fig. 6-S3). Intriguingly, though CS and LE followed a highly similar pattern of lignin degradation in time (Fig. 6.2), they vastly differed in the remaining lignin structures after their growth. To further substantiate these findings, we also assessed the residual lignin structures by whole cell wall 2D-NMR.

\section{D HSQC NMR of fungal-treated straw.}

Sample preparation for in situ whole cell wall gel state 2D-NMR requires finely divided, planetary ball milled samples. Planetary ball milling is associated with structural changes in lignin, mainly with regards to the cleavage of $\beta-O-4$ inter-unit linkages (Fujimoto et al., 2005). ${ }^{13} \mathrm{C}$-IS Py-GC/MS analysis of the ball-milled samples showed that the milling did not induce structural changes in the lignin present and that the inter-unit linkages remained unaffected $\left(\mathrm{PhC}_{\gamma}\right.$ constant). Thus, 2D NMR could be appropriately used.

The aliphatic $\left(\delta_{\mathrm{C}} / \delta_{\mathrm{H}} 50-90 / 2.5-6.0\right)$ and aromatic/unsaturated $\left(\delta_{\mathrm{C}} / \delta_{\mathrm{H}} 90-160 / 6.0-8.0\right)$ regions of the recorded HSQC spectra of untreated and CS1 treated wheat straw are presented in Fig. 6.4, with structures of the assigned correlation peaks shown in Fig. 6.5, 

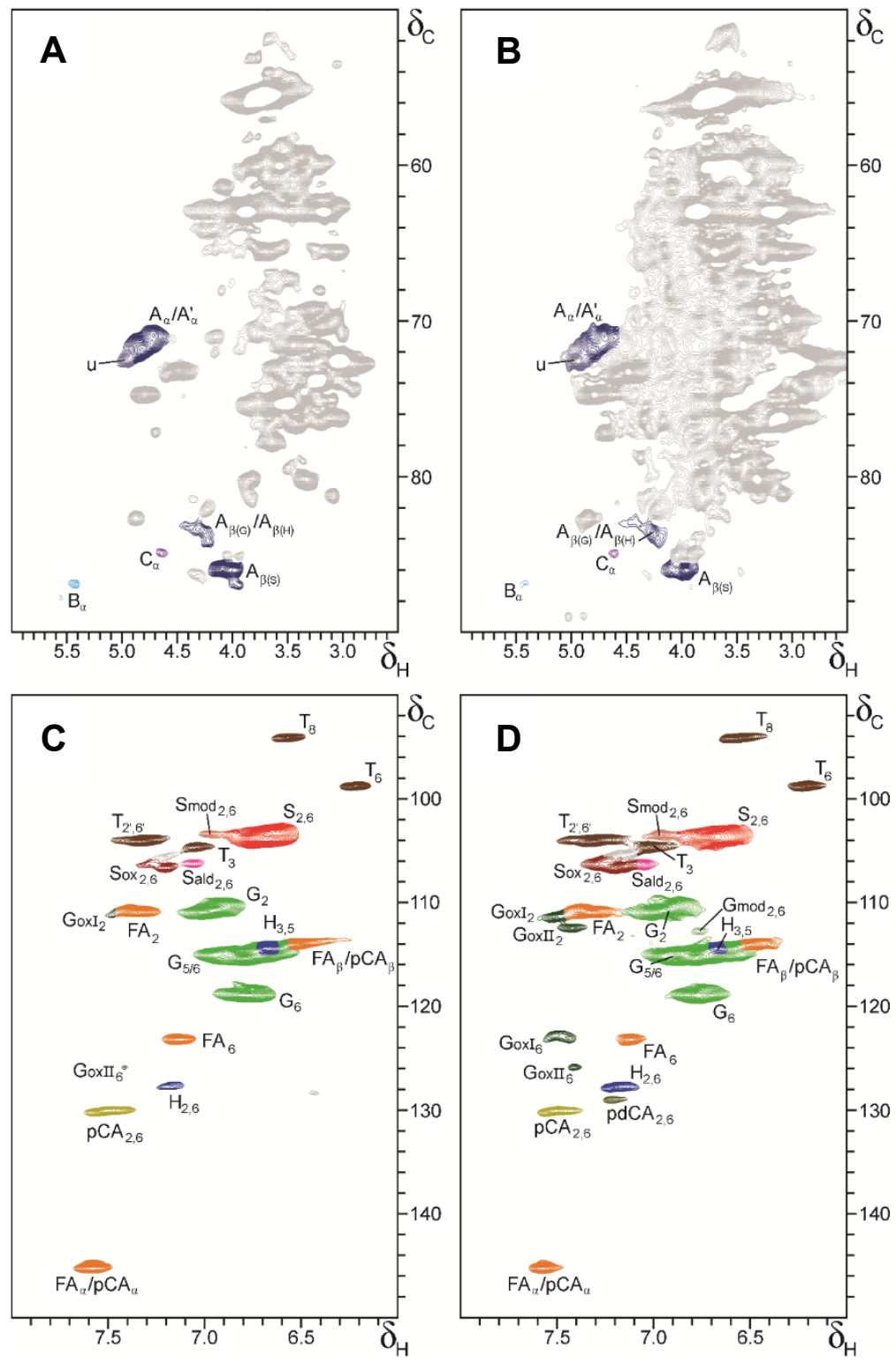

Fig. 6.4: HSQC NMR spectra of control $(A, C)$ and CS1-treated wheat straw (B, D). A,B: aliphatic $\left(\delta_{\mathrm{C}} / \delta_{\mathrm{H}} 50-90 / 2.5-6.0\right)$ region, C,D: aromatic/unsaturated $\left(\delta_{\mathrm{C}} / \delta_{\mathrm{H}} 90-160 / 6.0-8.0\right)$ region. Structures of annotated correlation peaks are presented in Fig. 6.5. GoxII $\mathrm{G}_{2}$ and $\mathrm{G}_{\mathrm{ox}} \mathrm{II}_{6}$ are tentatively assigned. $\mathrm{G}_{\text {mod }}$ and $\mathrm{S}_{\mathrm{mod}}$, being unknown derivatives of $\mathrm{G}$ and $\mathrm{S}$ units, respectively, are presented in a lighter color of the original subunit. Carbohydrate and unassigned signals are presented in gray. u: unassigned signal overlapping $\mathrm{A}_{a} / \mathrm{A}^{\prime}{ }_{\alpha}$. 


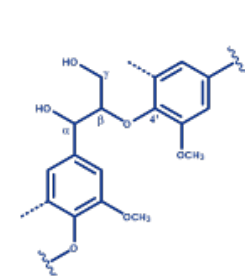

A<smiles>C=C(C)CCC(Cc1c(C)cc(CC)cc1CC)C(C)c1cc(C)c(CC)c(C)c1</smiles>

$\mathbf{A}^{\prime}$<smiles>CCCc1c(C)cc(C(=O)C(Cc2c(C)cc(C)cc2C)C(C)C)cc1C</smiles>

$\mathbf{A}_{\text {ox }}$

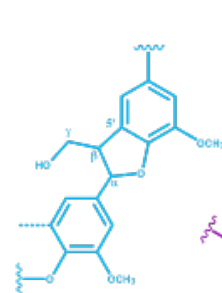

B<smiles>CCCc1c(C)cc(C2CCC3C(c4cc(C)c(CC)c(C)c4)CCC3C2CCC)cc1CC</smiles>

C<smiles>Cc1cc(C(C)C)cc(C)c1CCS</smiles><smiles>C=C(C)c1cc(C)c(CCS)c(C)c1</smiles><smiles>C=C(C)C=Cc1cc(C)c(CCC)c(CC)c1</smiles>

S Ald
$\mathbf{T}$<smiles>CCCc1ccc(C(C)C)cc1</smiles><smiles>CCCC=Cc1ccc(Cl)cc1</smiles><smiles>C=C(CCCC)CCc1ccc(C)cc1</smiles>

pdCA

Fig. 6.5: Structures annotated by HSQC NMR. A: $\beta$-O-4'alkyl-aryl ether; $\mathbf{A}^{\prime}$ : $\beta$ - $O-4$ 'alkyl-aryl ether $\gamma$-acylated; $\mathrm{A}_{\mathrm{ox}}$ : $\beta$-O-4'alkyl-aryl ether $\mathrm{C}_{\alpha}$-oxidized; $\mathrm{B}$ : phenylcoumaran; $\mathrm{C}$ : resinol; $\mathrm{T}$ : tricin; $p \mathrm{CA}$ : p-coumarate; pdCA: p-dihydrocoumarate; FA: ferulate; $\mathrm{G}$ : guaiacyl unit; $\mathrm{G}_{\mathrm{ox}}$ : $\mathrm{C}_{\alpha}$-oxidized guaiacyl unit; S: syringyl unit; $\mathrm{S}$ : $\mathrm{C}_{\alpha}$-oxidized syringyl unit; $\mathrm{H}$ : $p$-hydroxyphenyl unit; $\mathrm{S}_{\text {ald: }}$ syringaldehyde; Dotted line represents $-\mathrm{H}$ or $-\mathrm{OCH}_{3}$. $\mathrm{R}$ in $\mathrm{G}_{\text {ox }}$ and $\mathrm{S}_{\text {ox }}$ can be a side chain in ketones or hydroxyl in carboxylic acids. Wavy lines indicate main positions of further coupling. Colors match the assigned contours in Fig. 6.4. 
of which chemical shift assignments were based on literature and shown in Supplementary Information Table 6-S3 (Ralph et al., 2009b; Villaverde et al., 2009; Rencoret et al., 2010; Yuan et al., 2011; Del Río et al., 2012; Del Río et al., 2015; Rencoret et al., 2017; Das et al., 2018). Aliphatic and aromatic/unsaturated regions of the HSQC spectra of the wheat straw treated by the other fungi are shown in Supporting Information Fig. 6-S3. The aliphatic regions were dominated by polysaccharide signals, mainly derived from xylan and acetylated xylan moieties, which (partially) overlapped with $\beta-O-4$ ' substructures. This overlap was more severe for fungal-treated samples, from which lignin was selectively removed. Despite this overlap, phenylcoumaran $\left(\beta-5^{\prime}\right)$ and resinol $(\beta-\beta)$ substructures were readily observed, whereas $\mathrm{C}_{\alpha}$-oxidized ( $\alpha$-keto) $\beta$ - $O-4$ ', dibenzodioxocins (5-5'/4-O- $\beta$ ), spirodienones $\left(\beta-1^{\prime} / \alpha-O-\alpha\right)$ and $\alpha, \beta$-diaryl ether linkages were only observed at higher zoom levels. At these zoom levels other contours were not resolved anymore, which would result in a lower accuracy of volume integration.

In the aromatic region, clear lignin signals, typical for wheat straw, were observed $\left(\mathrm{S}_{2,6}, \mathrm{G}_{2}, \mathrm{H}_{2,6}\right.$ and several tricin (T), pCA and FA related signals) (Del Río et al., 2012; Zeng et al., 2013). Interestingly, in the fungal-treated samples $\mathrm{C}_{\alpha}$-oxidized aromatic units became more apparent, especially after treatment with CS and is discussed in detail below. Although $\mathrm{C}{ }^{-}$-oxidized S-units $\left(\delta_{\mathrm{C}} / \delta_{\mathrm{H}} 106.6 / 7.2\right)$ are commonly found in NMR studies on (native) lignin, $\mathrm{C}_{\alpha}$-oxidized G-units $\left(\delta_{\mathrm{C}} / \delta_{\mathrm{H}}\right.$ 111.2/7.5) are less often described and have, hitherto, never been observed at the levels shown here (Yuan et al., 2011; Rencoret et al., 2016; Rencoret et al., 2017). Notably, two different $\mathrm{C}_{\alpha}$-oxidized G-units substructures could be distinguished, although their exact structures remained unidentified ( $\mathrm{GoxI}_{2}$ $\left.\delta_{\mathrm{C}} / \delta_{\mathrm{H}} 111.2 / 7.5, \mathrm{GoxII}_{2} \delta_{\mathrm{C}} / \delta_{\mathrm{H}} 112.4 / 7.4\right)$. Another structural aspect resulting from fungal action, is the increased intensity of derivatives of both $S\left(\mathrm{~S}_{\bmod }, \delta_{\mathrm{C}} / \delta_{\mathrm{H}} 103.4 / 6.96\right)$ and $\mathrm{G}$ units $\left(\mathrm{G}_{\mathrm{mod}}, \delta_{\mathrm{C}} / \delta_{\mathrm{H}} 112.8 / 6.76\right)$. Though the NMR database of lignin and cell wall model compounds could confirm that these signals originated from either S or G units, their exact structures could not be elucidated (Ralph et al., 2009b). To identify both the unidentified oxidized G-units and S/G-derivatives, future extensive NMR-research is needed, not being the aim of the current research. A summary of the semi-quantitative analysis of the volume integrals of aromatic units and inter-unit linkages (see materials and methods for details) is given in Table 6.2.

Similar to ${ }^{13} \mathrm{C}$-IS Py-GC/MS (Table 6.1), 2D-NMR showed minor changes in H:G:S composition after fungal treatment (Table 6.2). For instance, the H:G:S composition changed from 2:54:44 in control to 4:56:36 in CS1-treated straw. Again a (slight) 


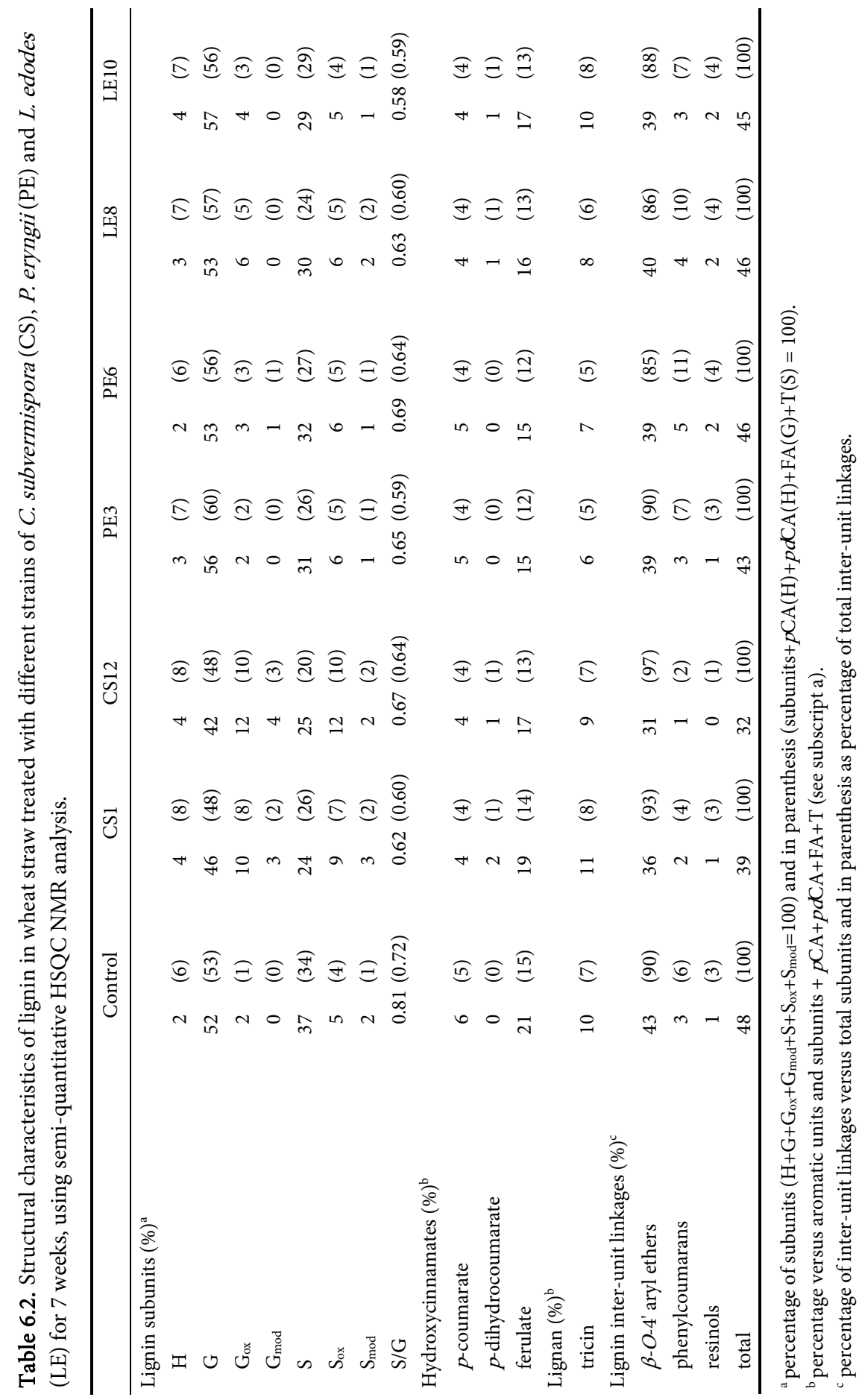


preferential removal of S-units was observed, thereby confirming our previous findings by Py-GC/MS. However, for a fair comparison of the H:G:S composition found by the two techniques, it should be considered that whereas the hydroxycinnamic acids ( $p C A$ and FA) and tricin (T) can be distinguished from 'core-lignin' substructures in 2D-NMR, in Py-GC/MS they result in similar pyrolysis products. Upon pyrolysis both $p C A$ and FA as well as inter-unit linkages result in the formation of 4-vinylphenol and 4-vinylguaiacol, respectively. Analogous, tricin is expected to result in S-unit derivatives upon pyrolysis.

To enable a comparison of both techniques in terms of $\mathrm{H}: \mathrm{G}: \mathrm{S}$ composition (mol based), pCA (H), FA (G) and T (S) were included in the determination of the subunit composition by NMR (Table 6.2, numbers in parentheses). Besides analytical comparability, the obtained subunit composition is, to our opinion, more representative of 'true lignin' as these substructures were shown to be an integral part of lignin (Ralph 2010; Lan et al., 2016). Upon inclusion of these substructures the obtained subunit compositions found by both techniques matched better, though they remained different $(\mathrm{CS1} H: G: S(N M R)=8: 58: 35, \mathrm{H}: \mathrm{G}: \mathrm{S}(\mathrm{Py}-\mathrm{GC} / \mathrm{MS})=12: 62: 26)$. It cannot be expected that both techniques result in identical values, as different entities are measured (Mansfield et al., 2012). Still, because similar trends were observed, complementary structural information can be obtained by comparing both techniques. One of the explanations for the observed difference is that the semi-quantitative nature of the NMR technique results in over-estimation of end-units as a result of differences in relaxation behavior compared to 'core-lignin' (Mansfield et al., 2012). Another explanation is that hydroxycinnamic acids are pyrolyzed more efficiently compared to 'core-lignin', which results in overestimation of their abundances and contributions to lignin (Del Río et al., 2012).

Most pronounced changes based on NMR was the significant increase in $\mathrm{C}_{\alpha}$-oxidized aromatic units in fungal-treated samples, with a three-fold accumulation in CS-treated lignin (19-24\% of total aromatic units; Table 6.2). This increase coincides with the increase in $\mathrm{C}_{\alpha}$-oxidized products in Py-GC/MS and these compounds, hence, were mostly derived from $\mathrm{C}_{\alpha}$-oxidized units initially present in the polymer. Even, relative abundances (\% mol) of $\mathrm{C}_{\alpha}$-oxidized substructures obtained by both techniques were in fairly good accordance $\left(\mathrm{CS} 1 \mathrm{C}_{\alpha}-\mathrm{ox}(\mathrm{NMR})=15 \%, \mathrm{C}_{\alpha}-\mathrm{ox}(\mathrm{Py}-\mathrm{GC} / \mathrm{MS})=14 \%\right)$. It can be assumed that the $\mathrm{C}_{\alpha}$-oxidized substructures accumulated in fungal-treated lignin due to the fact that, once oxidized, these units cannot be further oxidized (by the respective fungal oxidases present) and are therefore resistant against further degradation and further metabolization. $\mathrm{C}_{\alpha^{-}}$-oxidized S-units appeared more prone to accumulate than their $\mathrm{C}_{\alpha^{-}}$ oxidized G-unit counterparts $\left(\mathrm{S}_{\mathrm{ox}} / \mathrm{S}>\mathrm{G}_{\mathrm{ox}} / \mathrm{G}\right)$ for all fungi. This might on the one hand be 
explained by their ease of formation, as discussed in the previous section. On the other hand, S-units might be more difficult to be consumed and fully metabolized.

Interestingly, while the $\mathrm{C}_{\alpha}$-oxidized aromatic units clearly increased, no apparent increase of $\mathrm{C}_{\alpha}$-oxidized ( $\alpha$-keto) $\beta$-O-4' substructures could be observed. The latter observation shows that the $\mathrm{C}_{\alpha}$-oxidized signals mainly originated from cleaved linkages, and simultaneously highlights the importance of corresponding VAL and SAL compounds in the Py-GC/MS analysis. The suggestion that cleaved linkages accumulated in the residual lignin is further substantiated by the reduced amounts of intact inter-unit linkages in fungal-treated lignin. Intact inter-unit linkages were severely reduced by CS treatment (CS1 -20\%, CS12 -34\%; Table 6.2), which was also observed by Py-GC/MS. The abundance of $\mathrm{PhC}_{\gamma}$ products excluding acetaldehydes, thus, seems to be a highly valuable parameter for the investigation of lignin structure by Py-GC/MS.

Previous studies also reported on the reduction of inter-unit linkages in CS-treated lignin (Guerra et al., 2004; Choi et al., 2006). However, these studies were conducted on wood, of which the lignin is of different structure. Still, in these biomasses the $\beta-O-4$ interunit linkage is most abundant and, therefore, can be used to compare fungal action. Guerra et al. (2004) found that the CS-treated pine was preferentially reduced in $\beta$ - $O-4$ linkages, while carbon-carbon linked units were more resistant against fungal degradation (Guerra et al., 2004). Our results, on the contrary, indicated that all interunit linkages in wheat straw lignin were comparable in their susceptibility towards fungal degradation as their relative composition was rather stable $(<10 \%$ different from control; Table 6.2). Another significant result from 2D-NMR was the reduction of FA moieties after fungal treatment, particularly by PE strains (around 30\% reduction; Table 6.2). Possibly, the lignin-carbohydrate linkages in which FA participates, were targeted in a more preferential manner (Ralph 2010; Hatfield et al., 2017). Though, the specific removal of glucuronoarabinoxylan (GAX) linked ferulates and crosslinked diferulates cannot be excluded. Such structures could be cleaved by for example feruloyl esterases, shown to occur extracellularly for PE and LE (Haase-Aschoff et al., 2013).

The specific targeting of FA moieties is in line with the concurrent lignin and GAX degradation during fungal growth. The magnitudes of FA and GAX removal were, however, not directly linked (Fig. 6-S1 and 6-S2). In contrast to FA, pCA moieties were not preferentially removed, but shown to be partially reduced to dihydro analogues (Table 6.2). Esterified at the $\gamma-\mathrm{OH}, \mathrm{pCA}$ moieties are in the vicinity of the bonds that are being oxidized, and, therefore, might play a role in redox cycling. 
Tricin was surprisingly shown to be specifically targeted during fungal growth, in particular by PE strains (-40\% vs total lignin; Table 6.2). Tricin has recently been suggested to play an important role in the biosynthesis of lignin in poaceous crops, by functioning as a nucleation site for lignin formation (Del Río et al., 2012; Lan et al., 2015; Lan et al., 2016; Li et al., 2016). The preferential removal of tricin suggests that, besides lignin formation, tricin may play a crucial role in the fungal degradation of lignin as well.

\section{Mechanistic insight in fungal delignification by combining results of ${ }^{13} \mathrm{C}$-IS Py- GC/MS and 2D-NMR}

Excitingly, the combination of 2D-NMR and ${ }^{13} \mathrm{C}-\mathrm{IS}$ Py-GC/MS gave more insight in the reaction mechanisms underlying delignification by the studied fungi, in particular for CS strains. The absence of $\mathrm{C}_{\alpha}$-oxidized ( $\alpha$-keto) $\beta-O-4$ ' substructures in 2D-NMR combined with decreased amounts of intact inter-unit linkages (both techniques) confirmed that the $\mathrm{C}_{\alpha}$-oxidized substructures were present in the fungal-treated lignin macromolecule as cleavage products of the inter-unit linkages. Upon pyrolysis, these cleavage products resulted in the formation of the acetaldehydes VAL and SAL. Since these pyrolysis products contain an intact $\alpha, \beta, \gamma$ carbon side chain, the structures they originate from should contain this three-carbon side chain as well. Hence, we postulate that acetaldehyde pyrolysis products originated from remaining structures after $\mathrm{C}_{\beta^{-}} O$ cleavage of the $\beta-O-4$ ' ether. $\mathrm{C}_{\alpha}$-oxidized pyrolysis products with an $\alpha$-carbon side-chain, like vanillin and syringaldehyde, were likewise, but not specifically, formed from cleavage products and thus are suggested to be the result of $\mathrm{C}_{\alpha}-\mathrm{C}_{\beta}$ cleavage.

The high proportion of acetaldehyde pyrolysis products formed from CS-treated lignin suggests that $\mathrm{C}_{\beta^{-}} O$-aryl cleavage was the main underlying mechanism of lignin degradation, while for PE and LE on the contrary $\mathrm{C}_{\alpha}-\mathrm{C}_{\beta}$ cleavage predominated. The latter two species, however, showed less accumulation of $\mathrm{C}_{\alpha}$-oxidized substructures in treated lignin, at the respective levels of lignin removal. This might indicate that other cleavage reactions not yielding $\mathrm{C}_{\alpha}$-oxidation might be more dominant than previously thought (Crestini et al., 2003). On the other hand, if $\mathrm{C}_{\beta^{-}} \mathrm{O}$-aryl cleavage did occur, but the resulting intermediate products were further degraded in follow-up reactions, we cannot pick this up in residual lignin structures after 7 weeks of fungal growth. Collectively, the enzymes produced by LE and PE might thus be able to degrade each lignin subunit further, without resulting in increased, content-wise, lignin degradation. Our result clearly put forward that the delignification mechanism of CS is fundamentally different from LE and PE. 
Though the genomes of the studied fungi are known to differ considerably, the number of genes encoding for ligninolytic enzymes seems inadequate to explain the mechanistic differences observed between the studied fungi, primarily because of the lack of transcriptomic data and insight into the activities of the enzymes once produced (Nagai et al., 2007; Fernandez-Fueyo et al., 2012; Fernández-Fueyo et al., 2012; Yang et al., 2016; Park et al., 2017; Sakamoto et al., 2017). Given the number of genes encoding for the ligninolytic enzymes of these fungi (Table 6.3), PE and LE seem to rely mainly on laccase, while a more prominent role of $\mathrm{MnP}$ is suggested for CS. This is supported by the fact that delignification of CS was inhibited when the $\mathrm{Mn}^{2+}$ concentration was severely reduced and stimulated by addition of $\mathrm{Mn}^{2+}$, whereas $\mathrm{Mn}^{2+}$ addition did not stimulate delignification by LE (Jensen et al., 1996; Van Kuijk et al., 2016a). Moreover, it was shown that, in the presence of unsaturated fatty acids, MnP can degrade lignin model compounds via lipid peroxidation into products that, upon pyrolysis, could yield the acetaldehyde products we observed (Bao et al., 1994; Jensen et al., 1996). Interestingly, a similar MnP-peroxidation reaction was suggested for alkylitaconic acids, secondary metabolites that are produced by CS but not by LE and PE. As peroxidation was shown to shift the $\beta-O-4$ ' cleavage reaction more towards $\mathrm{C}_{\beta^{-}} O$-aryl cleavage, it can be postulated that the presence of alkylitaconic acids underlies the observed predominance of this cleavage reaction by CS. However, laccases and the recently identified enzymes with a LiP/VP like activity could have resulted in similar products, due to which unambiguity regarding the underlying enzyme system remains (Srebotnik et al., 1997; Kawai et al., 2002; Cantarella et al., 2003; Yelle et al., 2014). For further validation and

Table 6.3. Number of genes encoding for ligninolytic enzymes in C. subvermispora (CS), $P$. eryngii (PE) and L. edodes (LE). Based on Nagai et al. (2007), Fernandez-Fueyo et al. (2012), Yang et al. (2016), Park et al. (2017) and Sakamoto et al. (2017).

\begin{tabular}{lccc}
\hline Enzyme & CS & PE & LE \\
\hline LiP & N/D & N/D & N/D \\
MnP & 13 & 4 & 3 \\
VP & N/D & 2 & N/D \\
Laccase & 7 & 9 & 11 \\
AAO & 5 & 10 & 4 \\
LiP/VP like & 2 & N/D & N/D \\
\hline
\end{tabular}

LiP: lignin peroxidase, MnP: manganese peroxidase, VP: versatile peroxidase, AAO: aryl alcohol oxidase, N/D: not detected. 
interpretation of our observations isolation of lignin from treated wheat straw during fungal growth combined with comprehensive structural analysis (e.g. quantitative combinatorial ${ }^{13} \mathrm{C} / \mathrm{HSQC}$ NMR) should be applied next to proteomics and transcriptomics.

\section{CONCLUSIONS}

Our results show that Ceriporiopsis subvermispora (CS) and Lentinula edodes (LE) are more effective and selective wheat straw lignin degrading species than Pleurotus eryngii (PE). They degraded more than $60 \%(\mathrm{w} / \mathrm{w})$ of lignin without extensive carbohydrate degradation within 7 weeks of treatment. Though CS and LE followed a similar pattern of lignin degradation in time, the structural-features of residual lignin as determined by quantitative ${ }^{13} \mathrm{C}$-IS Py-GC/MS and in situ HSQC NMR were vastly different. For example, both techniques revealed that CS-treated lignin was exceptionally high in $\mathrm{C}_{\alpha}$-oxidized substructures (up to $24 \%$ of aromatic units) and a factor two higher than LE-treated lignin. LE and PE, on the other hand, more specifically targeted ferulic acid substructures, while PE removed tricin up to $40 \%$ more preferentially than other substructures. Furthermore, $\mathrm{CS}$ delignification mainly proceeded via $\mathrm{C}_{\beta^{-}} \mathrm{O}$-aryl and $\mathrm{C}_{\alpha^{-}}$ $\mathrm{C}_{\beta}$ cleavage of the lignin inter-unit linkages, while inter-unit degradation by LE and PE seemed dominated by $\mathrm{C}_{\alpha}-\mathrm{C}_{\beta}$ cleavage. We, therefore, suggest that the underlying delignification mechanisms of these fungi are fundamentally different. Besides assisting the further optimization of fungal pre-treatment of plant biomass we highlight that the choice of fungus impacts the structure of residual lignin and results in lignin with remarkable structure. Thus, fungal pretreatment not only enhances the degradability of plant cell wall polysaccharides, but also results in an interesting lignin fraction that can be exploited to further increase the sustainability of the process.

\section{ACKNOWLEDGEMENTS}

The authors gratefully acknowledge the financial support from the University Fund Wageningen (UFW) as part of the project "More Meat and Milk from Straw" which is sponsored by DEKA, ForFarmers and the Victam Foundation. All funding bodies had no involvement in planning and conduct of the research. Maud Pfeiffer is acknowledged for formatting NMR spectra. 


\section{REFERENCES}

Bao, W., Fukushima, Y., Jensen Jr, K.A., Moen, M.A. and Hammel, K.E. (1994) Oxidative degradation of nonphenolic lignin during lipid peroxidation by fungal manganese peroxidase. FEBS letters 354, 297-300.

Behera, S., Arora, R., Nandhagopal, N. and Kumar, S. (2014) Importance of chemical pretreatment for bioconversion of lignocellulosic biomass. Renew. Sust. Energ. Rev 36, 91-106.

Björkman, A. (1956) Studies on finely divided wood. Part 1. Extraction of lignin with neutral solvents. Sven Papperstidn 59, 477-485.

Blumenkrantz, N. and Asboe-Hansen, G. (1973) New method for quantitative determination of uronic acids. Anal. Biochem. 54, 484-489.

Buranov, A.U. and Mazza, G. (2008) Lignin in straw of herbaceous crops. Ind. Crops Prod. 28, 237-259.

Camarero, S., Galletti, G.C. and Martinez, A.T. (1994) Preferential degradation of phenolic lignin units by two white rot fungi. Appl. Environ. Microbiol. 60, 4509-4516.

Camarero, S., Martínez, M.J. and Martínez, A.T. (2014) Understanding lignin biodegradation for the improved utilization of plant biomass in modern biorefineries. Biofuels Bioprod. Biorefin. 8, 615-625.

Cantarella, G., Galli, C. and Gentili, P. (2003) Free radical versus electron-transfer routes of oxidation of hydrocarbons by laccase/mediator systems: Catalytic or stoichiometric procedures. J. Mol. Catal. B: Enzym. 22, 135-144.

Chang, H.-m., Cowling, E.B. and Brown, W. (1975) Comparative studies on cellulolytic enzyme lignin and milled wood lignin of sweetgum and spruce. Holzforschung 29, 153-159.

Choi, J., Choi, D., Ahn, S., Lee, S., Kim, M., Meier, D., Faix, O. and Scott, G.M. (2006) Characterization of trembling aspen wood (Populus tremuloides L.) degraded with the white rot fungus Ceriporiopsis subvermispora and MWLs isolated thereof. Holz. Roh. Werkst. 64, 415-422.

Crestini, C., Jurasek, L. and Argyropoulos, D.S. (2003) On the mechanism of the laccase-mediator system in the oxidation of lignin. Chem. Eur. J. 9, 5371-5378.

Crestini, C., Sermanni, G.G. and Argyropoulos, D.S. (1998) Structural modifications induced during biodegradation of wheat lignin by Lentinula edodes. Bioorg. Med. Chem. 6, 967-973.

Das, A., Rahimi, A., Ulbrich, A., Alherech, M., Motagamwala, A.H., Bhalla, A., da Costa Sousa, L., Balan, V., Dumesic, J.A., Hegg, E.L., Dale, B.E., Ralph, J., Coon, J.J. and Stahl, S.S. (2018) Lignin conversion to lowmolecular-weight aromatics via an aerobic oxidation-hydrolysis sequence: Comparison of different lignin sources. ACS Sustain. Chem Eng 6, 3367-3374.

Del Río, J., Speranza, M., Gutiérrez, A., Martínez, M. and Martínez, A. (2002) Lignin attack during Eucalypt wood decay by selected basidiomycetes: a Py-GC/MS study. J. Anal. Appl. Pyrolysis 64, 421-431.

Del Río, J.C., Lino, A.G., Colodette, J.L., Lima, C.F., Gutiérrez, A., Martínez, Á.T., Lu, F., Ralph, J. and Rencoret, J. (2015) Differences in the chemical structure of the lignins from sugarcane bagasse and straw. Biomass Bioenergy 81, 322-338.

Del Río, J.C., Rencoret, J., Prinsen, P., Martínez, A.T., Ralph, J. and Gutiérrez, A. (2012) Structural characterization of wheat straw lignin as revealed by analytical pyrolysis, 2D-NMR, and reductive cleavage methods. J. Agric. Food Chem. 60, 5922-5935.

Dorado, J., Almendros, G., Camarero, S., Martínez, A.T., Vares, T. and Hatakka, A. (1999) Transformation of wheat straw in the course of solid-state fermentation by four ligninolytic basidiomycetes. Enzyme Microb. Technol. 25, 605-612. 
Englyst, H.N. and Cummings, J.H. (1984) Simplified method for the measurement of total non-starch polysaccharides by gas-liquid chromatography of constituent sugars as alditol acetates. Analyst. 109, 937942.

Fernandez-Fueyo, E., Ruiz-Dueñas, F.J., Ferreira, P., Floudas, D., Hibbett, D.S., Canessa, P., Larrondo, L.F., James, T.Y., Seelenfreund, D., Lobos, S., Polanco, R., Tello, M., Honda, Y., Watanabe, T., Watanabe, T., Ryu, J.S., Kubicek, C.P., Schmoll, M., Gaskell, J., Hammel, K.E., St. John, F.J., Vanden Wymelenberg, A., Sabat, G., Splinter Bondurant, S., Khajamohiddin, S., Jagit, Y.S., Doppapaneni, H., Subramanian, V., José, L.L., Oguiza, J.A., Perez, G., Pisabarro, A.G., Ramirez, L., Santoyo, F., Master, E., Coutinho, P.M., Henrissat, B., Lombard, V., Magnuson, J.K., Kües, U., Hori, C., Igarashi, K., Samejima, M., Held, B.W., Barry, K.W., Labutti, K.M., Lapidus, A., Lindquist, E.A., Lucas, S.M., Riley, R., Salamov, A.A., Hoffmeister, D., Schwenk, D., Hadar, Y., Yarden, O., de Vries, R.P., Wiebenga, A., Stenlid, J., Eastwood, D., Grigoriev, I.V., Berka, R.M., Blanchette, R.A., Kersten, P., Martinez, A.T., Vicuna, R. and Cullen, D. (2012) Comparative genomics of Ceriporiopsis subvermispora and Phanerochaete chrysosporium provide insight into selective ligninolysis. Proc. Natl. Acad. Sci. 109, 5458-5463.

Fernández-Fueyo, E., Ruiz-Dueñas, F.J., Miki, Y., Martínez, M.J., Hammel, K.E. and Martínez, A.T. (2012) Lignin-degrading peroxidases from genome of selective ligninolytic fungus Ceriporiopsis subvermispora. J. Biol. Chem. 287, 16903-16916.

Fujimoto, A., Matsumoto, Y., Chang, H.-M. and Meshitsuka, G. (2005) Quantitative evaluation of milling effects on lignin structure during the isolation process of milled wood lignin. J. Wood Sci. 51, 89-91.

Guerra, A., Mendonça, R., Ferraz, A., Lu, F. and Ralph, J. (2004) Structural characterization of lignin during Pinus taeda wood treatment with Ceriporiopsis subvermispora. Appl Environ Microbiol 70, 4073-4078.

Haase-Aschoff, P., Linke, D. and Berger, R.G. (2013) Detection of feruloyl-and cinnamoyl esterases from basidiomycetes in the presence of interfering laccase. Bioresour. Technol. 130, 231-238.

Hatakka, A. and Hammel, K.E. (2011) Fungal biodegradation of lignocelluloses. In Industrial applications The Mycota ed. Hofrichter, M. pp.319-340. Berlin: Springer-Verlag.

Hatfield, R.D., Rancour, D.M. and Marita, J.M. (2017) Grass cell walls: a story of cross-linking. Front. Plant. Sci. 7, 2056.

Hernández-Ortega, A., Ferreira, P. and Martínez, A.T. (2012) Fungal aryl-alcohol oxidase: a peroxide-producing flavoenzyme involved in lignin degradation. Appl. Microbiol. Biotech. 93, 1395-1410.

Isroi, Millati, R., Syamsiah, S., Niklasson, C., Cahyanto, M.N., Ludquist, K. and Taherzadeh, M.J. (2011) Biological pretreatment of lignocelluloses with white-rot fungi and its applications: a review. BioResources 6, 5224-5259.

Isikgor, F.H. and Becer, C.R. (2015) Lignocellulosic biomass: a sustainable platform for the production of biobased chemicals and polymers. Polym. Chem. 6, 4497-4559.

Jensen, K.A., Bao, W., Kawai, S., Srebotnik, E. and Hammel, K.E. (1996) Manganese-dependent cleavage of nonphenolic lignin structures by Ceriporiopsis subvermispora in the absence of lignin peroxidase. Appl. Environ. Microbiol. 62, 3679-3686.

Jurak, E., Punt, A.M., Arts, W., Kabel, M.A. and Gruppen, H. (2015) Fate of carbohydrates and lignin during composting and mycelium growth of Agaricus bisporus on wheat straw based compost. PLoS One 10, e0138909.

Kawai, S., Nakagawa, M. and Ohashi, H. (2002) Degradation mechanisms of a nonphenolic $\beta$-O-4 lignin model dimer by Trametes versicolor laccase in the presence of 1-hydroxybenzotriazole. Enzyme Microb. Technol. 30, 482-489. 
Keller, F.A., Hamilton, J.E. and Nguyen, Q.A. (2003) Microbial pretreatment of biomass. Appl. Biochem. Biotechnol. 105, 27-41.

Kim, H., Ralph, J. and Akiyama, T. (2008) Solution-state 2D NMR of ball-milled plant cell wall gels in DMSOd 6. BioEnergy Res 1, 56-66.

Kirk, T.K. and Chang, H.-m. (1974) Decomposition of lignin by white-rot fungi. I. Isolation of heavily degraded lignins from decayed spruce. Holzforschung 28, 217-222.

Lan, W., Lu, F., Regner, M., Zhu, Y., Rencoret, J., Ralph, S.A., Zakai, U.I., Morreel, K., Boerjan, W. and Ralph, J. (2015) Tricin, a flavonoid monomer in monocot lignification. Plant. Physiol. 167, 1284-1295.

Lan, W., Rencoret, J., Lu, F., Karlen, S.D., Smith, B.G., Harris, P.J., Río, J.C. and Ralph, J. (2016) Tricin-lignins: occurrence and quantitation of tricin in relation to phylogeny. Plant. J. 88, 1046-1057.

Li, M., Pu, Y., Yoo, C.G. and Ragauskas, A.J. (2016) The occurrence of tricin and its derivatives in plants. Green Chem. 18, 1439-1454.

Mansfield, S.D., Kim, H., Lu, F. and Ralph, J. (2012) Whole plant cell wall characterization using solution-state 2D NMR. Nat. Protoc. 7, 1579.

Martínez, A., Camarero, S., Gutiérrez, A., Bocchini, P. and Galletti, G. (2001) Studies on wheat lignin degradation by Pleurotus species using analytical pyrolysis. J. Anal. Appl. Pyrolysis 58, 401-411.

Martínez, A.T., Speranza, M., Ruiz-Dueñas, F.J., Ferreira, P., Camarero, S., Guillén, F., Martínez, M.J., Gutiérrez, A. and Del Río, J.C. (2005) Biodegradation of lignocellulosics: microbial, chemical, and enzymatic aspects of the fungal attack of lignin. Int. Microbiol. 8, 195-204.

Nagai, M., Sakamoto, Y., Nakade, K. and Sato, T. (2007) Isolation and characterization of the gene encoding a manganese peroxidase from Lentinula edodes. Mycosci. 48, 125-130.

Nayan, N., Sonnenberg, A.S., Hendriks, W.H. and Cone, J.W. (2018) Screening of white-rot fungi for bioprocessing of wheat straw into ruminant feed. J. Appl. Microbiol. 125, 368-379.

Nayan, N., Sonnenberg, A.S.M., Hendriks, W.H. and Cone, J.W. (2017) Differences between two strains of Ceriporiopsis subvermispora on improving the nutritive value of wheat straw for ruminants. J. Appl. Microbiol.

Park, S.-G., il Yoo, S., Ryu, D.S., Lee, H., Ahn, Y.J., Ryu, H., Ko, J. and Hong, C.P. (2017) Long-read transcriptome data for improved gene prediction in Lentinula edodes. Data in brief 15, 454-458.

Patwardhan, P.R., Brown, R.C. and Shanks, B.H. (2011) Understanding the fast pyrolysis of lignin. ChemSusChem 4, 1629-1636.

Ralph, J. (2010) Hydroxycinnamates in lignification. Phytochem. Rev. 9, 65-83.

Ralph, J., Brunow, G., Harris, P.J., Dixon, R.A., Schatz, P.F. and Boerjan, W. (2009a) Lignification: are lignins biosynthesized via simple combinatorial chemistry or via proteinaceous control and template replication? In Recent Advances in Polyphenol Research eds. Lattanzio, V. and Daayf, F. pp.36-66. Oxord: WileyBlackwell.

Ralph, J. and Hatfield, R.D. (1991) Pyrolysis-GC-MS characterization of forage materials. J. Agric. Food Chem. 39, 1426-1437.

Ralph, S.A., Ralph, J. and Landucci, L. (2009b) NMR database of lignin and cell wall model compounds. Available at URL www.glbrc.org/databases_and_software/nmrdatabase/.

Rencoret, J., Gutiérrez, A., Nieto, L., Jiménez-Barbero, J., Faulds, C.B., Kim, H., Ralph, J., Martínez, Á.T. and José, C. (2010) Lignin composition and structure in young versus adult Eucalyptus globulus plants. Plant Physiol., 155, 667-682. 
Rencoret, J., Pereira, A., del Río, J.C., Martínez, Á.T. and Gutiérrez, A. (2017) Delignification and Saccharification Enhancement of Sugarcane Byproducts by a Laccase-Based Pretreatment. ACS Sustain. Chem. Eng. 5, 7145-7154.

Rencoret, J., Pereira, A., José, C., Martínez, A.T. and Gutiérrez, A. (2016) Laccase-mediator pretreatment of wheat straw degrades lignin and improves saccharification. BioEnergy Res. 9, 917-930.

Sakamoto, Y., Nakade, K., Sato, S., Yoshida, K., Miyazaki, K., Natsume, S. and Konno, N. (2017) Lentinula edodes genome survey and postharvest transcriptome analysis. Appl. Environ. Microbiol. 83, e0299002916.

Sette, M., Wechselberger, R. and Crestini, C. (2011) Elucidation of lignin structure by quantitative 2D NMR. Chem. Eur. J. 17, 9529-9535.

Sindhu, R., Binod, P. and Pandey, A. (2016) Biological pretreatment of lignocellulosic biomass-An overview. Bioresour. Technol. 199, 76-82.

Srebotnik, E., Jensen, K., Kawai, S. and Hammel, K.E. (1997) Evidence That Ceriporiopsis subvermispora degrades nonphenolic lignin structures by a one-electron-oxidation mechanism. Appl. Environ. Microbiol. 63, 4435-4440.

Ten Have, R. and Teunissen, P.J. (2001) Oxidative mechanisms involved in lignin degradation by white-rot fungi. Chem. Rev. 101, 3397-3414.

Tian, X.f., Fang, Z. and Guo, F. (2012) Impact and prospective of fungal pre-treatment of lignocellulosic biomass for enzymatic hydrolysis. Biofuels Bioprod. Biorefin. 6, 335-350.

Van Erven, G., De Visser, R., Merkx, D.W., Strolenberg, W., De Gijsel, P., Gruppen, H. and Kabel, M.A. (2017) Quantification of lignin and its structural features in plant biomass using ${ }^{13} \mathrm{C}$ lignin as internal standard for pyrolysis-GC-SIM-MS. Anal. Chem. 89, 10907-10916.

Van Kuijk, S., Sonnenberg, A., Baars, J., Hendriks, W. and Cone, J. (2016a) The effect of adding urea, manganese and linoleic acid to wheat straw and wood chips on lignin degradation by fungi and subsequent in vitro rumen degradation. Anim. Feed Sci. Technol. 213, 22-28.

Van Kuijk, S.J., José, C., Rencoret, J., Gutiérrez, A., Sonnenberg, A.S., Baars, J.J., Hendriks, W.H. and Cone, J.W. (2016b) Selective ligninolysis of wheat straw and wood chips by the white-rot fungus Lentinula edodes and its influence on in vitro rumen degradability. J. Anim. Sci. Biotechnol. 7, 55.

Van Kuijk, S.J.A., Sonnenberg, A.S.M., Baars, J.J.P., Hendriks, W.H. and Cone, J.W. (2015a) Fungal treated lignocellulosic biomass as ruminant feed ingredient: a review. Biotechnol. Adv. 33, 191-202.

Van Kuijk, S.J.A., Sonnenberg, A.S.M., Baars, J.J.P., Hendriks, W.H. and Cone, J.W. (2015b) Fungal treatment of lignocellulosic biomass: Importance of fungal species, colonization and time on chemical composition and in vitro rumen degradability. Anim. Feed Sci. Technol. 209, 40-50.

Van Kuijk, S.J.A., Sonnenberg, A.S.M., Baars, J.J.P., Hendriks, W.H., Del Río, J.C., Rencoret, J., Gutiérrez, A., de Ruijter, N.C.A. and Cone, J.W. (2017) Chemical changes and increased degradability of wheat straw and oak wood chips treated with the white rot fungi Ceriporiopsis subvermispora and Lentinula edodes. Biomass Bioenergy 105, 381-391.

Vanholme, R., Demedts, B., Morreel, K., Ralph, J. and Boerjan, W. (2010) Lignin biosynthesis and structure. Plant. Physiol. 153, 895-905.

Villaverde, J.J., Li, J., Ek, M., Ligero, P. and de Vega, A. (2009) Native lignin structure of Miscanthus $x$ giganteus and its changes during acetic and formic acid fractionation. J. Agric. Food Chem. 57, 6262-6270.

Wen, J.-L., Sun, S.-L., Xue, B.-L. and Sun, R.-C. (2013) Recent advances in characterization of lignin polymer by solution-state nuclear magnetic resonance (NMR) methodology. Materials 6, 359-391. 
Chapter 6 | Mechanistic insight of different fungal species

Yang, R.-H., Li, Y., Wáng, Y., Wan, J.-N., Zhou, C.-L., Wāng, Y., Gao, Y.-N., Mao, W.-J., Tang, L.-H. and Gong, M. (2016) The genome of Pleurotus eryngii provides insights into the mechanisms of wood decay. J. Biotechnol. 239, 65-67.

Yelle, D.J., Kapich, A.N., Houtman, C.J., Lu, F., Timokhin, V.I., Fort, R.C., Ralph, J. and Hammel, K.E. (2014) A highly diastereoselective oxidant contributes to ligninolysis by the white rot basidiomycete Ceriporiopsis subvermispora. Appl. Environ. Microbiol. 80, 7536-7544.

Yuan, T.-Q., Sun, S.-N., Xu, F. and Sun, R.-C. (2011) Characterization of lignin structures and lignincarbohydrate complex (LCC) linkages by quantitative ${ }^{13} \mathrm{C}$ and $2 \mathrm{D}$ HSQC NMR spectroscopy. J. Agric. Food Chem. 59, 10604-10614.

Zeng, J., Helms, G.L., Gao, X. and Chen, S. (2013) Quantification of wheat straw lignin structure by comprehensive NMR analysis. J. Agric. Food Chem. 61, 10848-10857. 
Supplementary information for:

Mechanistic insight in the selective delignification of wheat straw by three whiterot fungal species through quantitative ${ }^{13} \mathrm{C}$-IS Py-GC/MS and whole cell wall HSQC-NMR

Gijs van Erven, Nazri Nayan, Anton S.M. Sonnenberg, Wouter H. Hendriks, John W.

Cone and Mirjam A. Kabel 
Table 6-S1. Identity, structural classification and relative abundance of lignin-derived pyrolysis products by ${ }^{13} \mathrm{C}$-IS Py-GC/MS. Control and fungal-treated wheat straw samples after 7 weeks of treatment. CS Ceriporiopsis subvermispora, PE Pleurotus eryngii, LE Lentinula edodes. Average of triplicates.

\begin{tabular}{|c|c|c|c|c|c|c|c|c|c|c|c|c|}
\hline \# & Compound & $\begin{array}{l}\text { Ret. time } \\
(\mathrm{min})\end{array}$ & $\begin{array}{l}\text { Structural } \\
\text { feature }\end{array}$ & $\begin{array}{l}\text { Sidechair } \\
\text { length }\end{array}$ & $\begin{array}{l}\mathrm{nM}_{\mathrm{w}}{ }^{12} \mathrm{C} \\
\left(\mathrm{g} \cdot \mathrm{mol}^{-1}\right)\end{array}$ & Control & CS1 & $\mathrm{CS} 12$ & PE3 & PE6 & LE8 & LE10 \\
\hline 1 & phenol & 10.03 & $\mathrm{H}$, unsub. & 0 & 94 & 0.7 & 2.0 & 1.9 & 1.1 & 0.9 & 1.5 & 1.6 \\
\hline 2 & guaiacol & 10.31 & G, unsub. & 0 & 124 & 2.1 & 4.2 & 4.0 & 2.7 & 2.5 & 3.2 & 3.4 \\
\hline 3 & 2-methylphenol & 11.29 & $\mathrm{H}$, methyl & $\mathrm{C}_{a}$ & 108 & 0.2 & 0.4 & 0.4 & 0.2 & 0.2 & 0.3 & 0.3 \\
\hline 4 & $\begin{array}{l}\text { 4-methylphenol } \\
\text { MP) }\end{array}$ & 12.23 & $\mathrm{H}$, methyl & $\mathrm{C}_{a}$ & 108 & 0.5 & 1.1 & 1.2 & 0.8 & 0.7 & 0.9 & 1.0 \\
\hline 5 & 4-methylguaiacol & 13.01 & G, methyl & $\mathrm{C}_{a}$ & 138 & 0.7 & 1.0 & 1.0 & 0.9 & 0.9 & 0.9 & 0.9 \\
\hline 6 & 2,4-dimethylphenol & 13.46 & $\mathrm{H}$, methyl & $\mathrm{C}_{a}$ & 122 & 0.1 & 0.2 & 0.2 & 0.1 & 0.1 & 0.1 & 0.2 \\
\hline 7 & 4-ethylphenol & 14.52 & $\mathrm{H}$, ethyl & $\mathrm{C}_{\beta}$ & 122 & 0.1 & 0.1 & 0.1 & 0.1 & 0.1 & 0.1 & 0.1 \\
\hline 8 & 4-ethylguaiacol & 15.19 & G, ethyl & $\mathrm{C}_{\beta}$ & 152 & 0.1 & 0.2 & 0.2 & 0.2 & 0.2 & 0.2 & 0.2 \\
\hline 9 & 4-vinylguaiacol & 16.64 & G, vinyl & $\mathrm{C}_{\beta}$ & 150 & 20.3 & 20.4 & 20.3 & 19.9 & 21.4 & 21.7 & 21.0 \\
\hline 10 & 4-vinylphenol & 16.77 & $\mathrm{H}$, vinyl & $\mathrm{C}_{\beta}$ & 120 & 7.8 & 7.7 & 7.8 & 7.3 & 7.8 & 7.8 & 7.9 \\
\hline 11 & eugenol & 17.26 & G, misc. & $\mathrm{C}_{\gamma}$ & 164 & 0.2 & 0.2 & 0.2 & 0.2 & 0.2 & 0.2 & 0.2 \\
\hline 12 & 4-propylguaiacol & 17.34 & $\mathrm{G}$, misc. & $\mathrm{C}_{\gamma}$ & 166 & 0.1 & 0.2 & 0.2 & 0.2 & 0.2 & 0.2 & 0.2 \\
\hline 13 & syringol & 18.00 & S, unsub. & 0 & 154 & 1.9 & 3.2 & 3.5 & 2.3 & 2.3 & 2.4 & 2.7 \\
\hline 14 & cis-isoeugenol & 18.63 & $\mathrm{G}$, misc. & $\mathrm{C}_{\gamma}$ & 164 & 0.1 & 0.1 & 0.1 & 0.1 & 0.1 & 0.1 & 0.1 \\
\hline 15 & 4-propenylphenol & 19.54 & $\mathrm{H}$, misc. & $\mathrm{C}_{\gamma}$ & 134 & 0.1 & 0.1 & 0.1 & 0.1 & 0.1 & 0.1 & 0.1 \\
\hline 16 & trans-isoeugenol & 19.90 & $\mathrm{G}$, misc. & $\mathrm{C}_{\gamma}$ & 164 & 0.8 & 1.0 & 0.9 & 1.1 & 1.1 & 1.1 & 1.1 \\
\hline 17 & 4-methylsyringol & 20.26 & S, methyl & $\mathrm{C}_{a}$ & 168 & 0.5 & 0.6 & 0.6 & 0.6 & 0.6 & 0.6 & 0.6 \\
\hline 18 & vanillin & 20.35 & $\mathrm{G}, \mathrm{C}_{a}-\mathrm{O}$ & $\mathrm{C}_{a}$ & 152 & 1.2 & 2.1 & 2.3 & 1.4 & 1.2 & 1.4 & 1.4 \\
\hline 19 & 4-propyneguaiacol & 20.64 & $\mathrm{G}$, misc. & $\mathrm{C}_{\gamma}$ & 162 & 0.1 & 0.1 & 0.1 & 0.1 & 0.1 & 0.1 & 0.1 \\
\hline 20 & 4-alleneguaiacol & 20.90 & $\mathrm{G}$, misc. & $\mathrm{C}_{\gamma}$ & 162 & 0.1 & 0.1 & 0.1 & 0.1 & 0.1 & 0.1 & 0.1 \\
\hline 21 & homovanillin & 21.81 & $\mathrm{G}, \mathrm{C}_{\beta^{-}} \mathrm{O}$ & $\mathrm{C}_{\beta}$ & 166 & 0.5 & 0.7 & 0.8 & 0.5 & 0.5 & 0.5 & 0.5 \\
\hline 22 & 4-ethylsyringol & 22.00 & S, ethyl & $\mathrm{C}_{\beta}$ & 182 & 0.0 & 0.0 & 0.1 & 0.1 & 0.0 & 0.0 & 0.0 \\
\hline 23 & acetovanillone & 22.27 & $\mathrm{G}, \mathrm{C}_{a^{-}} \mathrm{O}$ & $\mathrm{C}_{\beta}$ & 166 & 0.3 & 1.1 & 1.2 & 0.6 & 0.5 & 0.6 & 0.7 \\
\hline 24 & 4-hydroxybenzaldehyde & 23.01 & $\mathrm{H}, \mathrm{C}_{a}-\mathrm{O}$ & $\mathrm{C}_{a}$ & 122 & 0.2 & 0.3 & 0.3 & 0.2 & 0.1 & 0.2 & 0.2 \\
\hline 25 & 4-vinylsyringol & 23.32 & S, vinyl & $\mathrm{C}_{\beta}$ & 180 & 2.4 & 2.0 & 2.2 & 2.3 & 2.4 & 2.3 & 2.3 \\
\hline 26 & guaiacylacetone & 23.50 & $\mathrm{G}, \mathrm{C}_{\beta^{-}} \mathrm{O}$ & $\mathrm{C}_{\gamma}$ & 180 & 0.3 & 0.7 & 0.7 & 0.4 & 0.3 & 0.4 & 0.4 \\
\hline 27 & 4-allylsyringol & 23.75 & $\mathrm{~S}$, misc. & $\mathrm{C}_{\gamma}$ & 194 & 0.2 & 0.2 & 0.2 & 0.2 & 0.2 & 0.2 & 0.2 \\
\hline 28 & propiovanillone & 24.18 & $\mathrm{~S}, \mathrm{C}_{a^{-}}-\mathrm{O}$ & $\mathrm{C}_{\gamma}$ & 180 & 0.0 & 0.1 & 0.1 & 0.0 & 0.0 & 0.1 & 0.1 \\
\hline 29 & guaiacyl vinyl ketone & 24.47 & $\mathrm{G}, \mathrm{C}_{a^{-}} \mathrm{O}$ & $\mathrm{C}_{\beta}$ & 178 & 0.1 & 0.2 & 0.2 & 0.1 & 0.1 & 0.1 & 0.1 \\
\hline 30 & vanilloyl acetaldehyde & 24.69 & $\begin{array}{l}\mathrm{G}, \mathrm{C}_{a^{-}} \mathrm{O}, \mathrm{C} \\
\mathrm{O}\end{array}$ & $\mathrm{C}_{\gamma}$ & 194 & 0.2 & 4.3 & 3.9 & 0.9 & 0.6 & 1.5 & 1.5 \\
\hline 31 & cis-4-propenylsyringol & 24.88 & S, misc. & $\mathrm{C}_{\gamma}$ & 194 & 0.1 & 0.1 & 0.1 & 0.1 & 0.1 & 0.1 & 0.1 \\
\hline 32 & 4-propynesyringol & 25.52 & S, misc. & $\mathrm{C}_{\gamma}$ & 192 & 0.1 & 0.1 & 0.1 & 0.1 & 0.2 & 0.1 & 0.1 \\
\hline 33 & 4-allenesyringol & 25.73 & S, misc. & $\mathrm{C}_{\gamma}$ & 192 & 0.1 & 0.1 & 0.1 & 0.1 & 0.1 & 0.1 & 0.1 \\
\hline 34 & trans-4-propenylsyringol & 126.19 & S, misc. & $\mathrm{C}_{\gamma}$ & 194 & 0.9 & 0.8 & 0.9 & 1.0 & 0.6 & 0.9 & 0.9 \\
\hline 35 & dihydroconiferyl alcohol & 26.22 & $\mathrm{~S}, \mathrm{C}_{r}-\mathrm{O}$ & $\mathrm{C}_{\gamma}$ & 182 & 0.1 & 0.1 & 0.1 & 0.1 & 0.1 & 0.1 & 0.1 \\
\hline 36 & syringaldehyde & 26.75 & $\mathrm{~S}, \mathrm{C}_{a}-\mathrm{O}$ & $\mathrm{C}_{a}$ & 182 & 0.7 & 0.8 & 1.0 & 0.7 & 0.7 & 0.6 & 0.7 \\
\hline 37 & cis-coniferyl-alcohol & 26.82 & $\mathrm{G}, \mathrm{C}_{\gamma^{-}} \mathrm{O}$ & $\mathrm{C}_{\gamma}$ & 180 & 1.3 & 1.1 & 1.0 & 1.4 & 1.3 & 1.3 & 1.3 \\
\hline 38 & homosyringaldehyde & 27.75 & $\mathrm{~S}, \mathrm{C}_{\beta^{-}} \mathrm{O}$ & $\mathrm{C}_{\gamma}$ & 196 & 0.3 & 0.4 & 0.5 & 0.3 & 0.3 & 0.3 & 0.3 \\
\hline 39 & acetosyringone & 28.20 & $\mathrm{~S}, \mathrm{C}_{a^{-}}-\mathrm{O}$ & $\mathrm{C}_{\beta}$ & 196 & 0.6 & 1.2 & 1.4 & 0.9 & 0.8 & 0.8 & 0.8 \\
\hline 40 & trans-coniferyl alcohol & 28.55 & $\mathrm{G}, \mathrm{C}_{\gamma^{-}} \mathrm{O}$ & $\mathrm{C}_{\gamma}$ & 180 & 31.6 & 22.4 & 20.0 & 30.0 & 29.8 & 28.3 & 27.7 \\
\hline 41 & trans-coniferaldehyde & 28.92 & $\mathrm{G}, \mathrm{C}_{\gamma^{-}} \mathrm{O}$ & $\mathrm{C}_{\gamma}$ & 178 & 1.8 & 2.0 & 1.8 & 2.1 & 1.9 & 2.0 & 1.9 \\
\hline 42 & syringylacetone & 29.13 & $\mathrm{~S}, \mathrm{C}_{\beta^{-}} \mathrm{O}$ & $\mathrm{C}_{\gamma}$ & 210 & 0.3 & 0.7 & 0.8 & 0.4 & 0.4 & 0.5 & 0.5 \\
\hline 43 & propiosyringone & 29.75 & $\mathrm{~S}, \mathrm{C}_{a}-\mathrm{O}$ & $\mathrm{C}_{\gamma}$ & 210 & 0.0 & 0.1 & 0.1 & 0.1 & 0.1 & 0.0 & 0.1 \\
\hline 44 & syringoyl acetaldehyde & 29.90 & $\begin{array}{l}\mathrm{S}, \mathrm{C}_{a}-\mathrm{O} \\
\mathrm{O}\end{array}$ & $\mathrm{C}_{\gamma}$ & 224 & 0.2 & 3.4 & 4.0 & 1.0 & 0.9 & 1.1 & 1.4 \\
\hline 45 & syringyl vinyl ketone & 30.03 & $\mathrm{~S}, \mathrm{C}_{a}-\mathrm{O}$ & $\mathrm{C}_{\gamma}$ & 208 & 0.0 & 0.1 & 0.1 & 0.1 & 0.1 & 0.0 & 0.0 \\
\hline 46 & dihydrosinapyl alcohol & 30.22 & $\mathrm{G}, \mathrm{C}_{r} \mathrm{O}$ & $\mathrm{C}_{\gamma}$ & 212 & 0.0 & 0.0 & 0.0 & 0.0 & 0.0 & 0.0 & 0.0 \\
\hline 47 & cis-sinapyl alcohol & 32.07 & $\mathrm{~S}, \mathrm{C}_{r^{-}} \mathrm{O}$ & $\mathrm{C}_{\gamma}$ & 210 & 0.9 & 0.6 & 0.6 & 0.8 & 0.8 & 0.7 & 0.7 \\
\hline 48 & trans-sinapyl alcohol & 33.79 & $\mathrm{~S}, \mathrm{C}_{r}-\mathrm{O}$ & $\mathrm{C}_{\gamma}$ & 210 & 16.6 & 9.3 & 10.0 & 13.6 & 13.7 & 11.6 & 11.9 \\
\hline 49 & trans-sinapaldehyde & 34.00 & $\mathrm{~S}, \mathrm{C}_{r}-\mathrm{O}$ & $\mathrm{C}_{\gamma}$ & 208 & 2.0 & 2.3 & 2.4 & 2.4 & 2.3 & 2.1 & 2.0 \\
\hline
\end{tabular}




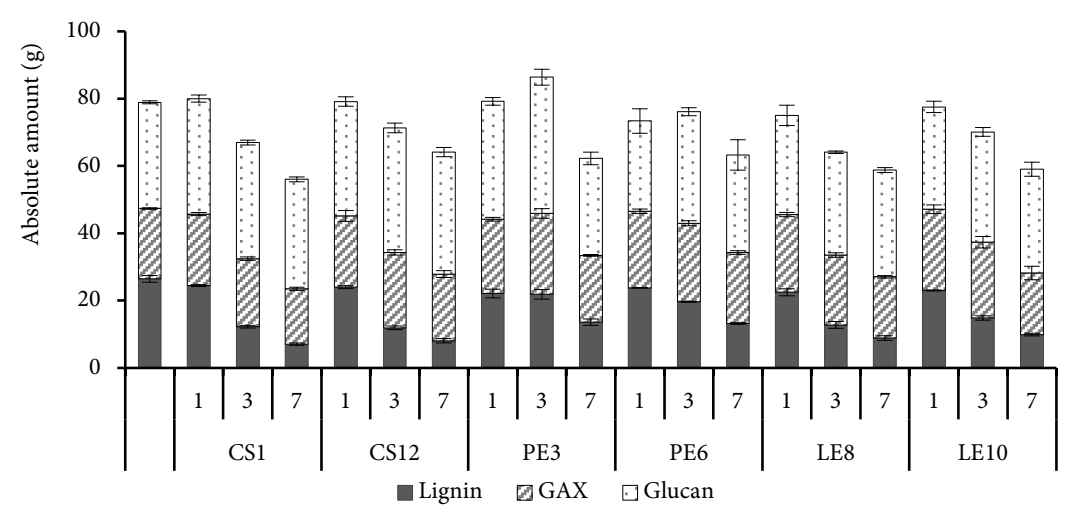

Fig. 6-S1. Residual lignin, glucuronoarabinoxylan (GAX) and glucan (cellulose) in fungal-spent wheat straw during growth (1, 3 and 7 weeks) of $C$. subvermispora (CS), P. eryngii (PE) and $L$. edodes (LE) strains. Average and standard deviation of triplicates.

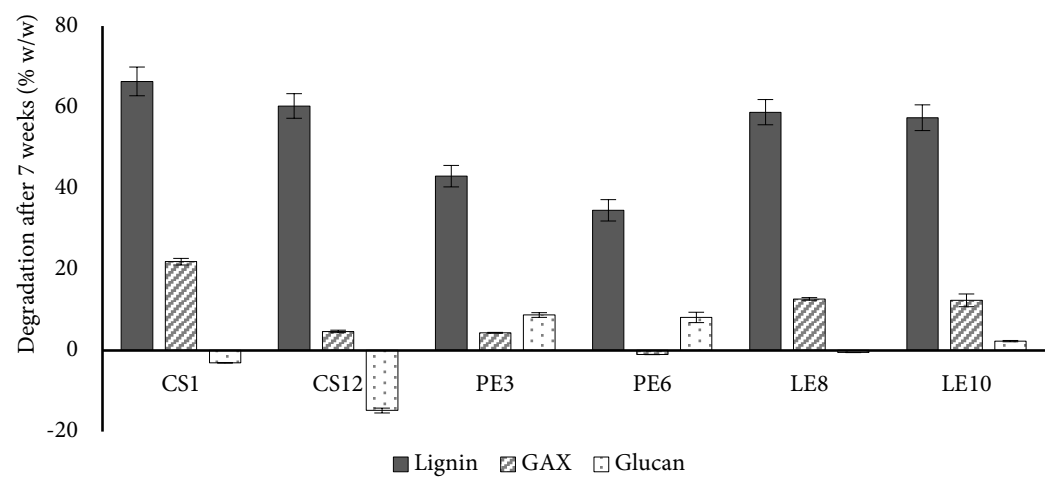

Fig. 6-S2. Lignin, glucuronoarabinoxylan (GAX) and glucan (cellulose) degradation after 7 weeks of fungal growth. Average and standard deviation of triplicates. 

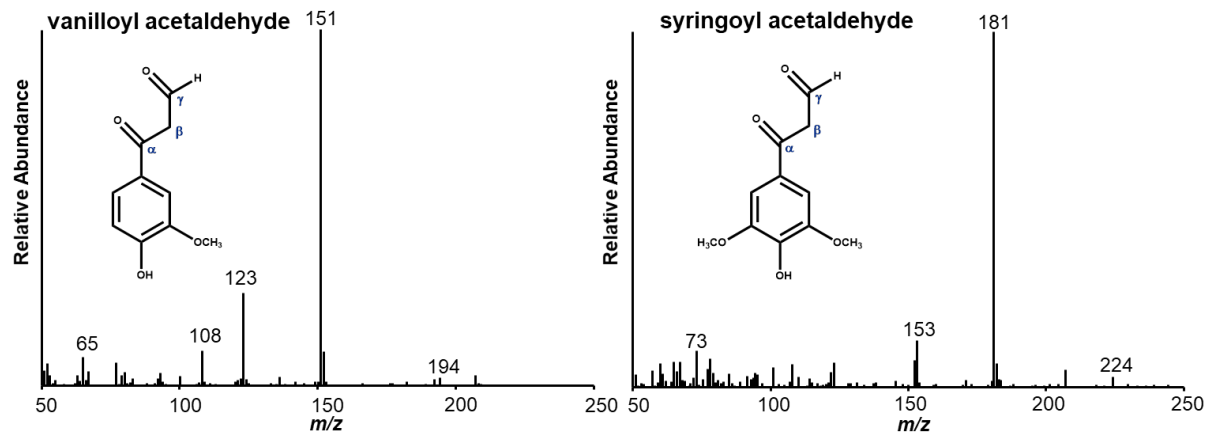

Fig. 6-S3. EI-MS (70 eV) spectra and structures of vanilloyl acetaldehyde (VAL) and syringoyl acetaldehyde (SAL) observed by Py-GC/MS. Compounds were identified on the basis of fragmentation pattern and retention time. Average mass spectrum across the chromatographic peak with noise subtraction at two sides. 
A

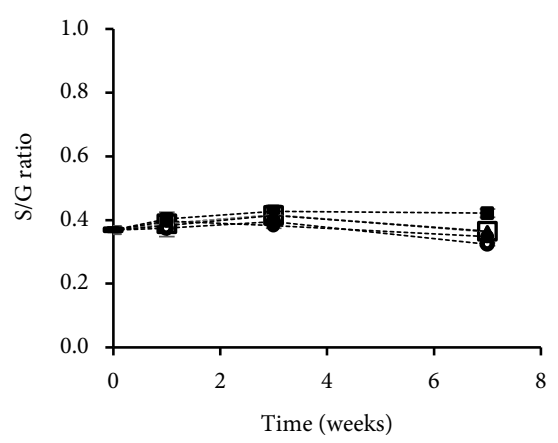

C

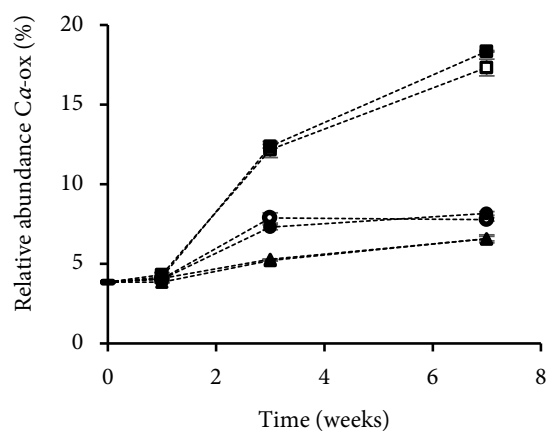

B

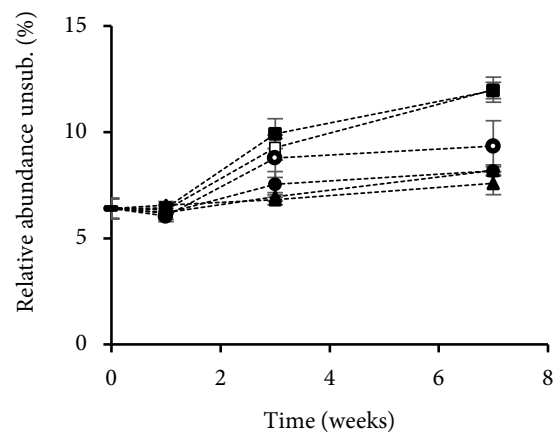

D

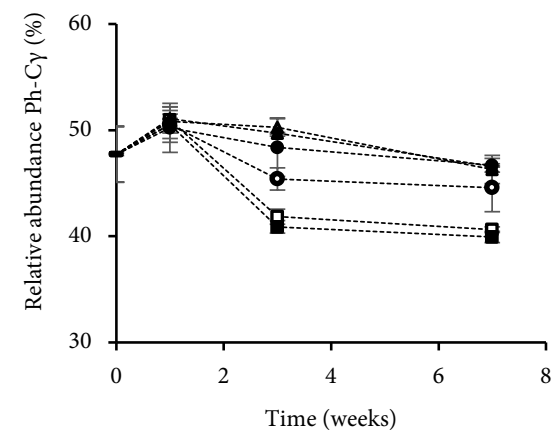

Fig. 6-S4. Structural features of fungal-spent wheat straw lignin during growth (1, 3 and 7 weeks) of C. subvermispora (CS), P. eryngii (PE) and L. edodes (LE) strains as determined by semiquantitative Py-GC/MS. S/G ratio (A) and relative abundances of unsubstituted (B), $\mathrm{C}_{\alpha}$-oxidized (C) and $\mathrm{Ph}-\mathrm{C}_{\gamma}(\mathrm{D})$ substructures are based on the structural classification shown in Supplementary Information Table 6-S1. $\square$ CS1, $\square$ CS12, O PE3, • PE6, $\triangle$ LE8, $\Delta$ LE10. Average and standard deviation of triplicates. 
Table 6-S3. Assignments of the lignin ${ }^{13} \mathrm{C}-{ }^{1} \mathrm{H}$ correlation peaks in the HSQC spectra of untreated and fungal-spent wheat straw. $(\mathrm{t})$ Tentative assignment. Assignment by comparison with literature*

\begin{tabular}{|c|c|c|}
\hline Label & $\delta_{\mathrm{C}} / \delta_{\mathrm{H}}(\mathrm{ppm})$ & Assignment \\
\hline$\overline{A_{a}(G)}$ & $70.9 / 4.70$ & $\mathrm{C}_{\alpha}-\mathrm{H}_{\alpha}$ in $\beta-O-4^{\prime}$ substructures linked to G-unit \\
\hline $\mathrm{A}_{a}(\mathrm{~S})$ & $71.8 / 4.82$ & $\mathrm{C}_{\alpha}-\mathrm{H}_{\alpha}$ in $\beta-O-4^{\prime}$ substructures linked to $\mathrm{S}$-unit \\
\hline $\mathrm{A}_{\beta}(\mathrm{G})$ & $83.5 / 4.25$ & $\mathrm{C}_{\beta}-\mathrm{H}_{\beta}$ in $\beta-O-4$ ' substructures linked to G-unit \\
\hline $\mathrm{A}_{\beta}(\mathrm{S})$ & $85.9 / 4.09$ & $\mathrm{C}_{\beta}-\mathrm{H}_{\beta}$ in $\beta-O-4^{\prime}$ substructures linked to S-unit \\
\hline $\mathrm{C}_{\alpha}$ & $84.9 / 4.64$ & $\mathrm{C}_{\alpha}-\mathrm{H}_{\alpha}$ in resinol substructures \\
\hline $\mathrm{B}_{\alpha}$ & $86.9 / 5.42$ & $\mathrm{C}_{\alpha}-\mathrm{H}_{\alpha}$ in phenylcoumaran substructures \\
\hline $\mathrm{T}_{8}$ & $94.1 / 6.56$ & $\mathrm{C}_{8}-\mathrm{H}_{8}$ in tricin \\
\hline $\mathrm{T}_{6}$ & $98.8 / 6.20$ & $\mathrm{C}_{6}-\mathrm{H}_{6}$ in tricin \\
\hline $\operatorname{Smod}_{2,6}$ & $103.5 / 6.97$ & $\mathrm{C}_{2}-\mathrm{H}_{2}$ and $\mathrm{C}_{6}-\mathrm{H}_{6}$ in S-unit derivative $(\mathrm{t})$ \\
\hline $\mathrm{S}_{2,6}$ & $103.6 / 6.68$ & $\mathrm{C}_{2}-\mathrm{H}_{2}$ and $\mathrm{C}_{6}-\mathrm{H}_{6}$ in S-unit \\
\hline $\mathrm{T}_{2^{\prime} 6^{\prime}}$ & $104.0 / 7.31$ & $\mathrm{C}_{2},-\mathrm{H}_{2}$, and $\mathrm{C}_{6}{ }^{\prime}-\mathrm{H}_{6}$, in tricin \\
\hline $\mathrm{T}_{3}$ & $104.6 / 6.99$ & $\mathrm{C}_{3}-\mathrm{H}_{3}$ in tricin \\
\hline Sox 2,6 & $106.4 / 7.32$ & $\mathrm{C}_{2}-\mathrm{H}_{2}$ and $\mathrm{C}_{6}-\mathrm{H}_{6}$ in $\mathrm{C}_{\mathrm{a}}$-oxidized $\left(\mathrm{C}_{\mathrm{a}}=O\right)$ S-unit \\
\hline Sox $_{2,6}$ & $106.5 / 7.18$ & $\mathrm{C}_{2}-\mathrm{H}_{2}$ and $\mathrm{C}_{6}-\mathrm{H}_{6}$ in $\mathrm{C}_{\mathrm{a}}$-oxidized $\left(\mathrm{C}_{\mathrm{a}} \mathrm{OOH}\right) \mathrm{S}$-unit \\
\hline Sald $_{2,6}$ & $106.3 / 7.03$ & $\mathrm{C}_{2}-\mathrm{H}_{2}$ and $\mathrm{C}_{6}-\mathrm{H}_{6}$ in cinnamaldehyde end-group S-unit \\
\hline $\mathrm{G}_{2}$ & $110.5 / 6.94$ & $\mathrm{C}_{2}-\mathrm{H}_{2}$ in $\mathrm{G}$-unit \\
\hline $\mathrm{FA}_{2}$ & $110.9 / 7.32$ & $\mathrm{C}_{2}-\mathrm{H}_{2}$ in ferulate \\
\hline $\mathrm{GoxI}_{2}$ & $111.4 / 7.53$ & $\mathrm{C}_{2}-\mathrm{H}_{2}$ in $\mathrm{C}_{\mathrm{a}}$-oxidized G-unit \\
\hline $\mathrm{GoxII}_{2}$ & $112.4 / 7.42$ & $\mathrm{C}_{2}-\mathrm{H}_{2}$ in $\mathrm{C}_{\mathrm{a}}$-oxidized G-unit $(\mathrm{t})$ \\
\hline $\mathrm{Gmod}_{2}$ & $112.7 / 6.76$ & $\mathrm{C}_{2}-\mathrm{H}_{2}$ in $\mathrm{G}$-unit derivative $(\mathrm{t})$ \\
\hline $\mathrm{FA}_{\beta} / p \mathrm{CA}_{\beta}$ & $113.9 / 6.51$ & $\mathrm{C}_{\beta}-\mathrm{H}_{\beta}$ in ferulate/ $p$-coumarate (and derivatives) \\
\hline $\mathrm{H}_{3,5} / \mathrm{FA}_{5}$ & $114.5 / 6.69$ & $\mathrm{C}_{3}-\mathrm{H}_{3}$ and $\mathrm{C}_{5}-\mathrm{H}_{5}$ in H-unit, $\mathrm{C}_{5}-\mathrm{H}_{5}$ in FA \\
\hline $\mathrm{G}_{5} / \mathrm{G}_{6} / p \mathrm{CA}_{3,5}$ & $115.1 / 6.94$ and $115.3 / 6.72$ & $\mathrm{C}_{5}-\mathrm{H}_{5}$ and $\mathrm{C}_{6}-\mathrm{H}_{6}$ in G-unit, $\mathrm{C}_{3}-\mathrm{H}_{3}$ and $\mathrm{C}_{5}-\mathrm{H}_{5}$ of $p \mathrm{CA}$ \\
\hline $\mathrm{G}_{5}$ & $118.9 / 6.77$ & $\mathrm{C}_{5}-\mathrm{H}_{5}$ in $\mathrm{G}$-unit \\
\hline $\mathrm{GoxI}_{6}$ & $122.8 / 7.49$ & $\mathrm{C}_{6}-\mathrm{H}_{6}$ in $\mathrm{C}_{\mathrm{a}}$-oxidized G-unit \\
\hline $\mathrm{FA}_{6}$ & $123.1 / 7.12$ & $\mathrm{C}_{6}-\mathrm{H}_{6}$ in ferulate \\
\hline GoxII $_{6}$ & $125.8 / 7.40$ & $\mathrm{C}_{2}-\mathrm{H}_{2}$ in $\mathrm{C}_{\mathrm{a}}$-oxidized G-unit $(\mathrm{t})$ \\
\hline $\mathrm{H}_{2,6}$ & $127.7 / 7.17$ & $\mathrm{C}_{2}-\mathrm{H}_{2}$ and $\mathrm{C}_{6}-\mathrm{H}_{6}$ in $\mathrm{H}$-unit \\
\hline $\operatorname{pdCA}_{2,6}$ & $129.0 / 7.20$ & $\mathrm{C}_{2}-\mathrm{H}_{2}$ and $\mathrm{C}_{6}-\mathrm{H}_{6}$ in $p$-dihydrocoumarate \\
\hline$p \mathrm{CA}_{2,6}$ & $130.1 / 7.48$ & $\mathrm{C}_{2}-\mathrm{H}_{2}$ and $\mathrm{C}_{6}-\mathrm{H}_{6}$ in $p$-coumarate \\
\hline $\mathrm{FA}_{\alpha} / p \mathrm{CA}_{\alpha}$ & $145.0 / 7.56$ & $\mathrm{C}_{\alpha}-\mathrm{H}_{\alpha}$ in ferulate/ $p$-coumarate \\
\hline
\end{tabular}

* Das et al. (2018); Del Río et al. (2012, 2015); Ralph et al. (2009b); Rencoret et al. (2010, 2017); Villaverde et al. (2009); Yuan et al. (2011). Refer to the main text for full references. 

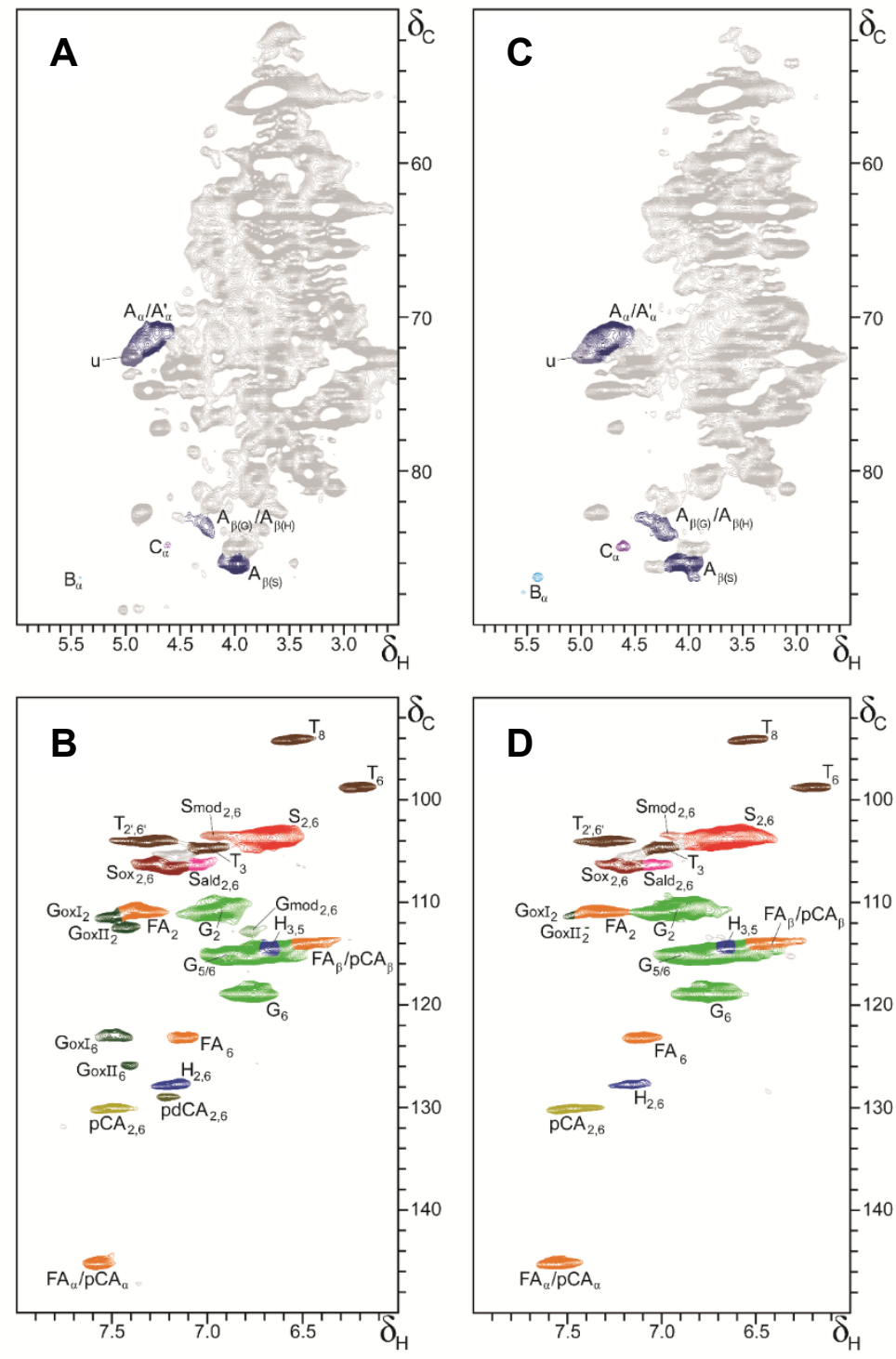

Fig. 6-S5. HSQC NMR spectra of fungal-spent wheat straw. CS12 (A,B), PE3 (C,D), PE6 (E,F) LE8 $(\mathrm{G}, \mathrm{H}) \mathrm{LE} 10(\mathrm{I}, \mathrm{J})$. A,C,E,G,I: aliphatic $\left(\delta_{\mathrm{C}} / \delta_{\mathrm{H}} 50-90 / 2.5-6.0\right)$ region, B,D,F,H,J: aromatic/unsaturated $\left(\delta_{\mathrm{C}} / \delta_{\mathrm{H}} 90-160 / 6.0-8.0\right)$ region. Structures of annotated correlation peaks are presented in Fig. 5. $\mathrm{G}_{\mathrm{mod}}$ and $\mathrm{S}_{\text {mod }}$ are presented in a lighter colour of $\mathrm{G}$ and $\mathrm{S}$, respectively. Carbohydrate and unassigned signals are presented in gray. u: unassigned signal overlapping $\mathrm{A}_{a} / \mathrm{A}^{\prime}{ }_{\alpha}$. 

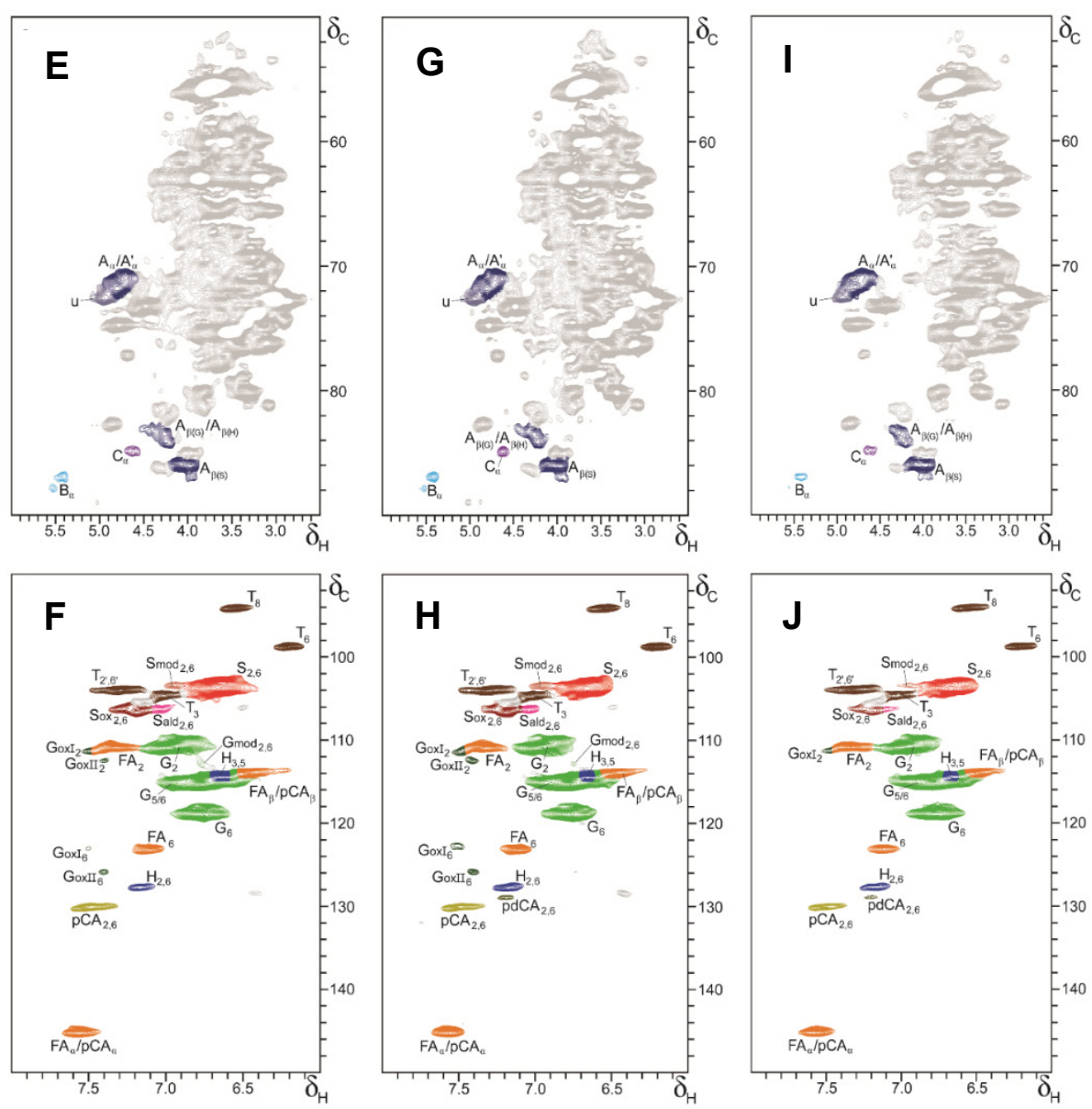

Fig. 6-S5. (continued) 
If you can, help others; if you cannot do that, at least do not harm them.

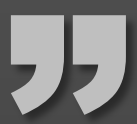

- DALAI LAMA 


\section{CHAPTER}

\section{Improving ruminal digestibility of various wheat straw types by white-rot fungi}

Nazri Nayan ${ }^{1}$, Gijs van Erven ${ }^{2}$, Mirjam A. Kabel ${ }^{2}$, Anton S.M. Sonnenberg ${ }^{3}$, Wouter H. Hendriks ${ }^{1}$, and John W. Cone ${ }^{1}$

J. Sci. Food Agric. (2018). In press.

1 Animal Nutrition Group, Wageningen University, De Elst 1, 6708 WD Wageningen, the Netherlands

2 Laboratory of Food Chemistry, Wageningen University \& Research, Bornse Weilanden 9, 6708 WG Wageningen, The Netherlands

3 Plant Breeding, Wageningen University and Research, Droevendaalsesteeg 1, 6708 PB Wageningen, the Netherlands 


\section{ABSTRACT}

The present study investigated the ruminal degradability of various wheat straw types by the white-rot fungi Ceriporiopsis subvermispora (CS) and Lentinula edodes (LE). Hereto, wheat straw of different maturity stages (MS) and cultivars (CV), were treated with the fungi for 7 weeks and assessed for chemical composition and in vitro gas production (IVGP). Both fungi showed more pronounced degradation of lignin on a more mature straw (MS3; 89.0\%), as compared to the straw harvested at an earlier stage (MS1; 70.7\%). Quantitative ${ }^{13} \mathrm{C}$-IS Py-GC/MS revealed that lignin in more mature straw was degraded and modified to larger extents. In contrast, cellulose was less degraded in MS3, as compared to MS1 ( 8.3 vs. 14.6\%). There was no effect of different MS on the IVGP of the fungal-treated straws. Of different straw cultivars, the extent of lignin degradation varied greatly (47 to $93.5 \%)$. This may explain the significant $(P<$ 0.001) effect of cultivar on the IVGP of the fungal-treated straws. Regardless of the factors tested, both fungi were highly capable to improve the IVGP of all straw types by 15.3 to $47.6 \%$, (as compared to untreated straw), with CS performing better than LE - either on different MS ( $33.6 \%$ vs. $20.4 \%$ ) or CVs ( 43.2 vs. $29.1 \%$ ). The extent of lignin degradation caused by fungal treatment was more pronounced on the more mature and lignified straw, while variable results were obtained with different cultivars. Both fungi were capable of improving the IVGP of various straw types.

Keywords: White-rot fungi; wheat straw cultivar; wheat straw maturity; in vitro gas production; ruminant feed; lignocellulosic biomass. 


\section{INTRODUCTION}

Talorization of lignocellulosic biomass, such as wheat straw, as an alternative feed ingredient is important for a sustainable animal production. To unlock the energy potential of lignocellulose, various physicochemical methods have been used, such as hydrothermal treatment, ammonia fiber expansion and the use of acids and alkaline media (Bals et al., 2010; Hendriks and Zeeman, 2009; Sarnklong et al., 2010). These methods are used to increase the enzymatic accessibility of the structural carbohydrates by breaking the lignin barrier and thus improving the degradability of the feedstock by ruminants. Although they are attractive for industrial-scale applications, due to time efficiency, the potential adverse impact on the environment is a major concern (Isroi et al., 2011). Therefore, biological pretreatments, particular using fungi, have become a favorable approach (Nayan et al., 2017; Tuyen et al., 2012; Van Kuijk et al., 2015a). Some strains of white-rot fungi possess unique capabilities in degrading highly-recalcitrant lignocellulosic biomass, whereby lignin is being selectively degraded, increasing the available carbohydrate contents of the biomass.

The effectiveness of a fungal pretreatment can be influenced by many factors, such as fungal strain, substrate and culture conditions (Tuyen et al., 2013; Van Kuijk et al., 2015a, 2015b). Variability in substrate and culture conditions used, leads to difficulties in comparing the effectiveness of fungi across different studies (Van Kuijk et al., 2015b). The quality of the straw, i.e. ratio of lignin to total carbohydrates, is not only an important factor influencing its digestibility in the rumen (Schiere et al., 2004), but may also affect the effectiveness of a fungal pretreatment (Van Kuijk et al., 2015b). Unfortunately, standardizing the straw for an optimal result is difficult and impractical, considering disparities among the straw types and conditions, as well as the differences in post-harvest residue management (Snyder et al., 2009). The present study was conducted to assess the effect of straw quality on lignocellulose degradation by fungi and the subsequent effect on ruminal degradability of the treated straw.

Straw quality is affected by many factors - among others, maturity stage, cultivar and other factors related to management and environment (Labuschagne et al., 2000; Moore and Jung, 2001). The maturity of the plant, in particular, correlates with the extent of lignin deposition in the plant tissues (Moore and Jung, 2001). The total fiber content increases as the plant matures (lower leaf to stem ratio (Martiniello et al., 1997)) and also the lignin, cellulose and hemicellulose composition changes. As straw consists mainly of fiber $(\sim 85 \%)$, changes in the cell wall composition with maturity may thus have an influence on the lignocellulose degradation by fungi. Another important factor is the 
wheat straw genotype. In wheat breeding, nutrient-use efficiency and disease resistance are among the selection parameters, in contrast to straw quality (Labuschagne et al., 2000; Lammerts Van Bueren et al., 2011).

Recently, high potential strains of the white-rot fungi species Ceriporiopsis subvermispora and Lentinula edodes have been selected for the bioprocessing of wheat straw into ruminant feed (Nayan et al., 2018). To determine if these high potential strains could perform well across different straw types, two independent trials were carried out in the present study. These trials investigated the effect of two main sources of straw variation: (1) different maturity of the straw around harvest and (2) different straw cultivars, on the fungal growth and their persistency in improving the in vitro degradability of the straw. Also the lignin degradation characteristics of wheat straw with different maturities were assessed, using pyrolysis coupled to gas chromatography with mass spectrometry (Py-GC/MS) (Van Erven et al., 2017).

\section{MATERIALS AND METHODS}

\section{Effect of different maturity stages}

\section{Harvesting wheat straw with different maturities}

Wheat straw (Triticum aestivum L.) of the same variety (Quintus) was harvested during the summer of 2015 from the experimental field UNIFARM of Wageningen University. Each harvest covered a plot size of $8.5 \times 1.5 \mathrm{~m}$. Zadoks et al. (1974) codes were used to characterize the following maturity stages of the wheat plant. The first harvest was carried out on 14 July (MS1, code 83 - soft dough development, 37.3\% dry weight), second harvest on 28 July (MS2, code 87 - hard dough development, 41.2\% dry weight) and the third harvest on 11 August (MS3, code 91 - ripening, 64.6\% dry weight). The wheat plants were cut at $10 \mathrm{~cm}$ above the ground and the fresh plants were dried on a drying panel for a week $\left(\sim 60^{\circ} \mathrm{C}\right)$. Prior to chopping, the spike containing the wheat grains was removed, leaving the straw (leaves and stalk) intact. The trimmed straw was chopped into approximately $3 \mathrm{~cm}$ pieces.

\section{Fungal pretreatment of the wheat straw}

The cultures of the white-rot fungi C. subvermispora (CS; CBS 347.63) and L. edodes (LE; sh 03/08) were maintained on malt agar extract, containing $\left(\mathrm{g} \mathrm{L}^{-1}\right): 20.0$ of malt extract, 0.5 of $\mathrm{KH}_{2} \mathrm{PO}_{4}, 0.5$ of $\mathrm{MgSO}_{4} \cdot 7 \mathrm{H}_{2} \mathrm{O}$ and 0.5 of $\mathrm{Ca}\left(\mathrm{NO}_{3}\right)_{2} \cdot 4 \mathrm{H}_{2} \mathrm{O}$ with pH 5.4 at $24^{\circ} \mathrm{C}$. Once the fungi fully colonized the agar surface, spawn was prepared by placing a 
piece of agar culture $(1.5 \times 2.0 \mathrm{~cm})$ into sterilized $\left(121^{\circ} \mathrm{C}, 20 \mathrm{~min}\right)$ sorghum grains. The spawn was incubated at $24^{\circ} \mathrm{C}$ for 4 or 5 weeks. The chopped straw was soaked in water for $3 \mathrm{~d}$ at room temperature and excess water was drained off for $5 \mathrm{~h}$. Adjustments were made based on the final moisture content of the straw - which ranged from 77 (MS1) to $80 \%$ (MS3), for each container $(172 \times 110 \times 70 \mathrm{~mm}$; Combiness, Nevele, Belgium) to contain $41.7 \pm 0.3 \mathrm{~g}$ of dry matter. After autoclaving at $121^{\circ} \mathrm{C}$ for $1 \mathrm{~h}$, the straw was aseptically inoculated with the previously prepared spawn at $10 \%$ of the dry weight. Control (untreated) and fungal-treated wheat straw were incubated in triplicate under solid state fermentation at $24^{\circ} \mathrm{C}$ for 7 weeks in a climate-controlled chamber. All weekly samples were freeze-dried and ground over a $1 \mathrm{~mm}$ sieve using a cross beater mill (100AN, Peppink, Olst, the Netherlands).

\section{Chemical analysis}

Each sample was analyzed for dry matter (DM; ISO 6496, 1999) and ash (ISO 5984, 2002) content. Crude protein was calculated by multiplying the nitrogen content (ISO $5983,2005)$ by 6.25 . The Van Soest et al. (1991) method was used to determine the cell wall composition. Neutral detergent fiber (NDF) was determined using a heat-stable amylase (thermamyl) and alcalase; acid detergent fiber (ADF) and acid detergent lignin (ADL) were determined by boiling the sample in an acid detergent solution, and the latter was further treated with $72 \%(\mathrm{v} / \mathrm{v}) \mathrm{H}_{2} \mathrm{SO}_{4}$. All fiber contents were corrected for ash. Hemicellulose was calculated as the difference between NDF and ADF, while cellulose was calculated as the difference between ADF and ADL. Reducing sugars in the ethanolextract of the straw were determined by measuring the oxidation reaction between the hydrolyzed monosaccharides with copper (II) and neocuproine at $460 \mathrm{~nm}$. Absolute amounts ( $\mathrm{g}$ ) of each component were calculated from the remaining amount $(\mathrm{g})$ of the freeze-dried samples.

\section{Ergosterol estimation}

Fungal biomass was estimated by determining the content of ergosterol. Details of the procedure have previously been described (Nayan et al., 2017; Niemenmaa et al., 2008). Samples ( 200 mg) were saponified with $10 \%(1: 9) \mathrm{KOH} / \mathrm{methanol}$ solution at $80^{\circ} \mathrm{C}$ for $60 \mathrm{~min}$. After cooling, the ergosterol was extracted from the samples through a series of mixing with $1 \mathrm{ml}$ water and $2 \mathrm{ml}$ hexane. The hexane layers from the same sample were collected by centrifuging and pooled into a tube. The pooled hexane layer was dried in a vacuum evaporation system (Rapidvap, Kansas, MO, USA) before re-dissolving in 
methanol. The solution was filtered into a high performance liquid chromatography (HPLC) vial for Waters HPLC-PDA analysis (Alliance HPLC system, Milford, USA). Cholecalciferol (vitamin $\mathrm{D}_{3}$ ) was used as an internal standard. The ergosterol peak was detected at $280 \mathrm{~nm}$.

\section{In vitro gas production (IVGP)}

The in vitro gas production (IVGP) was used to assess the ruminal degradability of the wheat straw. The gas production experiment was performed according to the procedures described by Cone et al. (1996). In brief, rumen fluid was collected from 2 non-lactating cows fed $1 \mathrm{~kg}$ concentrate and grass silage ad libitum. The rumen fluid was filtered through a cheesecloth and mixed (1:2 v/v) with phosphate-bicarbonate buffer solution, which also contained trace elements, hydrolyzed casein, redox indicator and reducing agent (Cone et al., 1996). The samples $(0.5 \mathrm{~g})$ were incubated in $60 \mathrm{ml}$ of buffered rumen fluid for $72 \mathrm{~h}$ and the gas production was automatically registered. The gas production data were fitted to a biphasic model (Groot et al., 1996) to determine the kinetic parameters $\left(A_{n}, B_{n}, C_{n}, t_{R \mathrm{~m} n}, R_{\mathrm{m} n}\right)$, where $n$ is the phase number (1 or 2). $A_{n}$ is the asymptotic gas production $\left(\mathrm{ml} \mathrm{g}^{-1} \mathrm{OM}\right)$ of phase $n ; B_{n}$ is the half time of the maximum gas production (h); $C_{n}$ is a parameter to determine the steepness of the curve; $t_{R \mathrm{~m} n}$ is the time of the maximum fractional rate of substrate degradation (h); and $R_{\mathrm{m} n}$ the maximum fractional rate of substrate degradation $\left(\mathrm{h}^{-1}\right)$.

\section{Quantitative pyrolysis GC/MS with ${ }^{13}$ Clignin as internal standard}

Prior to Py-GC/MS, ground wheat straw $(1 \mathrm{~mm})$ was ball-milled in a MM200 mixer mill (Retsch, Haan, Germany) and biological triplicates were mixed to one replicate. Pyrolysis of the ball-milled sample was carried out as previously described in detail (Van Erven et al., 2017). Briefly, $10 \mu \mathrm{L}$ of a ${ }^{13} \mathrm{C}$ lignin internal standard (IS) solution (1 mg ml ${ }^{1}$ ) was mixed with $\sim 80 \mu \mathrm{g}$ of sample and dried before analysis. Lignin-derived pyrolysis products were monitored in full MS mode on the two most abundant fragments per compound (both ${ }^{12} \mathrm{C}$ and ${ }^{13} \mathrm{C}$ ). Area for each compound was normalized by dividing by the respective relative response factor (RRF). RRF values were updated to system performance by recalculation to obtain an identical relative abundance of lignin-derived pyrolysis products of the ${ }^{13} \mathrm{C}$ IS added to a wheat straw reference sample. Lignin content $(\% \mathrm{w} / \mathrm{w})$ was determined as the sum of lignin-derived pyrolysis products, where RRF corrected areas for each compound were multiplied with the molecular weight of the respective compound and summed instead of the application of the published correction 
factor of 1.057 (Van Erven et al., 2017). Relative abundances of lignin-derived pyrolysis products were based on areas normalized for the ${ }^{13} \mathrm{C}$ analogues from the IS present in the same sample to distinguish matrix and treatment effects. Areas were not corrected for molecular weight before relative abundance determination as previously described by Del Río et al. (2012), as RRF values are mole-based. Compounds were classified according to their structural feature (Table 7-S1) and summed. All samples were prepared and analyzed in triplicate.

\section{Effect of different wheat cultivars}

An independent experiment of assessing the effects of different straw cultivars on the fungal pretreatment was carried out. Wheat straw from five winter wheat cultivars Britannia (CV1), Cellule (CV2), Henrik (CV3), Residence (CV4) and Tabasco (CV5), were purchased from Limagrain (Rilland, the Netherlands). Any remaining spike from the straw was removed prior to chopping. The wheat straw was chopped at $3 \mathrm{~cm}$ length. The chopped straw underwent the same processing and treatment procedures as previously described with the same fungal strains used as mentioned above. Solid state fermentation of the inoculated wheat straw was carried out at $24^{\circ} \mathrm{C}$ for 7 weeks in a climate controlled room with minimum exposure to light. The weekly samples were weighed, freeze-dried and ground over a $1 \mathrm{~mm}$ sieve for further analysis. All samples were subjected to the same chemical and ergosterol analyses as well as IVGP procedure as described above. No Py-GC/MS was conducted on these samples.

\section{Statistics}

Data from both experiments were independently analyzed by analysis of variance using the generalized linear model (GLM) in SAS 9.3, followed by post-hoc multiple comparison using least significance differences. The statistical model for the ergosterol and IVGP data included the effect of levels in each factor (maturity stage 1 to 3; or cultivar 1 to 5), treatment (control, C. subvermispora and L. edodes), week and the interaction effects of all three terms. For chemical analyses, the end point data were analyzed by excluding week and its interaction terms from the previous model. Analysis of pyrolysis data of different maturity stages reflected analytical rather than biological variances as three biological replicates of the same treatment (with an equal amount) were mixed prior to the analysis. Minimum significance threshold level was set at $P<0.05$. Pearson's Product-Moment Correlation $(r)$ coefficients were also determined among the measured variables. 


\section{RESULTS AND DISCUSSION}

\section{Effect of different maturity stages}

\section{Mass balances for the wheat straw at different maturities}

The dry matter, ash content and the mass balances of different wheat straw maturities treated with CS and LE for 7 weeks are reported in Table 7.1. The water holding capacity of the straw was increased with straw maturity, as evident by a 7\% lower DM content of MS3 straw as compared to MS1 and MS2 (Table 7.1). However, the total amounts of OM were not different for the untreated straws at different maturities. To allow a comparison across different maturity stages, the amounts of the quantified nutrients were expressed per $100 \mathrm{~g}$ of starting OM for the respective stages. For the untreated straws, higher amounts of ADL (12.2\%) and cellulose (6\%) were seen with increasing straw maturity. The untreated MS3 straw contained a significantly $(P<0.01)$ higher amount of ADL as compared to the rest. Hemicellulose was significantly $(P<0.001)$ lower in the MS3 straw as compared to its counterparts, while high $(P<0.01)$ amounts of free sugars and crude protein were observed for the MS1 straw.

There were significant $(P<0.001)$ losses of $\mathrm{OM}$ after 7 weeks of fungal pretreatment (17.5 to $25.3 \%$ ), with high losses observed for fungal-treated MS1 straw. LE resulted in a significantly $(P<0.01)$ higher loss of OM compared to CS at any maturity stage. Overall, both fungi significantly $(P<0.001)$ degraded all cell wall components and increased the amount of soluble sugars. A lesser amount of cellulose was degraded when both fungi grew on MS3 compared to MS1 ( 8.3 vs. 14.6\%, respectively). Interestingly, lignin degradation by both fungi was more pronounced on mature straw. The delignification by CS, for instance, was similar when grown on MS1 and MS2 straw ( 82\%), whereas on MS3 straw, CS degraded $98.2 \%$ of the total amount of ADL. The figures for lignin degradation presented here, were higher than that in previous reports (33 to 60\%), which were carried out under similar treatment conditions (Nayan et al., 2017; Tuyen et al., 2012; Van Kuijk et al., 2015a), but at an unknown stage of maturity. Meanwhile, a similar trend was also observed for the hemicellulose with a higher percentage of degradation (66.2 to $79.3 \%$ ) for both fungi. CS consistently resulted in a higher degradation of ADL and hemicellulose compared to LE for all straw maturities. In addition, both fungi also increased $(P<0.001)$ the amount of free sugars in the treated straw, which may arise from the breakdown of the cell wall polysaccharides. The apparent susceptibility of a more mature straw to fungal delignification is of particular interest here. To investigate the delignification characteristics of both fungi, the samples from the control (week 0) and 


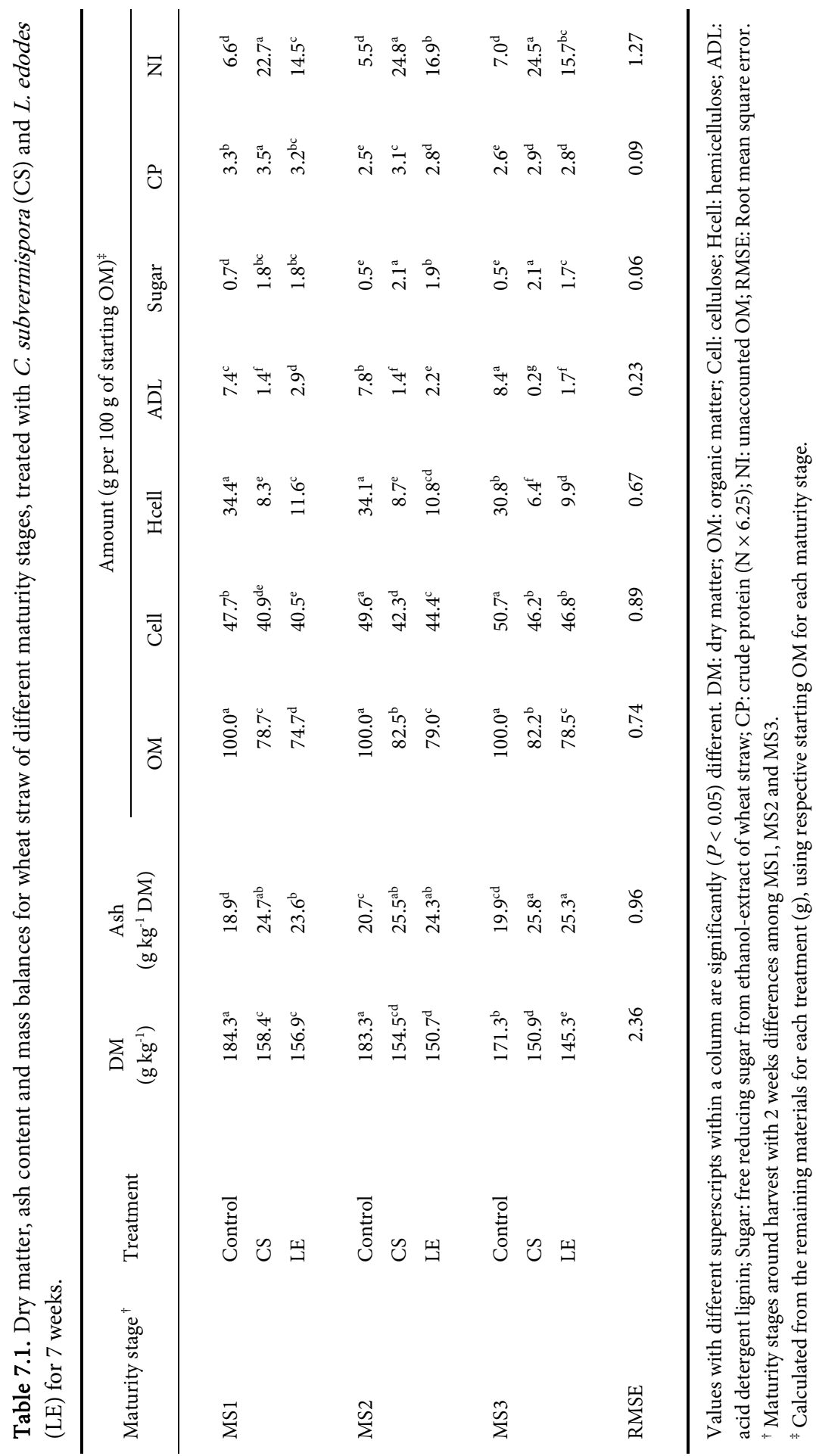


after 7 weeks of fungal pretreatment were subjected to quantitative ${ }^{13} \mathrm{C}$-IS Py-GC/MS analysis. There was an average variation of $8 \%$ in the ADL measurement of biological replicates of the same treatment. Hence, prior to Py-GC/MS, the biological replicates were thoroughly mixed to allow analytical triplicates for detailed and more accurate lignin analysis.

\section{Quantitative ${ }^{13} C-I S$ Py-GC/MS of the wheat straw}

A total of 34 lignin-derived compounds were released upon pyrolysis and monitored (see supporting information Table 7-S1). The lignin content as quantified using ${ }^{13} \mathrm{C}$-IS Py-GC/MS and its structural features are summarized in Table 7.2. Overall, the untreated straws showed comparable amounts of lignin ( 23.8 g per $100 \mathrm{~g} \mathrm{OM})$, which were in contrast to the previous ADL method. It is inferred that the mature straw may contain high amount of recalcitrant residual lignin that was retained in the ADL fraction, which explains a higher ADL in MS3 straw, compared to its counterparts. ADL is known to underestimate the total lignin content, as it does not take into account the acid soluble lignin (Jung et al., 1999). Both methods, however, seem in agreement on the extent of delignification by both fungi. CS showed a higher delignification capability on MS3 straw (87.6\%), compared to MS1 (84.4\%) and MS2 (82.4\%). Similar observations were also recorded for LE-treated MS3 straw (80.1\%), compared to MS1 and MS2 ( 75\%).

To explain this observation, we assessed the lignin structural features of all straws. The untreated MS3 straw contained 6\% more syringyl (S) unit compounds, compared to the other straws. This also resulted in a higher $S$ to guaiacyl $(G)$ ratio in MS3 (0.49), compared to MS1 and MS2 straws ( 0.45). Fungal pretreatment resulted in a minor changes of lignin subunit composition, with slight preference of fungi towards attacking the $S$ units, which is in agreement with previous reports (Del Río et al., 2002; Van Kuijk et al., 2016). The results also indicates that both fungi can degrade all lignin subunits at the magnitudes of lignin removal. The $S$-units result in more linear structures and have a lower redox potential compared to the G-units (Del Río et al., 2012; Vane et al., 2003), which made them more susceptible to the fungal attack (Van Kuijk et al., 2016). Hence, the relatively high S/G ratio may partly explain the higher fungal delignification of MS3 straw. Nevertheless, the $S / G$ ratio was poorly correlated to the total amount of lignin (Pearson's $r=-0.17$ ), due to a smaller change in the $S / G$ ratio. Fungal pretreatment resulted in reduced amounts of vinyl products, mainly 4-Vinylguaicol (Table 7-S1). These compounds are also derived from ferulic acids that links lignin to its associated 


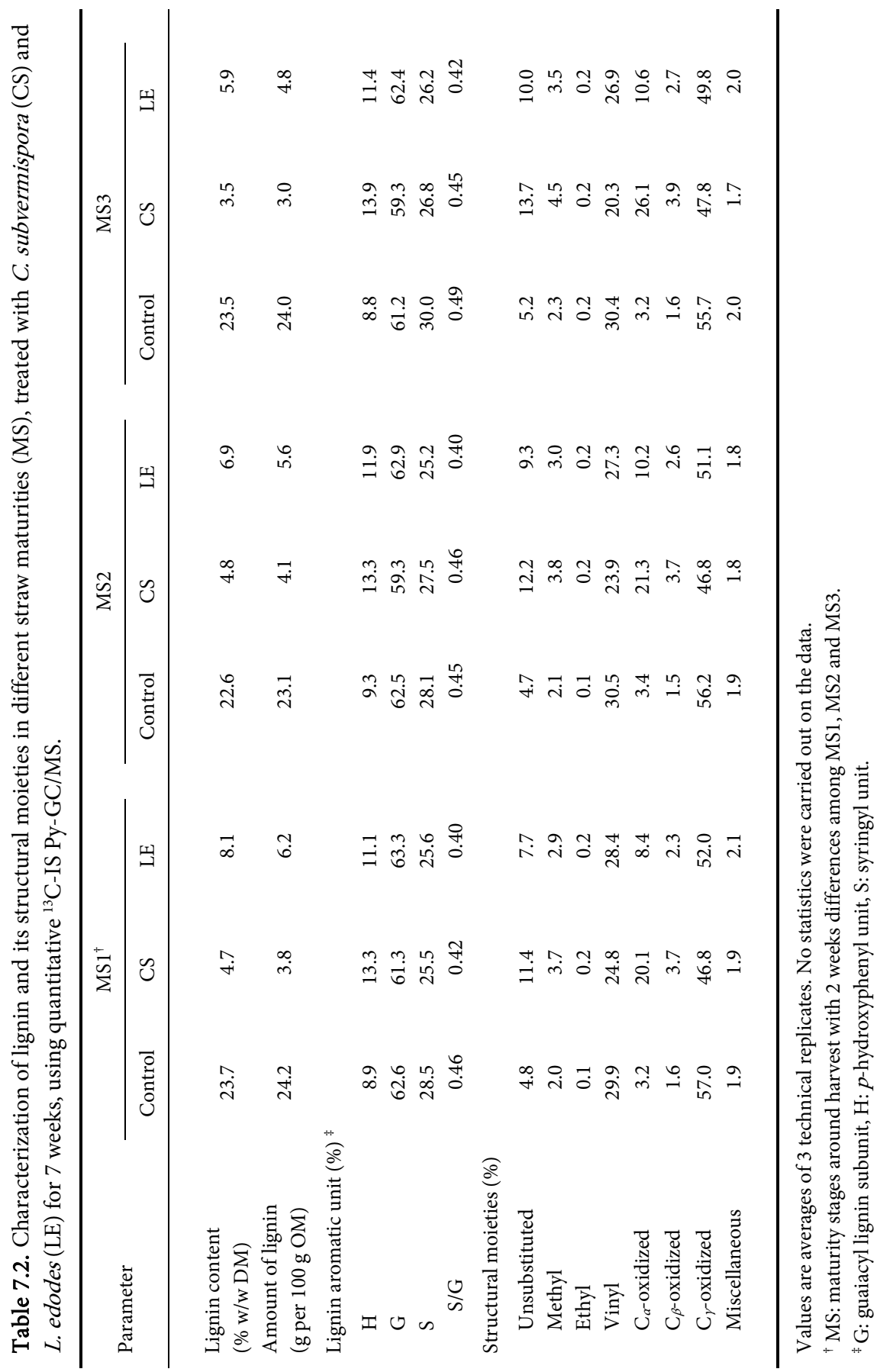


carbohydrates (Buranov and Mazza, 2008). The reduction of vinyl products was more pronounced on the more mature straw, particularly for the CS treatment. Other notable changes including the increases of unsubstituted and $\mathrm{C}_{\alpha}$-oxidized compounds with increasing straw maturity, particularly with the CS treatment, despite no difference was observed in the abundances of these compounds in the untreated straws. These observations clearly indicate more extensive degradation of inter-unit linkages within the lignin macromolecule of the more mature straw, which resulted in residual lignin with low intact linkages (Van Kuijk et al., 2016; Zeng et al., 2014). The ADL and Py-GC/MS assessments confirm the preference of both fungi in degrading the lignin of more mature straw - both by decreasing the amount of residual lignin and structural modifications.

\section{Fungal growth}

A successful colonization of the substrate is an important prerequisite for an effective fungal pretreatment (Van Kuijk et al., 2015b). Therefore, we assessed the growth of both fungi during the 7-week colonization period using an ergosterol assay (Fig. 7.1) (MilleLindblom et al., 2004; Niemenmaa et al., 2008). The baseline ergosterol content at week 0 was significantly $(P<0.001)$ lower in the untreated MS1 straw and increased with increasing maturity. The higher ergosterol content in MS3 straw may be due to its high water potential (high osmotic gradient) which lead to a high activity and growth of field fungi (Magan and Lynch, 1986). Another possible explanation is post-harvest fungal growth, which is a common occurrence (Schmidt et al., 2016). Although all processed straw was autoclaved prior to the fungal pretreatment, the persistence of ergosterol in the sterilized straw has been reported in several other studies (Mille-Lindblom et al., 2004; Nayan et al., 2017). The differences in the baseline ergosterol contents among the straw types produced unique colonization characteristics of both fungi, especially during the early growth stage. The growth of both fungi on MS3 at the beginning of the colonization weeks appeared slower, compared to their growth on MS1 and MS2. It can be that the existing ergosterol (or other components), belonging to the endogenous field fungi, may have 'masked' the initial growth of CS and LE. On MS3 straw, both fungi may have recycled these endogenous compounds and incorporated them in their own biomass, thus thereby erroneously indicating a slower growth or inability of these fungi to colonize the straw during early weeks. The dynamic in the fungal growth could be seen throughout the colonization period, especially for CS, which showed a low persistency in growth. This observation indicates a weaker colonization trait for this fungus on different straw types, compared to LE. 
A

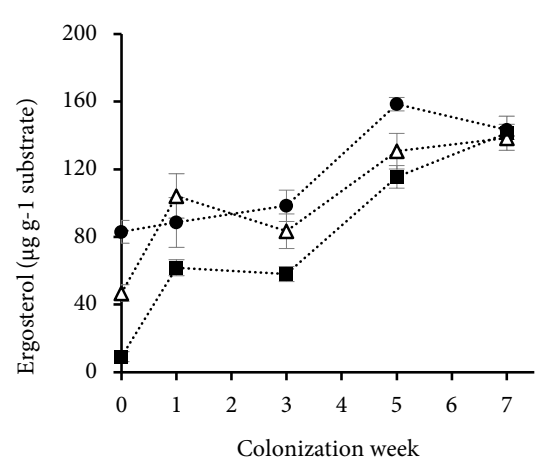

B

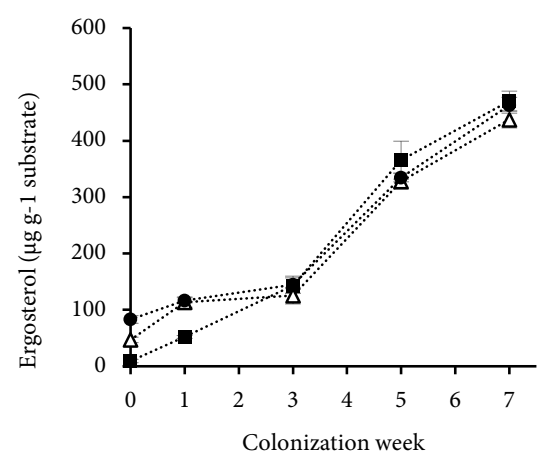

Fig. 7.1. Growth (based on ergosterol data) of C. subvermispora (A) and L. edodes (B) on the wheat straw harvested at different maturity stages - MS1 $(\mathbf{\square}), \operatorname{MS} 2(\triangle)$ and MS3 $(\bullet)$, for 7 weeks. Error bars indicate standard deviations.

\section{Assessing in vitro rumen degradability of the straw}

The effectiveness of both fungi to improve the rumen degradability of the straw was assessed by the in vitro gas production technique (IVGP), which has been used as a decisive parameter in selecting the strains used in the present study (Nayan et al., 2018). Table 7.3 summarizes the IVGP and its kinetic parameters for straw of different maturities, treated with the two fungal species. The changes in IVGP has been well explained by the changes in cell wall composition of the substrate (Tuyen et al., 2012; Van Kuijk et al., 2017). Although the control straws were noticeably different in their cell wall compositions, the IVGPs of all straw maturities were not different. There was no effect of maturity stage on the IVGP of the fungal-treated wheat straws. CS and LE significantly ( $P$ $<0.05$ ) improved the IVGP of all straw types by 33.6 and $20.4 \%$, respectively, which was within the range of previous reports (Nayan et al., 2017, 2018). CS performed significantly $(P<0.05)$ better than LE in improving the degradability of the straw at all stages. The highest increase in the IVGP by both fungal pretreatments was observed on MS1 straw with 38.4 and $23.3 \%$ increases for CS and LE, respectively.

The kinetic parameters were determined using a biphasic model approach (Groot et al., 1996) to differentiate the IVGP profile of all straws. This approach has been used to differentiate the fermentability of two fungal-treated wheat straws with similar total IVGP (Nayan et al., 2017). All fungal treated straws showed a better kinetic profile than control - among others, a shorter half time to the asymptotic gas production $\left(B_{2}\right)$ and a steeper 
Table 7.3. In vitro gas production and its kinetic parameters for wheat straw of different maturity stages, treated with C. subvermispora (CS) and L. edodes (LE) for 7 weeks.

\begin{tabular}{|c|c|c|c|c|c|c|c|c|}
\hline \multirow{2}{*}{$\begin{array}{l}\text { Maturity } \\
\text { stage }^{\dagger}\end{array}$} & \multirow{2}{*}{ Treatment } & \multirow{2}{*}{ IVGP } & \multicolumn{6}{|c|}{ Kinetic parameters } \\
\hline & & & $A_{1}$ & $A_{2}$ & $B_{2}$ & $C_{2}$ & $t_{R \mathrm{~m} 2}$ & $R_{\mathrm{m} 2}$ \\
\hline \multirow[t]{3}{*}{ MS1 } & Control & $241.4^{\mathrm{a}}$ & $32.0^{\mathrm{a}}$ & $193.6^{\mathrm{a}}$ & $13.93^{\mathrm{c}}$ & $2.39^{\mathrm{a}}$ & $15.99^{\mathrm{bc}}$ & $0.087^{\mathrm{a}}$ \\
\hline & CS & $334.2^{\mathrm{de}}$ & $61.4^{\mathrm{b}}$ & $262.8^{\mathrm{de}}$ & $10.52^{\mathrm{a}}$ & $2.88^{\text {cde }}$ & $13.09^{\mathrm{a}}$ & $0.143^{\mathrm{c}}$ \\
\hline & $\mathrm{LE}$ & $297.7^{\mathrm{bc}}$ & $52.3^{\mathrm{b}}$ & $231.5^{\mathrm{b}}$ & $12.72^{\mathrm{b}}$ & $2.74^{\mathrm{b}}$ & $15.57^{\mathrm{b}}$ & $0.112^{\mathrm{b}}$ \\
\hline \multirow[t]{3}{*}{ MS2 } & Control & $250.6^{\mathrm{a}}$ & $34.5^{\mathrm{a}}$ & $198.1^{\mathrm{a}}$ & $14.47^{\mathrm{c}}$ & $2.50^{\mathrm{a}}$ & $17.01^{\mathrm{d}}$ & $0.088^{\mathrm{a}}$ \\
\hline & CS & $323.6^{\text {cde }}$ & $61.5^{\mathrm{b}}$ & $253.2^{\text {cde }}$ & $10.70^{\mathrm{a}}$ & $2.94^{\mathrm{de}}$ & $13.39^{\mathrm{a}}$ & $0.145^{\mathrm{c}}$ \\
\hline & $\mathrm{LE}$ & $307.0^{\mathrm{bcd}}$ & $50.3^{\mathrm{b}}$ & $243.8^{\mathrm{bc}}$ & $13.15^{\mathrm{b}}$ & $2.79^{\mathrm{bc}}$ & $16.20^{\mathrm{bcd}}$ & $0.111^{\mathrm{b}}$ \\
\hline \multirow[t]{3}{*}{ MS3 } & Control & $254.5^{\mathrm{a}}$ & $34.5^{\mathrm{a}}$ & $202.3^{\mathrm{a}}$ & $14.36^{\mathrm{c}}$ & $2.48^{\mathrm{a}}$ & $16.84^{\mathrm{cd}}$ & $0.088^{\mathrm{a}}$ \\
\hline & CS & $339.5^{\mathrm{e}}$ & $60.6^{\mathrm{b}}$ & $269.8^{\mathrm{e}}$ & $10.48^{\mathrm{a}}$ & $3.00^{\mathrm{e}}$ & $13.20^{\mathrm{a}}$ & $0.152^{\mathrm{c}}$ \\
\hline & LE & $293.4^{\mathrm{b}}$ & $37.3^{\mathrm{a}}$ & $245.2^{\mathrm{bcd}}$ & $13.06^{\mathrm{b}}$ & $2.79^{\mathrm{bc}}$ & $16.09^{\mathrm{bc}}$ & $0.112^{\mathrm{b}}$ \\
\hline RMSE & & 17.00 & 7.87 & 10.98 & 0.39 & 0.07 & 0.52 & 0.005 \\
\hline
\end{tabular}

Values with different superscripts within a column are significantly $(P<0.05)$ different. RMSE: Root mean square error; IVGP: cumulative in vitro gas production after $72 \mathrm{~h}\left(\mathrm{ml} \mathrm{g}^{-1} \mathrm{OM}\right) ; A_{1}, A_{2}$ : asymptotic gas production $\left(\mathrm{ml} \mathrm{g}^{-1} \mathrm{OM}\right)$ phase 1 and 2, respectively; $B_{2}$ : half time of the maximum gas production of phase $2(\mathrm{~h}) ; C_{2}$ : parameters determine the curvature of the graph; $t_{R \mathrm{~m} 2}$ : time of the maximum fractional rate of substrate degradation (h); $R_{\mathrm{m} 2}$ : maximum fractional rate of substrate degradation $\left(\mathrm{h}^{-1}\right)$.

${ }^{\dagger}$ Maturity stages around harvest with 2 weeks differences among MS1, MS2 and MS3.

curve (greater $C_{2}$ ). There was no effect of straw maturity on the kinetic parameters of the fungal-treated straws; although a numerical increase of fractional fermentation rate at phase $2\left(R_{\mathrm{m} 2}\right)$ could be seen for CS-treated straws with increasing maturity. This observation indicates a strong capability of both fungi in improving the degradability of these straws to a similar extent.

\section{Effect of different cultivars}

\section{Mass balances for wheat straw of different cultivars}

Table 7.4 summarizes the mass balances of the different wheat straw cultivars, treated and not treated with fungi. There was considerable variation in the amount of nutrients among the different straw cultivars, particularly in the DM and ash contents. The absolute amounts of $\mathrm{OM}$ in the starting materials were comparable among the different untreated 


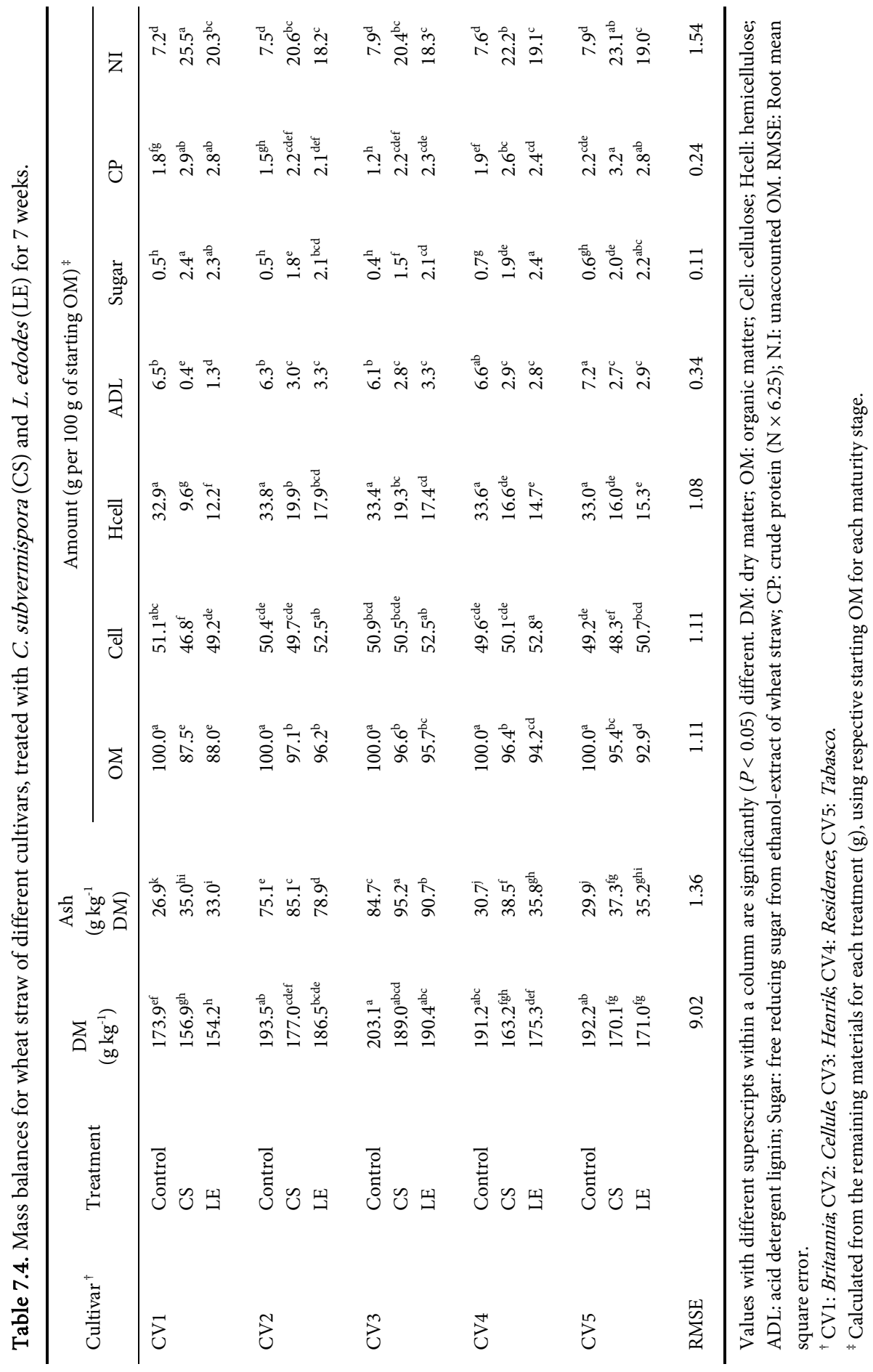


straw cultivars (ranging from 36.3 to $37.6 \mathrm{~g}$; Table 7.4). As in the previous experiment, the amount of nutrients was expressed per $100 \mathrm{~g}$ of starting OM. The starting amounts of all cell wall components were comparable among the different untreated straw cultivars, with CV5 high in lignin. Besides showing a high ash content, the untreated CV2 and CV3 straws contained lower amounts of $\mathrm{CP}$, compared to the other straw cultivars.

There were significant $(P<0.05)$ losses of $\mathrm{OM}$ in all fungal-treated straws, with relatively a higher loss observed for CV1 straw ( 12.2\%). The fungal degradation of lignin and hemicellulose for most straw cultivars were in the range of previous reports (Nayan et al., 2017; Tuyen et al., 2012; Van Kuijk et al., 2015a). The fungal-treated CV1 straw, however, showed high losses of lignin $(\sim 86.5 \%)$ and hemicellulose ( 67.0\%). Previously, CS has been shown to be superior over LE in its delignification capability (Nayan et al., 2018; Tuyen et al., 2012). In the present study, the delignification capability of CS was surprisingly comparable to LE for most straw cultivars (56.2 vs 53.3\%). CS degraded a significantly $(P<0.01)$ higher amount of lignin in CV1, compared to LE (93.5 vs $79.6 \%)$. Significant losses of cellulose were observed for both fungi for the CV1 straw. While other fungal-treated straws showed slight changes in their cellulose contents, a significant increase of cellulose was observed for LE-treated CV2 (4\%) and CV4 straws (6.5\%). Similar observations were also reported in several other studies (Tuyen et al., 2012; Van Kuijk et al., 2015a). The limitation in an accurate quantification of cellulose with regards to the interference of fungal biomass has been previously described (Nayan et al., 2018). Nonetheless, the variable observation in cellulose content among studies (based on the gravimetric method) triggers an intriguing question on how these different types and batches of straw affect the fungal growth and the extent of utilization of the polysaccharides.

\section{Fungal growth}

The growth of both fungi on wheat straw of different cultivars is illustrated in Fig. 7.2. The baseline ergosterol content varied considerably among all five cultivars, ranging from $28.4 \mu \mathrm{g} \mathrm{g}^{-1}$ (CV3) to $71.4 \mu \mathrm{g} \mathrm{g}^{-1}$ (CV5). LE showed a more consistent growth on all straw cultivars, compared to CS, although its overall growth was noticeably lower on CV2 and CV3 straw. Similar to the growth on MS3 in an earlier experiment (with high baseline ergosterol content), the growth of both fungi were more challenged on the CV5 straw. Due to a characteristically less formation of mycelium, CS was more affected by the variable baseline ergosterol content, compared to LE. On CV2 and CV3 straws, the CS 
A

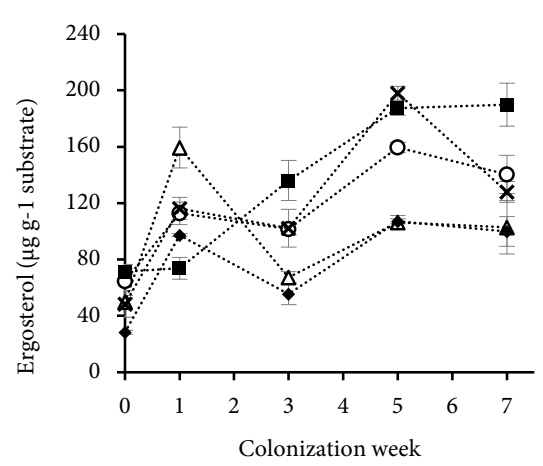

B

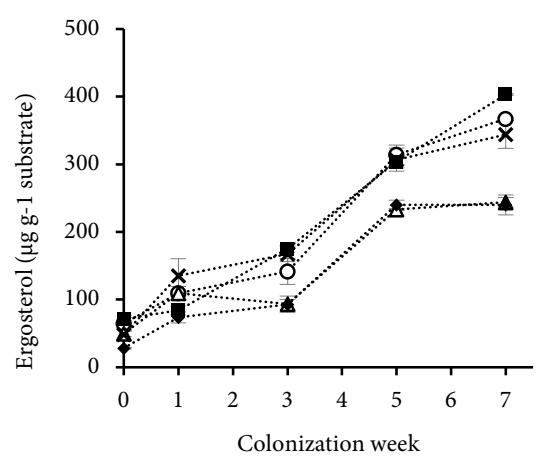

Fig. 7.2. Growth (based on ergosterol data) of C. subvermispora (A) and L. edodes (B) on the wheat straw of different cultivars - CV1 $(\mathrm{O}), \mathrm{CV} 2(\triangle), \mathrm{CV} 3(\bullet), \mathrm{CV} 4(\times)$ and CV5 $(\mathbf{\square})$ for 7 weeks. Error bars indicate standard deviations.

growth appeared 'stunted' after a rapid increase in ergosterol at week 1, before its growth continued at a slower rate towards the end of the colonization weeks. There were also significant $(P<0.05)$ decreases in the ergosterol content of CS grown on CV 1 and CV4 after week 5. These observations further indicate a weaker colonization trait of CS compared to LE on various types of straw used.

\section{Assessing in vitro rumen degradability of the straw}

The IVGP and its kinetic parameters for straw of different cultivars treated with CS and LE are summarized in Table 7.5. There were no differences in the IVGP between the different untreated straws, although a significantly $(P<0.05)$ lower $R_{\mathrm{m} 2}$ was observed for CV3 straw compared to CV1 and CV5. Although both fungi significantly $(P<0.001)$ increased the IVGP of the straws (compared to controls), the magnitude of the effects were significantly $(P<0.001)$ affected by the different straw cultivars. The IVGP of the fungal treated CV2 and CV3 were noticeably lower than the other treated straw cultivars with the difference between CS-treated CV3 and CV4 being significant $(P<0.05)$. In addition, the $R_{\mathrm{m} 2}$ of CV2 and CV3 treated with both fungi were significantly $(P<0.05)$ lower than the other treated straw cultivars. Overall, CS treatment resulted in a significantly $(P<0.05)$ higher increase in the IVGP, compared to LE ( 43 vs. $29 \%)$. 
Table 7.5. In vitro gas production and its kinetic parameters for wheat straw of different cultivars, treated with C. subvermispora (CS) and L. edodes (LE) for 7 weeks.

\begin{tabular}{|c|c|c|c|c|c|c|c|c|}
\hline \multirow{2}{*}{ Cultivar $^{\dagger}$} & \multirow{2}{*}{ Treatment } & \multirow{2}{*}{ IVGP } & \multicolumn{6}{|c|}{ Kinetic parameters } \\
\hline & & & $A_{1}$ & $A_{2}$ & $B_{2}$ & $C_{2}$ & $t_{R \mathrm{~m} 2}$ & $R_{\mathrm{m} 2}$ \\
\hline \multirow[t]{3}{*}{ CV1 } & Control & $223.8^{\mathrm{a}}$ & $16.9^{\mathrm{b}}$ & $199.9^{\mathrm{a}}$ & $14.45^{\mathrm{de}}$ & $2.41^{\mathrm{a}}$ & $16.68^{b c}$ & $0.085^{\mathrm{bcd}}$ \\
\hline & CS & $308.4^{\mathrm{fg}}$ & $49.4^{\mathrm{g}}$ & $255.6^{\mathrm{ef}}$ & $11.20^{\mathrm{a}}$ & $2.86^{\mathrm{d}}$ & $13.91^{\mathrm{a}}$ & $0.135^{j}$ \\
\hline & LE & $282.7^{\text {bcde }}$ & $32.1^{\mathrm{de}}$ & $243.7^{\mathrm{de}}$ & $12.57^{\mathrm{b}}$ & $2.67^{\mathrm{bcd}}$ & $15.22^{\mathrm{ab}}$ & $0.110^{\mathrm{h}}$ \\
\hline \multirow[t]{3}{*}{$\mathrm{CV} 2$} & Control & $205.4^{\mathrm{a}}$ & $6.0^{\mathrm{a}}$ & $191.3^{\mathrm{a}}$ & $15.38^{\text {ef }}$ & $2.41^{\mathrm{a}}$ & $17.76^{\text {cde }}$ & $0.080^{\mathrm{abc}}$ \\
\hline & CS & $294.6^{\text {defg }}$ & $41.9^{\mathrm{efg}}$ & $245.0^{\mathrm{de}}$ & $13.31^{\mathrm{bcd}}$ & $2.55^{\mathrm{abc}}$ & $15.79^{b c}$ & $0.099^{\text {efg }}$ \\
\hline & LE & $269.4^{\mathrm{bc}}$ & $33.5^{\mathrm{de}}$ & $224.6^{b c}$ & $14.39^{\mathrm{de}}$ & $2.53^{\mathrm{abc}}$ & $17.01^{b c}$ & $0.090^{\mathrm{de}}$ \\
\hline \multirow[t]{3}{*}{ CV3 } & Control & $203.9^{\mathrm{a}}$ & $9.2^{\mathrm{ab}}$ & $183.5^{\mathrm{a}}$ & $16.96^{\mathrm{g}}$ & $2.44^{\mathrm{a}}$ & $19.68^{\mathrm{e}}$ & $0.073^{\mathrm{a}}$ \\
\hline & CS & $289.2^{\text {cdef }}$ & $36.7^{\mathrm{def}}$ & $240.7^{\text {cde }}$ & $14.14^{\text {cde }}$ & $2.51^{\mathrm{abc}}$ & $16.63^{b c}$ & $0.091^{\mathrm{def}}$ \\
\hline & LE & $260.7^{\mathrm{b}}$ & $27.5^{\mathrm{cd}}$ & $219.6^{\mathrm{b}}$ & $14.81^{\mathrm{e}}$ & $2.49^{\mathrm{abc}}$ & $17.37^{\mathrm{cd}}$ & $0.086^{\mathrm{cd}}$ \\
\hline \multirow[t]{3}{*}{$\mathrm{CV} 4$} & Control & $213.1^{\mathrm{a}}$ & $9.4^{\mathrm{ab}}$ & $192.8^{\mathrm{a}}$ & $16.28^{\mathrm{fg}}$ & $2.47^{\mathrm{ab}}$ & $19.04^{\mathrm{de}}$ & $0.077^{\mathrm{ab}}$ \\
\hline & CS & $314.4^{\mathrm{g}}$ & $37.9^{\mathrm{def}}$ & $266.9^{f}$ & $12.86^{\mathrm{bc}}$ & $2.73^{\mathrm{cd}}$ & $15.69^{\mathrm{abc}}$ & $0.111^{\mathrm{h}}$ \\
\hline & LE & $281.0^{\text {bcde }}$ & $30.4^{\mathrm{d}}$ & $241.1^{\text {cde }}$ & $13.40^{\mathrm{bcd}}$ & $2.59^{\mathrm{abc}}$ & $16.04^{\mathrm{bc}}$ & $0.099^{\mathrm{fg}}$ \\
\hline \multirow[t]{3}{*}{ CV5 } & Control & $209.9^{\mathrm{a}}$ & $18.2^{\mathrm{bc}}$ & $183.1^{\mathrm{a}}$ & $15.12^{\mathrm{ef}}$ & $2.44^{\mathrm{ab}}$ & $17.56^{\mathrm{cd}}$ & $0.082^{\mathrm{bcd}}$ \\
\hline & CS & $305.2^{\text {efg }}$ & $47.4^{\mathrm{fg}}$ & $252.9^{\mathrm{ef}}$ & $12.23^{\mathrm{ab}}$ & $2.89^{d}$ & $15.24^{\mathrm{ab}}$ & $0.124^{\mathrm{i}}$ \\
\hline & LE & $269.6^{\mathrm{bcd}}$ & $34.9^{\mathrm{de}}$ & $225.8^{b c}$ & $12.58^{\mathrm{b}}$ & $2.62^{\mathrm{abc}}$ & $15.12^{\mathrm{ab}}$ & $0.107^{\text {gh }}$ \\
\hline RMSE & & 13.38 & 6.00 & 10.28 & 0.71 & 0.13 & 1.07 & 0.005 \\
\hline
\end{tabular}

Values with different superscripts within a column are significantly $(P<0.05)$ different. RMSE: Root mean square error; IVGP: cumulative in vitro gas production at $72 \mathrm{~h}\left(\mathrm{ml} \mathrm{g}^{-1} \mathrm{OM}\right) ; A_{1}, A_{2}$ : asymptotic gas production $\left(\mathrm{ml} \mathrm{g}^{-1} \mathrm{OM}\right)$ phase 1 and 2, respectively; $B_{2}$ : half time of the maximum gas production of phase $2(\mathrm{~h}) ; C_{2}$ : parameters determine the curvature of the graph; $t_{R \mathrm{~m} 2}$ : time of the maximum fractional rate of substrate degradation $(\mathrm{h}) ; R_{\mathrm{m} 2}$ : maximum fractional rate of substrate degradation $\left(\mathrm{h}^{-1}\right)$.

${ }^{\dagger}$ CV1: Britannia; CV2: Cellule, CV3: Henrik, CV4: Residence, CV5: Tabasco.

Correlating the IVGP to the fungal growth (ergosterol) is rather complex, although its relationship was statistically significant $(r=0.56 ; P<0.001)$. CS, which possessed a weaker colonization trait on any straw type, resulted in a more degradable straw compared to LE. Hence, the growth 'inconsistency' seen in CS more likely suggests a higher dynamic nutrient utilization and recycling of the field fungi biomass, contributing to an apparent slow growth rate. It does not indicate the inability of this particular fungus to successfully colonize the different straw types. When scaling-up the bioprocess in practice, the slow growth of CS may lead to a problem with undesirable microbial growth on the substrate. Nevertheless, an improved and optimized inoculation method can be 
used to ensure a quick colonization of the substrate. In both trials above, these high potential strains showed a high persistency in improving the degradability of the straw, although different straw cultivars affected the IVGP of the CS and LE treatments. Significant $(P<0.05)$ correlations were found between the IVGP and the cell wall compositions in both trials, with stronger correlations to lignin $(r \sim-0.91)$ and hemicellulose $(r \sim-0.92)$, than to cellulose $(r \sim 0.51)$. Nonetheless, the current results indicate that a careful assessment has to be made when describing the chemical changes (using the unspecific gravimetric method) and relate them to the subsequent changes in IVGP. As aforementioned, the interference of fungal biomass has to be taken into account. Based on this consideration, the IVGP is, therefore, the most potent method in assessing the success and effectiveness of a particular fungus in improving the ruminal degradability of different straw types.

\section{CONCLUSION}

Different straw types influenced the characteristics of $C$. subvermispora and $L$. edodes in degrading lignin. A more pronounced degradation of lignin was observed on mature straw, which was further confirmed by quantitative ${ }^{13} \mathrm{C}-\mathrm{IS}$ Py-GC/MS of the wheat straw. Variable results of lignin degradation were observed with different straw cultivars. Both high potential strains of $C$. subvermispora and L. edodes were able to improve the ruminal degradability of wheat straw, regardless of various straw types (maturity and cultivar) investigated. The magnitude of the effect, however, was only affected by different straw cultivars, but not by different maturities around harvest. Under all circumstances, C. subvermispora was more capable than L. edodes in improving the degradability of wheat straw. L. edodes had a better adaption in colonizing different straw types compared to C. subvermispora.

\section{ACKNOWLEDGEMENTS}

The authors gratefully acknowledge the financial support from the Wageningen UR Fund (WUF) as part of the project "More Meat and Milk from Straw" which is sponsored by DEKA, Forfarmers and the Victam Foundation. The authors would like to acknowledge the scholarship provided by the Ministry of Higher Education Malaysia and Universiti Putra Malaysia. Limagrain is acknowledged for providing the different straw cultivars. 
Chapter 7 | Improving digestibility of various straw types

\section{REFERENCES}

Bals, B., Rogers, C., Jin, M., Balan, V., and Dale, B. (2010). Evaluation of ammonia fibre expansion (AFEX) pretreatment for enzymatic hydrolysis of switchgrass harvested in different seasons and locations. Biotechnol. Biofuels 3, 1-11.

Buranov, A.U., and Mazza, G. (2008). Lignin in straw of herbaceous crops. Ind. Crops Prod. 28, 237-259.

Cone, J.W., van Gelder, A.H., Visscher, G.J.W., and Oudshoorn, L. (1996). Influence of rumen fluid and substrate concentration on fermentation kinetics measured with a fully automated time related gas production apparatus. Anim. Feed Sci. Technol. 61, 113-128.

Del Río, J.C., Rencoret, J., Prinsen, P., Martínez, Á.T., Ralph, J., and Gutiérrez, A. (2012). Structural characterization of wheat straw lignin as revealed by analytical pyrolysis, 2D-NMR, and reductive cleavage methods. J. Agric. Food Chem. 60, 5922-5935.

Del Río, J.C., Speranza, M., Gutiérrez, A., Martínez, M.J., and Martínez, A.T. (2002). Lignin attack during eucalypt wood decay by selected basidiomycetes: A Py-GC/MS study. J. Anal. Appl. Pyrolysis 64, 421431.

Groot, J.C., Cone, J.W., Williams, B.A., Debersaques, F.M.A., and Lantinga, E.A. (1996). Multiphasic analysis of gas production kinetics for in vitro fermentation of ruminant feeds. Anim. Feed Sci. Technol. 64, 77-89.

Hendriks, A.T.W.M., and Zeeman, G. (2009). Pretreatments to enhance the digestibility of lignocellulosic biomass. Bioresour. Technol. 100, 10-18.

Isroi, Millati, R., Syamsiah, S., Niklasson, C., Cahyanto, M.N., Lundquist, K., and Taherzadeh, M.J. (2011). Biological pretreatment of lignocelluloses with white-rot fungi and its applications: A review. BioResources 6, 5224-5259.

Jung, H.J.G., Varel, V.H., Weimer, P.J., and Ralph, J. (1999). Accuracy of Klason lignin and acid detergent lignin methods as assessed by bomb calorimetry. J. Agric. Food Chem. 47, 2005-2008.

Labuschagne, P.., Eicker, A., Aveling, T.A.., de Meillon, S., and Smith, M.. (2000). Influence of wheat cultivars on straw quality and Pleurotus ostreatus cultivation. Bioresour. Technol. 71, 71-75.

Lammerts Van Bueren, E.T., Jones, S.S., Tamm, L., Murphy, K.M., Myers, J.R., Leifert, C., and Messmer, M.M. (2011). The need to breed crop varieties suitable for organic farming, using wheat, tomato and broccoli as examples: A review. NJAS - Wageningen J. Life Sci. 58, 193-205.

Magan, N., and Lynch, J.M. (1986). Water potential, growth and cellulolysis of fungi involved in decomposition of cereal residues. J. Gen. Microbiol. 132, 1181-1187.

Martiniello, P., Paoletti, R., and Berardo, N. (1997). Effect of phenological stages on dry matter and quality components in lucerne. Eur. J. Agron. 6, 79-87.

Mille-Lindblom, C., von Wachenfeldt, E., and Tranvik, L.J. (2004). Ergosterol as a measure of living fungal biomass: persistence in environmental samples after fungal death. J. Microbiol. Methods 59, 253-262.

Moore, K.J., and Jung, H.-J.G. (2001). Lignin and Fiber Digestion. J. Range Manag. 54, 420.

Nayan, N., Sonnenberg, A.S.M., Hendriks, W.H., and Cone, J.W. (2017). Differences between two strains of Ceriporiopsis subvermispora on improving the nutritive value of wheat straw for ruminants. J. Appl. Microbiol. 123, 352-361.

Nayan, N., Sonnenberg, A.S.M., Hendriks, W.H., and Cone, J.W. (2018). Screening of white-rot fungi for bioprocessing of wheat straw into ruminant feed. J. Appl. Microbiol. 125, 368-379.

Niemenmaa, O., Galkin, S., and Hatakka, A. (2008). Ergosterol contents of some wood-rotting basidiomycete fungi grown in liquid and solid culture conditions. Int. Biodeterior. Biodegradation 62, 125-134. 
Sarnklong, C., Cone, J.W., Pellikaan, W., and Hendriks, W.H. (2010). Utilization of Rice Straw and Different Treatments to Improve Its Feed Value for Ruminants: A Review. Asian-Australasian J. Anim. Sci. 23, 680-692.

Schiere, J.B., Joshi, A.L., Seetharam, A., Oosting, S.J., Goodchild, A. V., Deinum, B., and Van Keulen, H. (2004). Grain and straw for whole plant value: Implications for crop management and genetic improvement strategies. Exp. Agric. 40, 277-294.

Schmidt, M., Horstmann, S., De Colli, L., Danaher, M., Speer, K., Zannini, E., and Arendt, E.K. (2016). Impact of fungal contamination of wheat on grain quality criteria. J. Cereal Sci. 69, 95-103.

Snyder, C.S., Bruulsema, T.W., Jensen, T.L., and Fixen, P.E. (2009). Review of greenhouse gas emissions from crop production systems and fertilizer management effects. Agric. Ecosyst. Environ. 133, 247-266.

Tuyen, V.D., Phuong, H.N., Cone, J.W., Baars, J.J.P., Sonnenberg, A.S.M., and Hendriks, W.H. (2013). Effect of fungal treatments of fibrous agricultural by-products on chemical composition and in vitro rumen fermentation and methane production. Bioresour. Technol. 129, 256-263.

Tuyen, V.D., Cone, J.W., Baars, J.J.P., Sonnenberg, A.S.M., and Hendriks, W.H. (2012). Fungal strain and incubation period affect chemical composition and nutrient availability of wheat straw for rumen fermentation. Bioresour. Technol. 111, 336-342.

Van Erven, G., De Visser, R., Merkx, D.W.H., Strolenberg, W., De Gijsel, P., Gruppen, H., and Kabel, M.A. (2017). Quantification of lignin and its structural features in plant biomass using ${ }^{13} \mathrm{C}$ lignin as internal standard for pyrolysis-GC-SIM-MS. Anal. Chem. 89, 10907-10916.

Van Kuijk, S.J.A., Del Río, J.C., Rencoret, J., Gutiérrez, A., Sonnenberg, A.S.M., Baars, J.J.P., Hendriks, W.H., and Cone, J.W. (2016). Selective ligninolysis of wheat straw and wood chips by the white-rot fungus Lentinula edodes and its influence on in vitro rumen degradability. J. Anim. Sci. Biotechnol. 7, 55.

Van Kuijk, S.J.A., Sonnenberg, A.S.M., Baars, J.J.P., Hendriks, W.H., and Cone, J.W. (2015a). Fungal treatment of lignocellulosic biomass: Importance of fungal species, colonization and time on chemical composition and in vitro rumen degradability. Anim. Feed Sci. Technol. 209, 40-50.

Van Kuijk, S.J.A., Sonnenberg, A.S.M., Baars, J.J.P., Hendriks, W.H., and Cone, J.W. (2015b). Fungal treated lignocellulosic biomass as ruminant feed ingredient: A review. Biotechnol. Adv. 33, 191-202.

Van Kuijk, S.J.A., Sonnenberg, A.S.M., Baars, J.J.P., Hendriks, W.H., del Río, J.C., Rencoret, J., Gutiérrez, A., de Ruijter, N.C.A., and Cone, J.W. (2017). Chemical changes and increased degradability of wheat straw and oak wood chips treated with the white rot fungi Ceriporiopsis subvermispora and Lentinula edodes. Biomass Bioenergy 105, 381-391.

Van Soest, P.J., Robertson, J.B., and Lewis, B.A. (1991). Methods for dietary fiber, neutral detergent fiber, and nonstarch polysaccharides in relation to animal nutrition. J. Dairy Sci. 74, 3583-3597.

Vane, C.H., Drage, T.C., and Snape, C.E. (2003). Biodegradation of oak (Quercus alba) wood during growth of the shiitake mushroom (Lentinula edodes): A molecular approach. J. Agric. Food Chem. 51, 947-956.

Zadoks, J.C., Chang, T.T., and Konzak, C.F. (1974). A Decimal Code for the Growth Stages of Cereals. Weed Res. 14, 415-421.

Zeng, J., Singh, D., Gao, D., and Chen, S. (2014). Effects of lignin modification on wheat straw cell wall deconstruction by Phanerochaete chrysosporium. Biotechnol. Biofuels 7, 161. 
Supplementary information for:

\section{Improving ruminal digestibility of various wheat straw types by white-rot fungi}

Nazri Nayan, Gijs van Erven, Mirjam A. Kabel, Anton S.M. Sonnenberg, Wouter H. Hendriks, and John W. Cone 


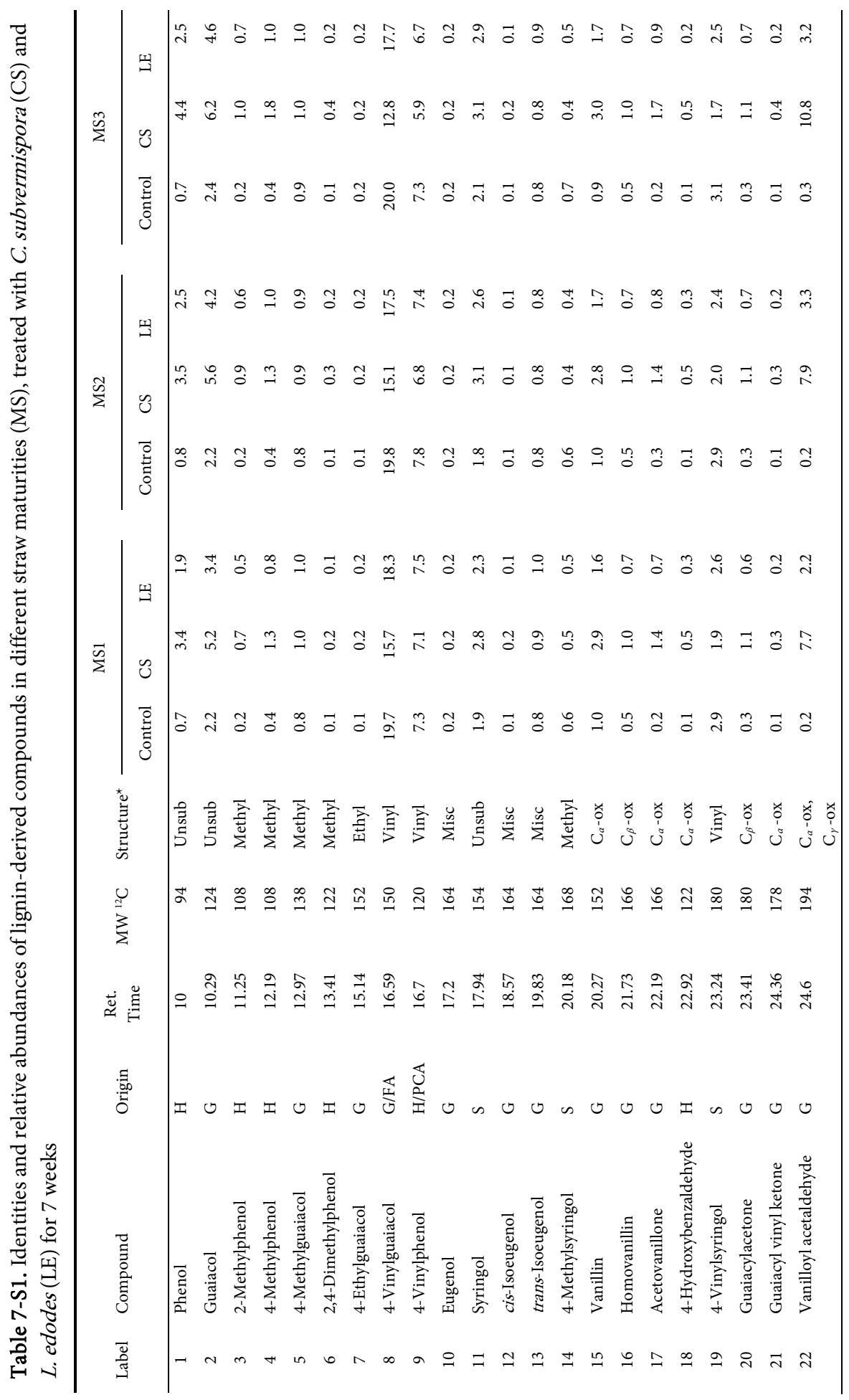


Chapter 7 | Improving digestibility of various straw types

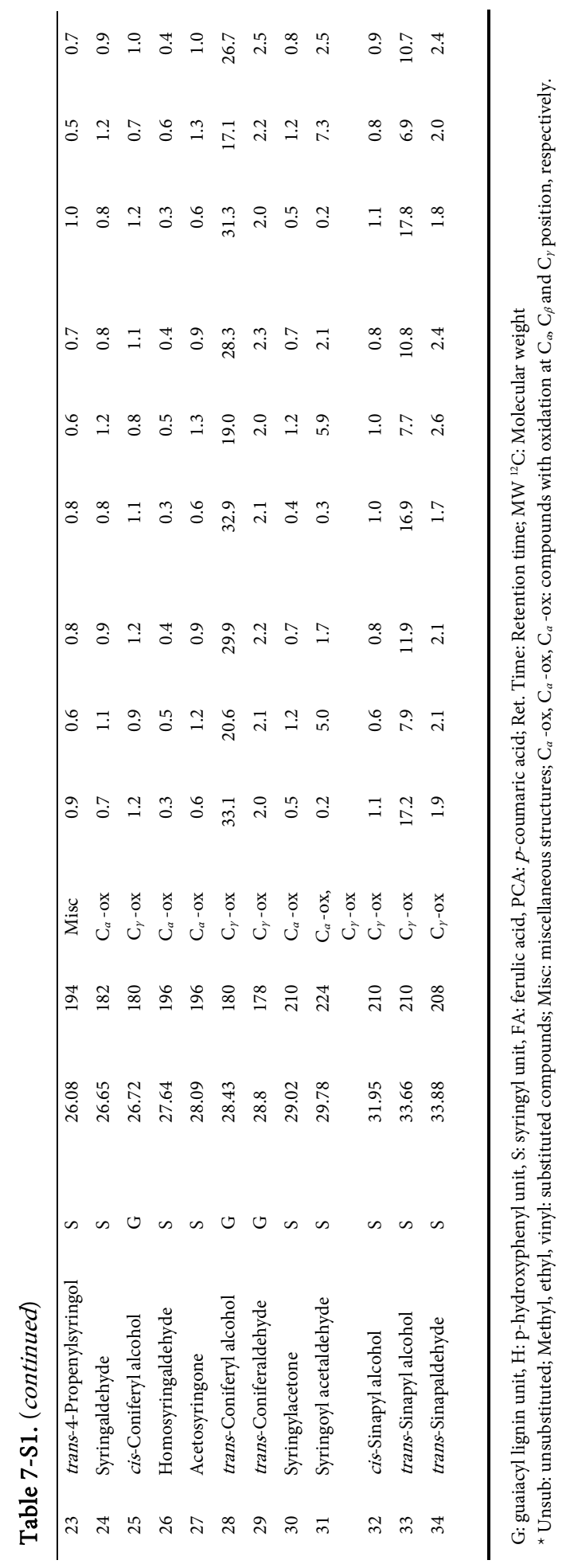


Chapter 7 | Improving digestibility of various straw types 


\section{4}

\section{Be kind, for whenever kindness}

becomes part of something, it beautifies it. Whenever it is taken from something, it leaves it tarnished.

- MUHAMMAD 


\section{General discussion}





\section{Understanding fungal variations}

7 he main focus of this thesis is to discern biological variation among different strains/species and select the best performing fungi as candidates for the bioprocessing of wheat straw into ruminant feed. In addition, the capabilities of the selected fungi in improving the degradability of various straw types were also studied. The selected high potential fungi were assessed for their capabilities to solubilize protein, modify lignin structures and improve various types of wheat straw. In Chapter 2, only two different strains of $C$. subvermispora were assessed to better understand variation that may exist between the two genetically related fungi. A qualitative assessment of 3 main lignin-degrading enzymes - lignin peroxidase (LiP), manganese peroxidase (MnP) and laccase, was performed in an attempt to relate the activity of these enzymes to the changes observed in other measured variables, in particular the lignin (ADL) content, and to see if this could be a potential selection parameter for Chapter 3. The results, however, showed no correlation of enzyme activities to the changes in the ADL content over the 7week period, which is in agreement with previous reports (Sharma and Arora, 2010; Shrivastava et al., 2011). This emphasizes the limited knowledge we have on the mechanism involved in the degradation of lignocellulose by these fungi and, for the time being, the inability to use enzyme assays in selecting the right fungi for the purpose in Chapter 3. A secretome analysis could be an answer for an in-depth understanding of variation in the enzyme expressions by different fungal species (Bianco and Perrotta, 2015). Other variables that are not measured, but might be significant to the understanding of fungal variations, include production of organic acids and secondary metabolites. In general, three basic parameters were used in the main experimental chapters (Chapter 2, 3 and 7) to assess the performance of each fungus tested: (1) the fermentation in rumen fluid, using the in vitro gas production (IVGP) technique, (2) assessment of fungal growth using ergosterol assay and (3) mass balance.

\section{Gas production as a screening criterion}

In Chapter 2, a distinct characteristic of two genetically related fungi was revealed, particularly in their growth and the kinetics of IVGP, although there was only a slight difference in the total IVGP of both fungal-treated wheat straws after 7 weeks. The assessment of IVGP is important as a tool of research in this thesis, since this is a good indicator for the fermentability in the rumen of ruminants (Cone et al., 1996). Therefore, the IVGP was used as a decisive screening parameter for the best performing fungi in Chapter 3. In the literature, several studies carried out fungal screening based on their 
enzyme activities (Chang et al., 2012; Cruz Ramírez et al., 2012), and some studies assessed the changes in the lignin and carbohydrate contents as criteria to screen for selective fungi (Blanchette, 1984; Li et al., 2008; Tripathi et al., 2008). While the inconvenience of enzyme assays has been described earlier, the assessment of the changes in the cell wall compositions and other nutrients using the standard laboratory analyses are reliable methods to examine the selectivity of fungi. However, the data obtained in Chapter 3 and 7 show that the changes in cell wall contents as determined by the routine method (Van Soest et al., 1991), does not always explain the subsequent effect on the gas production. For instance, strain CS12 degraded 17.6\% of the ADL content, while strain PE2 caused a significantly higher loss of ADL (23.5\%). However, a significantly higher IVGP was observed for CS12-treated wheat straw compared to PE2 (291.5 vs. $257.9 \mathrm{ml} \mathrm{g}$ ${ }^{1} \mathrm{OM}$ ) (Chapter 3). In Chapter 7, the ADL content of the untreated straw increased with increasing maturity; their IVGPs, however, were not significantly different. In addition, the ADL method underestimates the total lignin content due to the loss of acid-soluble lignin (Jung et al., 1999), which is definitely a major shortcoming in quantifying the true extent of delignification by a particular fungus. As discussed in Chapter 3, 5 and 7, one of the limitations of using the Van Soest et al. (1991) method to quantify the cell wall components, particularly cellulose, is the inclusion of chitin and $\beta$-glucan from fungal biomass in the acid detergent fraction, which will be discussed in a later section. The structural similarities of fungal biomass with the substrate polymers contribute to inaccuracy in mass balance. These observations suggest the insufficiency of this routine method in assessing the effectiveness of a particular fungus. The relevance of using the Van Soest method in explaining the subsequent effect on IVGP has been discussed in a greater depth in Chapter 5. Based on these premises, the IVGP is, therefore, a robust and effective technique in selecting the best performing fungal strain/species.

Assessment of the IVGP showed a clear variation in the capabilities of different strains within a particular fungal species, as illustrated in Fig. 8.1. The IVGP values (for all individual observations) ranged from 205.5 to $317.8 \mathrm{ml} \mathrm{g}^{-1} \mathrm{OM}$ for $C$. subvermispora strains; while the ranges of IVGP for P. eryngii and L. edodes strains were 206.6 to 267.0 and 183.5 to $306.6 \mathrm{ml} \mathrm{g}^{-1} \mathrm{OM}$, respectively. The mean IVGP of the untreated straw was $227.7 \pm 0.5 \mathrm{ml} \mathrm{g}^{-1} \mathrm{OM}$. This shows that not all strains of these previously identified high potential fungal species (Tuyen et al., 2012) can result in a significant improvement of the nutritive value of wheat straw. The boxplot (Fig. 8.1) also shows a larger variation among C. subvermispora and L. edodes strains compared to P. eryngii. Nonetheless, a higher 


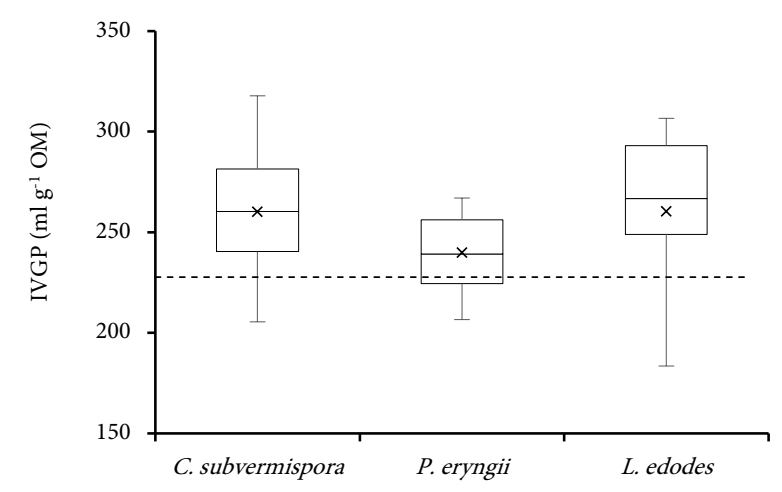

Fig. 8.1. Boxplot showing the variation in in vitro gas production (IVGP) of wheat straw treated with different strains for each fungal species after 7 weeks. Mean values are indicated with ' $x$ '. Dashed-line indicates the mean for IVGP of the untreated wheat straw $\left(227.7 \mathrm{ml} \mathrm{g}^{-1} \mathrm{OM}\right)$. The whiskers indicate the variability outside the upper and lower quartiles.

number of $L$. edodes strains were able to improve the straw degradability (median $=266.7$ $\mathrm{ml} \mathrm{g}^{-1} \mathrm{OM}$ ), followed by C. subvermispora and P. eryngii with a median of 260.3 and 239.3 $\mathrm{ml} \mathrm{g}^{-1} \mathrm{OM}$, respectively. Three strains for each species with a high potential in improving the ruminal degradability of wheat straw were selected in Chapter 3. They were (in order of IVGP for each species): CS1, CS6 and CS12 (C. subvermispora); PE6, PE2 and PE3 ( $P$. eryngii); LE8, LE7 and LE10 (L. edodes). The selection carried out in Chapter 3 was based on the maximum IVGP reached after 7 weeks of treatment; its changes over time, however, have not being discussed or considered in the selection although the measurement for the weekly samples were also done. There are two reasons to justify this decision. First, the changes in IVGP over time for all treatments followed a similar pattern as previously reported in Chapter 2 and the literature (Tuyen et al., 2012; Van Kuijk et al., 2015), where a decrease in IVGP was observed at the beginning of the colonization weeks. In general, all C. subvermispora and L. edodes strains caused a decrease in the IVGP in the first week, before increasing until the end of the treatment period; while decreases of up to 3 week were observed for $P$. eryngii strains. Secondly, none of the IVGP values of the earlier weeks was significantly higher than the IVGP at week 7, except a numerical decrease was observed for LE6-treated straw (286.6 to $283.2 \mathrm{ml} \mathrm{g}^{-1} \mathrm{OM}$ ). Meanwhile, only wheat straw treated with LE4 and LE5 showed a constant decrease in the IVGP from the beginning of the colonization week. The two fungi were not capable of colonizing the wheat straw. These considerations support the reliability of the assessment (and 
screening) of fungi based on the IVGP after 7 weeks of treatment in Chapter 3. Nonetheless, selection based on the time of improvement in IVGP is undeniably important, especially when it comes to implementing this pretreatment method at an industrial scale, where efficiency in time matters. This selection perspective, together with other possible interventions to accelerate fungal pretreatment, can be considered for future research.

\section{Fungal growth and the difficulties in mass balances}

The ergosterol assay has been used to estimate fungal growth in Chapter 2, 3 and 7. With proper storage and care, the ergosterol in the untreated straw, which may originate from dead field fungi, are persistent even after autoclaving, although it can be subjected to photochemical degradation (Mille-Lindblom et al., 2004). There were considerable variations in the mean ergosterol contents measured for the untreated straw in Chapter 2, 3 and 7, which ranged from 9.2 to $83.1 \mu \mathrm{g}^{-1}$ substrate $(\mathrm{n}=42)$. In Chapter 7 , a high ergosterol content was found for the mature straw, showing an accumulation of the field fungi. In the same batch of wheat straw (Chapter 3), fungi clearly varied in their growth, although all strains within each species showed comparable growth patterns. Different batches of straw seemingly affected the fungal growth. This was especially evident when CS1 and LE8 grew on the different straws collected around harvest (Chapter 7). In that chapter, both fungi showed a slower growth rate on a mature straw (MS3) at the beginning of the colonization, compared to when they were grown on less mature wheat straw (MS1 and MS2). The apparent slow initial growth of these fungi on MS3, is attributed to the recycling of endogenous fungi components, which 'masked' the actual growth. The variable growth patterns observed in the three experimental chapters show the dynamic of fungi upon colonizing various types and conditions of straw, which led to the problem of defining a successful colonization.

The rate of initial growth is also important in defining a successful substrate colonization by fungi. C. subvermispora, in particular CS1, possesses unique growth characteristics, where it produces a visible thin mycelium throughout the colonization weeks (Fig. 8.2), while being the most potential fungus in our collection for degrading lignin and improving the IVGP of straw. This fungus has a faster colonization compared to other species, as shown in Chapter 5 , where a shorter period was required to harvest a fully colonized agar plate. Similar growth patterns were also observed when grown on wheat straw, with a steeper growing curve during the first week of colonization (Chapter 

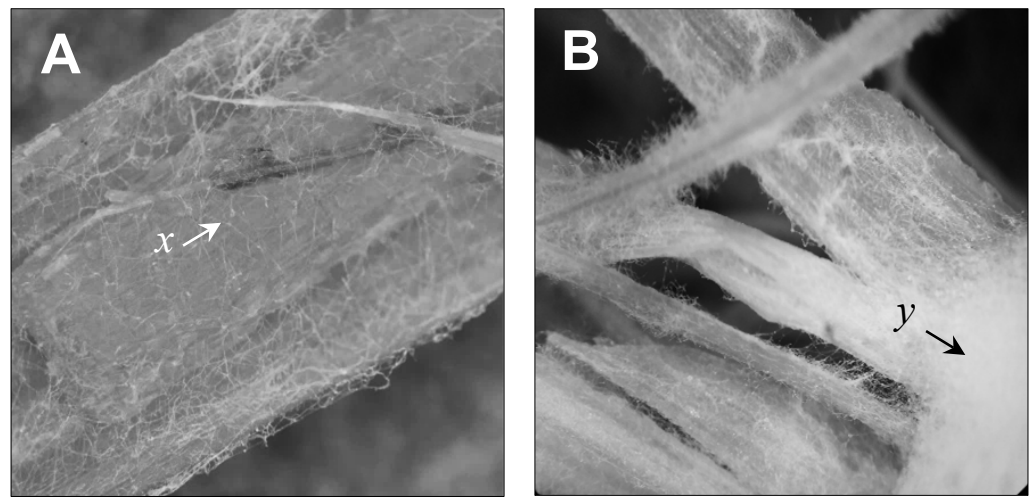

Fig. 8.2. Colonization of wheat straw by C. subvermispora after 2 weeks (A) and 7 weeks (B) as viewed with a light microscope at 50 and $32 \times$ magnification. In 2 weeks, a network of thin mycelia $(x)$ already colonized most of the substrate surface, while a formation of thick aerial mycelia $(y)$ can be seen after 7 weeks.

2, 3 and 7). L. edodes and P. eryngii strains clearly showed a longer lag phase, although both fungi generally produced thicker mycelia at week 7. A 'stunted' growth of $C$. subvermispora on CV2 and CV3 after week 1 observed in Chapter 7 does not indicate the inability of this particular fungus to colonize those substrates. A decrease in ergosterol content was also observed for C. subvermispora grown on MS3 and CV4 (Chapter 7), and also for all $P$. eryngii strains (Chapter 3 ) towards the end of the colonization. These observations indicate the dynamic of these fungi in utilizing available nutrients, as well as possible recycling of their own mycelia.

As heterotrophs, fungi hydrolyze polysaccharides for their growth and metabolism (Carlile et al., 2001). These polysaccharides are partly incorporated into fungal biomass, or can be mineralized to $\mathrm{CO}_{2}$ and water, explaining the losses in organic matter after fungal pretreatments. These changes present a great challenge, particularly for an accurate quantification of losses in cellulose, hemicellulose and lignin. As aforementioned, the inclusion of chitin and $\beta$-glucan from fungal biomass complicates the interpretation of mass balances, in relation to the efficiency of a particular fungus to depolymerize the cell wall polymers of the substrate. Fig. 8.3 illustrates a hypothetical proposition on the inclusion of fungal cell wall components in the measurements of cellulose, hemicellulose and lignin. Chitin is a polymer of $\beta$ - $(1 \rightarrow 4)$-linked $N$-acetyl-D-glucosamine (GlcNAc), which has a structural resemblance to cellulose $(\beta-(1 \rightarrow 4)$-linked D-glucose units) and is 


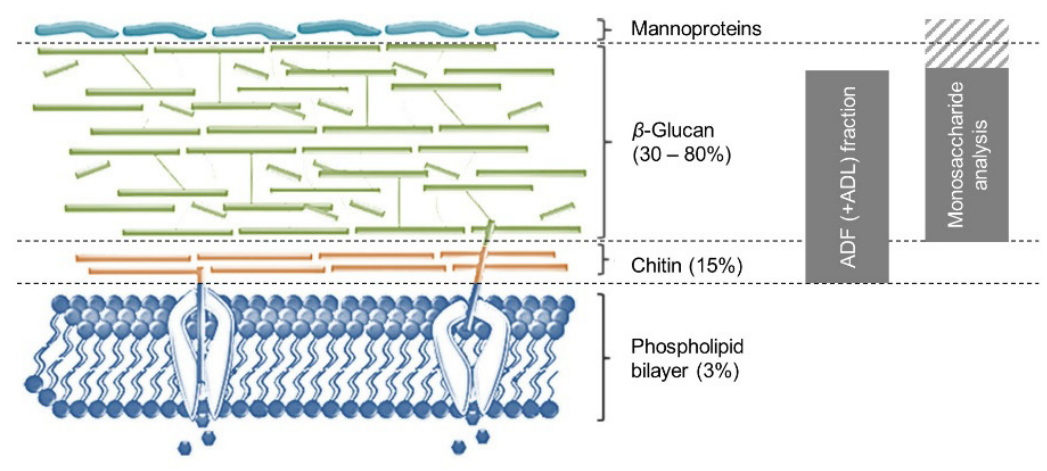

Fig. 8.3. Main components of the fungal cell wall and cell membranes, with estimated compositions (as a percentage of the total fungal biomass). A hypothetical proposition on the inclusion of these fungal components in acid detergent (ADF and ADL) and monosaccharide analysis is shown. The diagram is adapted from Fesel and Zuccaro (2016).

one of the most insoluble compounds in nature (Fesel and Zuccaro, 2016). Chitin is included in the ADF fraction, and probably in the ADL fraction as well due to the fact that a complete hydrolysis of chitin polymers requires a stronger concentrated acid (Einbu and Vårum, 2008). The acid hydrolysis step in the monosaccharide analysis (Englyst and Cummings, 1984) may also degrade part of the $\beta$-glucan layer of the fungal cell wall. Hence, it interferes with the quantification of cellulose and hemicellulose. Therefore, it was concluded in Chapter 5 that neither acid detergent nor monosaccharide analysis can produce an accurate quantification of the polysaccharides originating from the substrate. However, an accurate amount of lignin can be quantified using Py-GC/MS (Chapter 5) without interference of fungal biomass due the fact that lignification is an exclusive process occurring in higher plants (Ros Barceló, 1997). These observations provide a further justification of using IVGP as the main parameter in assessing the effectiveness of fungi in improving the nutritive value of wheat straw, and biomass in general.

The question remains - can we accurately quantify the absolute amount of fungal biomass grown on wheat straw? It is almost impossible to segregate and quantify the fungal biomass grown on a solid substrate, such as wheat straw. Fungi penetrate deep into the cell wall matrix, even for a selective fungus, such as $C$. subvermispora, as revealed by light microscopy of the sections of fungal-treated straw (Van Kuijk et al., 2017), which makes its absolute mass quantification difficult. Ergosterol, a sterol components in fungi, 
constitutes about 0.1 to $2.4 \%$ of the dry mycelia mass with large variations among different fungal species (Klamer and Bååth, 2004). Correlating mass conversion from ergosterol obtained for fungi grown on a liquid medium to a solid substrate has been shown to be problematic, especially in comparing the biomass of different fungal species (Niemenmaa et al., 2008). The ergosterol content varied with different media used and its content per dry weight of fungal mycelium is not constant at different stages of growth (Gao et al., 1993). While it is a good qualitative estimate of fungal growth, quantitation of the total amount of fungal biomass on wheat straw, based on an estimated ergosterol conversion factor, may not solve the problem encountered with the mass balances. As reported in Chapter 5, the fungal biomass only accounted for less than $3 \%$ of the total OM. It can be inferred that, about $3 \%$ of the total cell wall contents - measured using the Van Soest et al. (1991) method, is associated with the fungal cell wall. The interference of fungal biomass in the total cell wall contents also complicate the understanding of the subsequent effects on IVGP. In Chapter 5, results demonstrated the fermentation of pure fungal biomass in the rumen and contribute to the total IVGP. The relationship between IVGP and the cell wall contents was also validated using more specific analyses of lignin and carbohydrates in Chapter 5. This is important since the ADL does not account for the acid-soluble lignin fraction, besides an interference of fungal biomass in cellulose contents. The specific analysis of lignin and carbohydrates were carried out using PyGC/MS and monosaccharide analysis, respectively. In brief, inclusion of all lignin-derived compounds in the Py.lignin content led to a weaker inverse relationship with IVGP, compared to ADL. This indicates a slight degradation of the modified or fragmented lignin (with may contain intact associated carbohydrates) in the rumen. As for cellulose (and glucan) contents, neither of the two methods produce accurate quantification of the cellulose. The acid hydrolysis step in the monosaccharide analysis may also hydrolyze the $\beta$-glucan originating from the fungal cell wall (Fig. 8.3).

For mass balances of the (untreated) wheat straw, the percentage of recoveries for all quantified nutrients from the total amount of OM were comparable in Chapter 2, 3, 5 and 7 (ranging from 89.2 to $94.5 \%$ ). The unaccounted OM (5.5 to 10.8\%) may contain other nutrients, which were not measured in this thesis such as fat ( 1.5\%) (Gado et al., 2017) and probably other water-soluble carbohydrates and nitrogen-containing compounds (Jurak et al., 2015). After 7 weeks of fungal pretreatment, the recovery of OM significantly dropped and greatly varied among different fungal strains (69.9 to 88.3\%); hence, increases in the percentage of unaccounted OM were observed (11.3 to $25.5 \%)$. This observation indicates a clear increase of the water-soluble nutrient fraction in fungal- 
treated straw. Although an attempt to quantify these soluble lignin and carbohydrate fractions was made in Chapter 5, and soluble sugars in Chapter 7; none of these efforts were able to quantitate all unaccounted OM.

CS1 was consistently studied throughout this thesis (Chapter 2 to 7); hence, a good example to exhibit variations of the fungal pretreatment on the mass balances of different batches and types of straw, under the same treatment conditions. Figure 8.4 illustrates the mass balances of the control and CS1-treated wheat straw from different experimental chapters. The absolute amounts were expressed per $100 \mathrm{~g}$ of respective starting OM to compare across different chapters. For the untreated wheat straw, there were comparable amounts of cellulose (47.7 to $51.7 \mathrm{~g} / 100 \mathrm{~g}$ OM) and hemicellulose $(30.1$ to $34.4 \mathrm{~g} / 100 \mathrm{~g}$ $\mathrm{OM}$ ) in Chapter 2, 3 and 7. Meanwhile, lignin was slightly variable (6.1 to $9.1 \mathrm{~g} / 100 \mathrm{~g}$ $\mathrm{OM})$. In chapter 7 , the free sugars were also determined, which ranged from 0.4 to 0.7
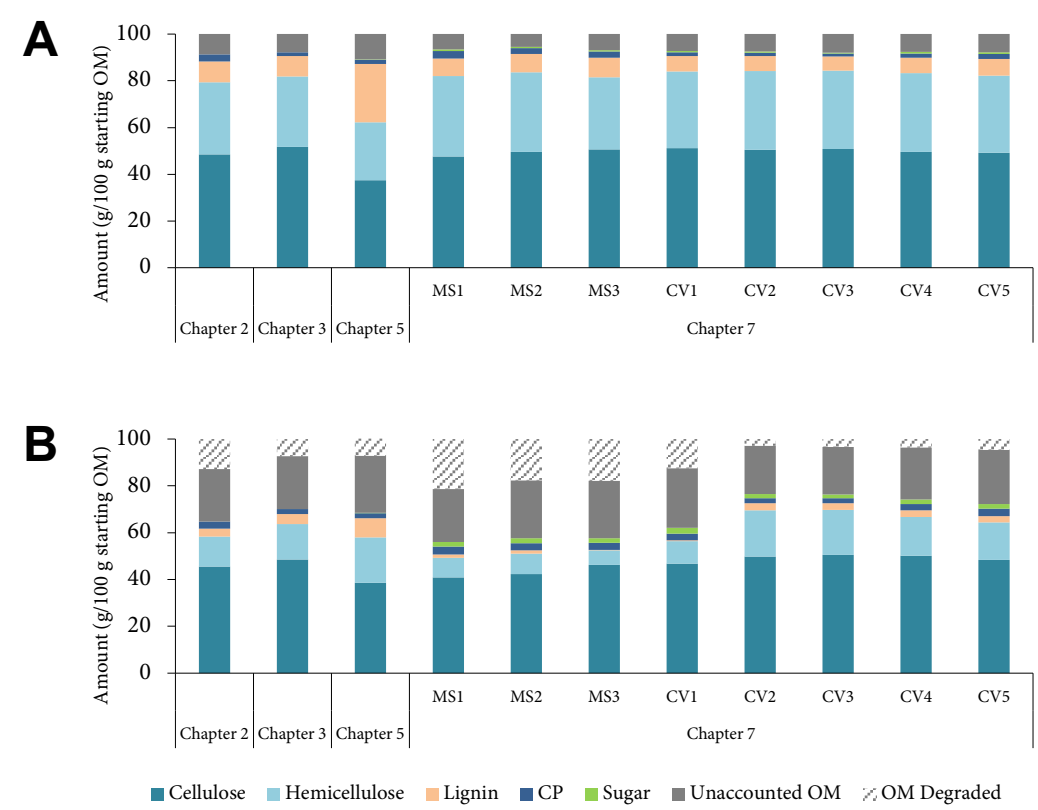

Fig. 8.4. Overview of the mass balances of the untreated wheat straw (A) and straw treated with $C$. subvermispora strain CS1 for 7 weeks (B) in different chapters. The cell wall components in Chapter 2, 3 and 7 were measured using Van Soest et al. (1991). Free sugars were also determined in Chapter 7. In Chapter 5, lignin was quantified using Py-GC/MS, while cellulose and hemicellulose were quantified from the respective sugar polymers. All amounts were expressed as per $100 \mathrm{~g}$ of the respective starting organic matter (OM). MS1-3: different maturity stages of straw; CV1-5: different straw cultivars (see Chapter 7). 
g/100 g OM for all different straw types. Using different analyses in Chapter 5, a higher amount of Py.lignin was quantified $(25.1 \pm 0.9 \mathrm{~g} / 100 \mathrm{~g} \mathrm{OM})$; while lower amounts of cellulose (measured as glucan; $37.4 \pm 0.7 \mathrm{~g} / 100 \mathrm{~g} \mathrm{OM}$ ) and hemicellulose (glucuronoarabinoxylan; $24.8 \pm 0.5 \mathrm{~g} / 100 \mathrm{~g} \mathrm{OM}$ ) were observed, compared to the other chapters. Across different chapters, the amount of crude protein (CP) was variable (1.2 to $3.3 \mathrm{~g} / 100$ $\mathrm{g} \mathrm{OM}$ ). After 7 weeks of treatment, CS1 caused a variable effect on the degradation of total OM. Large losses of OM (12.5 to $21.3 \%$ ) were observed for the treated straw in Chapter 2 and Chapter 7 (MS1-3, CV1). Most of CS1-treated straw had 0.8 to $14.6 \%$ loss of the amount of cellulose; in Chapter 5 and 7 (CV4), however, slight increases of cellulose were observed. The degradation of lignin and hemicellulose were mostly proportional with means of 69.2 and $56.0 \%$, respectively, which conforms to various reports (Tuyen et al., 2012; Van Kuijk et al., 2015). CS1 showed a higher delignification capability compared to the other fungi. Nonetheless, its effect on various straw batches in this thesis was clearly variable (52.2 to $98.2 \%)$.

\section{Solubilization of protein}

Two high-ranking strains of C. subvermispora (CS1 and CS12), P. eryngii (PE3 and PE6), and L. edodes (LE8 and LE10), were studied for their variation in the solubilization of protein (Chapter 4) and structural modification of wheat straw lignin (Chapter 6). The same set of fungi was also used in Chapter 5, to compare the two procedures of assessing lignin and carbohydrate contents, in relations to the IVGP. Throughout the thesis, most of the fungi tested, increased the concentration of CP in the substrate. Nonetheless, the magnitude of effects varied greatly, ranging from 3.4 to $82.3 \%$ for different fungal strains (Chapter 2, 3 and 7). Two treatments, however, resulted in a slight increase in CP, as observed for CS2 (3\%; Chapter 2) and LE8-treated MS1 straw (2\%; Chapter 7). As discussed in Chapter 4 , the relative increase in CP concentration was mainly due to degradation of the cell wall components, as fungi are not able to fix nitrogen $(\mathrm{N})$ from the atmosphere. Based fractionation of CP (Sniffen et al., 1992) and the in vitro assessment $\mathrm{N}$ availability $\left(\right.$ IVGP $_{\mathrm{N}}$ ) (Cone et al., 2009), fungi showed a unique ability in metabolizing protein. To my knowledge, the variation between fungi in solubilizing $\mathrm{N}$ that benefits ruminants has, hitherto, never been studied. The assessment of these parameters in Chapter 4 was mainly focused on the final changes of the CP fractions and IVGP $_{\mathrm{N}}$ after 7 weeks of fungal pretreatment. The data of their changes over time, however, were not provided in that chapter, although the measurements were also carried out on samples 

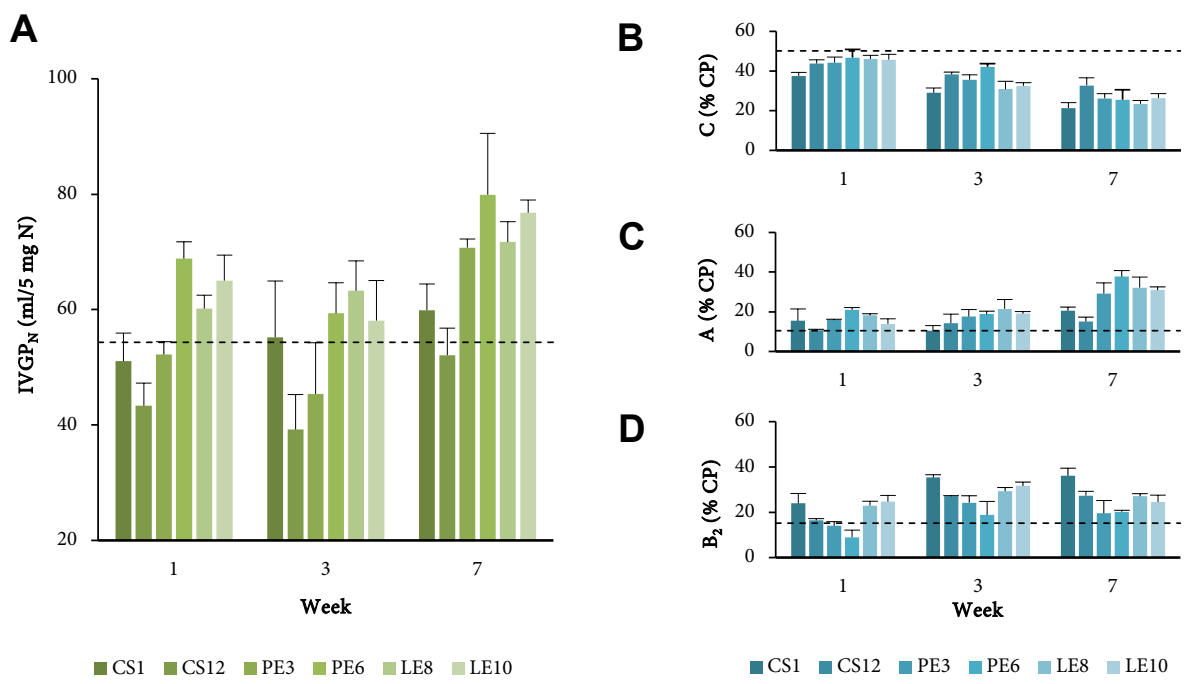

Fig. 8.5. Time-based changes of the modified in vitro gas production (IVGP $; A$ ) and selected crude protein fractions (B-D) of wheat straw treated with different fungi for 7 weeks. Dashed-lines indicate control values (at week 0; see Chapter 4) and error bars indicate standard deviations.

for week 1 and 3. Nonetheless, those weekly measurements were included in the statistical models. The changes in IVGP $_{\mathrm{N}}$ and selected CP fractions over the 7 week of treatment are shown in Fig. 8.5. In general, fungi that showed smaller changes in CP fractions and IVGP $_{\mathrm{N}}$ at the beginning of the colonization showed lower maximum/minimum values at week 7. Some variations among strains/species of the time-based changes were also noticed. For instance, CS1 showed a decrease in IVGP $_{\mathrm{N}}$ at week 1, then increased again until week 7; while, CS12 and PE3 showed decreases in IVGP $_{\mathrm{N}}$ until week 3. The changes in availability of $\mathrm{N}$ over time and their relationship to other variables that can be measured, such as enzyme activities/expressions, for a selected fungus can be an interesting subject for future research. This aspect, however, was not covered in Chapter 4 as the focus was more on exploring variations among different fungal strains in the solubilization of protein, using end-point measurements. 


\section{Assessing fungal delignification mechanisms: Accuracy matters}

As discussed earlier, the ADL method lead to a serious underestimation of the total lignin content, particularly in fungal-treated wheat straw; hence, limits a complete understanding of the fungal delignification mechanisms. Moreover, no lignin structural information can be obtained from this method. Therefore, Py-GC/MS (both semiquantitative and quantitative) was carried out on the samples, to quantify the lignin contents (Py.lignin) and simultaneously providing the structural features. Compared to the ADL, the Py.lignin contents were 1.4 to 2.8 times higher in fungal-treated straw (week 7). Interestingly, the Py.lignin content for the untreated straw was even higher (3.7 times), compared to ADL. One may expect higher figures for the fungal-treated straw (instead of control). A likely explanation is the degradation (mineralization) of lignin into $\mathrm{CO}_{2}$ by fungi. The soluble fraction of lignin in the untreated straw is probably due to sterilization steps (by autoclaving). Autoclaving of the wheat straw prior to the fungal pretreatment is hypothesized to result in a larger fraction of water-soluble lignin and other cell wall polymers.

Through quantitative ${ }^{13} \mathrm{C}$-IS Py-GC/MS, most of the extent of delignification by fungi were comparable with the assessment with ADL - except for CS12. The delignification of CS12 was only $27.1 \%$, based on ADL, but Py-GC/MS assessment gave a higher percentage (60.3\%). This resulted in an overall species-dependent order of the fungal delignification potential: C. subvermispora $(\sim 63.3 \%)>$ L. edodes $(\sim 58.0 \%)>$ P. eryngii $(\sim 38.7 \%)$, which was in agreement with the observed IVGPs (Chapter 3 ). In Chapter 5, the lignin subunits and also its structural features were not correlated to total lignin contents and the subsequent IVGP. This clearly indicates a large variation among different fungal strains/species in modifying certain moieties of lignin. To uncover possible unique mechanisms of these fungi, the fungal-treated wheat straws were subjected to a combined analysis of ${ }^{13} \mathrm{C}$-IS Py-GC/MS and whole cell wall HSQC nuclear magnetic resonance (NMR) (Chapter 6). It is commonly reported for the preference of fungi to degrade syringyl (S) unit compounds, rather than the guaiacyl (G) units (lower S/G ratio) (Del Río et al., 2002; Van Kuijk et al., 2016). In this thesis, however, there was hardly any clear preference shown by these fungi (Chapter 5 and 6), probably due to extensive degradation of the Py.lignin contents. The largest effect was observed for LE8 (H:G:S = 11:64:25), as compared to control (H:G:S = 10:62:28). 
The combined ${ }^{13} \mathrm{C}$-IS Py-GC/MS and 2D-NMR analysis gives a novel insight into the fundamental mechanistic differences among fungal species, based on the specific structural moieties. Among the important highlights of this analysis - although $C$. subvermispora and L. edodes showed a similar pattern of lignin degradation with time, the remaining lignin structures were greatly differed, confirming the fundamental differences among fungi. It is suggested that the main underlying mechanisms of $C$. subvermispora strains is through the cleavage of $\mathrm{C}_{\beta^{-}} \mathrm{O}$-Aryl, besides $\mathrm{C}_{\alpha}-\mathrm{C}_{\beta}$ cleavage. The former was confirmed by ${ }^{13} \mathrm{C} \mathrm{Py}-\mathrm{GC} / \mathrm{MS}$, whereby high increases of $\mathrm{C}_{\alpha}$-oxidized pyrolysis products were observed, particularly vanilloyl acetaldehyde (VAL) and syringoyl acetaldehyde (SAL). It is hypothesized that these acetaldehydes are solely formed from the oxidized $\beta-O-4$ linkages. For $L$. edodes and $P$. eryngii, the cleavage of $\mathrm{C}_{\alpha}-\mathrm{C}_{\beta}$ cleavage is the predominant mechanism. Interestingly, the reduction of ferulic acids moieties, which participate in lignin-carbohydrate linkages, was more pronounced in $P$. eryngii treated lignin (30\%). No isolation of lignin was carried out in Chapter 6, as normally done to characterize the inter-unit linkages of the 'pure' lignin, e.g. as milled-straw lignin (Zeng et al., 2013). The idea of having whole cell wall or in situ NMR of the samples was to avoid extensive isolation procedures, which may lead to partial modification of the polymer (Rencoret et al., 2011). Although a severe signal overlapping was observed, particularly for the fungal-treated wheat straw, some substructures such as phenylcoumaran $\left(\beta-5^{\prime}\right)$ and resinol $(\beta-\beta)$ substructures were readily annotated. Other structures such as $\mathrm{C}_{\alpha^{-}}$ oxidized ( $\alpha$-keto) $\beta$ - $O-4^{\prime}$ and dibenzodioxocins $(5-5 / 4-O-\beta)$ can be observed only at higher zoom levels. For future research, a combined Py-GC/MS and 2D-NMR analysis on the lignin isolates or its various fractions (based on their extractability in water and other solvents) can give a greater detail and accuracy in the delignification mechanism of a particular fungus (on-going research at the Laboratory of Food Chemistry, Wageningen University). 


\section{Concluding remarks}

\section{Contribution to the current knowledge}

This thesis showed a large variation among different fungal strains in terms of their bioprocessing capabilities, growth characteristics, utilization of a certain nutrient and structural modification of lignin - even if they are grown on the same biomass with similar growth and culture conditions. Despite these variations, the selected fungal strains performed well on different wheat straw types and conditions, as well as across different independent experiments carried out for this thesis. The same experimental setup can be replicated for other biomasses, such as rice straw, oil palm fronds and sugarcane bagasse, either using the identified high performers in this thesis; or using locally available fungal strains/species. Two unique contributions of this thesis to the current knowledge are variability among different fungal strains in solubilizing protein and modifying the lignin structure of wheat straw. The former, in particular, could pave the way to study the interrelationship between protein and the delignification mechanisms of white-rot fungi. This can also be applied to different fibrous biomasses with an interest on improving its protein availability.

One of the main issues highlighted in this thesis is the difficulty to produce a sound mass balance for all nutrients in the fungal-treated wheat straw, particularly for the cell wall. Since fungi greatly differ in their capabilities to solubilize cell wall components and also growth characteristics, comparisons among different strains/species are difficult. The current methodologies of quantifying lignin and carbohydrate contents cannot provide a satisfactory answer. An accurate assessment of these components is crucial, especially when it comes to bioprocessing of biomass at a larger scale, where the ratio of lignin to carbohydrate losses (i.e. bioprocess efficiency) is an important parameter. However, the interference of fungal biomass in this analysis limits its usability and may be inconclusive. Lignin is the only parameter that can be quantified without (or less) interference of fungal biomass, especially with the accurate ${ }^{13} \mathrm{C}$-lignin Py-GC/MS method. Nevertheless, quantifying the lignin content alone may not be sufficient to describe fungal delignification, without providing the changes on its fractions, structural features and the associated cell wall polysaccharides (lignin-carbohydrate complex). The IVGP was exclusively used in this thesis to assess the capability of a particular fungus in the bioprocessing of wheat straw. Although, this method is not specific, due to the marginal contribution of fungal biomass to the total IVGP, it is a highly effective and practical technique to evaluate the end-product of fungal pretreatments. 


\section{Limitation and recommendation for future research}

The experimental setup employed in this thesis was intended to discern the fundamental biological variations among different fungal strains/species; and to select the best performing strains for future research. Due to the limited scope of this thesis, there are many other important elements of the fungal activity that are not covered, such as enzymes, organic acids and secondary metabolites production. These elements are significant for a complete understanding of fungal actions. Considering the large variation observed among different fungal strains, it is worthwhile to perform in-depth studies to uncover the underlying mechanisms of these fungi. Several interventions for future research have been mentioned earlier and will be briefly mentioned here. Two main aspects can be outlined: (1) biological and (2) chemical aspects. The biological aspect is important for an in-depth understanding of fungal action on lignocellulosic biomass. Assessing the enzymatic apparatus of the fungi is one of them and a secretomic or proteomic approach is the only way forward (Salvachúa et al., 2013). The production of organic acids and secondary metabolites are among important biological aspects to understand the underlying cellular mechanisms (Nishimura et al., 2012). Some of the chemical aspects have been covered in this thesis by investigating variations in the modification of lignin structures. To deal with the inaccuracy in mass balance, more advanced techniques have to be considered. The feasibility to quantify fungal biomass grown on the solid substrate needs to be explored, which could be done through labelling of the substrate (or fungi) with stable isotopes $\left({ }^{13} \mathrm{C}\right)$ or using a chemical marker on a specific fungal component such as chitin and ergosterol (Wallander et al., 2013). A nonequilibrium thermodynamic approach can also be considered for this purpose (Das and Karim, 1995). Optimization of the Van Soest et al. (1991) method for fungal-treated materials should also be considered. This includes improving the extraction and filtration steps involved.

The information from the two aspects can be corroborated to optimize the pretreatment method, e.g. through mathematical modelling, which could expedite the advancement of the bioprocess. This is particularly useful for an industrial application, i.e. solid state fermentation of biomass using fungi that is conducted in a controlled bioreactor. For the on-farm application, the future optimization work (using the selected fungi) should mainly focus on: (1) scaling-up the pretreatment method, which includes sterilization/pasteurization procedures, inoculation and other practical problems; (2) inclusion levels of the fungal-treated biomass in ruminant rations, without causing adverse effects on the animal performance or health. 


\section{Conclusions}

The main outcomes of this thesis can be summarized as follows:

- There is a large biological variation among strains belonging to the same fungal species, particularly for their growth characteristics and bioprocessing capabilities. High potential strains of C. subvermispora, P. eryngii and L. edodes were selected, based on the in vitro gas production.

- The high potential strains of C. subvermispora and L. edodes perform well on different wheat straw maturities and cultivars. Nonetheless, the magnitude of ruminal degradability is affected by different cultivars, but not by straw maturities.

- Two strains of C. subvermispora differ in their growth and enzyme activity characteristics. Both strains were similar in their capabilities to improve the degradability of wheat straw, although the gas production profiles can be differentiated by curve fitting.

- Fungi are able to solubilize nitrogen from the cell wall and make them more available for fermentation in the rumen. The high potential strains differ in their capabilities to solubilize nitrogen in the substrate. P. eryngii and L. edodes strains increased the available nitrogen for fermentation, but not $C$. subvermispora.

- Specific analyses of lignin and carbohydrates contents are required for accurate description of the ruminal degradability of wheat straw treated with different fungal strains.

- Each fungal species is fundamentally different in their delignification mechanisms. It is proposed that the cleavage of $\mathrm{C}_{\beta^{-}} \mathrm{O}$-Aryl linkages as the main mechanism for $C$. subvermispora. While the predominant mechanism for $L$. edodes and $P$. eryngii is through the cleavage of $\mathrm{C}_{\alpha}-\mathrm{C}_{\beta}$ linkages. 
Chapter 8 | General discussion

\section{REFERENCES}

Bianco, L., and Perrotta, G. (2015). Methodologies and perspectives of proteomics applied to filamentous fungi: From sample preparation to secretome analysis. Int. J. Mol. Sci. 16, 5803-5829.

Blanchette, R. (1984). Screening wood decayed by white rot fungi for preferential lignin degradation. Appl. Environ. Microbiol. 48, 647-653.

Carlile, M.J., Watkinson, S.C., Gooday, G.W., Carlile, M.J., Watkinson, S.C., and Gooday, G.W. (2001). 3 Fungal Cells and Vegetative Growth. In: Carlile, M.J. (Ed.), The Fungi. Academic Press, London, pp. 85184.

Chang, A.J., Fan, J., and Wen, X. (2012). Screening of fungi capable of highly selective degradation of lignin in rice straw. Int. Biodeterior. Biodegrad. 72, 26-30.

Cone, J.W., Rodrigues, M.A.M., Guedes, C.M., and Blok, M.C. (2009). Comparison of protein fermentation characteristics in rumen fluid determined with the gas production technique and the nylon bag technique. Anim. Feed Sci. Technol. 153, 28-38.

Cone, J.W., van Gelder, A.H., Visscher, G.J.W., and Oudshoorn, L. (1996). Influence of rumen fluid and substrate concentration on fermentation kinetics measured with a fully automated time related gas production apparatus. Anim. Feed Sci. Technol. 61, 113-128.

Cruz Ramírez, M.G., Rivera-Ríos, J.M., Téllez-Jurado, A., Maqueda Gálvez, A.P., Mercado-Flores, Y., and Arana-Cuenca, A. (2012). Screening for thermotolerant ligninolytic fungi with laccase, lipase, and protease activity isolated in Mexico. J. Environ. Manage. 95, S256-S259.

Das, P., and Karim, M.N. (1995). Mass-Balance and Thermodynamic Description of Solid-State Fermentation of Lignocellulosics By Pleurotus-Ostreatus for Animal Feed Production. J. Ind. Microbiol. 15, 25-31.

Del Río, J.C., Speranza, M., Gutiérrez, A., Martínez, M.J., and Martínez, A.T. (2002). Lignin attack during eucalypt wood decay by selected basidiomycetes: A Py-GC/MS study. J. Anal. Appl. Pyrolysis 64, 421431.

Einbu, A., and Vårum, K.M. (2008). Characterization of chitin and its hydrolysis to GlcNAc and GlcN. Biomacromolecules $9,1870-1875$.

Englyst, H.N., and Cummings, J.H. (1984). Simplified method for the measurement of total non-starch polysaccharides by gas-liquid chromatography of constituent sugars as alditol acetates. Analyst 109, 937.

Fesel, P.H., and Zuccaro, A. (2016). $\beta$-glucan: Crucial component of the fungal cell wall and elusive MAMP in plants. Fungal Genet. Biol. 90, 53-60.

Gado, H.M., Elghandour, M.M.Y., Cipriano, M., Odongo, N.E., and Salem, A.Z.M. (2017). Rumen degradation and nutritive utilization of wheat straw, corn stalks and sugarcane bagasse ensiled with multienzymes. J. Appl. Anim. Res. 45, 485-489.

Gao, Y., Chen, T., and Breuil, C. (1993). Ergosterol - A measure of fungal growth in wood for staining and pitch control fungi. Biotechnol. Tech. 7, 621-626.

Jung, H.J.G., Varel, V.H., Weimer, P.J., and Ralph, J. (1999). Accuracy of Klason lignin and acid detergent lignin methods as assessed by bomb calorimetry. J. Agric. Food Chem. 47, 2005-2008.

Jurak, E., Punt, A.M., Arts, W., Kabel, M.A., and Gruppen, H. (2015). Fate of carbohydrates and lignin during composting and mycelium growth of Agaricus Bisporus on wheat straw based compost. PLoS One 10 , $1-16$.

Klamer, M., and Bååth, E. (2004). Estimation of conversion factors for fungal biomass determination in compost using ergosterol and PLFA 18:2w6,9. Soil Biol. Biochem. 36, 57-65. 
Li, L., Li, X.Z., Tang, W.Z., Zhao, J., and Qu, Y.B. (2008). Screening of a fungus capable of powerful and selective delignification on wheat straw. Lett. Appl. Microbiol. 47, 415-420.

Mille-Lindblom, C., von Wachenfeldt, E., and Tranvik, L.J. (2004). Ergosterol as a measure of living fungal biomass: persistence in environmental samples after fungal death. J. Microbiol. Methods 59, 253-262.

Niemenmaa, O., Galkin, S., and Hatakka, A. (2008). Ergosterol contents of some wood-rotting basidiomycete fungi grown in liquid and solid culture conditions. Int. Biodeterior. Biodegradation 62, 125-134.

Nishimura, H., Sasaki, M., Seike, H., Nakamura, M., and Watanabe, T. (2012). Alkadienyl and alkenyl itaconic acids (ceriporic acids $\mathrm{G}$ and $\mathrm{H}$ ) from the selective white-rot fungus Ceriporiopsis subvermispora: a new class of metabolites initiating ligninolytic lipid peroxidation. Org. Biomol. Chem. 10, 6432.

Rencoret, J., Gutiérrez, A., Nieto, L., Jiménez-Barbero, J., Faulds, C.B., Kim, H., Ralph, J., Martínez, A.T., and Del Río, J.C. (2011). Lignin composition and structure in young versus adult Eucalyptus globulus plants. Plant Physiol. 155, 667-82.

Ros Barceló, A. (1997). Lignification in plant cell walls. Int. Rev. Cytol. 176, 87-132.

Salvachúa, D., Martínez, A.T., Tien, M., López-Lucendo, M.F., García, F., de Los Ríos, V., Martínez, M.J., and Prieto, A. (2013). Differential proteomic analysis of the secretome of Irpex lacteus and other white-rot fungi during wheat straw pretreatment. Biotechnol. Biofuels 6, 115.

Sharma, R.K., and Arora, D.S. (2010). Changes in biochemical constituents of paddy straw during degradation by white rot fungi and its impact on in vitro digestibility. J. Appl. Microbiol. 109, 679-686.

Shrivastava, B., Thakur, S., Khasa, Y.P., Gupte, A., Puniya, A.K., and Kuhad, R.C. (2011). White-rot fungal conversion of wheat straw to energy rich cattle feed. Biodegradation 22, 823-831.

Sniffen, C.J.J., Connor, D.O., and Russell, J.B. (1992). A Net Carbohydrate and Protein System for evaluating cattle diets : II . Carbohydrate and protein availability. J. Anim. Sci. 70, 3562-3577.

Tripathi, M.K., Mishra, A.S., Misra, A.K., Vaithiyanathan, S., Prasad, R., and Jakhmola, R.C. (2008). Selection of white-rot basidiomycetes for bioconversion of mustard (Brassica compestris) straw under solid-state fermentation into energy substrate for rumen micro-organism. Lett. Appl. Microbiol. 46, 364-370.

Tuyen, V.D., Cone, J.W., Baars, J.J.P., Sonnenberg, A.S.M., and Hendriks, W.H. (2012). Fungal strain and incubation period affect chemical composition and nutrient availability of wheat straw for rumen fermentation. Bioresour. Technol. 111, 336-342.

Van Kuijk, S.J.A., Del Río, J.C., Rencoret, J., Gutiérrez, A., Sonnenberg, A.S.M., Baars, J.J.P., Hendriks, W.H., and Cone, J.W. (2016). Selective ligninolysis of wheat straw and wood chips by the white-rot fungus Lentinula edodes and its influence on in vitro rumen degradability. J. Anim. Sci. Biotechnol. 7, 55.

Van Kuijk, S.J.A., Sonnenberg, A.S.M., Baars, J.J.P., Hendriks, W.H., and Cone, J.W. (2015). Fungal treatment of lignocellulosic biomass: Importance of fungal species, colonization and time on chemical composition and in vitro rumen degradability. Anim. Feed Sci. Technol. 209, 40-50.

Van Kuijk, S.J.A., Sonnenberg, A.S.M., Baars, J.J.P., Hendriks, W.H., del Río, J.C., Rencoret, J., Gutiérrez, A., de Ruijter, N.C.A., and Cone, J.W. (2017). Chemical changes and increased degradability of wheat straw and oak wood chips treated with the white rot fungi Ceriporiopsis subvermispora and Lentinula edodes. Biomass and Bioenergy 105, 381-391.

Van Soest, P.J., Robertson, J.B., and Lewis, B.A. (1991). Methods for dietary fiber, neutral detergent fiber, and nonstarch polysaccharides in relation to animal nutrition. J. Dairy Sci. 74, 3583-3597. 
Wallander, H., Ekblad, A., Godbold, D.L., Johnson, D., Bahr, A., Baldrian, P., Björk, R.G., Kieliszewska-Rokicka, B., Kjøller, R., Kraigher, H., Plassard, C., and Rudawska, M. (2013). Evaluation of methods to estimate production, biomass and turnover of ectomycorrhizal mycelium in forests soils - A review. Soil Biol. Biochem. 57, 1034-1047.

Zeng, J., Helms, G.L., Gao, X., and Chen, S. (2013). Quantification of wheat straw lignin structure by comprehensive NMR analysis. J. Agric. Food Chem. 61, 10848-10857. 
Summary 
$\mathrm{T}$ The use of white-rot fungi in bioprocessing of lignocellulosic biomass such as wheat straw into valuable ruminant feed ingredients is promising. Fungi are capable of degrading lignin - a cell wall polymer that negatively affects ruminal degradability of the biomass. For this purpose, fungi, such as C. subvermispora, P. eryngii and L. edodes, have been identified as potential species. The vast availability of strains of these species, as well various wheat straw types and conditions lead to four main research questions: (1) Do strains of the same fungal species differ in their extent of lignocellulose degradation and the subsequent improvement in the ruminal degradability of wheat straw? (2) How do high potential strains/species vary in utilizing a certain nutrient, such as protein? (3) Do different fungal strains/species possess unique delignification mechanisms? (4) Do various wheat straw types have effects on how fungi degrade the cell wall components?

As a start to the screening trial, in Chapter 2, the bioprocessing capabilities of two strains of C. subvermispora, CS1 and CS2, were compared. Both fungi were capable of selectively degrading lignin and improve in vitro gas production (IVGP) of wheat straw, with CS1 showing a higher potential than CS2. The two fungi also differed in their growth pattern and enzymatic activities, as well as in the degree of selectivity in lignin degradation. There was no correlation between the activities of the lignin-degrading enzymes and the extent of lignin degradation, indicating that more complex mechanisms are involved in modifying the cell wall. In Chapter 3, the IVGP was used as a decisive screening parameter for the best performing fungi. A number of strains of the fungal species $C$. subvermispora, P. eryngii and L. edodes were screened based of their IVGPs. All strains that belonged to the same species showed a distinctive pattern of growth and changes in the $\mathrm{pH}$ of substrate. Nonetheless, large variations of their bioprocessing capabilities were observed. Out of the 32 fungal strains studied, 17 strains showed a significantly higher $(P<0.05)$ IVGP, compared to the control after 7 weeks of treatment. The best performing strains for each species were selected. They were (in order of IVGP for each species): CS1, CS6 and CS12 (C. subvermispora); PE6, PE2 and PE3 (P. eryngii); LE8, LE7 and LE10 (L. edodes).

Two high-ranked strains for each species in Chapter 3 were subjected to three followup studies on variation in protein solubilization and modification of lignin structures. In Chapter 4, different fractions of crude protein (CP) and in vitro protein fermentation of wheat straw treated with six fungal strains (2 strains per species) were evaluated. All fungal strains caused a relative enrichment of the CP content (23.3 to 30.9\%) in wheat straw. There was no quantitative difference in the total amount of $\mathrm{CP}$ among different fungal-treated straws. However, the $\mathrm{CP}$ fraction provided a unique insight into the 
variation among fungi in solubilizing protein. The results showed that fungi increased the soluble protein fractions and decreased the cell wall bound protein. Only wheat straw treated with $P$. eryngii and $L$. edodes strains resulted in a higher protein availability for fermentation in the rumen (30.2 to $47.1 \%$ ). C. subvermispora strains on the other hand, did not improve the protein availability. To validate the established relationship between IVGP and the cell wall contents, determined using the Van Soest method (Procedure A), more specific analyses of the cell wall (Procedure B) were used in Chapter 5. In Procedure $\mathrm{B}$, pyrolysis (Py-GC/MS) and alditol-acetates were used to determine Py-lignin and carbohydrates content, respectively. Procedure A showed a higher correlation coefficient of lignin/carbohydrate to the IVGP, compared to Procedure B (Pearson's $r$ of -0.84 vs. 0.69 , respectively). The large differences between methods indicate disparities in the mass recovery of cell wall components, which complicates the understanding of degradation of cell wall components and its effect on IVGP. Procedure A is more indicative of the cell wall solubility - which explained the IVGP well, rather than indicating the actual cell wall degradation by fungi. The more specific Procedure B better elucidates the structure, which helps with the understanding of variations among fungal strains in modifying the cell wall. As for the cellulose (and glucan) contents, neither procedure resulted in an accurate quantification of the cellulose due to interference of fungal biomass. A contribution of pure fungal biomass to the total IVGP was expected, since it showed higher IVGP than its corresponding treated wheat straw. Hence, specific analyses of the lignin and carbohydrates contents are required for accurate description of the ruminal degradability of wheat straw.

The combined pyrolysis-GC/MS and 2D-nuclear magnetic resonance (NMR) analysis in Chapter 6, revealed fundamentally different delignification mechanisms among fungal species. It was proposed that the cleavage of $\mathrm{C}_{\beta^{-}} O$-aryl linkages as the main mechanism for $C$. subvermispora, besides $\mathrm{C}_{\alpha}-\mathrm{C}_{\beta}$ cleavage. While the predominant mechanism for L. edodes and P. eryngii was through the cleavage of $\mathrm{C}_{\alpha}-\mathrm{C}_{\beta}$ linkages. In Chapter 7, the persistence of the high potential strains of C. subvermispora and L. edodes in improving the ruminal degradability of wheat straw of different maturities and cultivars was studied. The degradation of lignin by both fungi was more pronounced on mature straw (MS3; 89.0\%), compared to the MS1 ( 70.7\%). In contrast, cellulose was less degraded on MS3 compared to MS1 ( 8.3 vs. 14.6\%). The 'preference' of fungi in the delignification of a more mature straw was confirmed by Py-GC/MS. A higher abundance of the S-unit compounds was found on MS3, which made the mature straw more susceptible to fungal attack. A variable extent of degradation of lignin (47 to 93.5\%) was 
observed when both fungi were grown on different straw cultivars. The high potential strains of C. subvermispora and L. edodes were able to improve the IVGP of various straw types. However, the magnitude of IVGP was only affected by different cultivars, but not by straw maturity.

Research presented in this thesis discerned the biological variation of different fungal strains/species in modifying the cell wall contents, producing variable effects on the ruminal degradability of wheat straw. The new finding on the capability of some fungi to solubilize protein from the cell wall is important, which could pave the way for more advanced and in-depth studies in the future. The high potential strains selected in Chapter 3 were proven capable of improving the nutritive value of various batches of wheat straw, indicating the potential of bringing this eco-friendly pretreatment method into practice. 


\section{Acknowledgement}


Tirst and foremost, الحمد لله. All praises belong to God. In the midst of trials and challenges, He has bestowed upon me and giving me unimaginable strength and wisdom to achieve my dream of holding a $\mathrm{PhD}$ degree. For the past 4 years, it has been a memorable journey. Along the way, I have met many tremendous people and great colleagues, who became the key to successful completion of this thesis. I would like to take the opportunity here to thank all of them for the unconditional love and support. If I missed some names here - het spijt me!

First of all, I would like to thank the Ministry of Higher Education Malaysia and Universiti Putra Malaysia for financing my study in Wageningen University, the Netherlands. I also sincerely thank DEKA, ForFarmers and the Victam Foundation, whom through the Wageningen University Fund (WUF) have provided financial support for the $\mathrm{PhD}$ project.

The accomplishment of this thesis has been with the help and passionate supervision of my promotor, co-promotors and people who were directly involved with this project. I would like to express my sincere gratitude to my promotor, Prof. Wouter Hendriks, for being a passionate leader. He helped me through the problems I've encountered during my PhD, not to mention the critical and constructive comments on the manuscripts. I also enjoyed the informal and personal talks we had, including with his wife, Mirian. I am highly indebted to my co-promotors, Dr. John Cone and Dr. Anton Sonnenberg for their invaluable guidance, support, encouragement and the sharing of knowledge. I appreciate the fruitful discussions we had on the data, manuscripts and other technical aspects of the project, especially at the beginning of my $\mathrm{PhD}$. These people have been instrumental for me to become an independent scientist. I would like to extend my gratitude to Dr. Mirjam Kabel, and Gijs van Erven from the Laboratory of Food Chemistry, for their significant contribution to this thesis, especially in Chapter 5 to 7 . I enjoyed the meetings and discussions we had that always gave me new insights into this project.

I would like to acknowledge all staff and group members of the Animal Nutrition group (ANU) for their assistance and cooperation. I really admire our enthusiastic secretaries, Betty Looijen and Yvonne van Holland. Dear Betty and Yvonne, from the day I arrived at ANU, I cannot thank you enough for your endless help and support in all administrative matters. A special thanks to the laboratory staff members - Leon de Jonge, Saskia van Laar, Michel Breuer, Jane-Martine Muijlaert, Xuan Huong van der Schans-Le and Erika Beukers, for helping me out with the lab analyses. Also the Mushroom Research 
Group and Biochemical lab members - Patrick Hendrickx, Marcel Visser, José Kuenen, Brian Lavrijssen, Annemarie Dechesne and Heleen Furrer. Being skilful in the lab was never part of my training, but I just did - thanks to these dedicated people. Believe it or not, I cherished every moment I spent in the lab, which taught me of being patience, punctual, well-organized and to persevere. I also would like to acknowledge the unsung heroes - the lab trainees and students, who helped me a lot in the lab. To Laura Biesenack, Karlok Ho, Steven Wouthuyzen, Wenqiang Gou and Yang Li - thank you!

"Friends are the siblings God never gave us" - Mengzi, a Chinese philosopher.

This adventurous journey is incomplete without the presence of other (current and former) PhD colleagues. There are too many of you - so, I will not be able to mention all names here (no offense!). To Sandra van Kuijk, Eli Ratni and Lei Mao - I will always remember the works we did together and thanks for sharing your knowledge. Hsuan, Felicidade, Cẩm Tú, Tinh, Thuat, Genet, Duong Huyen, Thi Huyen, Yixin, Viviane and Marco - together with Xuan Huong, we shared a lot of things during our regular lunch breaks; something I won't forget for the rest of my life. Kelly, thanks for being my morning buddy! To Sergio, Bayissa, Kim, Marijke, Lotte, Sanne, Rik, Bianca, Miranda, Tetske, Geronda, Nikkie and Sholeha- it's always a pleasure to talk to you about anything, from $\mathrm{PhD}$ to personal matters. I also enjoyed the nice talks with Myrthe, Henk, Yvonne, Pierre, Michel, Chantal and Elmira during the coffee breaks and other social activities. To my other colleagues (you-know-who), nice to meet you and I wish you all the best in your future endeavours!

To my lovely 'Vietnamese mother' - Cô Huong, thank you for being there for me and lending me an ear when things got difficult for me. I cherished every moment we spent together and cảm ơn cô! I would like to thank my Malaysian friends, who made Wageningen a second home - Razak \& Norzie, Aidil \& Fatihah, Amir \& Zuhaira, Zulkhairi \& Adlini, Sharul \& Ashikin, Mustaqim \& Farhana, Hafeez \& Nurul, Nurulamin \& Roshahiva, Zulfakri \& Hafiza, Hafiz \& Hayati, Moritz \& Mas, Mursyid \& Umi; Norulhuda, Termizi, Teo Pey Sze, Teo Phuey, Rozaini, Siew Ling, Nurul Huda, Suryani, Shakila, Sabrina and Loo Wee. Special thanks to 'Azyyati for the invaluable sharing sessions. I also would like to acknowledge other Malaysian friends in Leiden, Eindhoven, Rotterdam, Groningen, Enschede, Utrecht and Amsterdam; as well as my Indonesian friends in Wageningen. May our friendship last forever. Terima kasih! 
(Malay) Ke hadapan keluarga kandung dan mertua yang tercinta, terima kasih yang tidak terhingga di atas kasih sayang dan doa yang dikirimkan selama ini. Mak, terima kasih kerana melahir dan membesarkan abang. Abah... saat menulis coretan ini, tanpa sedar air mata mengalir membasahi pipi abang. Abang tahu abah pasti bangga dengan kejayaan anak abah ini. Namun tiada lagi insan yang akan dengan penuh bangga mencanang kejayaan anaknya kepada sesiapa sahaja yang ditemuinya. Dari kecil, abang sematkan dalam-dalam pesanan mak abah dalam hati abang - "Tiada harta yang abah mak dapat berikan, cuma ilmu yang dapat mengubah nasib keluarga kita”. Abang dengan berbesar hati ingin hadiahkan kejayaan ini kepada abah dan mak. Abang sayang kalian berdua. Akhir sekali, kepada isteriku Nur Eershan Namira, maafkan abang tidak dapat memberi sebuah keluarga yang 'normal' untuk kita berdua. Pengorbanan untuk perjalanan $\mathrm{PhD}$ ini ada harga tinggi yang harus kita bayar. Terima kasih atas segalagalanya. Walau apa pun yang akan terjadi di kemudian hari, abang akan tetap sayangkan mira setulus ikhlas hati abang, sehingga ke akhir hayat.

Sincerely,

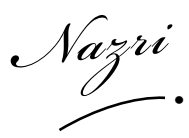




\section{About the author}

Résumé • Publication • Training \& supervision plan 


\section{Résumé: About the author}

\section{V $\int_{\text {on } 7^{\text {th }} \text { May } 1986 \text { in Pahang, Malaysia. }}^{\text {ohd Nazri Bin Md Nayan was born }}$}

Born to oil palm farmer parents, he received his early education at FELDA Sungai Retang Primary School, Jerantut, Pahang, before continuing his secondary education at Sultan Haji Ahmad Shah Science School, Pekan, Pahang. In 2008, he obtained a BSc in Biomedical Sciences from Universiti Putra Malaysia (UPM), Serdang, before pursuing

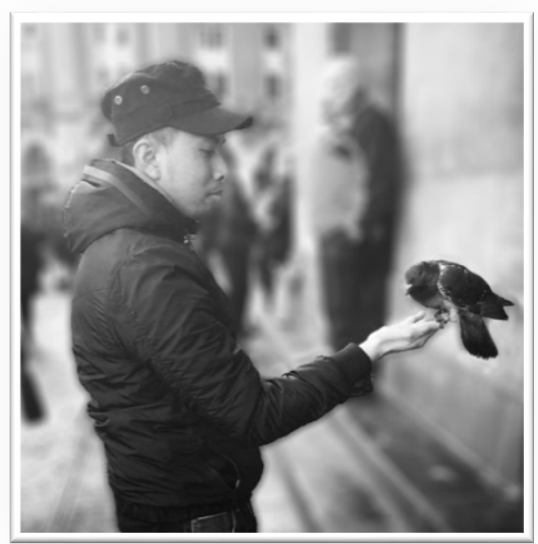
an MSc degree at the same university in Animal Physiology. During his MSc study, he was awarded Erasmus-Mundus scholarship to do a research internship at Universitat Autònoma de Barcelona, Spain for 10 months. His research was about supplementing soybean oil to alleviate effect of heat stress on dairy goats by assessing the urine metabolomics. After completing his MSc study, he started his PhD study at the Animal Nutrition group, Wageningen University \& Research (WUR) from September 2014. He was involved with "More Meat and Milk from Straw” project, which focused on variation among different fungal strains in bioprocessing of wheat straw into ruminant feed. The results of his $\mathrm{PhD}$ study are presented in this thesis. Currently, he is working as a researcher cum laboratory technician at the Animal Nutrition group, WUR. When returning to his home country, he will resume his job as an assistant lecturer at the Department of Animal Science, Faculty of Agriculture, Universiti Putra Malaysia. 


\section{Publications}

Nayan, N., Sonnenberg, A.S.M., Hendriks, W.H. and Cone, J.W. (2017). Differences between two strains of Ceriporiopsis subvermispora on improving the nutritive value of wheat straw for ruminants. J. Appl. Microbiol. 123, 352-361.

Nayan, N., Sonnenberg, A.S.M., Hendriks, W.H. and Cone, J.W. (2018). Screening of white-rot fungi for bioprocessing of wheat straw into ruminant feed. J. Appl. Microbiol. 125, 368-379.

Nayan, N., Sonnenberg, A.S.M., Hendriks, W.H. and Cone, J.W. (2018). Variation in the solubilization of crude protein of wheat straw by different white-rot fungi. Anim. Feed Sci. Technol. 242, 135-143.

Nayan, N., Van Erven, G., Kabel, M.A., Sonnenberg, A.S.M., Hendriks, W.H. and Cone, J.W. (2018). Improving ruminal digestibility of various wheat straw types by white-rot fungi. J. Sci. food Agric. In press.

Van Erven, G., Nayan, N., Kabel, M.A., Sonnenberg, A.S.M., Hendriks, W.H. and Cone, J.W. (2018). Mechanistic insight in the selective delignification of wheat straw by three white-rot fungal species through quantitative ${ }^{13} \mathrm{C}$-IS py-GCMS and whole cell wall HSQC-NMR. Biotechnol. Biofuels, 11, 1-16.

Nayan, N., Van Erven, G., Kabel, M.A., Sonnenberg, A.S.M., Hendriks, W.H. and Cone, J.W. The relevance of different analytical methods to assess fungal degradation of lignocellulose and explaining the subsequent ruminal degradability. Submitted to J. Sci. Food Agric.

\section{Conferences and Symposia Proceedings}

Nayan, N., Sonnenberg, A.S.M., Hendriks, W.H. and Cone, J.W. (2016). Evaluation of two strains of Ceriporiopsis subvermispora on improving the nutritive values of wheat straw for ruminant feed. WIAS Science Day 2015, 4 February, Wageningen, the Netherlands.

Nayan, N., Sonnenberg, A.S.M., Hendriks, W.H. and Cone, J.W. (2016). Evaluation of Ceriporiopsis subvermispora on improving the nutritive value of wheat straw. Proceedings $67^{\text {th }}$ Annual Meeting of the European Federation of Animal Science, 29 August, Belfast, United Kingdom. 
Nayan, N., Sonnenberg, A.S.M., Hendriks, W.H. and Cone, J.W. (2017). Selection of white-rot fungi for bioprocessing of wheat straw into ruminant feed: Preliminary results. Proceedings $42^{\text {nd }}$ Animal Nutrition Research Forum, 7 April, Gent, Belgium.

Nayan, N., Sonnenberg, A.S.M., Hendriks, W.H. and Cone, J.W. (2017). Selection of White-Rot Fungi for Bioprocessing of Wheat Straw into Ruminant Feed. Proceedings First ASAS-CSAS Annual Meeting \& Trade Show, 8 July, Baltimore, MD, USA.

Nayan, N., Sonnenberg, A.S.M., Hendriks, W.H. and Cone, J.W. (2018). Variation in the solubilization of nitrogenous compounds in wheat straw by different white-rot fungi. Proceedings $43^{\text {rd }}$ Animal Nutrition Research Forum, 11 April, Wageningen, the Netherlands.

Nayan, N., Sonnenberg, A.S.M., Hendriks, W.H. and Cone, J.W. (2018). Variation in the solubilization of nitrogenous compounds in wheat straw by different white-rot fungi. Proceedings $69^{\text {th }}$ Annual Meeting of the European Federation of Animal Science, 28 August, Dubrovnik, Croatia. 
The Basic Package (3 ECTS) ${ }^{2}$

WIAS Introduction Day 2014

WIAS Ethics and Philosophy of Life Science 2014

$\begin{array}{ll}\text { WIAS Course on essential skills } & 2014\end{array}$

\section{Disciplinary Competences (10 ECTS)}

$\begin{array}{ll}\text { Writing research proposal } & 2015\end{array}$

$\begin{array}{ll}\text { WIAS Design of Experiment } & 2015\end{array}$

WIAS Statistics for Life Sciences 2016

$\begin{array}{ll}\text { Advances in Feed Evaluation Science } & 2017\end{array}$

\section{Professional Competences (11 ECTS)}

High-Impact Writing in Science 2015

Techniques for Writing and Presenting a Scientific Paper 2015

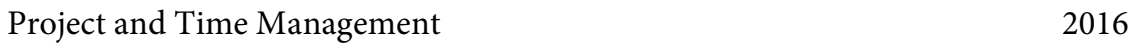

Interpersonal Communication for PhD Students 2016

$\begin{array}{ll}\text { Scientific Publishing } & 2017\end{array}$

$\begin{array}{ll}\text { Brain Training } & 2017\end{array}$

$\begin{array}{ll}\text { WAPS council } & 2017\end{array}$

Effective behavior in your professional surroundings 2016

The Final Touch: Writing the General Introduction and Discussion 2018

${ }^{1}$ Completed in the fulfilment of requirements for the education certificate of the Graduate School, Wageningen Institute of Animal Science (WIAS)

${ }^{2}$ One ECTS equals a study load of 28 hours 


\section{Presentation Skills (4 ECTS)}

WIAS Science Day, Wageningen, Netherlands; poster 2016

European Federation of Animal Science, Belfast, UK; poster 2016

Animal Nutrition Forum, Belgium; oral 2017

ASAS-CSAS Annual Meeting, USA; oral 2017

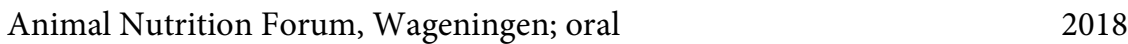

European Federation of Animal Science, Dubrovnik, Croatia; oral 2018

\section{Teaching competences (6 ECTS)}

$\begin{array}{ll}\text { Supervising MSc thesis } & 2016\end{array}$

$\begin{array}{ll}\text { Supervising BSc Thesis } & 2017\end{array}$

Supervising practical - BSc course "Principles of Animal Nutrition" ～2016-2018 



\section{Colophon}

The work described in this thesis was performed at the Animal Nutrition Group, Plant Breeding and Laboratory of Food Chemistry, Wageningen University. The scholarship for the author was provided by Ministry of Higher Education Malaysia, Universiti Putra Malaysia. The project was financed by DEKA, ForFarmers and the Victam Foundation a research grant managed by Wageningen University Fund. The financial support from Wageningen University for printing of this thesis is gratefully acknowledged.

Cover design and layout by Nazri Nayan

Printed by Proefschriftmaken || Digiforce 
